\title{
Proteomics as a tool for biomarker detection : protein profiling in chronic and vascular disease
}

Citation for published version (APA):

Bons, J. (2008). Proteomics as a tool for biomarker detection : protein profiling in chronic and vascular disease. [Doctoral Thesis, Maastricht University]. Universitaire Pers Maastricht. https://doi.org/10.26481/dis.20080328jb

Document status and date:

Published: 01/01/2008

DOI:

10.26481/dis.20080328jb

Document Version:

Publisher's PDF, also known as Version of record

\section{Please check the document version of this publication:}

- A submitted manuscript is the version of the article upon submission and before peer-review. There can be important differences between the submitted version and the official published version of record.

People interested in the research are advised to contact the author for the final version of the publication, or visit the DOI to the publisher's website.

- The final author version and the galley proof are versions of the publication after peer review.

- The final published version features the final layout of the paper including the volume, issue and page numbers.

Link to publication

\footnotetext{
General rights rights.

- You may freely distribute the URL identifying the publication in the public portal. please follow below link for the End User Agreement:

www.umlib.nl/taverne-license

Take down policy

If you believe that this document breaches copyright please contact us at:

repository@maastrichtuniversity.nl

providing details and we will investigate your claim.
}

Copyright and moral rights for the publications made accessible in the public portal are retained by the authors and/or other copyright owners and it is a condition of accessing publications that users recognise and abide by the legal requirements associated with these

- Users may download and print one copy of any publication from the public portal for the purpose of private study or research.

- You may not further distribute the material or use it for any profit-making activity or commercial gain

If the publication is distributed under the terms of Article $25 \mathrm{fa}$ of the Dutch Copyright Act, indicated by the "Taverne" license above, 
Proteomics as a tool for biomarker detection

Protein profiling in chronic and vascular disease 
(C) Judith Bons, Maastricht 2008

ISBN: 9789052787053

Cover design: Guido van Gageldonk, Unit040 Ontwerp Eindhoven Layout: Tiny Wouters

Production: Datawyse | Universitaire Pers Maastricht

Financial support by Bio-Rad Laboratories, Beckman Coulter, EC Noyons Stichting is gratefully acknowledged. 


\title{
Proteomics as a tool for biomarker detection \\ Protein profiling in chronic and vascular disease
}

\author{
Proefschrift \\ ter verkrijging van de graad van doctor \\ aan de Universiteit Maastricht, \\ op gezag van de Rector Magnificus, Prof. mr. G.P.M.F. Mols, \\ volgens het besluit van het College van Decanen, \\ in het openbaar te verdedigen \\ op vrijdag 28 maart 2008 om 12.00 uur
}

door

Judith Anna Petronella Bons

geboren op 16 augustus 1981 te Tegelen

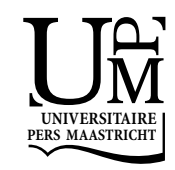




\section{Promotor}

Prof. dr. M.P. van Dieijen-Visser

Co-promotor

Dr. W.K.W.H. Wodzig

\section{Beoordelingscommissie}

Prof. dr. J.F.C. Glatz, voorzitter

Dr. J.M.G. Bonfrer, Het Nederlands Kanker Instituut / Antoni van Leeuwenhoek Ziekenhuis, Amsterdam

Prof. dr. J.W. Cohen Tervaert

Prof. dr. J.C.S. Kleinjans

Prof. dr. E.C.M. Mariman 
Aan: mijn ouders en Jens 



\section{Contents}

Abbreviations

Chapter 1 Introduction

Chapter 2 Protein profiling as a diagnostic tool in clinical chemistry,

a review. Influence of pre- and post-analytical aspects

Chapter 3 Standardization of calibration and quality control using

Surface-Enhanced Laser Desorption/Ionization Time-of-Flight Mass Spectrometry

Chapter 4 Clinical proteomics in chronic inflammatory diseases, a review

Chapter 5 Potential biomarkers for diagnosis of sarcoidosis using proteomics in serum

Chapter 6 Potential biomarkers for diagnosis of ankylosing spondylitis using SELDI-TOF-MS

Chapter 7 Haptoglobin in lacunar stroke: a SELDI-TOF-MS study with subsequent phenotyping

Chapter 8 A specific immunoprecipitation method for isolating isoforms of insulin-like growth factor binding protein-3 from serum

Chapter 9 General discussion

Summary

Samenvatting

Publications

Dankwoord

Curriculum vitae 

Abbreviations 



\section{Abbreviations}

\begin{tabular}{|c|c|}
\hline 1-DE & one- dimensional gel electrophoresis \\
\hline 2-DE & two-dimensional gel electrophoresis \\
\hline ACE & angiotensin converting enzyme \\
\hline ALS & acid-labile subunit \\
\hline APO & apomyoglobin \\
\hline ApoAl & apolipoprotein Al \\
\hline ApoAll & apolipoprotein All \\
\hline AS & ankylosing spondylitis \\
\hline AUCs & areas under the curves \\
\hline BALF & bronchoalveolar lavage fluid \\
\hline BNP & B-type natriuretic peptide \\
\hline $\mathrm{BPH}$ & benign prostate hyperplasia \\
\hline BPS & Biomarker Patterns Software \\
\hline CDG & congenital disorders of glycolysation \\
\hline $\mathrm{CF}$ & cystic fibrosis \\
\hline CFTR & CF-transmembrane conductance regulator \\
\hline CHAPS & ([3-[(3-cholamidopropyl)-dimethylammonio]propanesulfonate]) \\
\hline $\mathrm{CHCA}$ & $\alpha$-cyano-4-hydroxy-cinnamic acid \\
\hline CIS & clinically isolated syndromes \\
\hline CM10 & weak cation exchange ProteinChip array \\
\hline CRP & C-reactive protein \\
\hline CSF & cerebrospinal fluid \\
\hline cTnT & cardiac troponin $\mathrm{T}$ \\
\hline CV & coefficient of variation \\
\hline CXR & chest X-ray stages \\
\hline $\mathrm{Da}$ & Dalton \\
\hline DLCO & diffusing capacity for carbon monoxide \\
\hline DMP & dimethyl pimelimidate \\
\hline EAM & energy absorbing matrix \\
\hline EDTA & sodium ethylenediamine tetraacetic acid \\
\hline ELISA & enzyme-linked immunosorbent assay \\
\hline Fc region & fragment crystallizable region \\
\hline $\mathrm{FEV}_{1}$ & forced expiratory volume in $1 \mathrm{~s}$ \\
\hline FVC & forced vital capacity \\
\hline G6PD & glucose-6-phosphate dehydrogenase \\
\hline $\mathrm{H} 4$ & hydrophobic ProteinChip array \\
\hline $\mathrm{H} 50$ & hydrophobic ProteinChip array \\
\hline HIV & human immunodeficiency virus \\
\hline HLA-B27 & human leucocyte antigen B-27 \\
\hline $\mathrm{Hp}$ & haptoglobin \\
\hline
\end{tabular}




\begin{tabular}{|c|c|}
\hline Hsp & heat shock protein family \\
\hline HUPO & Human Proteome Organization \\
\hline ICAT & isotope-coded affinity tags \\
\hline IFCC & International Federation of Clinical Chemistry \\
\hline IGF-I & insulin-like growth factor type I \\
\hline IGFBP-3 & insulin-like growth factor binding protein-3 \\
\hline IGFs & insulin-like growth factors \\
\hline $\lg G$ & immunoglobulin $\mathrm{G}$ \\
\hline $\mathrm{IMAC}-\mathrm{Cu}^{2+}$ & metal affinity binding ProteinChip array coupled with copper \\
\hline INS & insulin \\
\hline iTRAQ & isotope tags for relative and absolute quantification \\
\hline LC-MS/MS & Liquid Chromatography Tandem Mass Spectrometry \\
\hline $\mathrm{LI}$ & laser intensity \\
\hline MALDI-TOF-MS & $\begin{array}{l}\text { Matrix Assisted Laser Desorption/Ionization Time of Flight Mass } \\
\text { Spectrometry }\end{array}$ \\
\hline MIF & macrophage migration inhibitory factor \\
\hline MRI & magnetic resonance imaging \\
\hline MRP-8 & Myeloid-Related protein 8 \\
\hline mSASSS & modified Stoke Ankylosing Spondylitis Spine Score \\
\hline MS/MS & tandem mass spectrometry \\
\hline$m / z$ & mass-to-charge ratio \\
\hline MW & molecular weight \\
\hline NP20 & normal phase ProteinChip array \\
\hline PAP & prostate acid phophatase \\
\hline PBS & phosphate buffered saline \\
\hline PBSII & Protein Biosystem II \\
\hline PBSIlc & Protein Biosystem Ilc \\
\hline PBST & PBS containing $0.2 \mathrm{ml} / \mathrm{l}$ Tween-20 \\
\hline PSA & prostate specific antigen \\
\hline PSI & Proteomics Standards Initiative \\
\hline PSMA & prostate specific membrane antigen \\
\hline PSP & prostate specific peptide \\
\hline $\mathrm{QC}$ & quality control \\
\hline $\mathrm{QC}_{1}$ & $1 \mu \mathrm{L} \mathrm{QC} \mathrm{sample}$ \\
\hline $\mathrm{QC}_{5}$ & $5 \mu \mathrm{L}$ diluted QC sample \\
\hline RA & rheumatoid arthritis \\
\hline RP-HPLC & Reverse Phase High Performance Liquid Chromatography \\
\hline SAA & serum amyloid $A$ \\
\hline $\operatorname{SCX}$ & strong cation-exchange chromatography \\
\hline SDS & sodium dodecyl sulphate \\
\hline SDS-PAGE & sodium dodecyl sulphate-polyacrylamide gel electrophoresis \\
\hline SE & detector sensitivity \\
\hline
\end{tabular}




$\begin{array}{ll}\text { SELDI-TOF-MS } & \begin{array}{l}\text { Surface-Enhanced Laser Desorption/lonization Time-of-Flight } \\ \text { Mass Spectrometry }\end{array} \\ \text { SF } & \text { synovial fluid } \\ \text { SIL-2R } & \text { soluble Interleukin-2 Receptor } \\ \text { S/N } & \text { signal-to-noise ratio } \\ \text { SPA } & \text { sinapinic acid } \\ \text { SpA } & \text { spondyloarthropathy } \\ \text { SVD } & \text { small vessel disease } \\ \text { TCTP } & \text { translationally controlled tumor protein } \\ \text { TFA } & \text { trifluoroacetic acid } \\ \text { TFAH } & \text { trifluoroacetic anhydride } \\ \text { TRIS-HCL } & \text { 2-amino-2-(hydroxymethyl)-1,3-propanediol hydrochloride } \\ \text { WASOG } & \text { World Association of Sarcoidosis and Other Granulomatous } \\ & \text { Disorders } \\ \text { WHO } & \text { World Health Organization } \\ \text { WML } & \text { white matter lesions }\end{array}$





\section{Chapter 1}

Introduction 



\section{Introduction}

\section{Proteomics}

The field of proteomics has developed rapidly in recent years. Until the mid-1990s scientists studied individual genes and proteins or a handful biologically related genes and proteins. Basis of proteomics is to characterize the behavior of the system rather than the behavior of any single component. The proteome is dynamic and in constant flux due to a combination of factors. These factors include posttranslational modifications and functional regulation of gene expression ${ }^{1}$. Moreover, in proteomics protein identification is not necessarily performed by complete sequence analysis, but can also be performed by partial sequence analysis with the aid of database matching tools.

Proteomic analysis requires the combination of various technologies, including biochemistry, mass spectrometry and bioinformatics. Important techniques for expression analysis of proteins are two-dimensional electrophoresis (2-DE) combined with Matrix Assisted Laser Desorption/lonization Time-of-Flight Mass Spectrometry (MALDI-TOF-MS), and Surface-Enhanced Laser Desorption/Ionization Time-of-Flight Mass Spectrometry.

\section{2-DE}

The principle of 2-DE is separation on a gel of the protein content of a sample in two dimensions according to charge and mass. Separation of protein extracts by 2-DE followed by MALDI-TOF-MS is a well-established and powerful method in the identification of differentially expressed proteins. The gels can be stained with Coomassie brilliant blue staining, radioactive or fluorescent labeling, and silver staining. The spot intensities in samples are compared among different gels. The differentially expressed proteins can be excised from the gel and after destaining, in-gel digestion with trypsin and extraction, the peptide mixtures are spotted on the target plate and analyzed with MALDI-TOF-MS. A high separation is achieved with 2-DE, but a major disadvantage of this technique, however, is its lack of real high throughput capability and the large amount of starting material required.

\section{SELDI-TOF-MS versus MALDI-TOF-MS}

There have been many reports on the application of SELDI-TOF-MS technology since its first introduction in 1993 by Hutchens and Yip². SELDI-TOF-MS is an approach that tries to overcome the requirements for purification and separation of proteins prior to mass spectrometry analysis ${ }^{3}$. It is a novel approach to biomarker discovery that combines two powerful techniques: chromatography and mass spectrometry. One of the key features of SELDI-TOF-MS is its ability to provide a rapid protein expression profile from a variety of biological and clinical samples 4 . It consists of selective protein extraction and retention on chromatographic chip 
surfaces and their subsequent analysis by a simple laser desorption/ionization mass spectrometer ${ }^{5}$. It differs in several aspects from conventional MALDI-TOF-MS. For MALDI-TOF-MS, analytes are directly spotted onto a plate. This is usually a metal plate. The applied samples are usually tryptic digests from proteins separated by 2-DE, although proteins purified by other separation methods are also compatible with the method. Before deposition of the analytes, the energy absorbing matrix (EAM) is placed on the plate or mixed in with the sample. The matrix will absorb energy from the laser causing the analytes to be ionized by MALDI-TOF-MS ${ }^{6}$. The disadvantage of the MALDI-TOF-MS technique is that for complex samples fractionation needs to take place before spotting on the gold plate. This means that there is more starting material needed for the offline sample fractionation compared to SELDI-TOF-MS analyses. The advantages of the SELDITOF-MS technique are the high throughput capability, the low amounts of sample material. The SELDI-TOF-MS can effectively resolve polypeptides and peptides smaller than $20 \mathrm{kDa}$.

\section{ProteinChip arrays}

For the SELDI-TOF-MS technique different ProteinChip arrays (Ciphergen Biosystems Inc.) are used. The chromatographic surfaces that make up the various ProteinChip arrays are uniquely designed to retain proteins from a complex sample mixture according to specific properties such as hydrophobicity, charge ${ }^{4}$ (Figure 1.1).
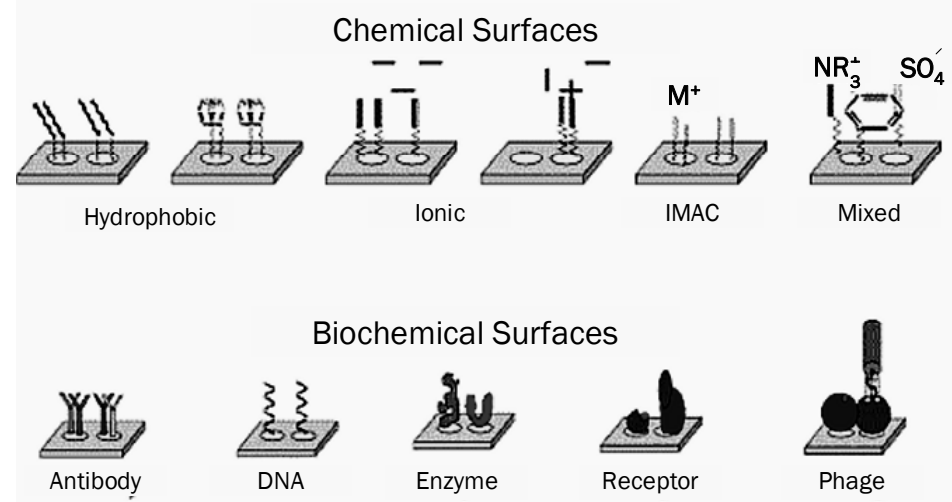

Figure 1.1 The different types of ProteinChip arrays.

The chemical surfaces are chromatographic ProteinChip arrays with hydrophobic, cationic, anionic, metal ions for immobilized metal affinity binding (IMAC) or hydrophilic spots. The biochemical surfaces are designed for coupling of biomolecules in antibody-antigen assays, DNA-protein binding experiment, coupling of enzymes, receptor-ligand interaction and for coupling of phages. 
The procedure for detecting protein biomarkers is very simple. A few microliters of the sample are dispensed onto the ProteinChip surface under specific binding conditions that determine which proteins will be retained by the surface. Protein specificity is achieved through the application of a series of washes with an appropriate solvent or buffer designed to elute unbound proteins and interfering substances, such as salts, detergents, lipids. Only proteins actively interacting with the spot surfaces are analyzed in the SELDI-TOF-MS (Protein Biosystem series instrument) (Ciphergen Biosystems Inc.) because all other components are washed off in advance. One of the most obvious advantages of this surface-enhanced process is that components such as salts or detergents which commonly cause problems with other analytical tools are washed away as part of the SELDI process $^{8}$.

By choosing different ProteinChip arrays with array-specific surface components, different proteins will be analyzed depending on the chip characteristics. In fact the interaction of the analyte and the chip introduces a purification step. Each combination of ProteinChip arrays together with the binding and washing buffers of choice results in a unique binding capacity for a special subset of peptides and proteins. After addition of sample and washing buffers, the EAM is applied to the ProteinChip array. The EAM will facilitate desorption and ionization in the SELDITOF-MS.

\section{Desorption/Ionization process}

After introducing the ProteinChip array into the SELDI-TOF-MS, a laser beam is directed onto the sample on the spot. Upon laser activation, the sample becomes irradiated and the desorption and ionization proceeds to liberate gaseous ions from the ProteinChip arrays. These gaseous ions enter the TOF-MS region of the instrument, which measures the mass-to-charge ratio $(\mathrm{m} / \mathrm{z})$ of molecular ions of each protein, based on its velocity through a vacuum tube 4 . The time-of-flight corresponds to the $m / z$ value. As a first result, the molecules in the sample are represented in a graph with the $m / z$ value on the $x$-axis and the corresponding signal intensity on the $y$-axis ${ }^{8}$ (Figure 1.2). 


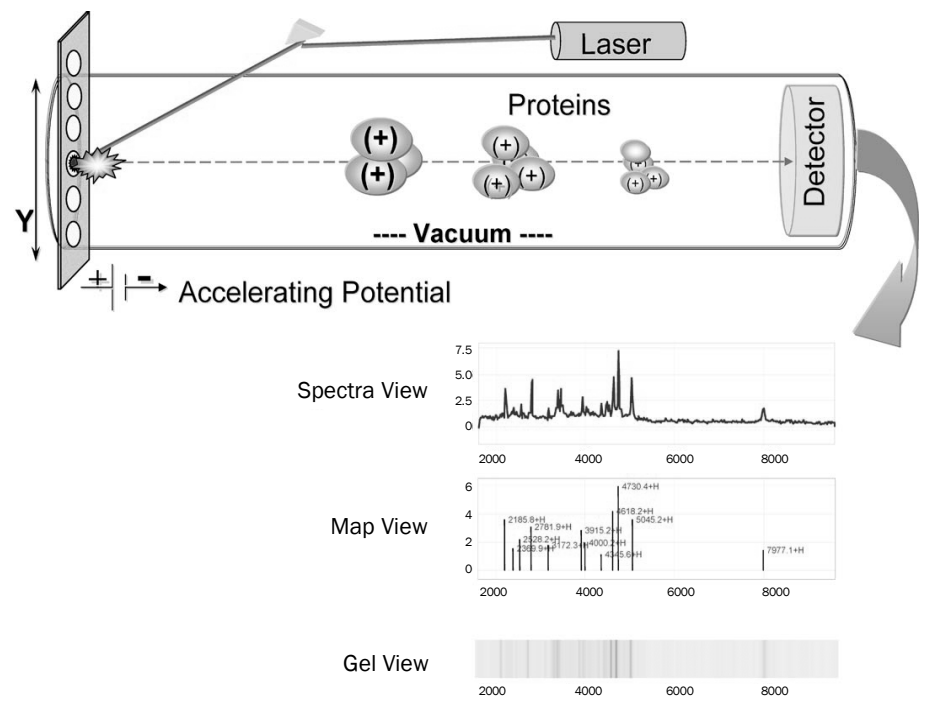

Figure 1.2 The ions of the molecules in the sample are represented in a spectra, map and gel view with the mass-to-charge ratio $(\mathrm{m} / \mathrm{z})$ on the $\mathrm{x}$-axis and the corresponding signal intensity on the $y$-axis.

\section{Biomarker Discovery}

The true scientific goal of serum proteomic pattern analysis is in fact biomarker discovery. However, since the study by Petricoin et al. ${ }^{9}$ on proteomic patterns to detect ovarian cancer, the use of SELDI-TOF-MS protein profiling as a diagnostic tool, has become an important subject of investigation too ${ }^{10}$. Until now, this approach has been suggested for different diseases, like ovarian ${ }^{9,11-15}$, prostate $^{7,16-19}$ and lung ${ }^{20}$ cancer, but also for inflammatory diseases ${ }^{21,22}$.

Currently, the pipeline from translation of new biomarkers into tests appears to have a bottleneck at the early stages of translation of research markers into clinical tests. Research groups performing discovery and clinical studies rarely have the resources to develop prototype analyzers or test reagent sets, to manufacture them, or to proceed with other steps in commercialization. These steps usually rely on the in vitro diagnostics industry, which has had relatively low investment in the development of new markers. After development of tests, there is a need for evaluation in clinical laboratories, submission for approval by the US Food and Drug Administration ${ }^{23}$, establishment of reimbursement rates by the Medicare system and insurers, and education of physicians about test ordering and interpretation. The process of translating new markers into clinical laboratory test entails contributions from multiple disciplines, including scientists; engineers; business, legal, and regulatory professionals; clinicians; and clinical laboratorians ${ }^{24}$. 


\section{Detection of potential biomarkers}

The SELDI-TOF-MS technique was used to detect potential biomarkers for two chronic inflammatory diseases; sarcoidosis, ankylosing spondylitis, and to compare protein profiles of two types of lacunar stroke. These studies are described in this thesis.

\section{Sarcoidosis}

Sarcoidosis is a systemic granulomatous disorder of unknown cause characterized by its pathological hallmark, the noncaseating granuloma25,26. The clinical presentation of sarcoidosis is highly variable 27 . Involvement of the lungs or intrathoracic lymph nodes becomes clinically evident in $90 \%$ of the symptomatic patients during their disease and up to $30 \%$ show spontaneous remission ${ }^{28}$. A chronic course occurs in $10-30 \%$ of the patients, at times resulting in significant impairment of lung function ${ }^{29,30}$. Unfortunately, till now there is no good marker for both diagnosis and prognosis of sarcoidosis.

\section{Ankylosing spondylitis}

Ankylosing spondylitis (AS) is a chronic systemic inflammatory rheumatic disorder that primarily affects the axial skeleton, with sacroliitis as its hallmark. Spinal structural damage can be assessed on conventional radiographs as destructive and proliferative lesions ultimately leading to syndesmophyte formation. It has been estimated that at least $30 \%$ of patients do develop severe spinal restriction during the natural course of the disease. Until now there is no satisfying biomarker for diagnosis or prognosis of AS.

\section{Lacunar stroke}

Lacunar infarcts are small, deeply in the brain located infarcts, mostly caused by local pathology in a small perforating artery31. Lacunar stroke patients in whom cerebral imaging shows multiple additional "silent" lacunar lesions, differ clinically from those patients with only a single symptomatic lesion in that they show more extensive cerebral white matter lesions on neuro-imaging, have more often hypertension, and have worse prognosis on functional outcome, a higher stroke recurrence rate, higher short- and long-term mortality and higher rate of asymptomatic lesion progression ${ }^{32-36}$. Whether these two types are both ends of one pathogenetic spectrum, or represent two pathogenetically different entities, remains subject of debate. Research into the underlying pathogenetic mechanisms thus far focused on known proteins that are thought to be involved in vascular pathogenesis. 


\section{Glycomics}

Glycomics or glycobiology deals with the structure and function of oligosaccharides (chains of sugars). The entire repertoire of carbohydrates in an organ is thus collectively referred to as the glycome. This area of research has to deal with an inherent level of complexity. The saccharides have a multitude of building blocks. In this thesis, we look for glycosylation defects in galactosemia. Patients with classical galactosemia, an inborn error of galactose metabolism with secondary glycosylation abnormalities, are at risk for a diminished bone mass since early age. The lack of evidence for the presence of any of the well established risk factors for a diminished bone mass such as nutritional deficiencies or other diet-related factors led us to hypothesize a glycosylation defect of proteins involved in bone metabolism in these patients. Human Insulin-like Growth Factor type I (IGF-I), a key role player in bone metabolism is over $75 \%$ bound in ternary complexes with IGFbinding protein-3 (IGFBP-3) and the acid-labile subunit (ALS). The level of IGFBP-3 glycosylation modulates the cell-binding activity of IGFBP-3. In order to elucidate if pediatric galactosemic patients have glycan abnormalities in IGFBP-3 and because IGFBP-3 levels are in the range of 10-100 nM, a specific immunoprecipitation method is needed to isolate and purify IGFBP-3. The aim was to compare 1-DE and 2-DE western blots of pediatric galactosemic patients, CDG patients and healthy controls. The discriminating isoforms need to be identified with MALDI-TOF-MS. 


\section{Scope and the aims of the thesis}

The first aim of the studies presented in this thesis was to evaluate the prominent analytical aspects, which are involved in proteomics studies. The importance of the pre- and post analytical strategies in proteomics studies were outlined in Chapter 2. Any new technology, particularly one being presented as a potential clinically used diagnostic tool, requires stringent quality control to evaluate analytical performance over time. In Chapter 3 a standard protocol for calibration of the MALDI-TOF-MS part of the SELDI-TOF-MS instrument was defined and acceptance criteria for the independent certified QC samples were established.

This thesis is focused on proteomics studies in different diseases. In Chapter $\mathbf{4}$ an overview of the different proteomics techniques to detect potential and/or common biomarkers in chronic inflammatory diseases was shown. The identified and validated proteins detected in the different studies are compared and discussed to conclude if there are some common markers which can be used in the diagnosis and prognosis of the three chronic inflammatory diseases described in this study; multiple sclerosis, rheumatic diseases and lung inflammatory diseases.

The aim of Chapter $\mathbf{5}$ and $\mathbf{6}$ was to detect potential biomarkers, using the SELDITOF-MS technique, for sarcoidosis and ankylosing spondylitis, respectively.

Another SELDI-TOF-MS protein profiling study with subsequent phenotyping analysis was described in Chapter $\mathbf{7}$ to differentiate between two types of lacunar stroke.

Another application of proteomics was to detect the glycosylation defects in galactosemia. In Chapter 8, a specific immunoprecipitation method to isolate IGFBP-3 from serum was described to compare 1-DE and 2-DE western blots of pediatric galactosemic patients, CDG patients and healthy controls. 


\section{References}

1. Srinivas PR, Srivastava S, Hanash S, Wright GL Jr. Proteomics in Early Detection of Cancer. Clin Chem 2001;47:1901-1911.

2. Hutchens TW, Yip T. New Desorption strategies for the mass spectrometric analysis of macromolecules. Rapid Commun Mass Spectrom 1993;7:576-580.

3. Bischoff R, Luider TM. Methodological advances in the discovery of protein and peptide disease markers. J Chromatogr B Analyt Technol Biomed Life Sci 2004;803:27-40.

4. Issaq HJ, Veenstra TD, Conrads TP, Felschow D. The SELDI-TOF MS Approach to Proteomics: Protein Profiling and Biomarker Identification. Biochemical and Biophysical Research Communications 2002;292:587-592.

5. Caputo E, Moharram R, Martin BM. Methods for on-chip protein analysis. Anal Biochem 2003; 321:116-124.

6. Aebersold R, Goodlett DR. Mass spectrometry in proteomics. Chem Rev 2001;101:269-295.

7. Qu Y, Adam BL, Yasui Y, Ward MD, Cazares LH, Schellhammer PF, Feng Z, Semmes OJ, Wright GL Jr. Boosted decision tree analysis of surface-enhanced laser desorption/ionization mass spectral serum profiles discriminates prostate cancer from noncancer patients. Clin Chem 2002;48: 1835-1843.

8. Wiesner A. Detection of Tumor Markers with ProteinChip(R) Technology. Curr Pharm Biotechnol 2004;5:45-67.

9. Petricoin III EF, Mills GB, Kohn EC, Liotta LA. Proteomic patterns in serum and identification of ovarian cancer. Lancet 2002;360:170-171.

10. Petricoin EF, Ardekani AM, Hitt BA, Levine PJ, Fusaro VA, Steinberg SM, Mills GB, Simone C, Fishman DA, Kohn EC, Liotta LA. Use of proteomic patterns in serum to identify ovarian cancer. Lancet 2002;359:572-577.

11. Kozak KR, Amneus MW, Pusey SM, Su F, Luong MN, Luong SA, Reddy ST, Farias-Eisner R. Identification of biomarkers for ovarian cancer using strong anion-exchange ProteinChips: potential use in diagnosis and prognosis. Proc Natl Acad Sci U S A 2003;100:12343-12348.

12. Zhang Z, Bast RC Jr, Yu Y, Li J, Sokoll LJ, Rai AJ, Rosenzweig JM, Cameron B, Wang YY, Meng XY, Berchuck A, Van Haaften-Day C, Hacker NF, de Bruijn HW, van der Zee AG, Jacobs IJ, Fung ET, Chan DW. Three biomarkers identified from serum proteomic analysis for the detection of early stage ovarian cancer. Cancer Res 2004;64:5882-5890.

13. Vlahou A, Schorge JO, Gregory BW, Coleman RL. Diagnosis of Ovarian Cancer Using Decision Tree Classification of Mass Spectral Data. J Biomed Biotechnol 2003;2003:308-314.

14. Ye B, Cramer DW, Skates SJ, Gygi SP, Pratomo V, Fu L, Horick NK, Licklider L, Schorge JO, Berkowitz RS, Mok SC. Haptoglobin-alpha subunit as potential serum biomarker in ovarian cancer: identification and characterization using proteomic profiling and mass spectrometry. Clin Cancer Res 2003;9:2904-2911.

15. Rai AJ, Zhang Z, Rosenzweig J, Shih le M, Pham T, Fung ET, Sokoll LJ, Chan DW. Proteomic approaches to tumor marker discovery. Arch Pathol Lab Med 2002;126:1518-1526.

16. Banez LL, Prasanna P, Sun L, Ali A, Zou Z, Adam BL, McLeod DG, Moul JW, Srivastava S. Diagnostic potential of serum proteomic patterns in prostate cancer. J Urol 2003;170:442-446.

17. Adam BL, Qu Y, Davis JW, Ward MD, Clements MA, Cazares LH, Semmes OJ, Schellhammer PF, Yasui Y, Feng Z, Wright GL Jr. Serum protein fingerprinting coupled with a pattern-matching algorithm distinguishes prostate cancer from benign prostate hyperplasia and healthy men. Cancer Res 2002;62:3609-3614.

18. Petricoin EF $3^{\text {rd }}$, Ornstein DK, Paweletz CP, Ardekani A, Hackett PS, Hitt BA, Velassco A, Trucco C, Wiegand L, Wood K, Simone CB, Levine PJ, Linehan WM, Emmert-Buck MR, Steinberg SM, Kohn EC, Liotta LA. Serum proteomic patterns for detection of prostate cancer. J Natl Cancer Inst 2002; 94:1576-1578.

19. Li J, White N, Zhang Z, Rosenzweig J, Mangold LA, Partin AW, Chan DW. Detection of prostate cancer using serum proteomics pattern in a histologically confirmed population. J Urol 2004;171: 1782-1787. 
20. Zhukov TA, Johanson RA, Cantor AB, Clark RA, Tockman MS. Discovery of distinct protein profiles specific for lung tumors and pre-malignant lung lesions by SELDI mass spectrometry. Lung Cancer 2003;40:267-279.

21. Poon TC, Hui AY, Chan HL, Ang IL, Chow SM, Wong N, Sung JJ. Prediction of Liver Fibrosis and Cirrhosis in Chronic Hepatitis B Infection by Serum Proteomic Fingerprinting: A Pilot Study. Clin Chem 2004;51:328-335.

22. Zhu XD, Zhang WH, Li CL, XU Y, Liang WJ, Tien P. New serum biomarkers for detection of HBVinduced liver cirrhosis using SELDI protein chip technology. World J Gastroenterol 2004;10: 2327-2329.

23. Hackett JL, Gutman SI. Introduction to the Food and Drug Administration (FDA) regulatory process. J Proteome Res 2005;4:1110-1113.

24. Hortin GL, Jortani SA, Ritchie JC Jr, Valdes R Jr, Chan DW. Proteomics: A New Diagnostic Frontier. Clin Chem 2006;52:1218-1222.

25. Baughman RP, Lower EE, Du Bois RM. Sarcoidosis. Lancet 2003;361:1111-1118.

26. Kataria YP, Holter JF. Sarcoidosis: A Model of Granulomatous Inflammation of Unknown Etiology Associated with a Hyperactive Immune System. Methods 1996;9:268-294.

27. Judson MA, Baughman RP, Thompson BW, Teirstein AS, Terrin ML, Rossman MD, Yeager H Jr, McLennan G, Bresnitz EA, DePalo L, Hunninghake G, lannuzzi MC, Johns CJ, Moller DR, Newman LS, Rabin DL, Rose C, Rybicki BA, Weinberger SE, Knatterud GL, Cherniak R. Two year prognosis of sarcoidosis: the ACCESS experience. Sarcoidosis Vasc Diffuse Lung Dis 2003;20:204-211.

28. Rybicki BA, Maliarik MJ, Major M, Popovich J Jr, lannuzzi MC. Epidemiology, demographics, and genetics of sarcoidosis. Semin Respir Infect 1998;13:166-173.

29. Baughman RP, Winget DB, Bowen EH, Lower EE. Predicting respiratory failure in sarcoidosis patients. Sarcoidosis Vasc Diffuse Lung Dis 1997;14: 154-158.

30. Arcasoy SM, Christie JD, Pochettino A, Rosengard BR, Blumenthal NP, Bavaria JE, Kotloff RM. Characteristics and outcomes of patients with sarcoidosis listed for lung transplantation. Chest 2001;120:873-880.

31. Fisher CM. The arterial lesions underlying lacunes. Acta neuropath (Berl) 1969;12:1-15.

32. Boiten J, Lodder J, Kessels F. Two clinically distinct lacunar infarct entities? A hypothesis. Stroke 1993;24:652-656.

33. Mast H, Thompson JLP, Lee S-H, Mohr JP, Sacco RL. Hypertension and diabetes mellitus as determinants of multiple lacunar infarcts. Stroke 1995;26:30-33.

34. Spolveri S, Baruffi MC, Cappelletti C, Semerano F, Rossi S, Pracucci G, Inzitari D. Vascular risk factors linked to multiple lacunar infarcts. Cerebrovascular Diseases 1998;8:152-157.

35. de Jong G, Kessels F, Lodder J. Two types of lacunar infarcts, further arguments from a study on prognosis. Stroke 2002;33:2072-2076.

36. van Zagten M, Boiten J, Kessels F, Lodder J. Significant progression of white matter lesions and small deep (lacunar) infarcts in patients with stroke. Arch Neurol 1996;53:650-655. 



\section{Chapter 2}

Protein profiling as a diagnostic tool in clinical chemistry, a review

Influence of pre-and post-analytical aspects

Judith A.P. Bons, Will K.W.H. Wodzig, Marja P. van Dieijen-Visser

Clin Chem Lab Med 2005;43:1281-1290 


\section{Abstract}

Serum protein profiling by Surface-Enhanced Laser Desorption/Ionization Time-of-Flight Mass Spectrometry appears to be an important diagnostic tool for a whole range of diseases. Sensitivities and specificities obtained with this new technology often seem superior to those obtained with current biomarkers. However, reproducibility and standardization are still problematic.

The present report shows an overview of the diagnostic value of protein profiles obtained with SurfaceEnhanced Laser Desorption/Ionization Time-of-Flight Mass Spectrometry in studies on prostate and ovarian cancer. To identify aspects important for protein profiling, we compare and discuss differences in pre- and post-analytical conditions presented in the literature supplemented with some of our own data. Further progress in protein profiling as a diagnostic tool requires a more comprehensive description of technical details in all future studies. 


\section{Introduction}

Surface-Enhanced Laser Desorption/lonization Time-of-Flight Mass Spectrometry (SELDI-TOF-MS) is a promising new technology which was introduced by Hutchens and Yip ${ }^{1}$. The ProteinChip system manufactured by Ciphergen Biosystem Inc. (Fremont, CA, USA) indicated as SELDI-TOF-MS has the potential to discover useful biomarkers faster than any existing technology. The true scientific goal of serum proteomic pattern analysis is in fact biomarker discovery. However, since the study by Petricoin et al. ${ }^{2}$ on proteomic patterns to detect ovarian cancer, the use of SELDI-TOF-MS protein profiling as a diagnostic tool, has become an important subject of investigation ${ }^{3}$. Until now, this approach has been suggested for diseases such as ovarian $2,4-8$, prostate ${ }^{9-13}$ and lung ${ }^{14}$ cancer, as well as for inflammatory diseases ${ }^{15,16}$. For the principle of SELDI-TOF-MS, we refer to a recent overview by Wiesner et al. ${ }^{17}$. Figure 2.1 illustrates the serum protein profiles of two healthy controls compared to the profiles of two sarcoidosis patients.

The aim of this report is to discuss differences between the pre- and post-analytical strategies used in the various studies and to identify aspects that could be responsible for the discrepancies and might be important for future studies on protein profiling. Prostate and ovarian cancer were selected, because several studies on SELDI-TOF-MS protein profiling as a diagnostic tool for these two diseases have been published, allowing more extensive comparison with a special focus on the technical details.

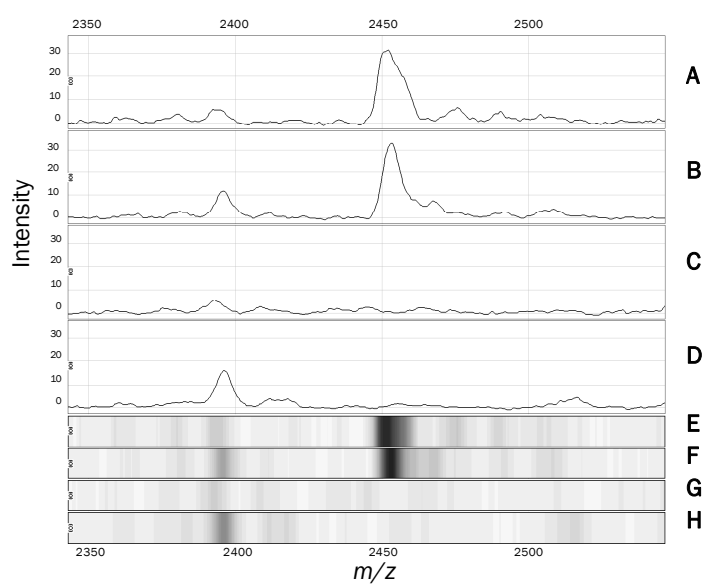

Figure 2.1 SELDI-TOF mass spectra and gel views of fractionated serum samples by centrifugation on a 30,000 Da cut-off filter on a normal phase (NP20) ProteinChip array.

Panel A and B show spectra of two healthy control samples. Panel $C$ and $D$ show spectra of two sarcoidosis patient samples. Panel $E$ and $F$ show healthy control spectra in gel view and panel $\mathrm{G}$ and $\mathrm{H}$ show sarcoidosis spectra in gel view. The intensity is displayed along the $y$-axis and the mass is given as mass-to-charge ratio $(\mathrm{m} / \mathrm{z})$ ratio on the $\mathrm{x}$-axis. 


\section{Comparison of prostate and ovarian studies}

Tables 2.1 and 2.2 present an overview of studies on prostate ${ }^{9-13}$ and ovarian cancer $2,4-8$ where SELDI-TOF-MS was used to discover potential biomarkers in serum by protein profiling. Many small studies have been published, but essential data on sample collection, sample preparation and post-analytical strategies are often lacking in their reports (Tables 2.1 and 2.2, open fields).

However, a comparison of different studies on protein profiling with SELDI-TOF-MS requires a clear description of all technical details. If protein profiling is to become a diagnostic tool, it is essential that the data are reproducible, which is only possible if an adequate description of the methods is included in all reports. The present review discusses aspects essential for a comparison of methods used in different studies and their influence on the final results.

Comparative studies on protein profiling have been published by Diamandis ${ }^{18}$ and Xiao et al. ${ }^{19}$. Both studies clearly addressed the problems of standardization and reproducibility of protein profiling. Diamandis ${ }^{18}$ focused on the decision algorithms obtained in three different studies on prostate cancer by Adam et al., Qu et al. and Petricoin et al. ${ }^{10-12}$ and tried to find an explanation for the fact that they found completely different decision trees, although they used identical chip types and comparable study populations. Xiao et al. ${ }^{19}$ compared different cancer types, ovarian, breast and prostate cancer and indicated that various statistical methods eventually constructed different classifiers with different statistical results. Preanalytical aspects and technical details were only briefly discussed in both reviews. Therefore, our review focuses on both pre- and post-analytical aspects, supplemented with some of our own data. The description of the methods used in the different studies is summarized in the Tables 2.1 and 2.2 and discussed below.

\section{Pre-analytical aspects}

\section{Storage effects}

To avoid pre-analytical errors, sample collection for proteomic analysis should be accurately described and standardized. Until now, the effects of sample storage have not been addressed systematically and the consequences of differences in sample preparation are highly underestimated. The different studies on prostate and ovarian cancer cited here generally give insufficient information on the preanalytical conditions. In most studies, the storage-temperature of the serum samples was $-80^{\circ} \mathrm{C}$ except in the studies by Qu et al. ${ }^{12}$ and Zhang et al. ${ }^{5}$ where the samples were frozen at $-8^{\circ} \mathrm{C}$ and $-70^{\circ} \mathrm{C}$, respectively (see Table 2.1). Table 2.1 also illustrates that reports do not systematically describe how many freeze-thaw cycles were performed. Only the articles by Adam et al. ${ }^{10}$ and Li et al. ${ }^{13}$ indicate that only one freeze-thaw cycle was used. The effects of using more freeze-thaw cycles have not been investigated systematically. 
Therefore we compared freshly frozen serum samples with frequently thawed serum samples. The samples were thawed at least eight times and were stored at $-80^{\circ} \mathrm{C}$. Freshly frozen serum and frequently thawed serum from eight sarcoidosis patients and eight healthy controls were spotted on a CM10 (weak cation exchange) and on a NP20 (normal phase) ProteinChip array. In the frequently freeze-thawed sera, three peaks were detected, allowing clear discrimination of sarcoidosis from healthy controls using the CM10 chip ( $\mathrm{m} / \mathrm{z}$ values: 3808 (upregulation in sarcoidosis), 4277 (down-regulation in sarcoidosis), 8932 (upregulation in sarcoidosis). However, exactly the same experiment using freshly frozen sera no longer allowed us to discriminate between sarcoidosis and controls, because the peak differences were not significant. In contrast, in the freshly frozen samples only one significant peak, with an $\mathrm{m} / \mathrm{z}$ value of 8702 was found. This peak was different from the ones found in the frequently thawed samples. The fact that another single marker was found on the CM10 indicates that it concerns a freezethaw artefacts and underlines the importance standardization.

For the NP20 experiment, crude sera of 16 sarcoidosis and 16 healthy persons was fractionated by centrifugation with a $30 \mathrm{kDa}$ cut-off filter. The filter was used to eliminate highly expressed proteins such as human serum albumin and immunoglobulins that interfere with the detection and identification of potentially relevant less abundant proteins. For frequently freeze-thawed filtrated sera, one peak was found to discriminate sarcoidosis from healthy controls on the NP20 $(\mathrm{m} / \mathrm{z}$ 2454) with a mean intensity of 32.0 for healthy controls and 1.0 for sarcoidosis. However, when using freshly frozen serum samples, the peak was no longer visible, again indicating that it concerns a freeze-thaw artefact. Both experiments indicate that standardization of sample pre-treatment is essential.

However, in most proteomics evaluations archived samples are used, which are often thawed more than once. As also becomes apparent from our own data the number of freeze-thaw cycles and the freezing temperature should at least be identical for both study and control population. The problem can easily be overcome by dividing the samples in aliquots before storage.

\section{Serum or plasma}

Until now, insufficient information is available to decide whether serum or plasma should be preferred in proteomic studies. Most studies have used serum, but further research on this topic is required. The studies in this review all used human serum, except for the study of Rai et al.8 (Table 2.1), which used human sodium ethylenediamine tetraacetic acid (EDTA) plasma for both patients and controls. 


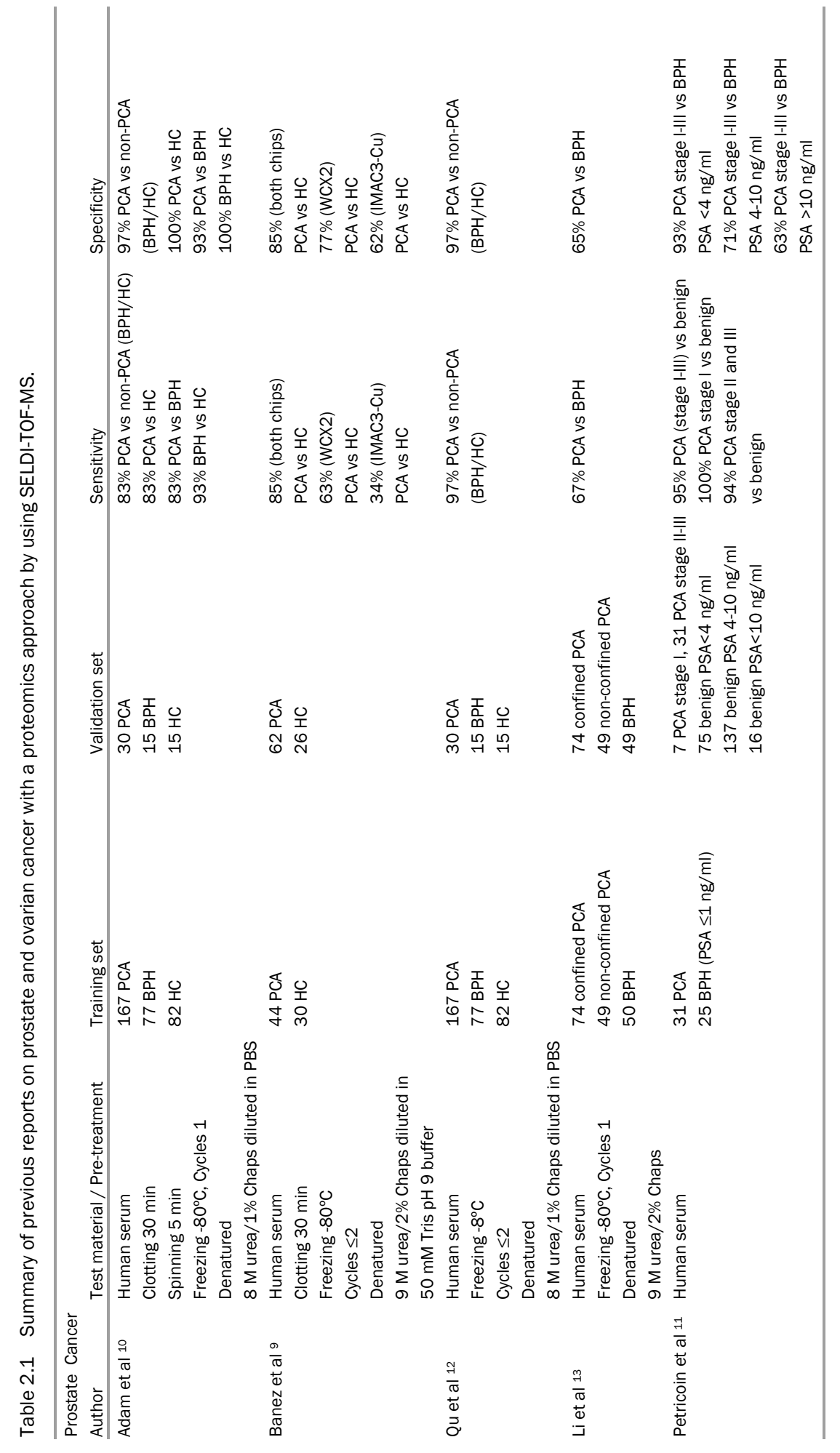




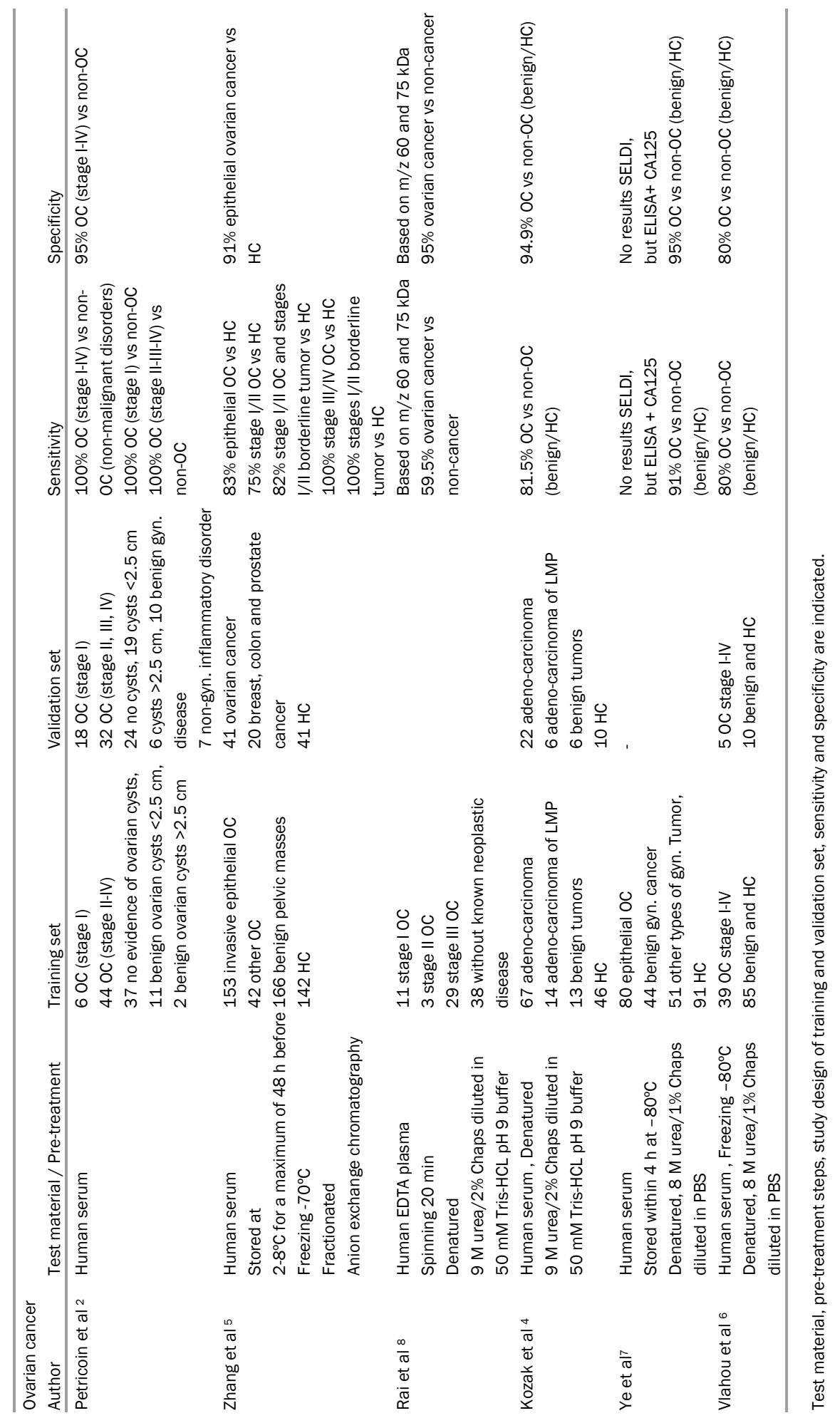




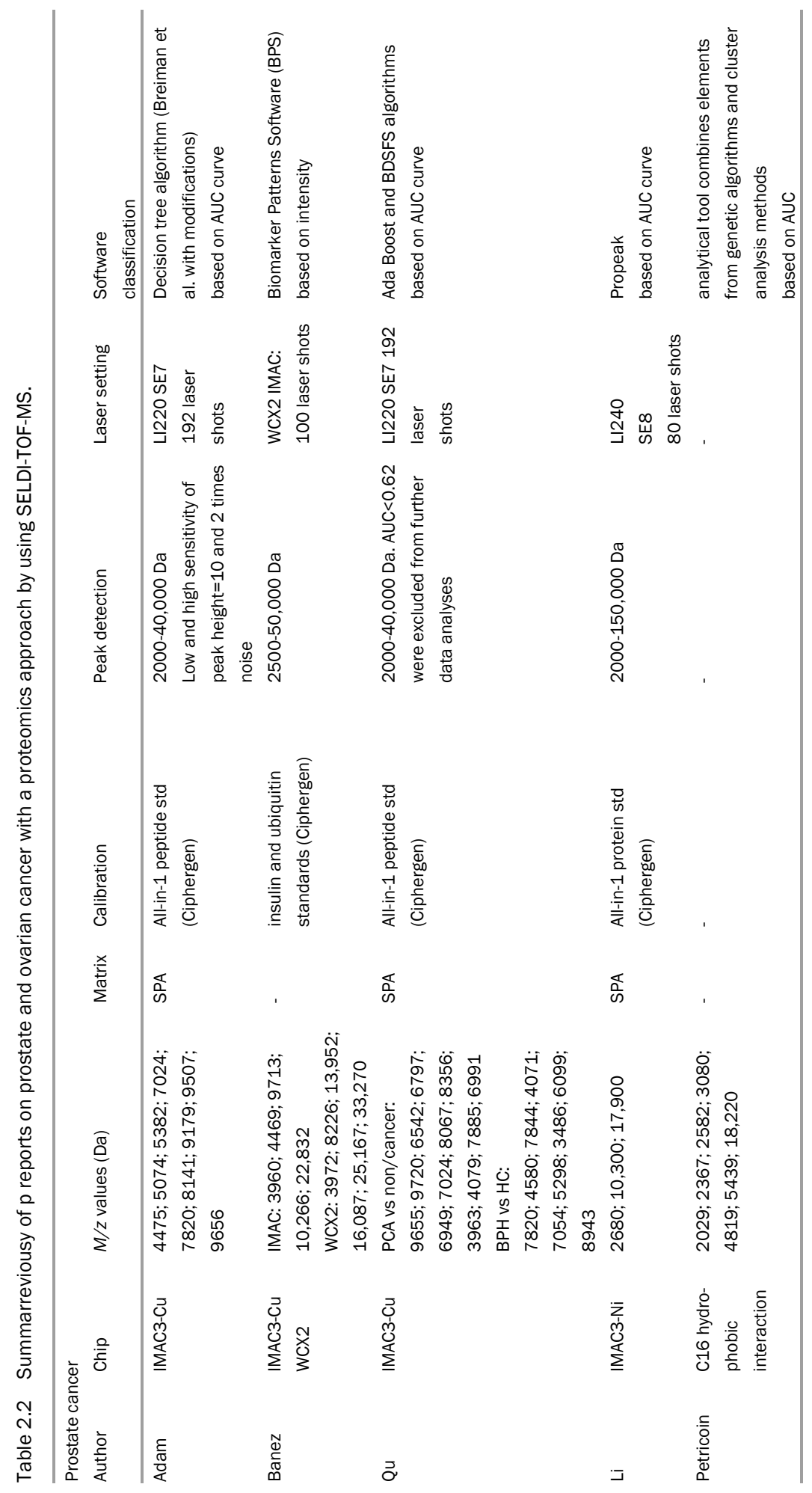




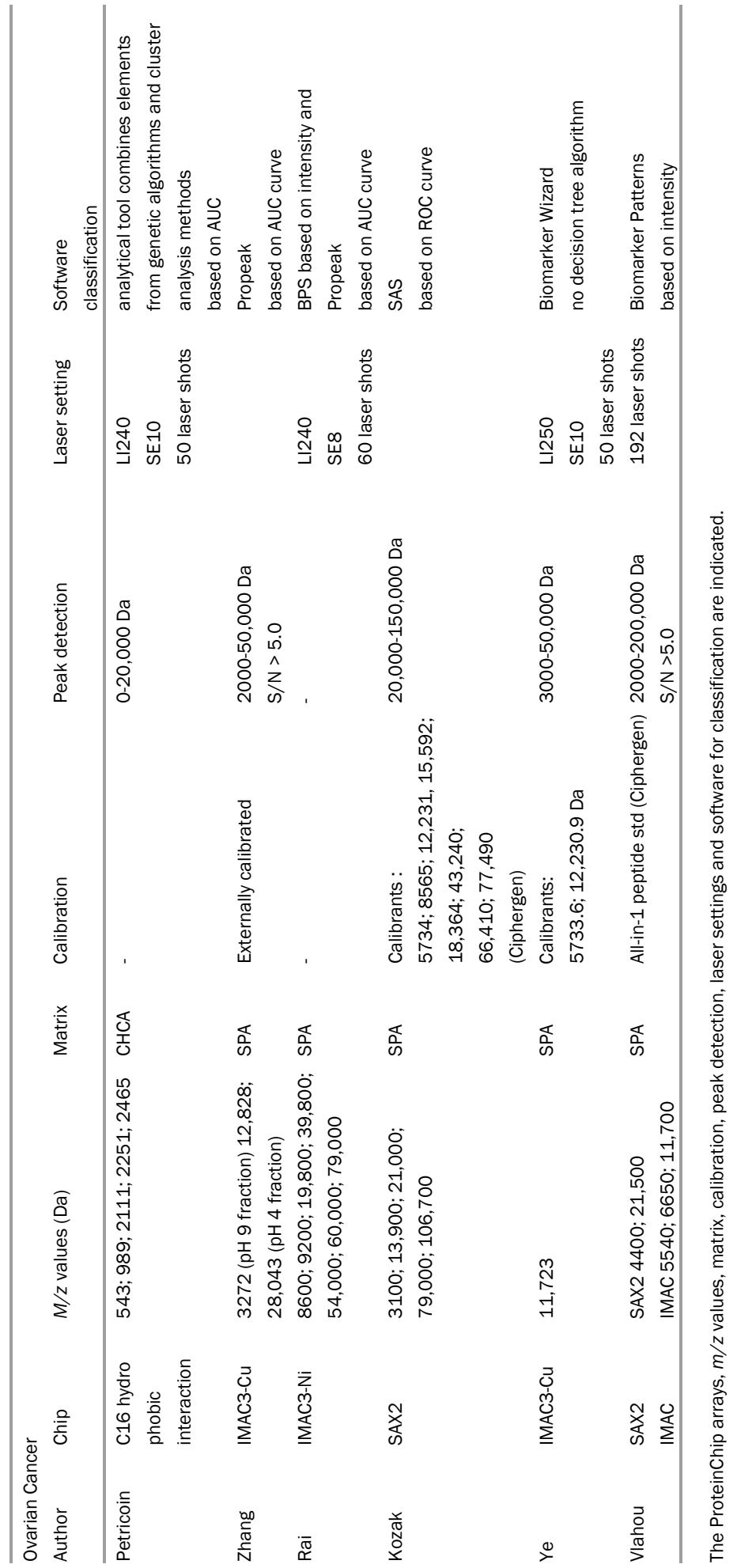


In particular, proteolytic proteins released in serum during the clotting phase can cause fragmentation of proteins and influence the final serum protein composition. In general, proteolytic activity in serum samples may have considerable consequences for protein profiling studies. Table 2.1 indicates that the pretreatment of serum before spotting on the ProteinChip arrays varies considerable in the different studies making comparison of the obtained peaks/profiles difficult. However, as long as pre-treatment of serum is the same for all samples within a study, the differences observed can be considered as relevant differences between controls and the disease population.

In our own study we compared serum and EDTA plasma with and without protease inhibitors. Serum and plasma samples of eight sarcoidosis patients and eight healthy persons were spotted on CM10 and NP20 ProteinChip arrays. The mean protein peaks in serum with and without protease inhibitors were compared with the mean protein peaks in plasma with and without protease inhibitors.

Table 2.3 shows that in the $\mathrm{m} / \mathrm{z}$ range of $2500 \mathrm{Da}$ to 150,000 Da serum without protease inhibitors showed slightly more protein peaks $(n=64)$ than serum with inhibitors $(n=63)$. EDTA plasma with and without protease inhibitors was inferior (both $n=28$ ) on the CM10 ProteinChip array. On the NP20 ProteinChip array serum without protease inhibitors showed slightly fewer protein peaks $(n=58)$ in the same $m / z$ range than serum with inhibitors $(n=63)$, but EDTA plasma with $(n=11)$ or without $(n=14)$ protease inhibitors was evidently inferior. More significant peaks that could discriminate sarcoidosis from healthy control samples were found in the serum samples with and without protease inhibitors compared to plasma samples with and without protease inhibitors on the CM10 and NP20 ProteinChip array. It is generally assumed that, more peaks can lead to more significant differences between populations as was the case in our study. Theoretically, however, plasma with protease inhibitors contains more intact proteins not attacked by proteolytic enzymes. Further examinations on the differences between serum and plasma are required.

Table 2.3 Serum and plasma samples with and without protease inhibitors were spotted on CM10 and NP20 ProteinChip arrays.

\begin{tabular}{lcc}
\hline & CM10 (N peaks) & NP20 (N peaks) \\
\hline Serum & 64 & 58 \\
Serum with protease inhibitors & 63 & 63 \\
Plasma & 28 & 11 \\
Plasma with protease inhibitors & 28 & 14 \\
\hline
\end{tabular}

The mean number of peaks $(\mathrm{N})$ in the protein spectra ( $\mathrm{m} / \mathrm{z}$ range of $2500 \mathrm{Da}$ to $150,000 \mathrm{Da})$ from eight sarcoidosis and eight healthy control samples are indicated.

\section{Sampling time}

It is known that the serum concentration of certain proteins is influenced by the sampling time, i.e., time between puncture and storage (clotting time, spinning 
time and time between spinning and storage). However, the type of material also plays a role. For instance B-type natriuretic peptide (BNP) a well-known marker for heart failure, is instable in serum, as a result of the presence of proteolytic enzymes. The degradation progresses even during storage at $-20^{\circ} \mathrm{C}$ and can only be prevented by addition of protease inhibitors or by measuring plasma BNP, instead of serum BNP20. Therefore, information on sampling-time should be indicated more clearly in the different studies. Table 2.1 shows that this information is lacking in most studies. This can be problematic when archived samples are used. However, in prospective proteomics studies clotting time and time between sample collection and storage should be standardized. We suggest, according to World Health Organization (WHO) recommendations on anticoagulants in diagnostic laboratory investigations (2002), the use of a clotting time of $30 \mathrm{~min}$ at room temperature, spinning for $15 \mathrm{~min}$ at a minimum speed of $1500 \mathrm{x} g$ and storage of the samples in aliquots within one hour at $-80^{\circ} \mathrm{C}$ after blood collection.

The consequences of differences in sample characteristics within a study population, as well as between the study and control populations, e.g., the use of fasting or non-fasting samples and age-matching of the samples should also be more rigorously standardized in future studies.

\section{Sample preparation}

Most studies used samples denatured with urea/([3-[(3-cholamidopropyl)dimethylammonio]propanesulfonate]) (CHAPS)4,6-10,12,13 while only one study used samples 5 fractionated with anion exchange chromatography. In the prostate and ovarian study of Petricoin et al.2,11 sample pre-treatment is not indicated at all. Denaturing conditions allow protein-protein interaction disruption before analysis by SELDI-TOF-MS. With fractionation, the serum proteome is divided into subproteomes and this method markedly increases resolution and sensitivity without any loss of minor proteins. With fractionation by anion exchange chromatography the highly abundant proteins such as albumin and immunoglobulins (60-80\% of total serum protein content), which can interfere with the resolution and sensitivity of the proteome profiling techniques, will be visible in specific fractions. The albumin signal will be mainly visible in fraction $3(\mathrm{pH} \mathrm{5)}$, fraction $4(\mathrm{pH} \mathrm{4})$ and fraction $5(\mathrm{pH} 3)$. Similarly, the immunoglobulins signal should be observed in fraction $1(\mathrm{pH} \mathrm{9)}$ and fraction $2(\mathrm{pH} 7)$. In this procedure, the highly abundant proteins are not removed, but they are localized to one or a few particular fractions ${ }^{21}$.

Table 2.1 shows that the denaturing steps also vary in the different studies as a result of the use of different buffer concentrations. The loss of these high abundant protein signals increased the detection of less abundant protein signals. Moreover, the total number of protein peaks with fractionated samples was larger than that seen with crude serum samples. Linke et al. ${ }^{22}$ also illustrated that fractionation greatly increases the number of peptide and protein ion signals that can be 
observed by SELDI-TOF-MS when compared to both unfractionated (only denatured) and albumin-depleted samples. By using different denaturing steps or fractionated samples, other significant peaks resulting in different biomarkers can be detected. This is one of the aspects responsible for the different results in the studies discussed here.

\section{Calibration}

The calibration step is very important to calculate the exact mass accurately. Table 2.2 illustrates that different calibrants have been used in the prostate and ovarian studies. In the prostate studies Adam et al. ${ }^{10}$ and Qu et al. ${ }^{12}$ used the All-in-1 peptide molecular weight standard of Ciphergen, while Li et al. ${ }^{13}$ used the All-in-1 protein molecular weight standard of Ciphergen. Banez et al. ${ }^{9}$ used two calibrants from Ciphergen (insulin and ubiquitin standards). The article by Petricoin et al. ${ }^{11}$ provided no information about the calibration. In the ovarian studies, also different calibrants were used (see Table 2.2). Vlahou et al. ${ }^{6}$ used All-in-1 peptide molecular weight standard of Ciphergen, while Kozak et al. ${ }^{4}$ used eight calibrants ranging from 5734-77,490 Da from Ciphergen. Ye et al. ${ }^{7}$ used two calibrants of 5734 and $12,231 \mathrm{Da}$. Zhang et al. ${ }^{5}$ described that the spectra were externally calibrated, but did not mention the calibrants. The articles by Petricoin et al. ${ }^{2}$ and Rai et al. ${ }^{8}$ gave no information at all about the calibration process. Because not all groups used the same calibrants, their studies may not be directly comparable. For comparison of data between laboratories, it is necessary to use the same calibrants.

The consequence of using different calibrants is that different $m / z$ values are detected. If potential biomarkers of small molecular weight are found, it is important to calibrate with calibrants of low molecular weight; similarly, for larger proteins, calibrants with higher molecular weight have to be used.

For instance, the $m / z$ values of albumin $(m / z 66,433)$ and IgG $(m / z 147,300)$ are approximately $500(0.8 \%)$ and $700 \mathrm{Da}(0.5 \%)$ lower with the All-in-protein standard than with the All-in-1 peptide standard. Dynorphin $(\mathrm{m} / z$ 2148) and human insulin $(\mathrm{m} / \mathrm{z} 5808)$ are approximately 900 (42\%) and $700 \mathrm{Da}(12 \%)$ higher with the All-in-1 protein standard than with the All-in-1 peptide standard (own data). In fact, the best way to calculate mass accuracy is to calibrate internally because of the spotto-spot variability. For the identification step, it is even more important to calibrate internally, because exact mass accuracy is needed for the peptide mapping. It should be noted that the Protein Biosystem II (PBSII) is a low resolution instrument and peptide mass fingerprinting is better performed on high resolution mass spectrometers. Although the PBSII can be used for peptide mass fingerprinting, the mass ranges of the measured fragments need a very large window for database searching. 


\section{Matrix}

After addition of the sample and washing buffers, the EAM is applied on the ProteinChip array. The EAM facilitates desorption and ionization in the ProteinChip Reader. The molecular weight of the proteins and peptides dictates which matrix should be used. In theory, sinapinic acid (SPA) is used for proteins larger than $15,000 \mathrm{Da}$ and $\alpha$-cyano-4-hydroxy-cinnamic acid (CHCA) is used for the proteins and peptides smaller than $15,000 \mathrm{Da}$. In practice, SPA is used with a low and high laser intensity. The laser intensity needs to be increased by increasing molecular weights. Table 2.2 shows that all prostate studies used SPA, except the study by Petricoin et al.11 for which no matrix information was given. The ovarian studies used SPA, except in the study by Petricoin et al. ${ }^{2}$ in which CHCA was used. The $m / z$ values found in the study by Petricoin et al. are also much smaller than the $m / z$ values found in the other ovarian studies. This might explain the choice for $\mathrm{CHCA}$ as a matrix.

Baggerly et al. ${ }^{23}$ found that the first two biomarkers $(\mathrm{m} / \mathrm{z} 435$ and 466$)$ in the ovarian study by Petricoin et al. $^{2}$ are below 600 Da and thus questionable in terms of matrix contamination.

\section{Post-analytical aspects}

\section{Patient population}

Table 2.1 indicates that the number of patients and healthy controls in the training and validation sets of the different studies varied enormously. The reliability of the results improves with increasing numbers of patients and healthy controls in the training and test sets. For different studies a clear description of the training and validation population is essential, such as the severity of disease. Because SELDITOF-MS fingerprinting probably measures peptides present in high abundance in serum (e.g. $\mathrm{mg} / \mathrm{l}$ to $\mathrm{g} / \mathrm{l}$ range) the molecules detected probably originate from common disease mechanisms or general protection mechanisms, i.e. epiphenomena of the diseases, such as acute phase response, cachexia etc. It is clear that the robustness of the technology should be validated by comparing patient groups with comparable disease mechanisms. Method validation should therefore be extended not only to healthy controls, but also to diseases with comparable generalized disease conditions (infection, cachexia etc).

\section{Bioinformatics and biostatistics}

Peak detection, laser settings and data analysis software affect the ultimate $\mathrm{m} / \mathrm{z}$ values found. Table 2.2 shows that the laser intensity and laser sensitivity and the number of averaged laser shots varied or were not indicated in the different 
studies. Peak detection was described in minimal detail. Since different software was used in the prostate cancer studies as well as in the ovarian cancer studies it is very difficult to compare the different $m / z$ values and sensitivities and specificities found in studies using the same ProteinChip array. Decision trees can be based on Area Under the ROC curves, but also on intensities making it hard to compare the results of studies using different kind of software for the final classification.

Recently Diamandis ${ }^{18}$ compared the decision algorithms obtained in three different studies on prostate cancer and tried to explain the fact that completely different decision trees were found even when using identical chip types and comparable study populations $2,10,12$. According to Diamandis the most likely explanation for these differences is that the methods for extracting potential molecules are very sensitive to the experimental details or to serum storage conditions, even if the same extraction devices are used. We now include a comparison with other prostate studies and have included ovarian studies. The $m / z$ values and the sensitivity and specificity results are completely different for all studies. Different software was used in all studies, which makes it very hard to compare these results. As for the pre-analytical strategy, the post-analytical strategy has an enormous impact on the final results. It should be noted that careful and precise selection of the peak labeling settings and normalization of peak intensities are considered critical for biomarker identification and for the efficient and reliable performance of any learning algorithm used in conjunction with the SELDI-TOF-MS system ${ }^{6}$.

\section{Identification}

Recently Malik et al.24 identified an isoform of apolipoprotein All (ApoA-II) giving rise to a $m / z 8946$ SELDI-TOF-MS "peak" that is specifically over expressed in prostate disease. Immunochemistry revealed that ApoA-II is indeed over-expressed in prostate tumors. The fact that this peak was detected only in the study by Qu et al. ${ }^{12}$ and not in the other prostate studies discussed here (Table 2.2) again shows the limited agreement between the different studies, obviously caused by differences in the experimental set-up.

Ye et al. ${ }^{7}$ identified the $\alpha$-chain of haptoglobin giving rise to a peak at $m / z 11,700$. The peak intensity was significantly higher in ovarian cancer. The candidate biomarker was purified by affinity chromatography, and its sequence was determined by liquid chromatography-tandem mass spectrometry. An antibody was generated from the synthesized peptide for quantitative validation of the patients and controls. This peak was not detected in the other ovarian studies, which used serum samples. However, Rai et al. ${ }^{8}$ identified another haptoglobin peak in plasma samples at $9.2 \mathrm{kDa}$ as a putative biomarker for ovarian cancer. 


\section{Immunoassay using SELDI-TOF MS}

Wright et al. ${ }^{25}$ described a novel SELDI-TOF-MS immunoassay using a ProteinChip platform to capture and detect prostate cancer-associated biomarkers by either binding single or two different antibodies to pre-activated chips. Four wellcharacterized prostate cancer-associated biomarkers, prostate specific antigen (PSA)(free and complexed forms), prostate specific peptide (PSP), prostate acid phophatase (PAP) and prostate specific membrane antigen (PSMA), were identified in cell lysates, serum and seminal plasma. This study successfully demonstrated the direct capture and detection of the four known prostate cancer biomarkers on both chemical and biologically defined chip surfaces. Xiao et al. ${ }^{26}$ used the same SELDI-TOF-MS immunoassay and patient population as described by Wright et al. ${ }^{25}$ to capture PSMA, followed by mass spectrometry to detect and quantify the antigen. This SELDI immunoassay format was successful in measuring PSMA in serum from normal healthy men and men diagnosed with either benign or malignant prostate disease. PSMA was captured from serum by anti-PMSA antibody bound to ProteinChip arrays. The captured PSMA was detected by SELDITOF-MS and quantified by comparing the mass signal integrals to a standard curve established using purified recombinant PSMA. The average serum PSMA value for prostate cancer was significantly different from that of benign prostate hyperplasia (BPH) and the control group. These results suggest that serum PSMA may be a more effective biomarker than prostate-specific antigen for differentiating benign from malignant prostate disease and warrants additional evaluation of the SELDITOF-MS PSMA immunoassay to determine its diagnostic utility. These two studies indicate that standardization using the same serum samples and performing the same specific immunoassay, leads to the same results with respect to PSMA.

\section{Reproducibility}

Recently, Semmes et al. ${ }^{27}$ published the first study on reproducibility of serum protein profiling by SELDI-TOF-MS. Across-laboratory measurement of three $\mathrm{m} / \mathrm{z}$ peaks in a standard pooled serum revealed $0.1 \%$ coefficient of variation (CV) for mass accuracy. The CV's for signal-to-noise ratio's were $34-40 \%$ and the variations in the intensities of the three peaks for all laboratories were $15-36 \% 27$. Using an algorithm developed in a single laboratory, all six laboratory sites achieved perfect blinded classification for all samples when boosted alignment of raw intensities was used. Although these results look promising and show that under strict operating procedures good across-laboratory reproducibility can be achieved, further examination of the reproducibility of peak finding and algorithm assessment is required. The fact that Semmes et al. demonstrated that good across-laboratory reproducibility can be achieved after instrument calibration and 
output standardization, again underlines that sample collection and handling are of extreme importance in proteomic studies. Invalid sample collection seems an important source of error.

Lee et al. ${ }^{28}$ also indicated that it is hard to reproduce experiments. They investigated renal cell carcinoma and included samples from patients with renal cell carcinoma, patients with benign urological diseases and healthy controls in the training set. An initial blind group of samples was used to test the models. Sensitivities and specificities of $81.3-83.3 \%$ were achieved. However, subsequent testing 10 months later with a different blind group of samples resulted in much lower sensitivities and specificities (41.0-76.6\%). Factors such as changing laser performance and a different batch of ProteinChips might be responsible for the different results.

Baggerly et al. ${ }^{23}$ indicated that artifacts associated with the technology could be responsible for the discrimination between cancer and healthy samples. Changes that could introduce such artifacts include differential handling and/or processing of the samples, changes in the type of ProteinChip array and mechanical adjustments to the mass spectrometer itself. Whenever possible, standard protocols should be drawn up to minimize the effect of irrelevant sources of variation to prevent major technological differences from overwhelming the biology associated with the outcome of interest. Careful experimental design can help. Randomizing the samples, can ensure that changes in the machine calibration, differences in chip quality and variations in the reagents, are not accidentally detected as biological differences. Keeping the operators blinded to the nature of the samples can also help ensure that systematic differences in processing do not occur inadvertently. Results must also be carefully calibrated and revalidated after every shift in the protocol. The same samples must be processed using both versions of the protocol, and the classification results confirmed. On the analytical side, standardization of for instance baseline correction is also important. With the current technology this is essential, since matrix distortions are often severe. After baseline correction, normalization is necessary. Normalizing for total ion current can ensure that the same amount of ion current has reached every spot.

\section{Conclusions}

The aim of this review was to discuss differences and to identify aspects important for future studies on protein profiling. The most important aspects appear to be differences in sample storage and pre-treatment, as well as the data analysis strategy. Pre-analytical strategies, such as storage conditions and sample pretreatment, varied enormously between the different studies and the effects were highly underestimated, as was illustrated by our own data. 
It is essential that sample collection from both the patient and control populations should be completely identical and accurately standardized in future studies. Because of the enormous variation between the different studies in both pre- and post-analytical aspects and the poor description of technical details and software, it is hard to find a clear explanation for the fact that completely different $\mathrm{m} / \mathrm{z}$ values, sensitivities and specificities were found, even in studies using identical chip types and comparable study populations ${ }^{9,10,12}$.

We conclude that protein profiling seems promising regarding the reported diagnostic values. However, it can only become a reliable diagnostic tool if in the end, it fulfils the criteria for reproducibility and standardization that are generally accepted for diagnostic tests in clinical chemistry.

The present overview clearly underlines the need for better standardization and careful description of the methods including technical details in all future studies, in order to allow comparison between studies. Moreover, the effect of pre-and postanalytical variables on protein profiling needs further and more systematic investigation.

Since different studies have shown the importance of standardization, standard protocols for proteomic studies using the SELDI-TOF-MS would be useful. A standard protocol for the collection of serum samples according to WHO (2002) is suggested. Other international organizations, such as the International Federation of Clinical Chemistry (IFCC) and Human Proteome Organization (HUPO) that are looking into some standardization issues. The HUPO Proteomics Standards Initiative (PSI) defines community standards for data representation in proteomics to facilitate data comparison, exchange and verification. PSI currently develops standards for two key areas of proteomics, mass spectrometry and protein-protein interaction data, as well as a standardized general proteomics format. Although, the IFCC and HUPO focus on standardization in proteomics studies, further recommendations for protein profiling studies with the SELDI-TOF-MS analysis are not available yet and could be very useful29,30. 


\section{References}

1. Hutchens TW, Yip T. New Desorption strategies for the mass spectrometric analysis of macromolecules. Rapid Commun Mass Spectrom 1993;7:576-580.

2. Petricoin III EF, Mills GB, Kohn EC, Liotta LA. Proteomic patterns in serum and identification of ovarian cancer. Lancet 2002;360:170-171.

3. Petricoin EF, Ardekani AM, Hitt BA, Levine PJ, Fusaro VA, Steinberg SM, Mills GB, Simone C, Fishman DA, Kohn EC, Liotta LA. Use of proteomic patterns in serum to identify ovarian cancer. Lancet 2002;359:572-577.

4. Kozak KR, Amneus MW, Pusey SM, Su F, Luong MN, Luong SA, Reddy ST, Farias-Eisner R. Identification of biomarkers for ovarian cancer using strong anion-exchange ProteinChips: potential use in diagnosis and prognosis. Proc Natl Acad Sci U S A 2003;100:12343-12348.

5. Zhang Z, Bast RC Jr, Yu Y, Li J, Sokoll LJ, Rai AJ, Rosenzweig JM, Cameron B, Wang YY, Meng XY, Berchuck A, Van Haaften-Day C, Hacker NF, de Bruijn HW, van der Zee AG, Jacobs IJ, Fung ET, Chan DW. Three biomarkers identified from serum proteomic analysis for the detection of early stage ovarian cancer. Cancer Res 2004;64:5882-5890.

6. Vlahou A, Schorge JO, Gregory BW, Coleman RL. Diagnosis of Ovarian Cancer Using Decision Tree Classification of Mass Spectral Data. J Biomed Biotechnol 2003;2003:308-314.

7. Ye B, Cramer DW, Skates SJ, Gygi SP, Pratomo V, Fu L, Horick NK, Licklider L, Schorge JO, Berkowitz RS, Mok SC. Haptoglobin-alpha subunit as potential serum biomarker in ovarian cancer: identification and characterization using proteomic profiling and mass spectrometry. Clin Cancer Res 2003;9:2904-2911.

8. Rai AJ, Zhang Z, Rosenzweig J, Shih le M, Pham T, Fung ET, Sokoll U, Chan DW. Proteomic approaches to tumor marker discovery. Arch Pathol Lab Med 2002;126:1518-1526.

9. Banez LL, Prasanna P, Sun L, Ali A, Zou Z, Adam BL, McLeod DG, Moul JW, Srivastava S. Diagnostic potential of serum proteomic patterns in prostate cancer. J Urol 2003;170:442-446.

10. Adam BL, Qu Y, Davis JW, Ward MD, Clements MA, Cazares LH, Semmes OJ, Schellhammer PF, Yasui Y, Feng Z, Wright GL Jr. Serum protein fingerprinting coupled with a pattern-matching algorithm distinguishes prostate cancer from benign prostate hyperplasia and healthy men. Cancer Res 2002;62:3609-3614.

11. Petricoin EF $3^{\text {rd }}$, Ornstein DK, Paweletz CP, Ardekani A, Hackett PS, Hitt BA, Velassco A, Trucco C, Wiegand L, Wood K, Simone CB, Levine PJ, Linehan WM, Emmert-Buck MR, Steinberg SM, Kohn EC, Liotta LA. Serum proteomic patterns for detection of prostate cancer. J Natl Cancer Inst 2002; 94:1576-1578.

12. Qu Y, Adam BL, Yasui Y, Ward MD, Cazares LH, Schellhammer PF, Feng Z, Semmes OJ, Wright GL,Jr. Boosted decision tree analysis of surface-enhanced laser desorption/ionization mass spectral serum profiles discriminates prostate cancer from noncancer patients. Clin Chem 2002; 48:1835-1843.

13. Li J, White N, Zhang Z, Rosenzweig J, Mangold LA, Partin AW, Chan DW. Detection of prostate cancer using serum proteomics pattern in a histologically confirmed population. J Urol 2004;171: 1782-1787.

14. Zhukov TA, Johanson RA, Cantor AB, Clark RA, Tockman MS. Discovery of distinct protein profiles specific for lung tumors and pre-malignant lung lesions by SELDI mass spectrometry. Lung Cancer 2003;40:267-279.

15. Poon TC, Hui AY, Chan HL, Ang IL, Chow SM, Wong N, Sung JJ. Prediction of Liver Fibrosis and Cirrhosis in Chronic Hepatitis B Infection by Serum Proteomic Fingerprinting: A Pilot Study. Clin Chem 2004;51:328-335.

16. Zhu XD, Zhang WH, Li CL, Xu Y, Liang WJ, Tien P. New serum biomarkers for detection of HBVinduced liver cirrhosis using SELDI protein chip technology. World J Gastroenterol 2004;10: 2327-2329.

17. Wiesner A. Detection of Tumor Markers with ProteinChip(R) Technology. Curr Pharm Biotechnol 2004;5:45-67.

18. Diamandis EP. How Are We Going to Discover New Cancer Biomarkers? A Proteomic Approach for Bladder Cancer. Clin Chem 2004;50:793-795. 
19. Xiao Z, Prieto D, Conrads TP, Veenstra TD, Issaq HJ. Proteomic patterns: their potential for disease diagnosis. Mol Cell Endocrinol 2005;230:95-106.

20. Belenky A, Smith A, Zhang B, Lin S, Despres N, Wu AH, Bluestein BI. The effect of class-specific protease inhibitors on the stabilization of B-type natriuretic peptide in human plasma. Clin Chim Acta 2004;340:163-172.

21. Solassol J, Marin P, Demettre E, Rouanet P, Bockaert J, Maudelonde T, Mange A. Proteomic detection of prostate-specific antigen using a serum fractionation procedure: potential implication for new low-abundance cancer biomarkers detection. Anal Biochem 2005;338:26-31.

22. Linke T, Ross AC, Harrison EH. Profiling of rat plasma by surface-enhanced laser desorption/ ionization time-of-flight mass spectrometry, a novel tool for biomarker discovery in nutrition research. J Chromatogr A 2004;1043:65-71.

23. Baggerly KA, Morris JS, R., C. K., Cautions about reproducibility in mass spectrometry patterns: joint analysis of several proteomic data sets. http://www.mdanderson.org/pdf/biostats_ utmdabtr00103.pdf 2003, 1-15.

24. Malik G, Ward MD, Gupta SK, Trosset MW, Grizzle WE, Adam BL, Diaz JI, Semmes OJ. Serum levels of an isoform of apolipoprotein A-II as a potential marker for prostate cancer. Clin Cancer Res 2005;11:1073-1085.

25. Jr GW, Cazares LH, Leung SM, Nasim S, Adam BL, Yip TT, Schellhammer PF, Gong L, Vlahou A. Proteinchip(R) surface enhanced laser desorption/ionization (SELDI) mass spectrometry: a novel protein biochip technology for detection of prostate cancer biomarkers in complex protein mixtures. Prostate Cancer Prostatic Dis 1999;2:264-276.

26. Xiao Z, Adam BL, Cazares LH, Clements MA, Davis JW, Schellhammer PF, Dalmasso EA, Wright GL Jr. Quantitation of serum prostate-specific membrane antigen by a novel protein biochip immunoassay discriminates benign from malignant prostate disease. Cancer Res 2001;61: 6029-6033.

27. Semmes OJ, Feng Z, Adam BL, Banez LL, Bigbee WL, Campos D, Cazares LH, Chan DW, Grizzle WE, Izbicka E, Kagan J, Malik G, McLerran D, Moul JW, Partin A, Prasanna P, Rosenzweig J, Sokoll L, Srivastava S, Thompson I, Welsh MJ, White N, Winget M, Yasui Y, Zhang Z, Zhu L. Evaluation of Serum Protein Profiling by Surface-Enhanced Laser Desorption/Ionization Time-of-Flight Mass Spectrometry for the Detection of Prostate Cancer: I. Assessment of Platform Reproducibility. Clin Chem 2005;51:102-112.

28. Lee SW, Lee KI, Kim JY. Revealing urologic diseases by proteomic techniques. J Chromatogr B Analyt Technol Biomed Life Sci 2005;815:203-213.

29. Orchard S, Zhu W, Julian RK Jr, Hermjakob H, Apweiler R. Further advances in the development of a data interchange standard for proteomics data. Proteomics 2003;3:2065-2066.

30. Orchard S. Hermjakob, H.; Apweiler, R., The proteomics standards initiative. Proteomics 2003;3: 1374-1376. 



\section{Chapter 3}

Standardization of calibration and quality control using Surface-Enhanced Laser Desorption/lonization Time-of-Flight Mass Spectrometry

Judith A. P. Bons, Douwe de Boer, Marja P. van Dieijen-Visser, Will K.W.H. Wodzig Clin Chim Acta 2006;366:249-56 


\section{Abstract}

\section{Background}

Protein profiling by Surface-Enhanced Laser Desorption/Ionization Time-of-Flight Mass Spectrometry is gaining importance as a diagnostic tool for a whole range of diseases. This report describes a quality control procedure, which acts prospectively by checking the calibration before starting profiling experiments.

\section{Methods}

A well-defined protocol for calibration of the Protein Biosystem Ilc instrument was established, using a commercial quality control sample containing independent certified standards and by determination of acceptance criteria. Instrument calibration was performed externally every week with the standards provided by the manufacturer. Quality control was performed for the period of five months.

\section{Results}

According to the acceptance criteria defined in this study, data points should be in the established range of the process mean \pm two standard deviations for the mass-to-charge ratio values, peak intensities, signal-to-noise ratios, and peak resolutions for insulin and apomyoglobin in the quality control sample. Moreover, it was demonstrated that the pipetting variability in the handling of the quality control sample significantly contributed to systematic errors and that spotting of a larger volume of quality control sample resulted in a better reproducibility.

\section{Conclusions}

Stringent quality control of the calibration part of Surface-Enhanced Laser Desorption/Ionization Timeof-Flight Mass Spectrometry experiments prevents unreliable data acquisition from the very start. 


\section{Introduction}

Proteomic pattern analysis by Surface-Enhanced Laser Desorption/Ionization Timeof-Flight Mass Spectrometry (SELDI-TOF-MS) is one of the most promising new approaches for the discovery and identification of potential biomarkers for various diseases. The first clinical investigations using SELDI-TOF-MS for different types of cancer, e.g., ovarian ${ }^{1-6}$, prostate ${ }^{7-11}$, lung ${ }^{12}$, and brain cancer or inflammatory diseases ${ }^{13,14}$ revealed high diagnostic sensitivities and specificities. Notwithstanding using identical types of biological specimens and the same analytical platform ${ }^{15}$, several groups identified different patterns for the same types of cancers. A recent study by Karsan et al. ${ }^{16}$ provided evidence that both preanalytical and analytical variation can affect profiled markers. They demonstrated that specimen collection and processing introduce significant biases in the spectral pattern. The differences between the pre-and post-analytical strategies used in various studies was also reviewed by Bons et al. ${ }^{17}$. The effect of pre- and postanalytical variables on protein profiling needs further and more systematic investigation. Therefore, a stringent standardized protocol is needed, not only for pre- and post-analytical aspects, but also for calibration and quality control (QC) performance.

In a recent study by Semmes et al. ${ }^{18}$ the reproducibility of the SELDI-TOF-MS was examined. Instruments of six different laboratories were calibrated by use of an established set of protocols and the instrument output was standardized with respect to three prominent mass-to-charge ratio $(\mathrm{m} / \mathrm{z})$ "peaks" present in a pooled QC serum sample. They also evaluated the ability of the calibrated and standardized instrumentation to accurately differentiate between selected cases of prostate cancer and control by use of an algorithm developed from data derived from a single laboratory two years earlier. In that study was demonstrated that under strict operating procedures, they were able to achieve across-laboratory reproducibility for SELDI-TOF-MS analysis and showed that adequate calibration was one of the critical steps.

Recently Plebani et al. ${ }^{19}$ indicated that only few studies have been made describing good quality control procedures that should be incorporated in proteomic experimental protocols. The aim of our study was to establish a well-defined protocol for calibration of the Protein Biosystem Ilc (PBSIlc) instrument, to implement a QC sample with independent certified standards and to determine acceptance criteria for quality control. Because the QC samples were spotted on a normal phase (NP-20) ProteinChip array, which is a normal phase array, without washing or selective binding steps, only the Matrix Assisted Laser Desorption/lonization Time-of-Flight Mass Spectrometry (MALDI-TOF-MS) part of the PBSIlc instrument was checked. Stable instrument performance over time is a prerequisite before any proteomic experiments should be performed. The QC procedure described in our report acts prospectively by checking the calibration 
every week in contrast to some other studies, where QC samples are included in the profiling studies and quality control thus acts retrospectively or where no quality control procedure is performed at all.

\section{Materials and Methods}

\section{Calibration samples}

Instrument calibration was performed externally with the All-in-1 peptide and All-in-1 protein standards (Ciphergen Biosystems, Inc., Fremont, CA, USA). Both standards as well as the sinapinic acid (SPA) solution as energy absorbing matrix (Ciphergen Biosystems) were prepared according to the recommendations of the manufacturer, with the exception that trifluoroacetic anhydride (TFAH) as a solvent component was used instead of trifluoroacetic acid (TFA). On a NP-20 array (Ciphergen Biosystems) with eight spots, $1 \mu$ l of All-in-1 peptide standard was applied to the spots A-D, while $1 \mu$ of All-in-1 protein standard was applied to the spots E-H. After preparation, the same calibration array was used for all experiments during the whole period, using one spot each week. The spots, including within-spot positions were alternated weekly. All seven calibrants of the All-in-1 peptide standard, ranging in molecular weight from 1084 to 7034 Dalton (Da), were used to generate the peptide calibration equation. The four lowest calibrants of the All-in-1 protein standard, ranging in molecular weight from 7034 to $29,023 \mathrm{Da}$, and the three highest calibrants, ranging in molecular weight from 46,671 to $147,300 \mathrm{Da}$ of the All-in-1 protein standard, were used to generate the protein-low calibration and protein-high calibration equations, respectively. In this study the protein-high calibration equation was not evaluated. The calibration array was stored in a dry and dark environment until further use.

\section{Quality control sample}

The QC sample consisted of the Proteomass MALDI-TOF-MS standards insulin and apomyoglobin (Sigma-Aldrich CO, St. Louis, MO, USA). According to the specifications the standards should produce in MALDI-TOF-MS analysis the $[\mathrm{M}+\mathrm{H}]^{+}$ ions at $m / z 5734.51$ and $m / z \quad 16,952.27$ for insulin and apomyoglobin, respectively. Insulin and apomyoglobin were mixed together according to the manufacturer's specifications. One $\mu \mathrm{l}$ of QC sample was applied on a NP-20 array. SPA was prepared as described above. The array was dried and afterwards $1 \mu \mathrm{l}$ SPA solution was applied. The spotting of SPA was repeated once. Each batch of the QC sample was divided into aliquots and stored at $-20^{\circ} \mathrm{C}$. A batch was used for one month, according to manufacturer's specifications and aliquots were spotted every week on a new spot of a NP-20 array. 


\section{Reproducibility}

For the reproducibility test, spotting of $1 \mu \mathrm{l} \mathrm{QC}$ sample $\left(\mathrm{QC}_{1}\right)$ was performed as described above. From the same batch, additional QC samples were prepared by diluting the QC sample five times with $1 \%$ of TFAH solution. Five $\mu$ of this diluted QC sample $\left(\mathrm{QC}_{5}\right)$ were spotted on a NP-20 array, so the absolute amount of insulin and apomyoglobin on the spot was identical for $\mathrm{QC}_{1}$ and $\mathrm{QC}_{5}$ samples. The reproducibility of $\mathrm{QC}_{1}$ and $\mathrm{QC}_{5}$ was determined with the following two experiments. In one experiment (A), two NP-20 arrays were spotted with $\mathrm{QC}_{1}$ samples and two other NP-20 arrays with $\mathrm{QC}_{5}$ samples, to compare the reproducibility of both QC samples and to determine the inter-chip variability. In the other experiment $(B)$ the $\mathrm{QC}_{1}$ and $\mathrm{QC}_{5}$ samples were spotted alternately over four NP-20 arrays to compare the reproducibility of both QC samples and to reduce the effect of inter-chip variability by dividing both QC samples over all NP-20 arrays. The reproducibility of $\mathrm{QC}_{1}$ and $\mathrm{QC}_{5}$ samples was determined by calculating the CV values for the $\mathrm{m} / \mathrm{z}$ values, intensities, signal-to-noise $(\mathrm{S} / \mathrm{N})$ ratios, and peak resolutions of the insulin and apomyoglobin signal.

\section{Instrumental settings and calibration}

The calibration and QC arrays were analyzed on a PBSIlc instrument (Ciphergen Biosystems). The high mass setting for the peptide standard was set at $10 \mathrm{kDa}$, with an optimization range between 1 and $7.5 \mathrm{kDa}$. Focus mass and deflector were set at $4 \mathrm{kDa}$ and $500 \mathrm{Da}$, respectively. Mass spectrometry profiles were generated by averaging 130 laser shots (laser intensity (LI) 165, detector sensitivity (SE) 6). For the protein standard low, the high mass setting was set at $50 \mathrm{kDa}$, with an optimization range between 7 and $30 \mathrm{kDa}$. The focus mass and deflector were set at 15 and $1 \mathrm{kDa}$, respectively. Mass spectrometry profiles were generated by averaging 130 laser shots (LI 215, SE 7). The high mass setting for the protein standard high was set at $200 \mathrm{kDa}$, with an optimization range between 25 and $150 \mathrm{kDa}$. Focus mass and deflector were set at 70 and $10 \mathrm{kDa}$, respectively. Mass spectrometry profiles were generated by averaging 130 laser shots (LI 220, SE 7). The calibration curves were generated with the 3-parameter calibration in the Biomarker ProteinChip Software 3.2.0 (Ciphergen Biosystems).

For the QC sample, the high mass setting was set at $20 \mathrm{kDa}$, with an optimization range between 5 and $20 \mathrm{kDa}$. Focus mass and deflector were set at 10 and $1 \mathrm{kDa}$, respectively. Mass spectrometry profiles were generated by averaging 130 laser shots (LI 160, SE 7). The mass accuracy of insulin and apomyoglobin were determined after calibrating with the most recent peptide and protein-low calibration equations, respectively. The mass accuracies were defined in this study as the quotient of the mass difference and the process mean of the $m / z$ values.

For the reproducibility test, the high mass setting, optimization range, focus mass, and deflector settings were the same as described above. The mass spectrometry 
profiles were also generated by averaging 130 laser shots and the optimal $\mathrm{LI}$ and $\mathrm{SE}$ for $\mathrm{QC}_{1}$ and $\mathrm{QC}_{5}$ samples were selected for both experiments. The spectra of the reproducibility test were normalized for total ion current, because they were generated during one experiment. However, the weekly generated QC spectra were not normalized.

\section{Data analysis}

Data analysis was performed with in house developed software (ShewhartPlots), which was based on the Shewhart control chart principle20. Two-dimensional Youden plots were made by drawing insulin (x-axis) and apomyoglobin (y-axis) in one plot for the $\mathrm{m} / \mathrm{z}$ values, intensities, $\mathrm{S} / \mathrm{N}$ ratios, and peak resolutions of insulin and apomyoglobin in the QC sample. The fulfilment of the following Westgard rules was checked: 13s, 22s, 41s, 8x, 10x, and $12 \mathrm{x}^{21}$.

Statistical analysis to compare CV values was performed with the two-tailed F-test.

\section{Results}

\section{Acceptance criteria}

The process mean and standard deviations for the $\mathrm{m} / \mathrm{z}$ values, intensities, $\mathrm{S} / \mathrm{N}$ ratios, and peak resolutions of insulin and apomyoglobin in the QC-sample are shown in Figure 4.1. A process mean will change when a new data point is added in comparison to a fixed mean, where the mean is always constant. A few data points occasionally exceeded the process mean \pm 2 SD range, which was noticed using the Westgard $1_{2 s}$ rule as the warning signal. After inspection it was clear that none of the measurements violated the rules 13s, 22s, 41s, 8x, 10x, and 12x and that therefore the $1_{2 s}$ observations were related to random errors.

The two dimensional Youden plots, in which the data points of insulin and apomyoglobin were combined in one plot, also demonstrated that most points were within the process mean $\pm 2 S D$ range and none of the points were outside the process mean $\pm 3 S D$ range. Figure 3.2 illustrates two examples of two-dimensional Youden plots, one of the $\mathrm{m} / \mathrm{z}$ values (Figure 3.2A) and the other of the intensities of insulin and apomyoglobin (Figure 3.2B). The advantage of two-dimensional Youden plots is that when the QC sample contains two proteins, random errors can be distinguished from systematic errors. In all cases evaluated this way, random errors were noticed, except for the intensities of insulin and apomyoglobin, where a systematic error was noticed (Figure 3.2B). As with the $1_{2 \mathrm{~s}}$ Westgard rule, the observation that the data points in the Youden plots are within the mean $\pm 3 S D$, but outside the mean $\pm 2 S D$ range, can be used as a warning signal. 

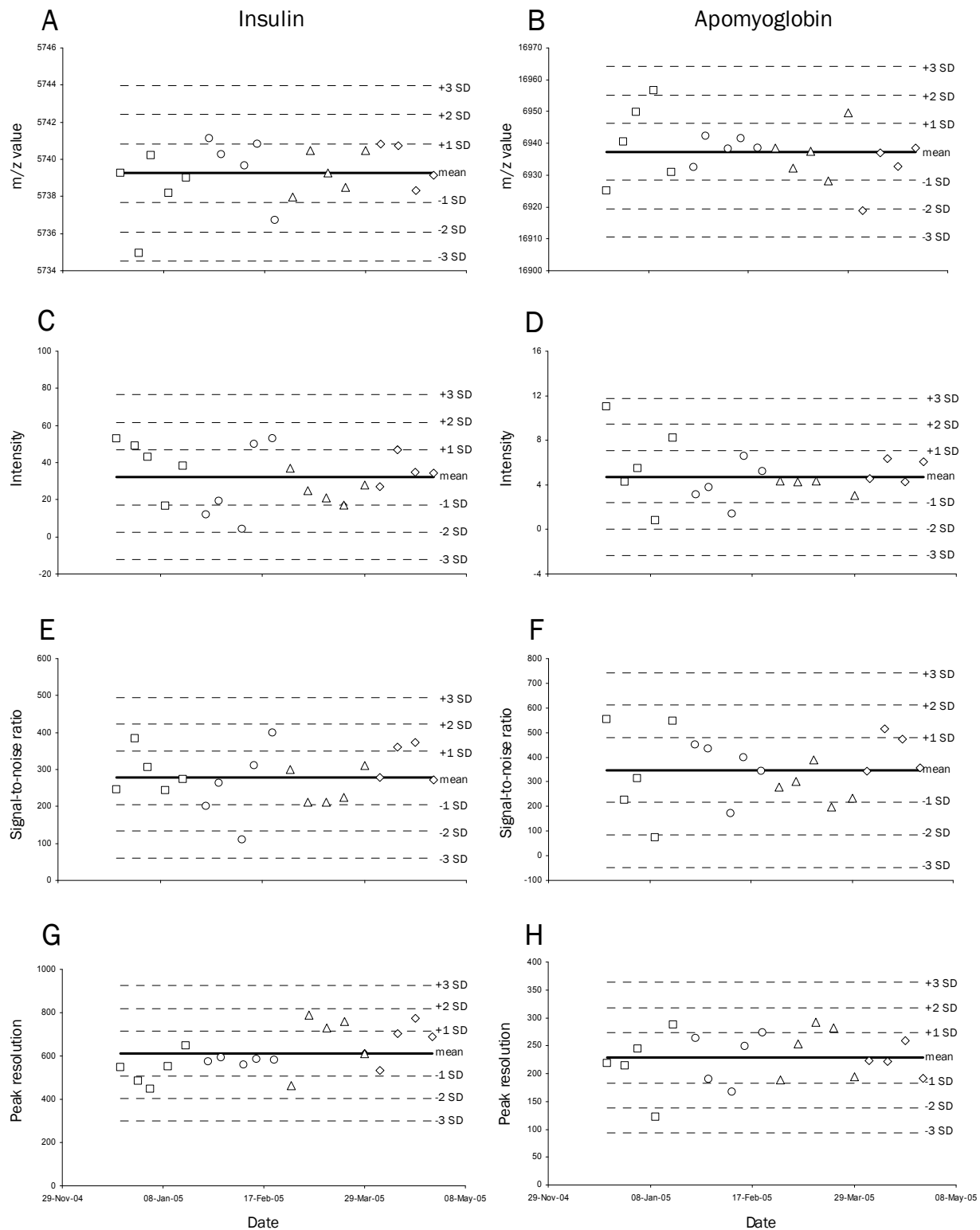

Figure 3.1 The $m / z$ values (A, B), intensities (C, D), S/N ratios (E, F), and peak resolutions $(\mathrm{G}, \mathrm{H})$ of insulin and apomyoglobin, respectively in the QC sample.

The process mean and standard deviations ( $+1,2$ and $3 \times$ SD, $-1,2$ and $3 \times$ SD) are indicated in the figures. Four different batches of QC sample were used; batch $1(\square)$, batch $2(\bigcirc)$, batch $3(\triangle)$, batch $4(\diamond)$. 


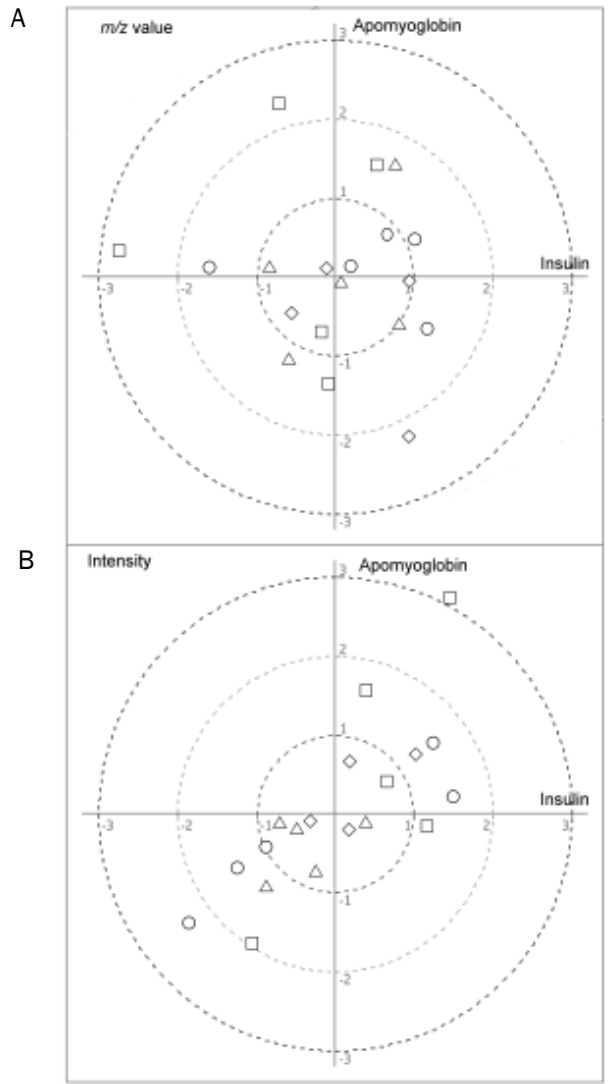

Figure 3.2 Two-dimensional Youden plots of the $m / z$ values (A), and intensities (B) of insulin and apomyoglobin in the QC sample.

The measurements of the insulin and apomyoglobin signals are indicated on the $x$ - and $y$-axis, respectively. The standard deviations (+1, 2 and $3 \times S D,-1,2$ and $3 \times S D$ ) are indicated on the $x$ - and $y$-axis. Four different batches of QC sample were used; batch 1 $(\square)$, batch $2(\bigcirc)$, batch $3(\triangle)$, batch $4(\diamond)$.

Taking into consideration the number of observations of the performance of the QC sample during five months, it was concluded that an adequate numbers of data points were collected to define acceptance criteria for the performance of the PBSIlc instrument. It was decided that data points should be in the range of the process mean $\pm 2 S D$ and accordingly that the acceptance criteria for $m / z$ values, intensities, S/N ratios and peak resolutions for insulin and apomyoglobin in the QC sample can be defined (Table 3.1). 
Table 3.1 Defined acceptance criteria (process mean $\pm 2 \mathrm{SD}$ ) for $\mathrm{m} / \mathrm{z}$ values, intensities, $\mathrm{S} / \mathrm{N}$ ratios and peak resolutions for insulin and apomyoglobin in the QC sample.

\begin{tabular}{lcccc}
\hline & $m / z$ value & Intensity & $\mathrm{S} / \mathrm{N}$ & Peak resolution \\
\hline Insulin & $5736.1-5742.4$ & $2.5-61.7$ & $133.3-422.6$ & $404.7-820.3$ \\
Apomyoglobin & $16,919.5-16,955.2$ & $0.03-9.4$ & $83.9-611.2$ & $138.2-318.3$ \\
\hline
\end{tabular}

The manufacturer has also defined specifications for the mass accuracy, which are $0.1 \%$ for masses with molecular weights ranging from 1 to $10 \mathrm{kDa}$ and $0.2 \%$ for masses with molecular weights ranging from 10 to $300 \mathrm{kDa}$ for the PBSIlc instrument. The mass accuracies of the insulin and apomyoglobin of the QC sample were exactly in accordance with the manufacturer's specifications.

\section{Reproducibility}

The reproducibility of $\mathrm{QC}_{1}$ and $\mathrm{QC}_{5}$ samples was compared in two experiments. In one experiment $(\mathrm{A})$, where two NP-20 arrays were spotted with $\mathrm{QC}_{1}$ samples and two other NP-20 arrays with $\mathrm{QC}_{5}$ samples, the pooled CV values were significantly better for $\mathrm{QC}_{1}$ samples for both insulin and apomyoglobin. However, for almost all parameters it was obvious for the $\mathrm{QC}_{5}$ samples that array two resulted in inferior $\mathrm{CV}$ values for insulin and apomyoglobin compared to array one (Table 3.2A). Different factors could have been responsible for the inferior CV values: the amount of sample spotted, the crystallization, and the chip quality.

In the other experiment $(\mathrm{B})$ the $\mathrm{QC}_{1}$ and $\mathrm{QC}_{5}$ samples were spotted alternately over four NP-20 arrays, the pooled CV values were significantly better for $\mathrm{QC}_{5}$ samples compared to $\mathrm{QC}_{1}$ samples (Table $3.2 \mathrm{~B}$ ). In general the reproducibility of $\mathrm{QC}_{5}$ samples was superior compared to the reproducibility of $\mathrm{QC}_{1}$ samples. This was also true for the individual arrays. 
Table 3.2 CV values (\%) of insulin (INS) and apomyoglobin (APO) in the $\mathrm{QC}_{1}$ and $\mathrm{QC}_{5}$ samples.

\begin{tabular}{|c|c|c|c|c|c|c|}
\hline \multirow[t]{20}{*}{$A$} & Mass accuracy & Array $1(n=8)$ & Array $2(n=8)$ & Pooled $(n=16)$ & & \\
\hline & QC1 INS & 0.04 & 0.04 & 0.04 & & \\
\hline & QC5 INS & 0.03 & 0.02 & 0.03 & & \\
\hline & QC1 APO & 0.04 & 0.05 & 0.04 & & \\
\hline & QC5 APO & 0.04 & 0.12 & 0.10 & & \\
\hline & Intensity & Array $1(n=8)$ & Array $2(n=8)$ & Pooled $(n=16)$ & & \\
\hline & QC1 INS & 30 & 21 & 25 & & \\
\hline & QC5 INS & 13 & 30 & 32 & & \\
\hline & QC1 APO & 19 & 18 & 18 & & \\
\hline & QC5 APO & 8 & 47 & 42 & & \\
\hline & $\mathrm{S} / \mathrm{N}$ & Array $1(n=8)$ & Array $2(n=8)$ & Pooled $(n=16)$ & & \\
\hline & QC1 INS & 28 & 24 & 26 & & \\
\hline & QC5 INS & 18 & 37 & 37 & & \\
\hline & QC1 APO & 74 & 62 & 67 & & \\
\hline & QC5 APO & 31 & 100 & 66 & & \\
\hline & Peak resolution & Array $1(n=8)$ & Array $2(n=8)$ & Pooled $(n=16)$ & & \\
\hline & QC1 INS & 8 & 10 & 9 & & \\
\hline & QC5 INS & 11 & 9 & 10 & & \\
\hline & QC1 APO & 15 & 13 & 14 & & \\
\hline & QC5 APO & 9 & 53 & 36 & & \\
\hline \multirow[t]{20}{*}{ B } & Mass accuracy & Array $1(n=4)$ & Array $2(n=4)$ & Array $3(n=4)$ & Array $4(n=4)$ & Pooled $(n=16)$ \\
\hline & QC1 INS & 0.02 & 0.03 & 0.03 & 0.03 & 0.02 \\
\hline & QC5 INS & 0.05 & 0.05 & 0.06 & 0.05 & 0.05 \\
\hline & QC1 APO & 0.02 & 0.03 & 0.03 & 0.03 & 0.03 \\
\hline & QC5 APO & 0.05 & 0.06 & 0.04 & 0.06 & 0.05 \\
\hline & Intensity & Array $1(n=4)$ & Array $2(n=4)$ & Array $3(n=4)$ & Array $4(n=4)$ & Pooled $(n=16)$ \\
\hline & QC1 INS & 28 & 30 & 47 & 35 & 32 \\
\hline & QC5 INS & 25 & 21 & 26 & 22 & 27 \\
\hline & QC1 APO & 14 & 3 & 3 & 8 & 8 \\
\hline & QC5 APO & 5 & 9 & 5 & 1 & 5 \\
\hline & $\mathrm{S} / \mathrm{N}$ & Array $1(n=4)$ & Array $2(n=4)$ & Array $3(n=4)$ & Array $4(n=4)$ & Pooled $(n=16)$ \\
\hline & QC1 INS & 31 & 35 & 52 & 39 & 36 \\
\hline & QC5 INS & 18 & 21 & 33 & 30 & 29 \\
\hline & QC1 APO & 11 & 17 & 10 & 14 & 13 \\
\hline & QC5 APO & 22 & 19 & 18 & 5 & 17 \\
\hline & Peak resolution & Array $1(n=4)$ & Array $2(n=4)$ & Array $3(n=4)$ & Array $4(n=4)$ & Pooled $(n=16)$ \\
\hline & QC1 INS & 18 & 13 & 16 & 16 & 15 \\
\hline & QC5 INS & 8 & 10 & 14 & 11 & 12 \\
\hline & QC1 APO & 15 & 8 & 12 & 2 & 11 \\
\hline & QC5 APO & 5 & 10 & 11 & 2 & 7 \\
\hline
\end{tabular}

CV values of $\mathrm{m} / \mathrm{z}$ values, intensities, $\mathrm{S} / \mathrm{N}$ ratios, and peak resolutions were determined in two experiments. Two NP-20 arrays were spotted with $\mathrm{QC}_{1}$ samples and two NP-20 arrays with $\mathrm{QC}_{5}$ samples (A). In the other experiment (B), the arrays were alternately spotted with $\mathrm{QC}_{1}$ and $\mathrm{QC}_{5}$ samples divided over four NP-20 arrays. 


\section{Discussion}

Any new technology, particularly one being presented as a potential clinically used diagnostic tool, requires stringent quality control to evaluate analytical performance over time. Instrument performance, however, must be compared not only during one experiment, but also over the course of time 22 . In this study a standard protocol for calibration of the MALDI-TOF-MS part of the PBSIlc instrument was defined and acceptance criteria for the independent certified QC samples were established. This is also possible for other instrument types. By checking the calibration every week, the QC procedure acts prospectively, while in some studies the quality control acts retrospectively by including the QC samples in the profiling experiments and in some studies there is no quality control procedure described at all. In contrast to the acceptance criteria reported by Semmes et al. ${ }^{18}$ we also defined an upper limit and not only a threshold value for the $m / z$ values, intensities, $\mathrm{S} / \mathrm{N}$ ratios and peak resolutions. Actions need to be taken not only when the data of the QC samples are below the acceptance criteria, but also if the upper limit of the acceptance criteria are exceeded, because of processing or instrumental errors. During our prospective QC procedure, the QC samples were only spotted on a NP-20 array, to evaluate the MALDI-TOF-MS performance. However, during the profiling studies, the QC samples can also be spotted on other surfaces, whatsoever is appropriate to verify the quality of surface-enhanced arrays.

The composition of the QC samples was based in this case on the way of calibration, which was divided into a peptide, a protein-low and a protein-high calibration equation. Insulin and apomyoglobin were chosen to validate the peptide and protein-low calibration equations, respectively. The molecular weights of biomarkers investigated in proteomic patterns analysis by SELDI-TOF-MS are in general smaller than $20 \mathrm{kDa}$ and therefore justify the current composition of the QC sample. However, with respect to the molecular range of interest, different certified proteins with different molecular weights can be chosen to validate the MALDI-TOF-MS part of the instrument. If for example the protein-high calibration becomes relevant, the composition of the QC sample should be extended with a QC component in the respective molecular weight range or an additional QC sample should be implemented. Using the right calibration equation to determine the $\mathrm{m} / \mathrm{z}$ values is important. In our study, the peptide calibration was used to determine the $m / z$ value of insulin and the protein low calibration was used to determine the $m / z$ value of apomyoglobin. However, the $m / z$ values of insulin clearly increased after calibrating with the protein-low calibration and the $m / z$ values of apomyoglobin clearly decreased after calibrating with the peptide standard calibration. Choosing the wrong or an inadequate calibration equation can lead to a significant shift of the $m / z$ values for the peak maximum. In the report by Semmes et al. ${ }^{18}$ was also 
described that by using an inadequate calibration, the $m / z$ values shifted outside the acceptable range

Obviously, stringent quality control of the calibration part of the MALDI-TOF-MS experiments prevents unreliable data acquisition from the very start, because when the data of the QC sample exceeds the acceptance criteria, actions needs to be undertaken before starting new protein profiling experiments. The criteria can be exceeded because of different factors, like errors during preparations and handling of the calibration or QC sample as well as instrumental problems. In order to illustrate some of the errors we will discuss some experiences and problems we met. In the first example, an incorrect $m / z$ value was accidentally assigned to a calibrant in the software for generating the calibration equation, which resulted in a shift of the calibration equation. The mass accuracy of the standard was outside the defined acceptance criteria and specifications. By checking the calibration spectra and subsequently selecting the correct $m / z$ value, the mass accuracy changed and proved to be in accordance with the defined acceptance criteria. In the second case an instrumental problem with the spot alignment was detected. By adding QC samples every week, a decrease in signal from spot A to $\mathrm{H}$ was detected. After adjustment of the spot alignment, the signal was similar for spots A to $\mathrm{H}$. In the third case differences between batches were seen. In the figures with the process mean and SDs and in the two dimensional Youden plots was demonstrated that the intensities of the insulin and apomyoglobin signal in the third QC batch were lower compared to the other batches. Probably the handling of that batch preparation had been less adequate than usual. All these examples demonstrate how important it is to use a well-defined protocol for calibration and to determine acceptance criteria.

With the Youden plots random errors can be distinguished from systematic errors. Random errors can for instance be caused by residual potentials on the deflection plates after the deflection pulse, which affect the flight times for ions arriving at the deflection plates after the pulse. Plate planarity imperfections, which alter the distance between the sample and the first extraction element of the ion source, can result in mass errors with external calibration. So the ion flight times are dependent on the sample plate position ${ }^{23}$. Systematic errors can be caused by pipetting errors, crystallization process of the energy absorbing matrix, and chip variability. The systematic error for the intensities (Figure $2 \mathrm{~B}$ ) must be related to the pipetting variability in the handling of the $\mathrm{QC}$ sample. The intensities, $\mathrm{S} / \mathrm{N}$ ratios and peak resolutions were lower for some data points for both insulin and apomyoglobin (Figure 3.1 and 3.2). Probably variations in the amount of QC sample applied resulted in simultaneous variations in insulin and apomyoglobin signals.

The results of the reproducibility experiments also gave insight in the possible sources of systematic errors. At first sight, $1 \mu \mathrm{LC}$ sample was spotted, but because the $\mathrm{CV}$ values were not excellent, we tried to improve the reproducibility by spotting $5 \mu$ liluted $\mathrm{QC}$ sample. In the first experiment $(\mathrm{A})$, the $\mathrm{QC}_{5}$ experiment 
resulted in a large inter-chip variability, while the inter-chip variability of the $\mathrm{QC}_{1}$ samples was acceptable. Because differences in quality of chips can occur, it is important to divide the samples alternately or at random over all arrays especially in studies based on comparison of more groups. Chip variability may be controlled by using arrays from the same batch, and chemicals used during a single experiment should also be from the same batch ${ }^{22}$. In the other experiment (B) was shown that the pooled CV values and the CV values per array were superior by spotting of $\mathrm{QC}_{5}$ samples compared to $\mathrm{QC}_{1}$ samples when the $\mathrm{QC}$ samples were spotted alternately. This demonstrates that although all pipettes used were calibrated regularly, pipetting of a larger volume, but with the identical absolute amount spotted of insulin and apomyoglobin, gave a better reproducibility of the QC sample. Therefore, in the future, only $5 \mu \mathrm{l}$ QC sample will be spotted.

The CV values in our study are comparable with the CV values reported by Semmes et al. 18 for SELDI-TOF-MS serum profiling. Potential sources of variability that arise during SELDI-TOF-MS profiling include spot-to-spot variation of chip surfaces, laser detector variability over time, pipetting variability 24 , and the crystallization process of the energy absorbing matrix ${ }^{25,26}$. Colantonio et al.27 also described that the preanalytical variation and error can be reduced by using single lot reagents, chemicals and SELDI chips and proper specimen handling and processing should be utilized to reduce pre-analytical errors. It is important to use replicates especially when profiling experiments were performed with SELDI-TOF-MS. In the report by Aivado et al. ${ }^{28}$ was demonstrated that the use of $2-4$ replicates significantly increases the reliability of protein profiles. White et al. ${ }^{22}$ also reported that replicates of spotted samples are highly recommended. In this way, the effect of spotting errors is reduced. Variability can also be reduced by using an automated robot during sample transfer and processing. Because an error introduced during processing can be difficult or impossible to trace once the experiment is completed, it is best to rigorously control the experimental procedure to minimize the introduction of variation in the first place ${ }^{22}$. Unfortunately, the same machine parameters will not continue to generate identical spectra over time. In SELDI-TOF-MS, several parts of the instrument, such as the laser and detector, have a limited life span'22.

According to the manufacturer's protocols, the All-in-1 peptide and All-in-1 protein mixtures are stable for three months after reconstitution and storage in aliquots at $-20^{\circ} \mathrm{C}$ or lower. A new aliquot should be used before every new calibration, however in this study was demonstrated that after using the same calibration array for five months by alternating the spots and within-spot positions, there were still adequate signals of the calibrants. This indicates that the calibration array can be used for a longer time period when the array is stored under appropriate conditions. 


\section{References}

1. Petricoin III EF, Mills GB, Kohn EC, Liotta LA. Proteomic patterns in serum and identification of ovarian cancer. Lancet 2002;360:170-171.

2. Kozak KR, Amneus MW, Pusey SM, Su F, Luong MN, Luong SA, Reddy ST, Farias-Eisner R. Identification of biomarkers for ovarian cancer using strong anion-exchange ProteinChips: potential use in diagnosis and prognosis. Proc Natl Acad Sci U S A 2003;100:12343-12348.

3. Zhang Z, Bast RC Jr, Yu Y, Li J, Sokoll L, Rai AJ, Rosenzweig JM, Cameron B, Wang YY, Meng XY, Berchuck A, Van Haaften-Day C, Hacker NF, de Bruijn HW, van der Zee AG, Jacobs IJ, Fung ET, Chan DW. Three biomarkers identified from serum proteomic analysis for the detection of early stage ovarian cancer. Cancer Res 2004;64:5882-5890.

4. Ye B, Cramer DW, Skates SJ, Gygi SP, Pratomo V, Fu L, Horick NK, Licklider L, Schorge JO, Berkowitz RS, Mok SC. Haptoglobin-alpha subunit as potential serum biomarker in ovarian cancer: identification and characterization using proteomic profiling and mass spectrometry. Clin Cancer Res 2003;9:2904-2911.

5. Rai AJ, Zhang Z, Rosenzweig J, Shih le M, Pham T, Fung ET, Sokoll L, Chan DW. Proteomic approaches to tumor marker discovery. Arch Pathol Lab Med 2002;126:1518-1526.

6. Vlahou A, Schorge JO, Gregory BW, Coleman RL. Diagnosis of Ovarian Cancer Using Decision Tree Classification of Mass Spectral Data. J Biomed Biotechnol 2003;2003:308-314.

7. Banez LL, Prasanna P, Sun L, Ali A, Zou Z, Adam BL, McLeod DG, Moul JW, Srivastava S. Diagnostic potential of serum proteomic patterns in prostate cancer. J Urol 2003;170:442-446.

8. Adam BL, Qu Y, Davis JW, Ward MD, Clements MA, Cazares LH, Semmes OJ, Schellhammer PF, Yasui Y, Feng Z, Wright GL Jr. Serum protein fingerprinting coupled with a pattern-matching algorithm distinguishes prostate cancer from benign prostate hyperplasia and healthy men. Cancer Res 2002;62:3609-3614.

9. Petricoin EF $3^{\text {rd }}$, Ornstein DK, Paweletz CP, Ardekani A, Hackett PS, Hitt BA, Velassco A, Trucco C, Wiegand L, Wood K, Simone CB, Levine PJ, Linehan WM, Emmert-Buck MR, Steinberg SM, Kohn EC, Liotta LA. Serum proteomic patterns for detection of prostate cancer. J Natl Cancer Inst 2002; 94:1576-1578.

10. Qu Y, Adam BL, Yasui Y, Ward MD, Cazares LH, Schellhammer PF, Feng Z, Semmes OJ, Wright GL Jr. Boosted decision tree analysis of surface-enhanced laser desorption/ionization mass spectral serum profiles discriminates prostate cancer from noncancer patients. Clin Chem 2002;48: 1835-1843.

11. Li J, White N, Zhang Z, Rosenzweig J, Mangold LA, Partin AW, Chan DW. Detection of prostate cancer using serum proteomics pattern in a histologically confirmed population. J Urol 2004;171: 1782-1787.

12. Zhukov TA, Johanson RA, Cantor AB, Clark RA, Tockman MS. Discovery of distinct protein profiles specific for lung tumors and pre-malignant lung lesions by SELDI mass spectrometry. Lung Cancer 2003;40:267-279.

13. Zhu XD, Zhang WH, Li CL, Xu Y, Liang WJ, Tien P. New serum biomarkers for detection of HBVinduced liver cirrhosis using SELDI protein chip technology. World J Gastroenterol 2004;10: 2327-2329.

14. Poon TC, Hui AY, Chan HL, Ang IL, Chow SM, Wong N, Sung JJ. Prediction of liver fibrosis and cirrhosis in chronic hepatitis $B$ infection by serum proteomic fingerprinting: a pilot study. Clin Chem 2005;51:328-335.

15. Diamandis EP. Point: Proteomic patterns in biological fluids: do they represent the future of cancer diagnostics? Clin Chem 2003;49:1272-1275.

16. Karsan A, Eigl BJ, Flibotte S, Gelmon K, Switzer P, Hassell P, Harrison D, Law J, Hayes M, Stillwell M, Xiao Z, Conrads TP, Veenstra T. Analytical and Preanalytical Biases in Serum Proteomic Pattern Analysis for Breast Cancer Diagnosis. Clin Chem 2005;51:1525-1528.

17. Bons JA, Wodzig WK, van Dieijen-Visser MP. Protein profiling as a diagnostic tool in clinical chemistry: a review. Clin Chem Lab Med 2005;43:1281-1290. 
18. Semmes OJ, Feng Z, Adam BL, Banez LL, Bigbee WL, Campos D, Cazares LH, Chan DW, Grizzle WE, Izbicka E, Kagan J, Malik G, McLerran D, Moul JW, Partin A, Prasanna P, Rosenzweig J, Sokoll L, Srivastava S, Thompson I, Welsh MJ, White N, Winget M, Yasui Y, Zhang Z, Zhu L. Evaluation of Serum Protein Profiling by Surface-Enhanced Laser Desorption/Ionization Time-of-Flight Mass Spectrometry for the Detection of Prostate Cancer: I. Assessment of Platform Reproducibility. Clin Chem 2005;51:102-112.

19. Plebani M. Proteomics: the next revolution in laboratory medicine? Clin Chim Acta 2005;357: 113-122.

20. Westgard JO, Groth T, Aronsson T, de Verdier CH. Combined Shewhart-cusum control chart for improved quality control in clinical chemistry. Clin Chem 1977;23:1881-1887.

21. Westgard JO. Internal quality control: planning and implementation strategies. Ann Clin Biochem 2003;40:593-611.

22. White $\mathrm{CN}$, Chan DW, Zhang Z. Bioinformatics strategies for proteomic profiling. Clin Biochem 2004;37:636-641.

23. Gobom J, Mueller M, Egelhofer V, Theiss D, Lehrach H, Nordhoff E. A calibration method that simplifies and improves accurate determination of peptide molecular masses by MALDI-TOF MS. Anal Chem 2002;74:3915-3923.

24. Koopmann J, Zhang Z, White N, Rosenzweig J, Fedarko N, Jagannath S, Canto MI, Yeo CJ, Chan DW, Goggins M. Serum diagnosis of pancreatic adenocarcinoma using surface-enhanced laser desorption and ionization mass spectrometry. Clin Cancer Res 2004;10:860-688.

25. Jock CA, Paulauskis JD, Baker D, Olle E, Bleavins MR, Johnson KJ, Heard PL. Influence of matrix application timing on spectral reproducibility and quality in SELDI-TOF-MS. Biotechniques 2004; 37:30-2, 34.

26. Cordingley HC, Roberts SL, Tooke P, Armitage JR, Lane PW, Wu W, Wildsmith SE. Multifactorial screening design and analysis of SELDI-TOF ProteinChip array optimization experiments. Biotechniques 2003;34:364-5, 368-373.

27. Colantonio DA, Chan DW. The clinical application of proteomics. Clin Chim Acta 2005;357:151-158.

28. Aivado M, Spentzos D, Alterovitz G, Otu H, Grall F, Giagounidis A, Wells M, Cho J, Germing U, Czibere A, Prall W, Porter C, Ramoni M, Libermann T. Optimization and evaluation of surfaceenhanced laser desorption/ionization time-of-flight mass spectrometry (SELDI-TOF MS) with reversed-phase protein arrays for protein profiling. Clin Chem Lab Med 2005;43:133-140. 



\section{Chapter 4}

Clinical proteomics in chronic inflammatory diseases, a review

Judith A.P. Bons, Marja P. van Dieijen-Visser, and Will K.W.H. Wodzig Proteomics-Clin Appl 2007;1:1123-1133 


\section{Abstract}

There is a need for better markers for the diagnosis and prognosis of chronic inflammatory diseases. Proteomic strategies can be helpful to detect new biomarkers. Proteomic analyses are performed to characterize the behavior of the system rather than the behavior of any single component. Since the genome has been unraveled, the proteome received more attention. Aim of this review is to focus on the use of different proteomics techniques to detect potential and/or common biomarkers in chronic inflammatory diseases. The identified and validated proteins detected in the different studies are compared and discussed to conclude if there are some common markers which can be used in the diagnosis and prognosis of the three chronic inflammatory diseases described in this study; multiple sclerosis, rheumatic diseases and lung inflammatory diseases. The heat shock protein family were entitled as biomarkers with potential for further research in multiple sclerosis. Myeloid-Related protein 8 was found in three different rheumatoid arthritis studies with different sample materials and could be a potential marker for rheumatoid arthritis. Alpha1-antitrypsin was validated in two studies as a marker for sarcoidosis and $\alpha 1$-antitrypsin was also found to be a marker for cystic fibrosis, together with myeloperoxidase and immunoglobulin G. 


\section{Introduction}

Proteomics studies biological systems at the protein level. Proteomics is the study of the proteome, the protein complement of the genome. Proteomics can be viewed as an experimental approach to explain the information contained in genomic sequences in terms of the structure, function, and control of biological processes and pathways ${ }^{1}$. Until the mid-1990s scientists studied individual genes and proteins or a handful of biologically related genes and proteins. With proteomics multiprotein systems, the interplay of multiple, distinct proteins in their roles as part of a larger system or network are studied. The proteome is dynamic and in constant flux due to a combination of factors. These factors include posttranslational modifications and functional regulation of gene expression? Analyses are directed at complex mixtures and identification is not performed by complete sequence analysis, but instead by partial sequence analysis with the aid of database matching tools. The point of proteomics is to characterize the behavior of the system rather than the behavior of any single component.

On the basis of mRNA processing and post-translational modifications, the estimated number of different human proteins is about 500,000, more than 15 times higher than the estimated number of coding genes in humans. Although only a fraction of these proteins is present at any given time in any particular cell, it will be a special challenge to catalogue their structures and functions and also to describe their actual concentrations differing by orders of magnitude, and to detect their activities in complexes. Identifying, cataloging and functionally describing all human proteins will be much more challenging than it was to sequence the human genomes.

The true scientific goal of serum proteomic pattern analysis is in fact biomarker discovery. Biomarkers are biological molecules that are indicators of the physiological state and also of changes during a disease process. There is a great need to discover novel biomarkers and translate them to routine clinical use 4 . Mass spectroscopic serum proteomic pattern analysis can sort through tens of thousands of potential biomarkers. The utility of biomarkers lies in their ability to provide an early indication of the disease, to monitor disease progression, to provide ease of detection, and to provide a factor measurable across populations ${ }^{5}$. There are different techniques for expression analysis of proteins, like twodimensional gel electrophoresis (2-DE), Matrix Assisted Laser Desorption/ Ionization Time-of-Flight Mass Spectrometry (MALDI-TOF-MS), Surface-Enhanced Laser Desorption/lonization Time-of-Flight Mass Spectrometry (SELDI-TOF-MS), Liquid Chromatography Tandem Mass Spectrometry (LC-MS/MS), and the isotopecoded affinity tags (ICAT), and isotope tags for relative and absolute quantification (iTRAQ) technologies which are used for quantitative analysis. This review is focused on the use of different proteomics techniques to detect potential and/or common biomarkers in chronic inflammatory diseases. In our review we will summarize the proteomics studies in multiple sclerosis, rheumatic diseases and 
lung inflammatory diseases. We have chosen chronic inflammatory diseases because of existing expertise on these chronic inflammatory diseases in our own and in other hospital research settings. The identified proteins detected in the different studies will be compared and discussed in this review.

\section{Proteomics strategies}

Until recently, 2-DE has dominated the field of proteomics. The principle of 2-DE is separation on a gel of the protein content of a sample in two dimensions according to charge and mass (Figure 4.1). The gels are stained and spot intensities in samples are compared among different gels. The advantage of the 2-DE is the high separation, which can be achieved, and the fact that post-translational modifications can be detected with this technology. The disadvantages are its lack of real high throughput capability (only one sample per gel). The method is very time-consuming and difficult to automate for routine laboratory. Other limitations are that you have to deal with between-gel irreproducibility, a poor resolution for extreme high molecular weight proteins and extremely acidic or basic proteins, and hydrophobic proteins often do not enter the gel. There is also a lot of starting material needed compared with other techniques and you cannot perform direct protein identification.

Other techniques used for the expression analysis of proteins are MALDI-TOF-MS, SELDI-TOF-MS and LC-MS/MS. With MALDI-TOF-MS, protein mixtures are spotted on a gold plate and by using an energy-absorbing matrix, proteins are ionized and the protein masses and peak intensities can be measured with the time-of-flight principle. The peak intensities will be compared between samples. The SELDI-TOF-MS is a variant of MALDI-TOF-MS. Different surfaces (like hydrophobic, hydrophilic, ionic and metal affinity binding) are used to make a selection of proteins that will bind to these surfaces and the rest is washed away. An extensive overview of this ProteinChip technology has been described by Wiesner ${ }^{3}$. Both MALDI-TOF-MS and SELDI-TOF-MS have a high throughput capability. The disadvantage of the MALDI-TOF-MS is the need for sample fractionation of complex samples and the disadvantage of the SELDI-TOF-MS is the lower resolution and mass accuracy compared to MALDI-TOF-MS.

Most analytical proteomics problems begin with a protein mixture. Before peptide sequences can be obtained the proteins must be cleaved to peptides. Cleavage of proteins in peptides can be performed with trypsin digest. It is also possible to separate the proteins by 1-DE, 2-DE, MALDI-TOF-MS or SELDI-TOF-MS and then cleave them into peptides. By using database search algorithms, the peptide data can be matched with known proteins. This general principle of proteomic analysis is illustrated in Figure 4.2.

With LC-MS/MS peptide mixtures can be separated either after trypsin digestion by LC and measurement of peptide masses by MS/MS or directly through fragmentation. The advantage of this technique is the direct identification of a lot 
of proteins per sample by MS/MS of peptides. However, this technique is very time consuming, one sample can be running at a time. The MALDI-TOF-MS, SELDI-TOF-MS and LC-MS/MS techniques are particularly important for the low molecular weight fraction of the proteome because, in this part of the proteome, the use of immunological assays such as ELISA is limited owing to difficult antibody production for low molecular weight proteins ${ }^{6}$.

Other more quantitative techniques, which are used for the expression analysis of proteins, are ICAT and ITRAQ. With ICAT, protein samples from healthy and diseased (or perturbed) sources are denatured, reduced and labeled. All cysteines in the healthy sample are modified with one isotopic version of the tag, and the cysteines in the perturbed sample are tagged with the opposite isotopic reagent. The two labeled protein mixtures are combined, and proteolyzed to peptides with trypsin. Cysteine-tagged peptides are enriched by affinity chromatography and are subsequently chromatographed by Reverse Phase High Performance Liquid Chromatography (RP-HPLC), alone or in combination with ion exchange liquid chromatography. Both samples are analyzed concomitantly by LC-MS/MS. The advantage of the ICAT technology is the direct identification of peptides by MS/MS. The results are relative quantities. The ICAT technology has expanded greatly the range of proteins that can be analyzed (such as low-abundance, hydrophobic or highly charged proteins), and allows accurate quantification and concurrent sequence identification of individual proteins in complex mixtures. The disadvantage is the low throughput (only two samples per run). Another disadvantage is that other possible post-translational modifications can be missed, because only the cysteine-containing peptides are tagged 6,7 .

Recently, an improved approach analogous to ICAT has been developed called iTRAQ. The technique is based upon chemically tagging the N-terminus of peptides. The labeled samples of patient and control groups are then combined, fractionated by nanoLC and analyzed by tandem mass spectrometry. Database searching of the fragmentation data of the peptides results in the identification of the labeled peptides and hence the corresponding proteins. Measurement of the intensity of these reporter ions, enables relative quantification of the peptides in each digest and hence the proteins from where they originate. There are four tags available enabling four different conditions to be multiplexed together in one experiment. The advantage of the iTRAQ technology is the direct identification of peptides by tandem mass spectrometry (MS/MS). One can select MS/MS of the same peptide in the four conditions in the same single run. The disadvantage, is just like the ICAT technology, the low throughput (four samples per run). Each and every peptide must be subjected to tandem MS analysis, making iTRAQ both time consuming and sample-intensive for biomarker discovery applications. Furthermore, any untagged isobaric chemical noise may confound tandem-MS sequencing of the iTRAQ labeled peptides. Another disadvantage is the high sample complexity and the limited resolution of $\mathrm{LC}^{6,7}$. More technical information about these proteomics 
technologies are reviewed in the recent studies of Verills et al. ${ }^{8}$ and Engwegen et al. ${ }^{6}$.

\section{Two dimensional gel electrophoresis}

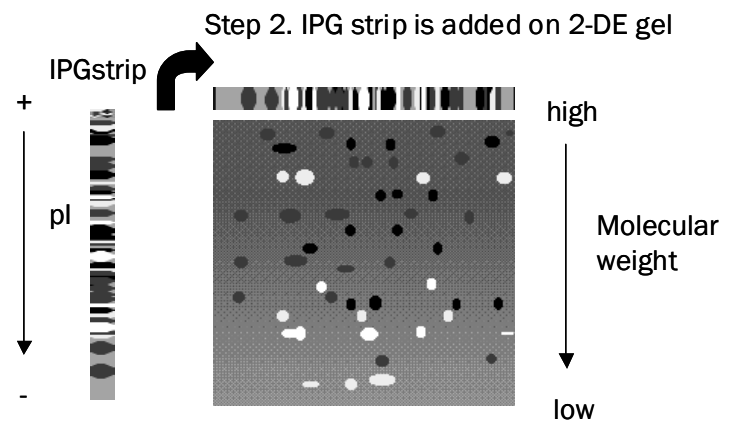

Step 1. Isoelectric focusing Step 3. SDS-PAGE

Figure 4.1 The proteins in the samples are separated in two dimensions.

By using IPGstrips, the proteins are first separated on base of their charge ( $p l$ value) and subsequently the strip is added on the gel and after isoelectric focusing the proteins are also separated according to mass. The proteins with a lower molecular weight migrate faster through the gel compared to the proteins with a higher molecular weight.

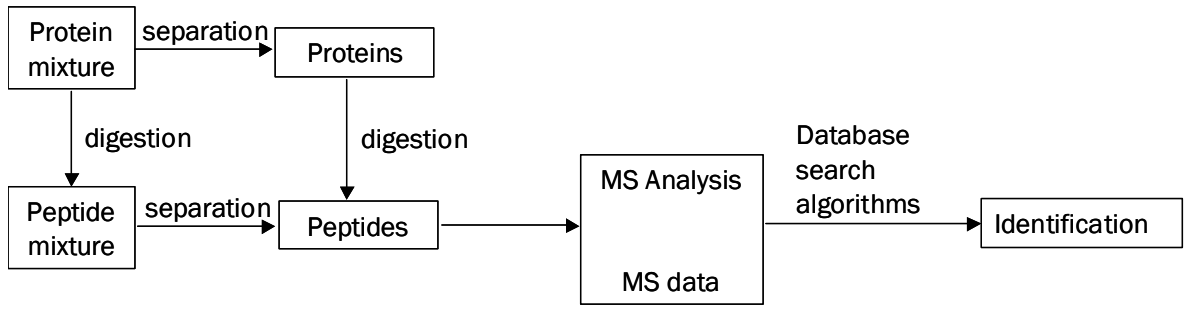

Figure 4.2 General principle of proteomic analysis.

Cleavage of proteins in peptides can be performed directly with trypsin digest. It is also possible to separate the proteins first by 1-DE, 2-DE, MALDI-TOF-MS or SELDI-TOF-MS and then cleave them into peptides. By using database search algorithms, the peptide data can be matched with known proteins.

\section{Multiple sclerosis}

Multiple sclerosis is an autoimmune inflammatory demyelinating disease of the central nervous system. Disease mechanisms in multiple sclerosis at the molecular level remain poorly understood and no reliable proteinaceous disease markers are available yet ${ }^{9}$. A definitive diagnosis is still difficult to ascertain, especially at disease onset, due to the lack of reliable molecular markers ${ }^{10}$. 
The most common clinical symptoms include paralysis, sensory disturbances, reduced coordination and visual impairment. The diagnosis is based on clinical examination, magnetic resonance imaging (MRI) and detection of oligoclonal immunoglobulins in cerebrospinal fluid (CSF) ${ }^{11}$. Although reliable serological tests are available for most autoimmune diseases, no such assay is available for the diagnosis of multiple sclerosis in part because no single antigen has been specifically associated with the disease. Nevertheless, the availability of effective immunomodulatory therapy makes it important to identify biological markers that reliably distinguish multiple sclerosis from other neurological diseases ${ }^{12}$.

\section{Rheumatic diseases}

Rheumatoid arthritis (RA) is a common human autoimmune disease. It is characterized by an inflammatory process in the synovium resulting in progressive destruction of the affected joints due to an infiltration of blood-derived cells, mainly memory $T$ cells, macrophages, and plasma cells ${ }^{13,14}$. Although the cause of this disease remains elusive, considerable advances have been made in the past few years towards identifying factors involved in the pathogenesis of RA such as auto antigens, which are recognized by autogen reactive T cells ${ }^{15}$. However, we are still far from understanding of the basic molecular grounds of the disease.

Up to now, routine clinical examination of synovial fluid (SF) including evaluation of physicochemical features, such as transparency, viscosity, glucose and protein concentrations, as well as determination of quantity and morphology of appearing cells turns out to be insufficient for the precise description of particular disease states $^{16}$.

\section{Lung inflammatory diseases}

In this review we focus on two chronic lung inflammatory diseases: sarcoidosis and cystic fibrosis. Sarcoidosis is a systemic granulomatous disorder of unknown cause characterized by its pathological hallmark, the noncaseating granuloma ${ }^{17,18}$. The clinical presentation of sarcoidosis is highly variable ${ }^{19}$. Involvement of the lungs or intrathoracic lymph nodes becomes clinically evident in $90 \%$ of the symptomatic patients during their disease and up to $30 \%$ show spontaneous remission ${ }^{20}$. A chronic course occurs in $10-30 \%$ of the patients, at times resulting in significant impairment of lung function21,22. Unfortunately, till now there is no good marker for both diagnosis and prognosis of sarcoidosis.

Cystic fibrosis (CF) is the most common lethal, autosomal, recessive, genetic disease among Caucasians. The gene, which when mutated is responsible for CF, encodes the CF-transmembrane conductance regulator (CFTR) protein. Progressive lung disease is the major cause of morbidity and mortality in patients with $\mathrm{CF}^{23}$. Although CF can be diagnosed in newborns by genetic screening, not all children will be screened for CF. Pilocarpine iontophoresis with quantitative chloride 
analysis (the sweat test) remains the gold standard for the diagnosis of CF. Clinicians have been concerned about the ability to get accurate sweat chloride results when performing early sweat tests on infants primarily because of concerns that either insufficient sweat volumes would be generated or falsely high sweat chloride concentrations might be measured during the first days to weeks of life ${ }^{24}$. Therapy is directed by evaluation, which includes review of symptoms, lung function, and to a lesser extent radiologic changes, and is therefore likely to lag behind the occurrence of established lung pathology. Until now, therapy approaches for CF lung disease have been largely symptomatic, namely through antibiotic treatment against bacterial lung infection, and also with antiinflammatory drugs ${ }^{25}$. The finding of novel therapeutic strategies that can efficiently overcome this pathology is even more complex as there is no straightforward correlation between CFTR genotype and CF lung disease severity 26 . Therefore, the identification of CF biomarkers may be of interest to help in the diagnosis, and perhaps prognosis and follow-up, of this disorder.

\section{Results}

The results of the different proteomics studies about multiple sclerosis, rheumatic diseases and sarcoidosis are illustrated in Table 4.1, 4.2, and 4.3, respectively.

\section{Multiple sclerosis}

The multiple sclerosis studies are summarized in Table 4.1. The SELDI-TOF-MS technique was used in the study of Irani et al. ${ }^{12}$ to compare CSF samples from patients with multiple sclerosis or clinically isolated syndromes (CIS), transverse myelitis, human immunodeficiency virus (HIV) and other neurological diseases. A peak around $\mathrm{m} / \mathrm{z} 12,540$, corresponding to a $12.5 \mathrm{kDa}$ protein was found in two thirds of multiple sclerosis and CIS samples and was absent in the controls with transverse myelitis or other neurological diseases. Tandem mass spectroscopy of a tryptic digest of this $12.5 \mathrm{kDa}$ protein identified it as a cleavage product of fulllength cystatin $\mathrm{C}(13.4 \mathrm{kDa})$. Although total cystatin $\mathrm{C}$ levels in the multiple sclerosis patients were not different compared with controls, the patients with the highest 12.5/13.4 peak ratios also had the greatest cathepsin B inhibitory activity. 


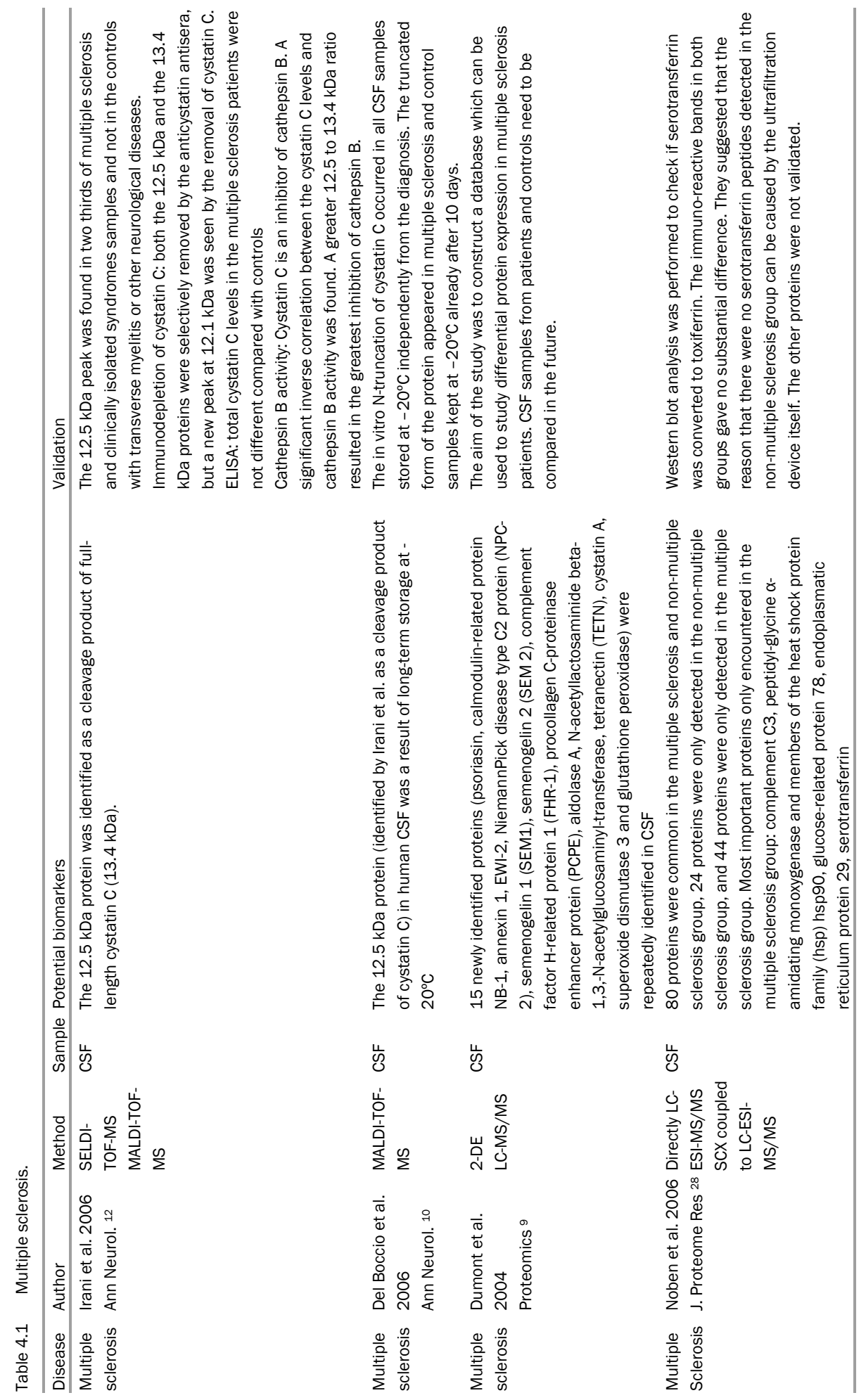


Cystatin C is an inhibitor of cathepsin B. A significant inverse correlation between the cystatin C levels and cathepsin B activity was found. A greater 12.5 to $13.4 \mathrm{kDa}$ ratio resulted in a greater inhibition of cathepsin $B$. They suggested that the cleavage of the carboxy terminus might lead to enhanced activity of this protein. They also tried to confirm their results with immunodepletion of cystatin $\mathrm{C}$. Both the $12.5 \mathrm{kDa}$ and the $13.4 \mathrm{kDa}$ proteins were selectively removed by the anticystatin antisera, but a new peak at $12.1 \mathrm{kDa}$ was seen after the removal of cystatin $\mathrm{C}$.

According to Del Boccio et al. ${ }^{10}$ is the cleavage product of cystatin C, found by Irani et al. ${ }^{12}$, a result of long-term storage at $-20^{\circ} \mathrm{C}$. In the article of Del Boccio et al. was illustrated that the N-terminal eight-amino acid-truncated form of cystatin $\mathrm{C}$ at $\mathrm{m} / \mathrm{z}$ 12,536 was always present in CSF samples which were stored more than ten days at $-20^{\circ} \mathrm{C}$, while this peak was absent in fresh samples or in samples stored at $-80^{\circ} \mathrm{C}$. This truncation at $-20^{\circ} \mathrm{C}$ occurred in all the CSF samples analyzed regardless of the underlying neurological status, indicating a storage-related phenomenon rather than physiological or pathological processing of the protein. So they suggested that the degradation is not specific in the CSF of multiple sclerosis, but rather is given by inappropriate sample storage at $-20^{\circ} \mathrm{C}$. These data are in agreement with the results of Carrette et al. $^{27}$. They studied patients with dementia of various origin and they also showed an $\mathrm{N}$-terminal truncated cystatin $\mathrm{C}$ in human CSF as a result of long-term storage at $-20^{\circ} \mathrm{C}$.

Dumont et al. ${ }^{9}$ used the 2-DE technique to construct a database of 2-DE separated CSF proteins from multiple sclerosis patients. With LC-MS/MS 65 different proteins were identified from 300 spots. Eighteen of these proteins have not been reported previously on 2-DE gels of CSF. Three of these were potential contaminants, and the other 15 newly identified proteins (see Table 4.1) were repeatedly identified in the CSF samples studied, providing supporting evidence for their presence in CSF. To detect multiple sclerosis biomarkers, the CSF samples from patients and controls need to be compared with the LC-MS/MS technique.

In the study of Noben et al. ${ }^{28}$ pooled and ultra filtered CSF of multiple sclerosis and non-multiple sclerosis patients was digested with trypsin and analyzed by off-line strong cation-exchange chromatography (SCX) coupled to on-line reversed-phase LC-ESI-MS/MS. In an alternative approach, the trypsin-treated subproteomes were analyzed directly by LC-ESI-MS/MS and gas-phase fractionation in the mass spectrometer. In total 148 proteins were identified and sixty proteins were identified in CSF for the first time. Eighty proteins were common in the multiple sclerosis and non-multiple sclerosis group, 24 proteins were only detected in the non-multiple sclerosis group, and 44 proteins were only detected in the multiple sclerosis group. The most important proteins which were only encountered in the multiple sclerosis group were: complement C3, peptidyl-glycine $\alpha$-amidating monoxygenase and members of the heat shock protein family (hsp) hsp90, glucose-related protein 78 , endoplasmatic reticulum protein 29 , serotransferrin. Hsp proteins were entitled as biomarkers with potential for further research since dysregulation in the hsp system was found to be the most prominent and 
consistent result of gene expression studies in multiple sclerosis and other autoimmune diseases. Western blot analysis was performed to check if serotransferrin was converted to toxiferrin. The immuno-reactive bands in both groups gave no substantial difference. They suggested that the reason that there were no serotransferrin peptides detected in the non-multiple sclerosis group could be caused by the ultrafiltration device itself. The other proteins were not validated.

\section{Rheumatic diseases}

The rheumatic disease studies are summarized in Table 4.2. To detect new rheumatoid arthritis biomarkers, the group of de Seny et al. ${ }^{29}$ used the SELDI-TOFMS technique. Serum samples from patients with rheumatoid arthritis (RA), psoriatic arthritis, asthma, Crohn's disease, knee osteoarthritis and healthy controls were compared. The following peaks were highlighted in the article as potential biomarkers: $\mathrm{m} / \mathrm{z} 2924$ (RA versus controls on hydrophobic (H4) ProteinChip arrays), 10,832 and 11,632 (RA versus controls on weak cationexchange (CM10) ProteinChip arrays), 4824 (RA versus psoriatic arthritis on H4 arrays), and 4666 (RA versus psoriatic arthritis on CM10 arrays). Sensitivities of $79-91 \%$ on $\mathrm{CM} 10$ and $88-97 \%$ on $\mathrm{H} 4$ arrays and specificities of $75-85.5 \%$ on $\mathrm{CM} 10$ and $87-91 \%$ on $\mathrm{H} 4$ arrays were achieved. According to the results obtained in previous studies, the 10,832 peak was suspected to be Myeloid-Related protein 8 (MRP-8). To confirm this hypothesis, Western blot analysis was performed. MRP-8 was detected in the RA patient samples and not in the control samples. Depletion of MRP-8 from RA serum using IDM affinity beads coated with MRP-8 monoclonal antibody resulted in a decreased peak at $m / z 10,832$. The definitive identification of the potential biomarkers will be obtained by MS/MS analysis in the future.

In the paper of Sinz et al. ${ }^{16}$ the 2-DE technique was combined with MALDI-TOF-MS for the analysis of proteins present in plasma and SF of patients suffering from RA, reactive arthritis or osteoarthritis. The most important findings were as follows: Calgranulin B was exclusively identified in SF samples from RA patients. Calgranulin B was not observed in SF from osteoarthritis patients, nor in plasma samples from either patient group. Serum amyloid A (SAA) protein spots were determined in plasma and SF from patients with RA, but not in patients with osteoarthritis. Fibrinogen $\beta$-chain degradation products, presumably plasminderived, appeared solely in SF and not in plasma. The biomarkers were not validated with other tests.

A reference map of the human normal articular chondrocyte was obtained by RuizRomero et al. ${ }^{30}$. Cells were isolated from cartilages and the cultured cells were used to obtain protein extracts, which were resolved, by 2-DE and visualized by silver nitrate or CBB staining. Ninety-three different proteins were identified. A significant proportion of proteins are involved in cell organization (26\%), energy $(16 \%)$, protein fate $(14 \%)$, metabolism $(12 \%)$, and cell stress $(12 \%)$. 


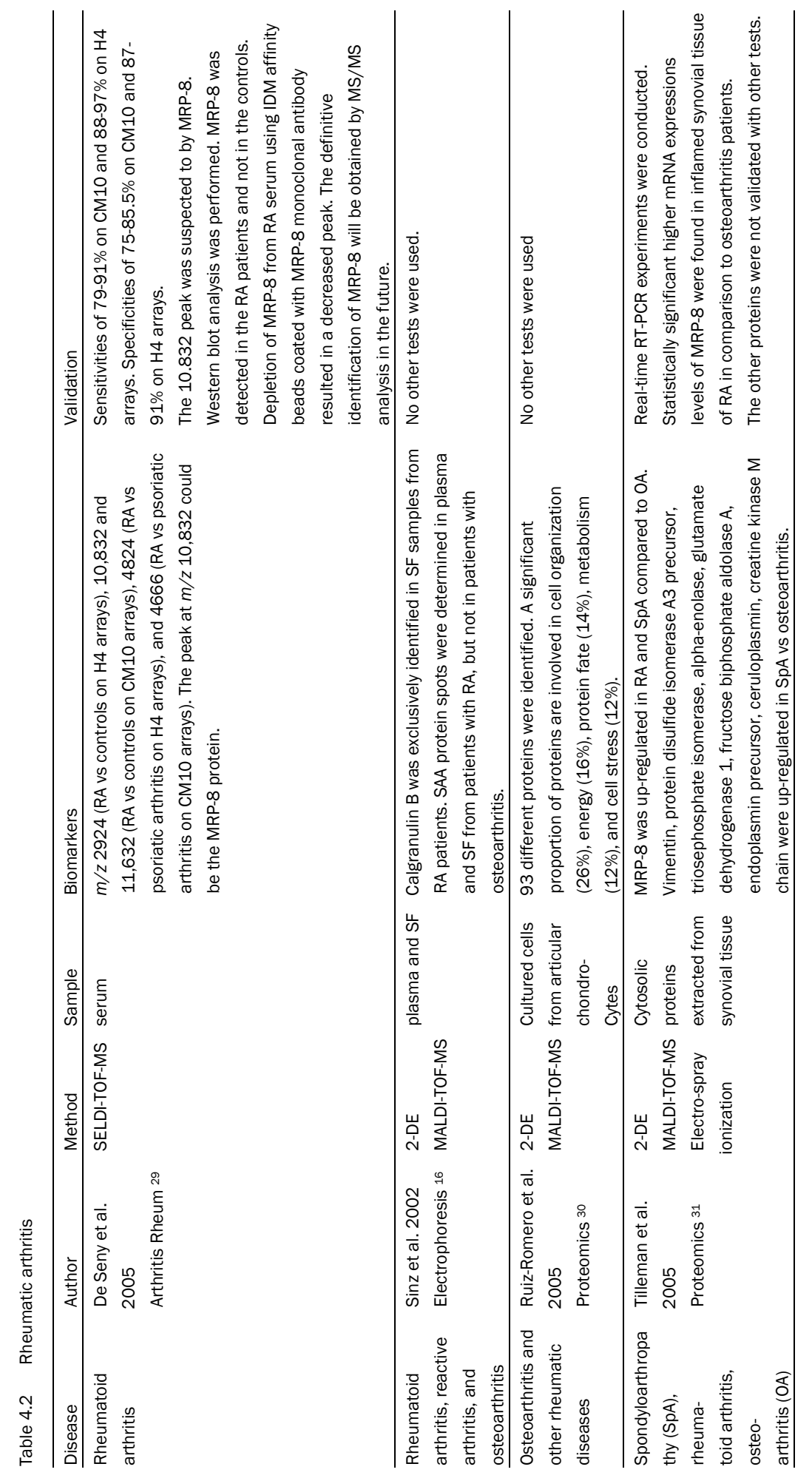




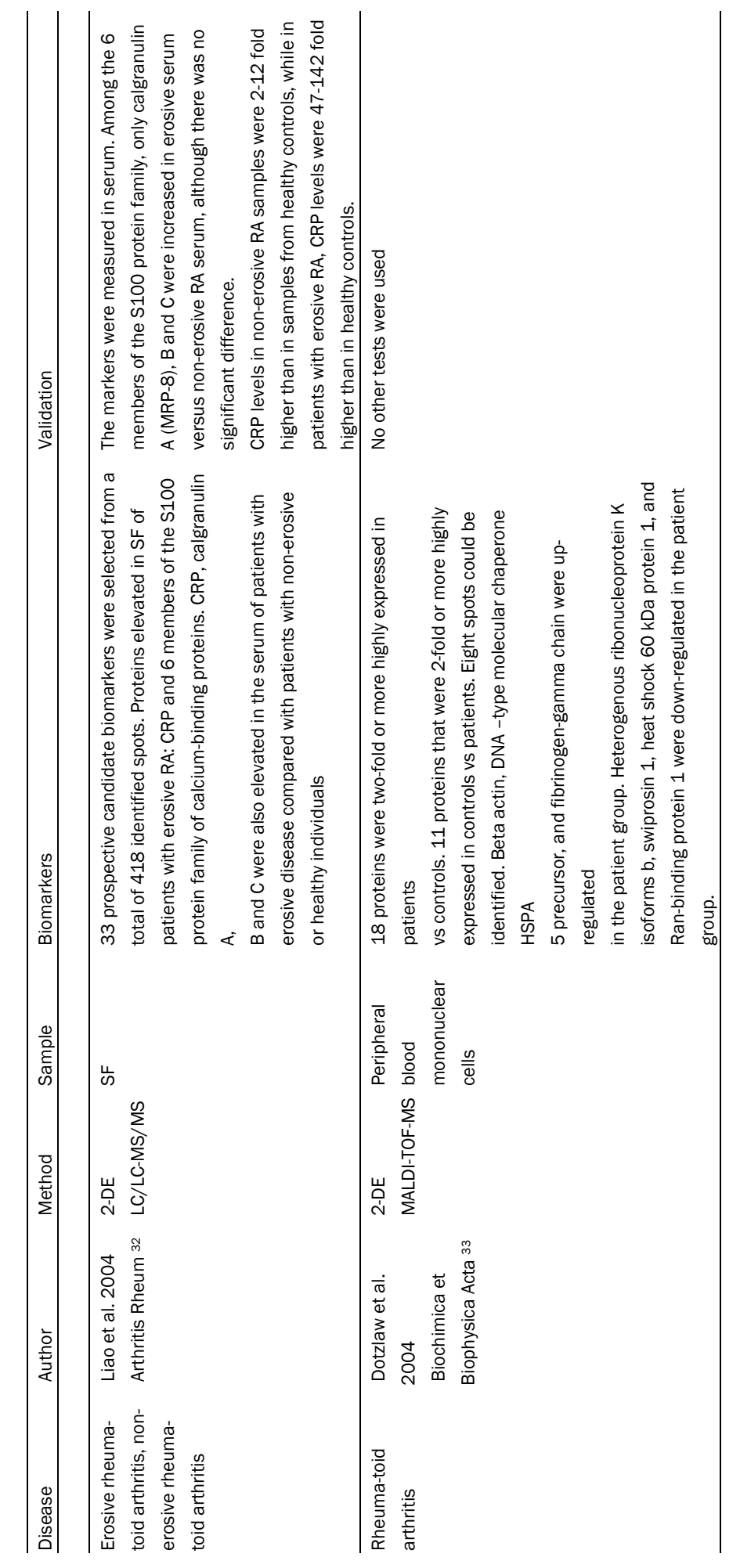


From all the identified proteins, annexins, vimentin, transgelin, destrin, cathepsin D, heat schock protein 47, and mitochondrial superoxide dismutase were more abundant in chondrocytes than in other types of mesenchymal cells.

Tilleman et al. ${ }^{31}$ investigated the cytosolic proteome of inflamed synovial tissue of patients with RA, spondyloarthropathy ( $\mathrm{SpA}$ ), and osteoarthritis. Cytosolic proteins were extracted from the tissue and subjected to 2-DE. Proteins of interest were independently identified by MALDI-TOF-MS and electrospray ionization-massspectrometry. Calgranulin A, also known as MRP-8, was up-regulated in RA and SpA compared to osteoarthritis. A real-time RT-PCR experiment was conducted. Statistically significant higher mRNA expressions levels of MRP-8 were found in inflamed synovial tissue of RA in comparison to osteoarthritis patients. Vimentin, protein disulfide isomerase A3 precursor, triosephosphate isomerase, a-enolase, glutamate dehydrogenase 1 , fructose biphosphate aldolase $A$, endoplasmin precursor, ceruloplasmin, creatine kinase M chain were up-regulated in SpA versus osteoarthritis. These proteins were not validated with other tests.

The aim of the study of Liao et al. ${ }^{32}$ was to identify a panel of candidate protein biomarkers of RA, that can predict which patients will develop erosive, disabling disease. 2-DE was combined with LC/LC-MS/MS to generate protein profiles of SF from patients with either RA or nonerosive RA and healthy controls. Thirty-three prospective candidate biomarkers were selected from a total of 418 identified spots. Among the proteins that were elevated in the SF of patients with erosive RA were C-reactive protein (CRP) and six members of the $\mathrm{S} 100$ protein family of calcium-binding proteins. These markers were also measured in serum. Among the six members of the S100 protein family, only calgranulin A (MRP-8), B and C were increased in erosive serum versus non-erosive RA serum, although there was no significant difference. CRP levels in non-erosive RA samples were 2-12 fold higher than in samples from healthy individuals, while in patients with erosive RA, CRP levels were 47-142 fold higher than in healthy controls (see Table 4.2).

Dotzlaw et al. ${ }^{33}$ compared the expression levels of proteins in peripheral blood mononuclear cells of healthy control individuals and RA patients. With 2-DE they detected 18 proteins that were two-fold or more highly expressed in patients versus controls, and 11 proteins that were two-fold or more highly expressed in controls versus patients. Eight spots could be identified. Beta actin, DNA -type molecular chaperone HSPA 5 precursor, and fibrinogen-gamma chain were upregulated in the patient group. Heterogenous ribonucleoprotein $K$ isoforms $b$, swiprosin 1, heat shock $60 \mathrm{kDa}$ protein 1 (Hsp60), and Ran-binding protein 1 were down-regulated in the patient group. No other tests were used to validate these potential biomarkers.

\section{Lung inflammatory diseases}

The sarcoidosis and cystic fibrosis studies are summarized in Table 4.3. To detect sarcoidosis biomarkers, bronchoalveolar lavage fluid (BALF) of sarcoidosis and 
healthy controls were compared using SELDI-TOF-MS in the study of Kriegova et al. ${ }^{34}$. Forty differentially expressed protein entities were detected in patients with pulmonary sarcoidosis versus control subjects $(p<0.05)$. Thirteen peaks were present across all chest X-ray stages (CXR) and 27 were specific for particular CXR stages. They were able to identify three proteins by peptide mapping and the results were confirmed by immunodepletion analysis. Human serum albumin, $\alpha 1$-antitrypsin and protocadherin-2 precursor were identified as sarcoidosis associated proteins. Albumin and protocadherin-2 precursor were up-regulated in the patients and $\alpha 1$-antitrypsin was down-regulated. The markers were confirmed with immunodepletion assays. A significant reduction of the peaks of interest was observed in immunodepletion assays. In the negative controls without the specific antibody the peaks were clearly detectable.

Magi et al. ${ }^{35}$ studied the protein composition of BALF using 2-DE. BALF samples from patients with sarcoidosis and idiopathic pulmonary fibrosis were compared. Sarcoidosis and idiopathic pulmonary fibrosis are both interstitial lung diseases, but hey have a different cellular composition and cytokine profile in BALF. Comparison of the BALF protein maps of the two groups of patients showed 32 spots with statistically significant disease-related variations in relative abundance (see Table 4.3). Alpha1-antitrypsin, macrophage migration inhibitory factor (MIF), and translationally controlled tumor protein (TCTP) were proved by Western blotting. The other potential markers were not validated.

The 2-DE technique was also used by Sabounchi-Schütt et al. ${ }^{36}$. The BALF protein patterns from sarcoidosis patients and healthy controls were compared. Eleven significantly different proteins could be successfully identified (see Table 4.3). No other tests were used to prove these proteins. Sabounchi-Schütt et al. ${ }^{37}$ also compared serum protein patterns using the 2-DE technique. Serum protein patterns from sarcoidosis patients and healthy controls were compared and 19 significantly different proteins were successfully identified (see Table 4.3). The total number of serum-protein spots was significantly increased in patients, although the total number of BALF-protein spots did not differ significantly36. When they compared the proteins found in BALF and serum, they found similar alterations of three identified proteins in BALF and serum, $\beta 2$-microglobulin, immunoglobulin kappa, and protein $\beta 2$-glycoprotein 1 , which is a plasma lipid binding protein. All three proteins are increased in the patients versus the controls.

Roxo-Rosa et al. ${ }^{38}$ identified potential biomarkers for CF lung disease by 2-DE of nasal cells from CF patients and non-CF controls. Thirteen proteins were significantly different in the CF patients versus non-CF controls (see Table 4.3). The independent validation of each protein identified will be performed in the future. The most important findings which fit with the clinical picture, are cathepsin D and Hsp 27. 


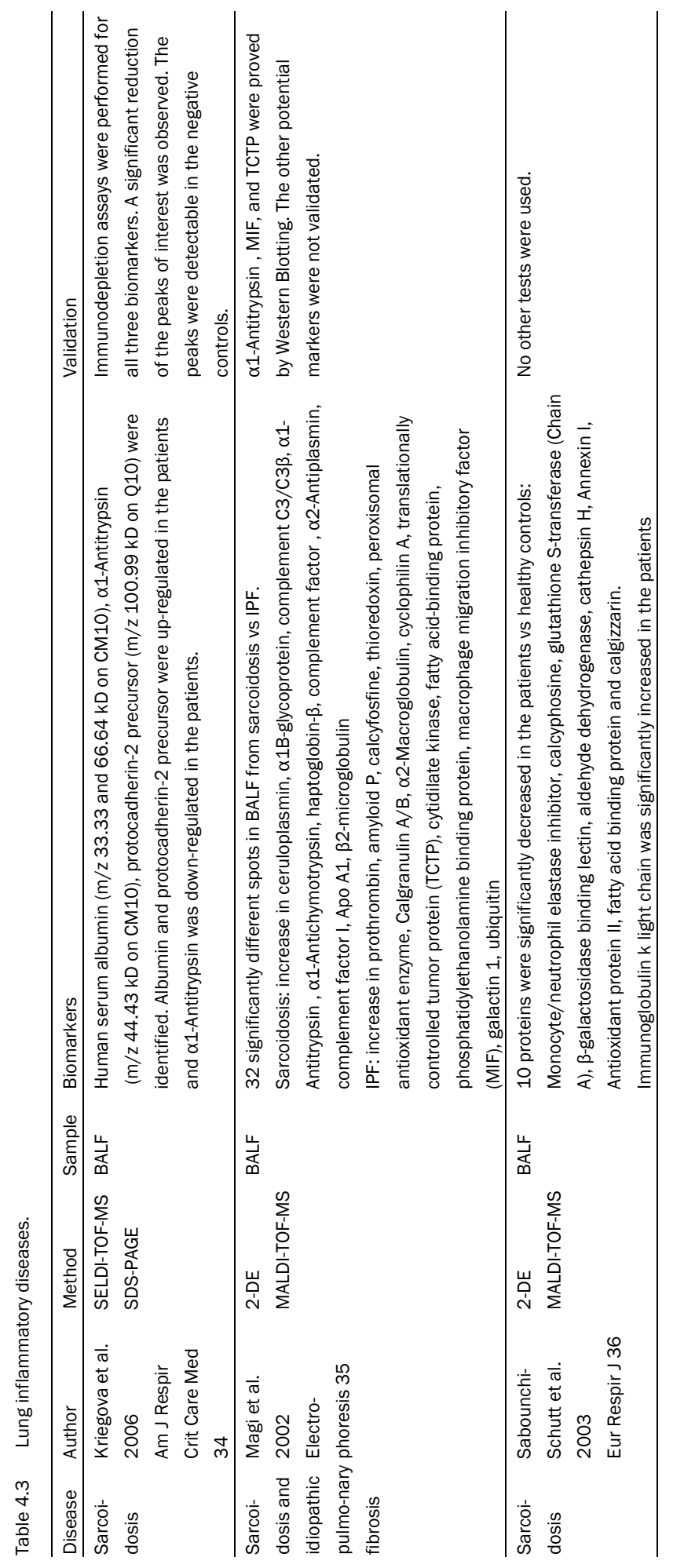




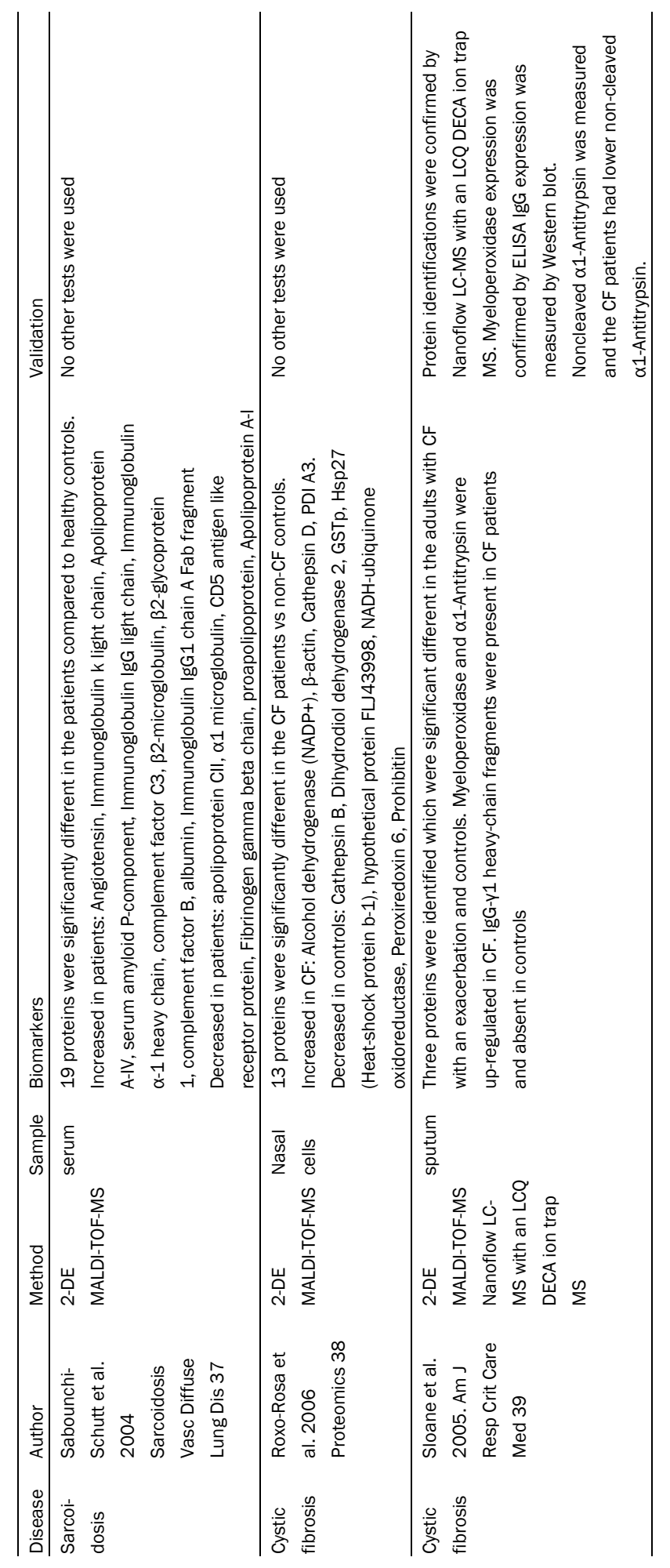


In the study of Sloane et al. ${ }^{39}$ the saline-induced sputum 2-DE protein profiles from adults with CF with an exacerbation and from children with CF with stable disease and preserved lung function were compared with profiles from adult and young controls. Three proteins were identified which were significantly different in the adults with CF with an exacerbation compared to control subjects. Myeloperoxidase and cleaved $\alpha 1$-antitrypsin were up-regulated in the CF patients. IgG degradation was present in the CF patients. Protein identifications were confirmed by Nanoflow liquid chromatography-MS with an LCQ DECA ion trap MS. Differential expression of myeloperoxidase in sputum between CF and control subjects was confirmed by ELISA. Western blotting and MALDI-TOF-MS analyses identified numerous IgG-y1 heavy-chain fragments in sputum, molecular mass around 25 to $45 \mathrm{kDa}$, from all adults with CF with an exacerbation, but only full-length chains in adult controls. Non-cleaved $\alpha 1$-antitrypsin was measured and the CF patients had lower noncleaved $\alpha 1$-antitrypsin. The relationship of each marker with FEV1 was assessed by statistical tests. Statistical correlation analyses indicated that changes in myeloperoxidase expression and IgG degradation were the strongest predictors of preserved lung function.

\section{Discussion}

The proteomics studies in multiple sclerosis, rheumatic diseases and lung inflammatory diseases are summarized in this review. A lot of proteins were identified and in some of the studies the identified proteins were also validated with other tests. The importance of pre-analytical strategies is also illustrated in this study. Del Boccio et al. ${ }^{10}$ confirmed that the in vitro $\mathrm{N}$-truncation of cystatin $\mathrm{C}$, the marker which was found by Irani et al. 12 for the diagnosis of multiple sclerosis, occurred because the CSF samples were stored at $-20^{\circ} \mathrm{C}$. This indicates that standard pre-analytical strategies need to be performed, like described in the review of Bons et al. ${ }^{40}$. The study of Noben et al. 28 illustrated that not only preanalytical, but also technical problems can cause artefacts.

In this overview we could not find a common marker for multiple sclerosis which was detected and validated in more studies, however Noben et al. ${ }^{28}$ described that the Hsp proteins were entitled as biomarkers with potential for further research in multiple sclerosis since dysregulation in the hsp system was found to be the most prominent and consistent results of gene expression studies in multiple sclerosis and other autoimmune diseases.

De Seny et al. 29 found a peak at $m / z$ 10,832 which was upregulated in rheumatoid arthritis patients and was suspected to be MRP-8. Western blot analysis and immunodepletion gave some evidence that it could be MRP-8, but the definitive identification of the peak needs to be done. Tilleman et al. ${ }^{31}$ also found MRP-8 as a potential marker for rheumatoid arthritis. In their study MRP-8 was also 
up-regulated in the RA group versus SpA and OA. They also identified other markers, but only MRP-8 was validated with real-time RT-PCR experiments. They found significant higher mRNA expressions levels of MRP-8 in inflamed synovial tissue of RA patients compared to osteoarthritis patients. Liao et al. ${ }^{32}$ identified some other markers in SF to differentiate between erosive and non-erosive rheumatoid arthritis. Four markers were validated in serum. Calgranulin A (MRP-8), $B$, and $C$ were increased (not significant) in erosive serum versus non-erosive RA serum and CRP levels were absolutely higher in the erosive RA patients versus the non-erosive patients. MRP-8 was found in three studies described in this report in different sample materials: serum, cytosolic proteins from synovial tissue and SF. The group of $\mathrm{Wu}$ et al. ${ }^{41}$ also discussed recent proteomic approaches, like twodimensional gel electrophoresis, liquid chromatography-MS/MS, capillary electrophoresis-MS/MS, SELDI-TOF-MS, and a variety of targeted antibody-based protein arrays, which can also be used for rheumatoid arthritis.

Kriegova et al. ${ }^{34}$ identified three potential markers for sarcoidosis, human serum albumin, $\alpha 1$-antitrypsin, and protocadherin-2 precursor. Albumin and protocadherin-2 precursor were up-regulated in the patients and $\alpha 1$-antitrypsin was down-regulated. All three markers were confirmed by immunodepletion assays. Magi et al. ${ }^{35}$ identified three proteins which were also validated by Western blotting. Alpha1-antitrypsin was increased in the sarcoidosis patients versus the idiopathic pulmonary fibrosis patients. Kriegova et al. ${ }^{34}$ also detected $\alpha 1$-antitrypsin, but in their study $\alpha 1$-antitrypsin was down-regulated in the patients versus healthy controls. MIF and TCTP were increased in the idiopathic pulmonary fibrosis patients versus the sarcoidosis patients.

According to Sloane et al. ${ }^{39}$, Myeloperoxidase, $\alpha 1$-antitrypsin, and the formation of more IgG- $\mathrm{1}$ heavy-chain fragments can be effective in monitoring pulmonary status in patients with CF. Total $\alpha 1$-antitrypsin was down-regulated in the patients, but the cleavage products of $\alpha 1$-antitrypsin were increased in the CF patients versus the controls. Roxo-Rosa et al. ${ }^{38}$ also detected an up-regulation of cathepsin $\mathrm{D}$ in CF patients versus controls. Cathepsin is an enzyme which is involved in the inflammatory process of CF. They also found Hsp 27 as an important marker. Hsp27 is an ATP-independent chaperone that functions as an inhibitor of nuclear factor kappa-B pathway. Therefore, the reduced levels of this negative regulator might explain the increased activation of the nuclear factor $\mathrm{kB}$ and overproduction of Interleukin 8 reported to occur in CF bronchial gland cells and CF lungs ${ }^{42,43}$.

In conclusion, the Hsp proteins were entitled as biomarkers with potential for further research in multiple sclerosis. MRP-8 was found in three different rheumatoid arthritis studies with different sample materials and could be a potential marker for rheumatoid arthritis. Alpha1-antitrypsin was validated in two studies as a marker for sarcoidosis, although in one study sarcoidosis patients were compared with idiopathic pulmonary fibrosis patients and in the other study the sarcoidosis patients were compared with healthy control samples. Alpha1-antitrypsin was also found as a marker for CF, together with 
myeloperoxidase and IgG. The use of these markers should be confirmed by increasing the sample sets. In the coming years, the following proteomics technologies will probably dominate the clinical proteomics field; two-dimensional fluorescence difference gel electrophoresis (2-DIGE), and multi-dimensional liquid chromatography approaches. With 2-DIGE, Cy dye fluorophores are used for prelabeling the protein samples. The 2-DIGE technology adds a quantitative component to conventional 2-DE analyses allowing comparison of protein expression changes across multiple samples simultaneously without gel-to-gel variation ${ }^{8}$. Most multi-dimensional liquid chromatography approaches utilize a strong cation exchange followed by a reverse phase separation, and the chromatography columns can be physically attached on-line to the mass spectrometer. Such multidimensional protein identification technology (also referred to as MudPit) is an attractive approach for analyzing complex samples in a large scale manner ${ }^{8}$. These new advances will also be suitable for the detection of potential biomarkers in chronic inflammatory diseases. 


\section{References}

1. Aebersold R, Goodlett DR. Mass spectrometry in proteomics. Chem Rev 2001;101:269-295.

2. Srinivas PR, Srivastava S, Hanash S, Wright GL Jr. Proteomics in Early Detection of Cancer. Clin Chem 2001;47:1901-1911.

3. Wiesner, A., Detection of Tumor Markers with ProteinChip(R) Technology. Curr Pharm Biotechnol 2004:5:45-67.

4. Anderson NL, Anderson NG. The human plasma proteome: history, character, and diagnostic prospects. Mol Cell Proteomics 2002;1:845-867.

5. Srinivas PR, Verma M, Zhao Y, Srivastava, S. Proteomics for cancer biomarker discovery. Clin Chem 2002;48:1160-1169.

6. Engwegen JY, Gast MC, Schellens JH, Beijnen JH. Clinical proteomics: searching for better tumour markers with SELDI-TOF mass spectrometry. Trends Pharmacol Sci 2006;27:251-259.

7. Schneider LV, Hall MP. Stable isotope methods for high-precision proteomics. Drug Discov Today 2005;10:353-363.

8. Verrills NM. Clinical proteomics: present and future prospects. Clin Biochem Rev 2006;27:99-116.

9. Dumont D, Noben JP, Raus J, Stinissen P, Robben J. Proteomic analysis of cerebrospinal fluid from multiple sclerosis patients. Proteomics 2004;4:2117-2124.

10. Del Boccio P, Pieragostino D, Lugaresi A, Di loia M, Pavone B, Travaglini D, D'Aguanno S, Bernardini S, Sacchetta P, Federici G, Di Ilio C, Gambi D, Urbani A. Cleavage of cystatin C is not associated with multiple sclerosis. Ann Neurol 2007;62:201-204.

11. Hellings N, Raus J, Stinissen P. Insights into the immunopathogenesis of multiple sclerosis. Immunol Res 2002;25:27-51.

12. Irani DN, Anderson C, Gundry R, Cotter R, Moore S, Kerr DA, McArthur JC, Sacktor N, Pardo CA, Jones M, Calabresi P,A, Nath A. Cleavage of cystatin C in the cerebrospinal fluid of patients with multiple sclerosis. Ann Neurol 2006;59:237-247.

13. Janossy G, Panayi G, Duke O, Bofill M, Poulter LW, Goldstein G. Rheumatoid arthritis: a disease of T-lymphocyte/macrophage immunoregulation. Lancet 1981;2:839-842.

14. Cush JJ, Lipsky PE. Phenotypic analysis of synovial tissue and peripheral blood lymphocytes isolated from patients with rheumatoid arthritis. Arthritis Rheum 1988;31:1230-1238.

15. Feldmann M, Brennan FM, Maini RN. Rheumatoid arthritis. Cell 1996;85:307-310.

16. Sinz A, Bantscheff M, Mikkat S, Ringel B, Drynda S, Kekow J, Thiesen HJ, Glocker MO. Mass spectrometric proteome analyses of synovial fluids and plasmas from patients suffering from rheumatoid arthritis and comparison to reactive arthritis or osteoarthritis. Electrophoresis 2002; 23:3445-3456.

17. Baughman RP, Lower EE, Du Bois RM. Sarcoidosis. Lancet 2003;361:1111-1118.

18. Kataria YP, Holter JF. Sarcoidosis: A Model of Granulomatous Inflammation of Unknown Etiology Associated with a Hyperactive Immune System. Methods 1996;9:268-294.

19. Judson MA, Baughman RP, Thompson BW, Teirstein AS, Terrin ML, Rossman MD, Yeager H Jr, McLennan G, Bresnitz EA, DePalo L, Hunninghake G, lannuzzi MC, Johns CJ, Moller DR, Newman LS, Rabin DL, Rose C, Rybicki BA, Weinberger SE, Knatterud GL, Cherniak R. Two year prognosis of sarcoidosis: the ACCESS experience. Sarcoidosis Vasc Diffuse Lung Dis 2003;20:204-211.

20. Rybicki BA, Maliarik MJ, Major M, Popovich J Jr, lannuzzi MC. Epidemiology, demographics, and genetics of sarcoidosis. Semin Respir Infect 1998;13:166-173.

21. Baughman RP, Winget DB, Bowen EH, Lower EE. Predicting respiratory failure in sarcoidosis patients. Sarcoidosis Vasc Diffuse Lung Dis 1997;14:154-158.

22. Arcasoy SM, Christie JD, Pochettino A, Rosengard BR, Blumenthal NP, Bavaria JE, Kotloff RM. Characteristics and outcomes of patients with sarcoidosis listed for lung transplantation. Chest 2001;120:873-880.

23. Collins FS. Cystic fibrosis: molecular biology and therapeutic implications. Science 1992;256: 774-779.

24. Parad RB, Comeau AM, Dorkin HL, Dovey M, Gerstle R, Martin T, O'Sullivan BP. Sweat testing infants detected by cystic fibrosis newborn screening. J Pediatr 2005;147(3 Suppl):S69-72.

25. Ratjen F, Doring G. Cystic fibrosis. Lancet 2003;361:681-689. 
26. Kerem E, Corey M, Kerem BS, Rommens J, Markiewicz D, Levison H, Tsui LC, Durie P. The relation between genotype and phenotype in cystic fibrosis--analysis of the most common mutation (delta F508). N Engl J Med 1990;323:1517-1522.

27. Carrette O, Burkhard PR, Hughes S, Hochstrasser DF, Sanchez JC. Truncated cystatin C in cerebrospiral fluid: Technical [corrected] artefact or biological process? Proteomics 2005;5: 3060-3065.

28. Noben JP, Dumont D, Kwasnikowska N, Verhaert P, Somers V, Hupperts R, Stinissen P, Robben J. Lumbar cerebrospinal fluid proteome in multiple sclerosis: characterization by ultrafiltration, liquid chromatography, and mass spectrometry. J Proteome Res 2006;5:1647-1657.

29. de Seny D, Fillet M, Meuwis MA, Geurts P, Lutteri L, Ribbens C, Bours V, Wehenkel L, Piette J, Malaise M, Merville MP. Discovery of new rheumatoid arthritis biomarkers using the surfaceenhanced laser desorption/ionization time-of-flight mass spectrometry ProteinChip approach. Arthritis Rheum 2005;52:3801-3812.

30. Ruiz-Romero C, Lopez-Armada MJ, Blanco FJ. Proteomic characterization of human normal articular chondrocytes: a novel tool for the study of osteoarthritis and other rheumatic diseases. Proteomics 2005;5:3048-3059.

31. Tilleman K, Van Beneden K, Dhondt A, Hoffman I, De Keyser F, Veys E, Elewaut D, Deforce D. Chronically inflamed synovium from spondyloarthropathy and rheumatoid arthritis investigated by protein expression profiling followed by tandem mass spectrometry. Proteomics 2005;5:2247-2257.

32. Liao H, Wu J, Kuhn E, Chin W, Chang B, Jones MD, O'Neil S, Clauser KR, Karl J, Hasler F, Roubenoff R, Zolg W, Guild BC. Use of mass spectrometry to identify protein biomarkers of disease severity in the synovial fluid and serum of patients with rheumatoid arthritis. Arthritis Rheum 2004;50:3792-3803.

33. Dotzlaw H, Schulz M, Eggert M, Neeck G. A pattern of protein expression in peripheral blood mononuclear cells distinguishes rheumatoid arthritis patients from healthy individuals. Biochim Biophys Acta 2004;1696:121-129.

34. Kriegova E, Melle C, Kolek V, Hutyrova B, Mrazek F, Bleul A, du Bois RM, von Eggeling F, Petrek M. Protein Profiles of Bronchoalveolar Lavage Fluid from Patients with Pulmonary Sarcoidosis. Am J Respir Crit Care Med 2006;173: 1145-1154.

35. Magi B, Bini L, Perari MG, Fossi A, Sanchez JC, Hochstrasser D, Paesano S, Raggiaschi R, Santucci A, Pallini V, Rottoli P. Bronchoalveolar lavage fluid protein composition in patients with sarcoidosis and idiopathic pulmonary fibrosis: a two-dimensional electrophoretic study. Electrophoresis 2002; 23:3434-3444.

36. Sabounchi-Schutt F, Astrom J, Hellman U, Eklund A, Grunewald J. Changes in bronchoalveolar lavage fluid proteins in sarcoidosis: a proteomics approach. Eur Respir J 2003;21:414-420.

37. Sabounchi-Schutt F, Mikko M, Eklund A, Grunewald J, AStröm J, Serum protein pattern in sarcoidosis analysed by a proteomics approach. Sarcoidosis Vasc Diffuse Lung Dis 2004;21:182-190.

38. Roxo-Rosa M, da Costa G, Luider TM, Scholte BJ, Coelho AV, Amaral MD, Penque D. Proteomic analysis of nasal cells from cystic fibrosis patients and non-cystic fibrosis control individuals: search for novel biomarkers of cystic fibrosis lung disease. Proteomics 2006;6:2314-2325.

39. Sloane AJ, Lindner RA, Prasad SS, Sebastian LT, Pedersen SK, Robinson M, Bye PT, Nielson DW, Harry JL. Proteomic analysis of sputum from adults and children with cystic fibrosis and from control subjects. Am J Respir Crit Care Med 2005;172:1416-1426.

40. Bons JA, Wodzig WK, van Dieijen-Visser MP. Protein profiling as a diagnostic tool in clinical chemistry: a review. Clin Chem Lab Med 2005;43:1281-1290.

41. Wu T, Mohan C. Proteomics on the diagnostic horizon: Lessons from rheumatology. Am J Med Sci 2007;333:16-25.

42. Tabary O, Escotte S, Couetil JP, Hubert D, Dusser D, Puchelle E, Jacquot J. Relationship between IkappaBalpha deficiency, NFkappaB activity and interleukin-8 production in CF human airway epithelial cells. Pflugers Arch 2001;443(Suppl 1):S40-44.

43. Knorre A, Wagner M, Schaefer HE, Colledge WH, Pahl HL. DeltaF508-CFTR causes constitutive NFkappaB activation through an ER-overload response in cystic fibrosis lungs. Biol Chem 2002;383:271-282. 


\section{Chapter 5}

\section{Potential biomarkers for diagnosis of sarcoidosis using proteomics in serum}

Judith A. Bons, Marjolein Drent, Freek G. Bouwman, Edwin C.M. Mariman, Marja P. van Dieijen-Visser, and Will K. Wodzig Resp Med 2007;101:1687-95 


\section{Abstract}

\section{Background}

Sarcoidosis is a multi-systemic inflammatory disorder, which affects the lungs in $90 \%$ of the cases. The main pathologic feature is chronic inflammation resulting in non-caseating granuloma formation. Until now there is no satisfying biomarker for diagnosis or prognosis of sarcoidosis. This study is focused on the detection of potential biomarkers in serum for the diagnosis of sarcoidosis using Surface-Enhanced Laser Desorption/Ionization Time-of-Flight Mass Spectrometry.

\section{Methods}

For detection of potential biomarkers, protein profiles of anion exchange fractionated serum of 35 sarcoidosis patients and 35 healthy controls were compared using Surface-Enhanced Laser Desorption/Ionization Time-of-Flight Mass Spectrometry. Sensitivities and specificities of the potential biomarkers obtained with Surface-Enhanced Laser Desorption/Ionization Time-of-Flight Mass Spectrometry generated with decision tree algorithm were compared to the conventional markers Angiotensin Converting Enzyme and soluble Interleukin-2 Receptor.

\section{Results}

Optimal classification was achieved with metal affinity binding arrays. A single marker with a mass-tocharge value of 11,955 resulted in a sensitivity and specificity of $86 \%$ and $63 \%$, respectively. A multimarker approach of two peaks with mass-to-charge values of 11,734 and 17,377 resulted in a sensitivity and specificity of $74 \%$ and $71 \%$, respectively. These sensitivities and specificities were higher compared to measurements of Angiotensin Converting Enzyme and soluble Interleukin-2 Receptor. Identification of the peak with a mass-to-charge value of 17,377 resulted in the alpha- 2 chain of haptoglobin.

\section{Conclusions}

This study acts as a proof-of-principle for the use of Surface-Enhanced Laser Desorption/Ionization Time-of-Flight Mass Spectrometry in the detection of new biomarkers for sarcoidosis. The peak of the multimarker with a mass-to-charge value of 17,377 was identified as the alpha- 2 chain of haptoglobin. 


\section{Introduction}

Sarcoidosis is a systemic granulomatous disorder of unknown cause characterized by its pathological hallmark, the noncaseating granuloma ${ }^{1,2}$. The clinical presentation of sarcoidosis is highly variable ${ }^{3}$. Involvement of the lungs or intrathoracic lymph nodes becomes clinically evident in $90 \%$ of the symptomatic patients during their disease and up to $30 \%$ show spontaneous remission 4 . A chronic course occurs in $10-30 \%$ of the patients, at times resulting in significant impairment of lung function 5,6 . Unfortunately, till now there is no good marker for both diagnosis and prognosis of sarcoidosis.

It is obvious that there is a great need to discover novel biomarkers for sarcoidosis and translate them to routine clinical use ${ }^{7}$, where they can play an important role in both diagnosis and follow-up. Proteomics analysis has been successfully employed in the discovery of new biomarkers in different human diseases ${ }^{8}$. SurfaceEnhanced Laser Desorption/Ionisation Time-of-Flight Mass Spectrometry (SELDITOF-MS) is a promising new technology in the search for new biomarkers and was first introduced by Hutchens and Yip ${ }^{9}$. The ProteinChip system manufactured by Ciphergen Biosystem Inc. indicated as SELDI-TOF-MS has the potential to discover useful biomarkers faster than any existing technology. For the detection of potential biomarkers, protein profiles of disease and control groups are compared to find distinctive patterns, which can clearly discriminate the disease and control group. Protein peaks can be either up- or down regulated in the disease group versus the control group.

Biomarker Patterns is a decision tree algorithm that easily can deal with the large amount of proteins that can be detected in the serum samples. Biomarker patterns, software program for pattern analysis, is very useful for the multimarker approach, which is used for the classification. Because of the multifactorial nature of sarcoidosis, it is very likely that a combination of several markers will be necessary to effectively detect and diagnose sarcoidosis. Since the study of Petricoin et al. ${ }^{10}$ on protein profiling to detect ovarian cancer, the use of SELDI-TOF-MS protein profiling as a diagnostic tool, has become an important subject of investigation ${ }^{11}$. Until now this approach has been suggested for different diseases, for example ovarian ${ }^{10,12-16}$ prostate $^{17-21}$ and lung ${ }^{22}$ cancer research, but also inflammatory diseases ${ }^{23,24}$. Recently, Kriegova et al. ${ }^{25}$ reported protein profiles of bronchoalveolar lavage fluid (BALF) from patients with pulmonary sarcoidosis using SELDI-TOF-MS. Furthermore, these protein patterns in sarcoid BALF were linked to particular disease course, i.e. stages of sarcoidosis. Sarcoidosis markers were also detected with a two-dimensional gel electrophoresis (2-DE) approach in BALF $^{26,27}$ and serum ${ }^{28}$. The group of Song et al. ${ }^{29}$ collected sarcoidosis tissue to detect sarcoidosis markers using a protein immunoblot assay. This is the first study that detected markers in serum using SELDI-TOF-MS. 
The aim of this study is focused on the detection of potential serum biomarkers for the diagnosis of sarcoidosis using SELDI-TOF-MS. In this study, the sensitivity and specificity obtained with the SELDI-TOF-MS technique will be compared with the sensitivities and specificities of the angiotensin converting enzyme (ACE) and soluble Interleukin-2 Receptor (sIL-2R) concentration measurements, because these two blood markers are often used in the assessment and the follow-up of sarcoidosis $30-32$

\section{Materials and methods}

\section{Patients and samples}

Sarcoidosis patients who visited an education meeting held at the University Hospital Maastricht February the $24^{\text {th }} 2005$ were asked to participate. Of the 120 attendees 100 agreed to participated. The diagnosis sarcoidosis was based on consistent clinical features and BAL fluid analysis results, according to the World Association of Sarcoidosis and Other Granulomatous Disorders (WASOG) guidelines ${ }^{33}$ with a biopsy confirming sarcoidosis in $80 \%$ of cases. A healthy control group consisted of partners of the patients and employees of the hospital without any relevant medical history. Finally, out these 100 sarcoidosis patients 35 cases were enrolled who met the following inclusion criteria: a time since diagnosis of less than ten years (12 patients with a time since diagnosis longer than ten years were excluded from the study), non smoker (18 patients which were smokers at the moment of blood collection were excluded from the study), using no medication and not suffering from other diseases (31 patients which used corticosteroids at the moment of blood collection and 25 patients who suffered from other diseases, like diabetes, heart failure, which were not related to sarcoidosis, were excluded from the study). Out of the healthy control also 35 persons were selected matched for sex and age. The Medical Ethical Committee of the Hospital approved the procedure followed. Informed consent was obtained from all participants.

Characteristics of the studied population are illustrated in Table 5.1. Collection of serum samples was standardized by using a clotting time of $30 \mathrm{~min}$ at room temperature, spinning for $15 \mathrm{~min}$ at a speed of 4000 RPM (3000 g) and storage of the samples in aliquots within one hour at $-80^{\circ} \mathrm{C}$ after blood collection ${ }^{34}$. All fractionated serum samples had only two thaw steps from collection to analyzing. Serum ACE activity was measured by colorimetric method (Cat. nr. FU 116; Fujirebio Inc.) and SIL-2R was determined by a two-site chemiluminescent enzyme immunometric assay (Cat. nr. LKIP1; Diagnostic Product Corporation) on the IMMULITE Automated Analyzer. Serum was also used for analyses of the possible biomarker haptoglobin detected during this study. Total haptoglobin was measured by particle-enhanced immunonephelometry on the BN Prospec (Dade Behring). 
Lung function indices, including the forced expiratory volume in one second $\left(\mathrm{FEV}_{1}\right)$ and forced vital capacity (FVC), were measured with a pneumotachograph. The diffusing capacity for carbon monoxide (DLCO) was measured by the single-breath method. Both measurements were performed on a Masterlab (Jaeger, Würzburg, Germany). Values were expressed as a percentage of those predicted ${ }^{35}$. Chest radiographs were graded according to the radiographic staging of DeRemee ( 0 to III), with stage IV, the end stage of lung fibrosis, added 36,37 . Both the radiographic staging and pneumotachography tests were performed and interpreted by two professionals who were blinded to the patient's histories.

Table 5.1 Clinical characteristics of the studied population.

\begin{tabular}{|c|c|c|}
\hline & Sarcoidosis patients & Healthy controls \\
\hline $\mathrm{n}$ & 35 & 35 \\
\hline Gender, M/F & $18 / 17$ & $16 / 19$ \\
\hline Agea $^{\text {, years }}$ & $45.6 \pm 8.8$ & $47.3 \pm 9.8$ \\
\hline Biopsy, n, (\%) & $27(77.1 \%)$ & \\
\hline Time since diagnosis, years, (mean) & $1-9(5)$ & \\
\hline \multicolumn{3}{|l|}{ Serological markers ${ }^{b}$} \\
\hline sIL-2R, U/mL & $632.0(437.5-859.5)$ & $506.0(394.0-597.5)$ \\
\hline ACE, U/L & $22.0(16.0-24.0)$ & $13.5(12.0-17.8)$ \\
\hline \multicolumn{3}{|l|}{ Lung function testsa } \\
\hline DLCO, \% & $85.9 \pm 16.3$ & \\
\hline FVC, \% & $106.9 \pm 16.5$ & \\
\hline $\mathrm{FEV}_{1}, \%$ & $100.1 \pm 16.8$ & \\
\hline \multicolumn{3}{|l|}{ Chest radiographic stage, $\mathrm{n}$} \\
\hline Stage $0 / \mathrm{I} / \mathrm{II} / \mathrm{III} / \mathrm{IV}$ & $3 / 9 / 15 / 8 / 0$ & \\
\hline
\end{tabular}

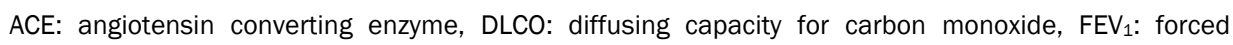
expiratory volume in $1 \mathrm{~s}$, FVC: forced vital capacity, sIL-2R: soluble Interleukin-2 Receptor. a Variables presented as mean $\pm S D$, as they follow a Gaussian distribution. ${ }^{b}$ Serological markers are presented as median with range $\left(25^{\text {th }}-75^{\text {th }}\right.$ percentiles) within parentheses.

\section{Statistical analysis}

Statistical analysis was performed with SPSS 11.0 for Windows (SPSS). ROC curve analyses $^{38}$ were performed for the ACE activity and SIL-2R concentrations. The optimal cut-off point coincides with the point on the ROC curve where the sum of sensitivity and specificity is maximal. When there were more cut-off point with the same sum, the one with the highest sensitivity was chosen. At this point the slope to the ROC curve equals unity, which is under certain conditions the result of minimization of the total costs attributable to false-positive and false negative outcomes. Groups comparisons were performed by means of parametric tests (Independent Samples t-test). A two-sided p-value of less than 0.05 was considered to be statistically significant. 


\section{SELDI-TOF-MS analysis}

An anion exchange procedure was used, which allowed high-throughput fractionation of serum based on the biophysical properties of proteins ${ }^{39}$. Serum was separated into six different fractions ( $\mathrm{pH} 9$ + flow through, $\mathrm{pH} 7, \mathrm{pH} 5, \mathrm{pH} 4, \mathrm{pH} 3$, and organic wash). The anion exchange fractionation was standardized according to the Ciphergen protocols. For the anion exchange fractionation, we used $20 \mu \mathrm{l}$ serum and $30 \mu \mathrm{l}(9 \mathrm{M}$ urea, $2 \%$ Chaps, $50 \mathrm{mM}$ Tris-HCL pH9) as starting material according to the Ciphergen protocols. Linke et al. ${ }^{40}$ illustrated that fractionation greatly increases the number of peptide and protein ion signals, when compared to both unfractionated as well as albumin-depleted samples and this will increase the chance to find potential biomarkers.

In the screening experiment, each fraction of eight sarcoidosis and eight healthy controls was applied to three different ProteinChip array surfaces (Ciphergen Biosystems Inc.) to find out the optimal array and fraction. The weak cation exchange (CM10), the immobilized metal affinity capture coupled with copper (IMAC-Cu2+) and normal phase (NP20) arrays were used.

For ProteinChip array binding, the spots on the IMAC arrays were preloaded with $50 \mu \mathrm{CuSO}_{4}(0.1 \mathrm{M})$. The CM10 and IMAC arrays were equilibrated twice with $100 \mu \mathrm{l}$ of binding buffer (Na-phosphate buffer $50 \mathrm{mM}, 0.5 \mathrm{M} \mathrm{NaCl}(\mathrm{pH} 7)$ for the IMAC arrays and Na-acetate ( $\mathrm{pH} 4)$ for the CM10 arrays). Ten $\mu$ l of each fraction was diluted in $90 \mu \mathrm{l}$ of the specific binding buffer as suggested by Ciphergen and added to each well of the bioprocessor and mixed for 45 min. After removing the remaining sample, the $\mathrm{CM} 10$ and IMAC arrays were washed and mixed three times with $150 \mu$ l binding buffer for 5 min followed by one brief wash with $200 \mu$ l Hepes buffer $(\mathrm{pH} 7)$. For the NP20 ProteinChip arrays, the fractions were diluted with Milli$\mathrm{Q}(1: 1 \mathrm{v} / \mathrm{v})$ and added directly on each spot. The arrays were incubated in a humid chamber for $30 \mathrm{~min}$, followed by a brief water rinse. All steps were performed at room temperature.

The sinapinic acid solution (SPA) as energy absorbing matrix was prepared according to the recommendations of the manufacturer, with the exception that trifluoroacetic anhydride (TFAH) as a solvent component was used instead of trifluoroacetic acid (TFA). After all the arrays were dried, $1 \mu$ SPA solution was applied. The spotting of SPA was repeated once and the Proteinchip arrays were stored at room temperature in the dark until further use.

The CM10, IMAC and NP-20 arrays were read on a Protein Biosystem IIc (PBS IIc) instrument. External calibration of the instrument was performed using the All-in-1 peptide and the All-in-1 protein molecular mass standards (Ciphergen Biosystems) on the NP-20 array. A well-defined protocol for calibration of the PBS Ilc, implementation of quality control (QC) samples and acceptance criteria for QC was used in this study, which was described in a previous study of Bons et al. ${ }^{34}$. 


\section{Data analysis}

For the detection of sarcoidosis biomarkers, serum protein profiles of sarcoidosis patients and healthy controls were compared. Peaks were auto detected using Ciphergen Express Data manager 3.0.6 (Ciphergen Biosystems, Inc.). The biomarker wizard clusters were exported to Biomarker Patterns Software (BPS) 5.0.2 (Ciphergen Biosystems Inc.). BPS uses the peak information generated by the training set of known samples to build a binary decision tree algorithm. The algorithm functions by assigning each sample in the data set into one of the two groups or nodes with a rule based on the intensity of a particular peak or splitter. Each sub node has a different rule that further divides the data set and this process continues until all cases are assigned into terminal nodes. This results in correct classification percentages of the so-called "learn set". The software generates and tests the models, using a process of cross-validation by randomly picking $10 \%$ of the samples. The peaks that formed the main splitters of the tree with the highest prediction rates in the cross-validation analysis were then selected to make a final decision tree with the greatest possible predictive power and this results in correct classification percentages of the so called "test set". So the classification ability of the decision tree algorithms in the learning set to distinguish between sarcoidosis and controls was validated after cross-validation, which results in a test set.

A Bayesian approach was used to calculate the expected probabilities of each class in each terminal node. Sensitivity was calculated as the ratio of the number of correctly classified disease samples to the total number of disease samples. Specificity was calculated as the ratio of the number of control samples correctly classified to the total number of control samples ${ }^{41}$.

\section{Identification}

\section{SDS-PAGE and 2-DE}

Twenty $\mu$ l of samples in which the peaks of the three biomarkers were present, but also samples in which the peaks of the three biomarkers were absent, were loaded on $12.5 \%$ sodium dodecyl sulphate-polyacrylamide gel electrophoresis (SDS-PAGE) gels. For the two-dimensional gel electrophoresis (2-DE), $40 \mu \mathrm{l}$ of the same samples used for the SDS-PAGE were loaded for the first dimension. The SDSPAGE, 2-DE and the digestion procedure were performed as described in the studies of Bouwman et al. ${ }^{42,43}$ with minor modifications.

\section{MALDI-TOF-MS}

For Matrix Assisted Laser Desorption/Ionization Time-of-Flight Mass Spectrometry (MALDI-TOF-MS), $1.5 \mu \mathrm{l}$ of each peptide mixture and $0.5 \mu \mathrm{l}$ matrix solution $(2.5 \mathrm{mg} / \mathrm{ml}$ alpha-cyano-4-hydroxy cinnamic acid (CHCA) in 50\% acetonitrile/0.1\% 
TFA) were spotted automatically onto a 96-well-format target plate. The spots were allowed to air dry for homogeneous crystallization. Spectra were obtained using a M@LDI-LR mass spectrometer (Waters). The instrument was operated in positive reflector mode.

The peptide mass list was searched with ProteinLynx Global Server v2.0 (Waters) or Mascot search engine against the Swiss-Prot database. One miss-cleavage was tolerated, carbamidomethylation was set as a fixed modification and oxidation of methionine as an optional modification. The peptide mass tolerance was set to $100 \mathrm{ppm}$. No restrictions were made on the protein $\mathrm{Mr}_{\mathrm{r}}$ and the pl. A protein was regarded as identified when it had a significant ProteinLynx or Mascot probability score $(p<0.05)$, a minimum of four peptides were required to match.

\section{Results}

\section{Serological markers}

The ROC curve analysis of the patient and control groups for the ACE and SIL-2R measurements are presented in Table 5.2. For both measurements, the areas under the curves (AUCs) were significantly different from the null-hypothesis, true area $=0.5$. For ACE the sensitivity and specificity percentages were 70.6 and 71.4 , respectively. For sIL-2R the sensitivity and specificity percentages were 62.9 and 57.1 , respectively.

Table 5.2 ROC curve analysis results for the inflammatory markers, ACE and SIL-2R

\begin{tabular}{lcccc}
\hline & $\begin{array}{c}\text { AUC } \\
\text { (95\% confidence intervals) }\end{array}$ & $\begin{array}{c}\text { Selected } \\
\text { cut-off }\end{array}$ & Sensitivity (\%) & Specificity (\%) \\
\hline ACE & $0.779(0.668-0.891)$ & 16.5 & 70.6 & 71.4 \\
sIL-2R & $0.667(0.539-0.795)$ & 515.5 & 62.9 & 57.1 \\
\hline
\end{tabular}

ACE: Angiotensin Converting Enzyme, AUC: Area Under Curve, sIL-2R: soluble Interleukin-2 Receptor.

\section{SELDI-TOF-MS analysis}

For choosing the optimal fraction and array, the number of significant mass-tocharge ratio $(\mathrm{m} / \mathrm{z})$ values and the cluster plots were evaluated for each condition with the Ciphergen Express software. For single charged molecules, the $m / z$ value is equal to the molecular weight (MW) in dalton (Da). The cluster plots illustrate the distribution of the intensities for each $\mathrm{m} / \mathrm{z}$ value. With an increased number of significant $m / z$ values $(p<0.05$ ) and superior cluster plots, the chance to detect a potential biomarker in a larger sample set is theoretically higher. A cluster plot is superior when there is minor or no overlap between the data points of the sarcoidosis patients compared to the control samples, which means that there is a good discrimination between both groups. By comparing the different chips and 
fractions in the screening experiments with eight sarcoidosis patients and eight healthy control samples, we detected the most significant $m / z$ values $(p<0.05)$ with superior cluster plots in fraction $3(n=5)$ and $4(n=7)$ on the IMAC array, these two conditions were used for performing the IMAC experiment with 35 sarcoidosis and 35 control samples.

By repeating the IMAC experiment with 35 sarcoidosis and 35 control samples, fraction 4 on the IMAC array resulted in two significant $m / z$ values $(p<0.05)$ and fraction 3 on the IMAC arrays resulted in seven significant $(p<0.05) m / z$ values. By using Biomarkers Patterns, decision trees were made and the decision trees generated from the fraction 3 samples resulted in a superior classification of the sarcoidosis and control samples, compared to the results from fraction 4 samples on the IMAC array.

For analysis of fraction 3 samples on the IMAC array, the following settings were chosen: laser intensity 220 and detector sensitivity 7. Biomarker Patterns generated a decision tree using 1 splitter with a $m / z$ value of 11,955 and a cut-off value of 1.113 that classified cases in two terminal nodes. The peak was upregulated in the samples of sarcoidosis patients. The control terminal node contained 28 samples (23 control and five sarcoidosis samples) and the sarcoidosis terminal node contained 42 samples (30 sarcoidosis and 12 control samples). This single marker could correctly classify 30 of 35 (86\%) sarcoidosis patients and 23 of 35 (66\%) controls in the training set. The ability of the decision tree algorithms to distinguish between sarcoidosis and controls was validated after cross-validation, which is called the test set. In the test set, 30 of 35 (86\%) samples were correctly classified as sarcoidosis and 22 of 35 (63\%) samples were correctly classified as controls (Table 5.3). With a lower laser intensity setting; laser intensity 190 and detector sensitivity 7 , Biomarkers Patterns generated a decisions tree using two splitters with $\mathrm{m} / \mathrm{z}$ values of 11,734 and 17,377 and cut-off values of 3.060 and 0.45 , respectively, which classified patients and controls in three terminal nodes. The peak with a $\mathrm{m} / \mathrm{z}$ value of 11,734 was upregulated and the peak with a $\mathrm{m} / \mathrm{z}$ value of 17,377 was downregulated in the sarcoidosis patient samples. The first control terminal node, which was based on the first splitter, contained 21 samples (17 control and four sarcoidosis samples). The other 49 samples were divided in a sarcoidosis and control terminal node using the second splitter. The sarcoidosis terminal node contained 32 samples (26 sarcoidosis and six control samples) and the control terminal node contained 17 samples (12 control and five sarcoidosis samples). In the training set, 26 of 35 (74\%) sarcoidosis and 29 of 35 (83\%) controls were correctly classified and in the test set, 26 of 35 (74\%) samples were correctly classified as sarcoidosis and 25 of 35 (71\%) samples were correctly classified as controls (Table 5.3). The SELDI-TOF-MS protein profiles and gel views of the three potential biomarkers are indicated in Figure 5.1. There is a variation in protein expression between patients and 
controls. This is seen in the cluster plots of the three $\mathrm{m} / \mathrm{z}$ peak splitters used in the Biomarker Patterns analysis (Figure 5.2).
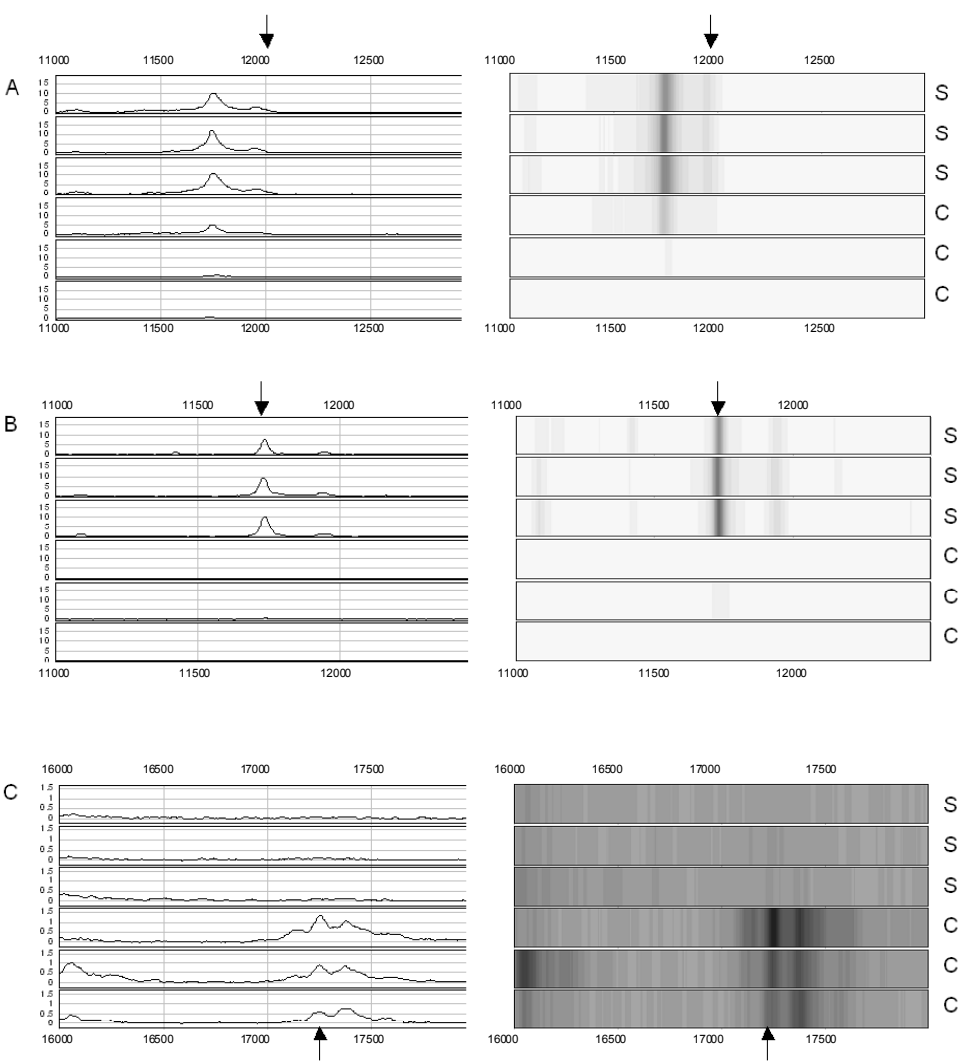

Figure 5.1 SELDI-TOF mass spectra and gel views of the three potential biomarkers with $\mathrm{m} / \mathrm{z}$ values of $11,955(A), 11,734(B)$, and 17,377 (C).

Representative protein spectra of three sarcoidosis $(\mathrm{S})$ and three control $(\mathrm{C})$ samples are illustrated per marker. The marker is indicated with a vector. The mass is given as $\mathrm{m} / \mathrm{z}$ values on the $x$-axis and the intensity is displayed along the $y$-axis. 
A
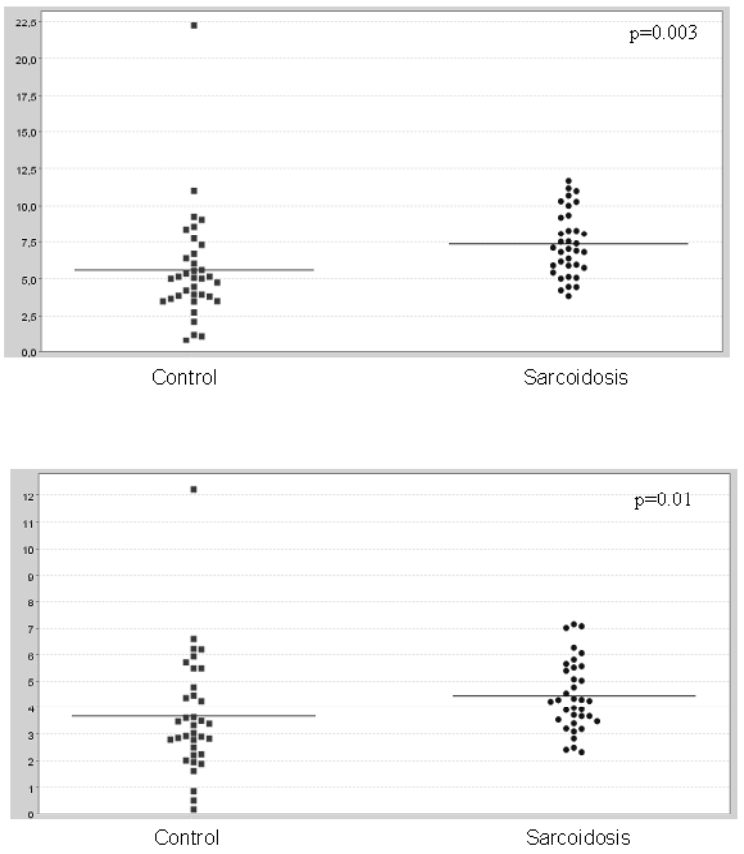

C

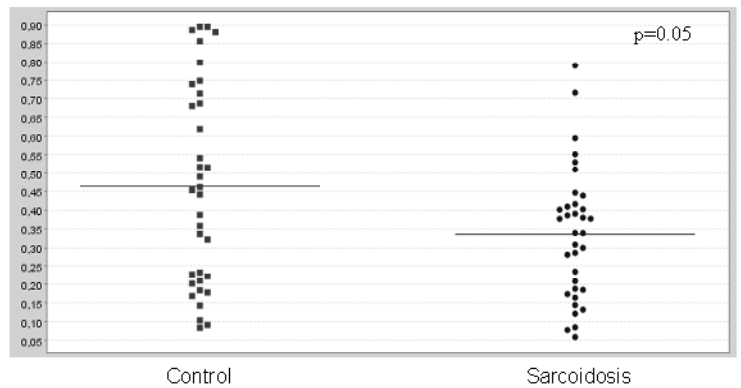

Figure 5.2 The cluster plots of the resulted peak splitters after Biomarker Patterns analysis; $m / z$ 11,955 (A), $m / z$ 11,734 (B), $m / z$ 17,377 (C).

The groups are indicated on the $x$-axis and the normalized intensities are indicated on the $y$-axis. The horizontal bars present the mean intensities for the control and the sarcoidosis group. 
Table 5.3 The $m / z$ values of the peak splitters, the cut-off values of the peak intensities, the $p$-values and the results of the learn and test set for the sarcoidosis and control samples per laser setting. The spectra were calibrated with the protein low calibration on the NP-20 array.

\begin{tabular}{lccccc}
\hline $\begin{array}{l}\text { Laser } \\
\text { setting }\end{array}$ & $\begin{array}{c}\mathrm{m} / z \text { value } \\
\text { protein-low } \\
\text { calibration } \\
\text { (NP-20) }\end{array}$ & $\begin{array}{c}\text { Cut-off } \\
\text { peak intensity }\end{array}$ & p-value & $\begin{array}{c}\text { Correct classification of } \\
\text { the learn set }\end{array}$ & $\begin{array}{c}\text { Correct classification of } \\
\text { the test set }\end{array}$ \\
\hline LI 220 & 11,955 & 1.113 & 0.003 & $\mathrm{~S}: 30 / 35=86 \%$ & $\mathrm{~S}: 30 / 35=86 \%$ \\
SE 7 & & & & $\mathrm{C}: 23 / 35=66 \%$ & $\mathrm{C}: 22 / 35=63 \%$ \\
LI 190 & 11,734 & 3.060 & 0.01 & $\mathrm{~S}: 26 / 35=74 \%$ & $\mathrm{~S}: 26 / 35=74 \%$ \\
SE 7 & 17,377 & 0.450 & 0.05 & $\mathrm{C}: 29 / 35=83 \%$ & $\mathrm{C}: 25 / 35=71 \%$ \\
\hline
\end{tabular}

LI: Iaser intensity, m/z: mass-to-charge ratio, SE: detector sensitivity, S: sarcoidosis, C: control
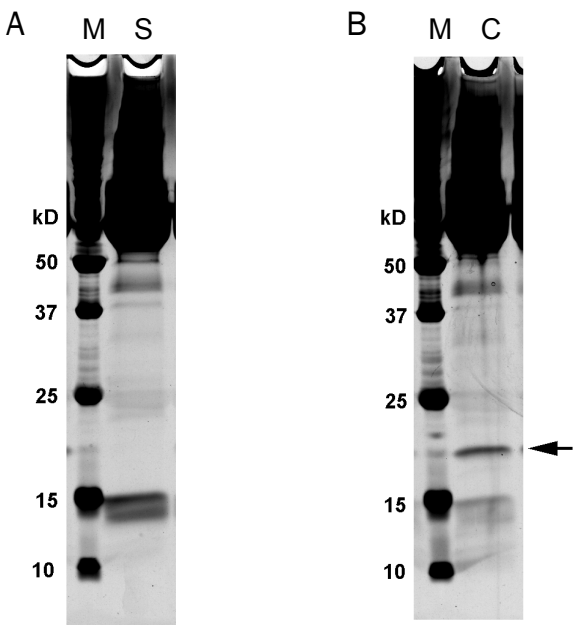

Figure 5.3 Silver stained band pattern of one fraction 3 sarcoidosis sample (A) and one fraction 3 healthy control sample (B) separated by SDS-PAGE.

The left lane shows the marker and the right lane shows the sarcoidosis sample (S) in Figure 5.3A and the healthy control sample (C) in Figure 5.3B. In Figure 5.3A there is no band visible at MW $17 \mathrm{kDa}$. Figure 5.3B clearly shows a band at $17 \mathrm{kDa}$ and this band is indicated with a vector.

\section{Identification}

SDS-PAGE and 2-DE were used for isolation and purification of the potential biomarkers and MALDI-TOF-MS was used for identification. We only tried to identify the three most discriminating markers described in our study. For the biomarker with a $\mathrm{m} / \mathrm{z}$ value of 17,377 a sarcoidosis and a healthy control sample were applied on a SDS-PAGE gel. In Figure 5.3 is illustrated that the band at a molecular weight (MW) of $17 \mathrm{kDa}$, which represents the peak at $\mathrm{m} / \mathrm{z} 17,377$, is not visible in the sarcoidosis patient sample $(\mathrm{A})$, but clearly visible in the healthy control 
sample (B). This also indicates that this peak is downregulated in the sarcoidosis patient versus the healthy control. This agrees with the SELDI-TOF-MS results. Identification of the $17 \mathrm{kDa}$ peak, after excising this peak out of the SDS-PAGE gel revealed the following protein as the best candidate of database searches: alpha chain of haptoglobin (P00738) with a probability Mascot score (probability based mowse score) of 86 . Protein scores greater than 67 are significant $(p<0.05)$. In the 2-DE gels was seen that there were more spots around the MW of $17 \mathrm{kDa}$ for the healthy control sample (Figure 5.4), but unfortunately in this study we were unable to identify the excised spots from the 2-DE gels. For the biomarkers with a $\mathrm{m} / \mathrm{z}$ value of 11,734 and 11,955 , also a sarcoidosis and control sample were applied on the SDS-PAGE gel, but it was also not possible to identify the bands or spots with MW around $11 \mathrm{kDa}$ which represent the peaks at $\mathrm{m} / \mathrm{z} 11,734$ and 11,955 on either the SDS-PAGE gels or the 2-DE gels.

A



B

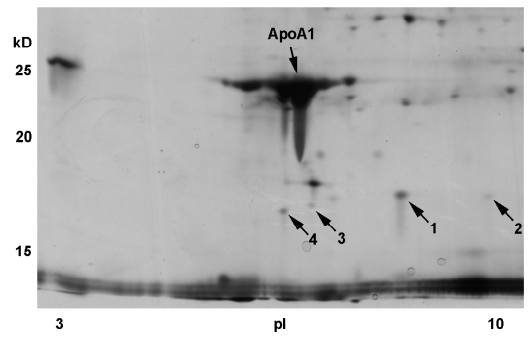

Figure $5.4 \quad$ Silver stained spot pattern of one fraction 3 sarcoidosis sample (A) and one fraction 3 healthy control sample (B) separated by 2-DE.

In both 2-DE gels ApoA1 was identified with a MW of $25 \mathrm{kDa}$. Figure $5.4 \mathrm{~B}$ clearly shows that below the Apo A1 spot, there are 4 protein spots around a MW of $17 \mathrm{kDa}$ with different pl values in the 2-DE gel. These protein spots are not visible in Figure 5.4 A.

In Figure 5.3A and Figure 5.3B there are also two bands visible around $15 \mathrm{kDa}$. These peaks are not the potential biomarkers with $m / z$ values 11,734 and 11,955 . The peaks corresponding to the bands at $15 \mathrm{kDa}$ gave no significant difference between sarcoidosis and control and were also not used for the Biomarker Patterns tree algorithm. Excising these peaks out of the SDS-PAGE revealed the following protein as the best candidate of database searches: Haemoglobin beta subunit (P68871) with a Mascot score (probability based mowse score) of 100.

\section{Total haptoglobin measurement}

Because the peak of the multimarker at $\mathrm{m} / \mathrm{z} 17,377$ was identified as the alpha chain of haptoglobin, the total haptoglobin was measured. The means and standard deviations (SD) for the haptoglobin concentration $(\mathrm{g} / \mathrm{l})$ were $1.32 \pm 0.48$ 
for the sarcoidosis group and $1.31 \pm 0.43$ for the healthy control group. There was no significant difference in total haptoglobin concentration between the sarcoidosis and healthy control group $(p=0.9)$.

\section{Discussion}

This is the first study that shows that protein profiling in serum using SELDI-TOF-MS can be used as a diagnostic tool for sarcoidosis. It was demonstrated that the diagnostic value of the biomarkers obtained with SELDI-TOF-MS appeared to be favourable compared to the diagnostic value of ACE and SIL-2R in the same study population. At present, there still is no appropriate parameter to assess the activity of sarcoidosis. Clinical activity is assessed based on onset, worsening or persistence of symptoms, or signs directly related to sarcoidosis and a combination of clinical parameters ${ }^{33}$.

Despite its shortcoming, ACE is mostly used in the assessment and the follow-up of sarcoidosis ${ }^{31}$. Recently some studies reported that SIL-2R appeared to be a better marker to predict disease severity compared to the traditionally used ACE, but there is a great overlap in the sensitivity and specificity results of both serum markers $30,32,44$. Although both ACE and sIL-2R are used in the assessment and the follow-up of sarcoidosis, they still appeared to be inferior to the SELDI-TOF-MS data in our study.

In the present study was also demonstrated that there appeared to be a great variety in the protein patterns between patients, but also within controls. This variation is caused by the biological variation and analytical variation of SELDI-TOF-MS ${ }^{34}$. Potential sources of variability that arise during SELDI-TOF-MS profiling include spot-to-spot variation of chip surfaces, laser detector variability over time, pipetting variability 45 and the crystallization process of the energy absorbing matrix ${ }^{46,47}$. But in spite of this variation in intensities and biological variability, we were able to find potential biomarkers with the Biomarker Patterns software. A sensitivity of $86 \%$ and a specificity of $63 \%$ was reached with a single marker with a $\mathrm{m} / \mathrm{z}$ value of 11,955 (upregulated in sarcoidosis versus control) and a sensitivity of $74 \%$ and a specificity of $71 \%$ was reached with a multimarker using two peaks with $\mathrm{m} / \mathrm{z}$ values 11,734 (upregulated in sarcoidosis versus control) and 17,377 (downregulated in sarcoidosis versus control). We only tried to identify the three most discriminating markers described in our study. The other $\mathrm{m} / \mathrm{z}$ peaks were not identified. Using Mascot search engine against the Swiss-Prot database we found that the peak at $17 \mathrm{kDa}$ excised from the SDS-PAGE gel was the alpha chain of haptoglobin. Haptoglobin consists of two different polypeptide chains; the $\alpha$-chain and the $\beta$-chain and these are linked by disulfide bonds. Three Haptoglobin (Hpt) phenotypes, Hpt 1-1 (structural formula: $\left.\left(\alpha^{1} \beta\right)_{2}\right)$ ) , Hpt 2-1 (structural formula: $\left.\left[\left(\alpha^{1} \beta\right)_{2}+\left(\alpha^{2} \beta\right)_{n}\right]\right)$ and Hpt 2-2 (structural formula: $\left(\alpha^{2} \beta\right)_{n}$, are genetically determined 
by a polymorphism with two alleles: Hpt-1 and Hpt-2. This polymorphism results in variants in alpha-chains: $\alpha^{1}(8.9 \mathrm{kDa})$ and $\alpha^{2}(16 \mathrm{kDa})$. The $\alpha^{1}$ is monomeric and the $\alpha^{2}$ is partially dimeric (probably the result of incomplete genetic crossover. The $\beta$-chain $(40 \mathrm{kDa})$ is heavier than the $\alpha$-chain and is identical in all haptoglobin phenotypes ${ }^{48}$. The marker at $17 \mathrm{kDa}$, which was detected in our study, is compatible with the alpha-2 chain of haptoglobin.

It is known that in the presence of oxidative stress, glucose-6-phosphate dehydrogenase (G6PD) deficiency leads to hemolysis ${ }^{49}$, which causes a decrease in haptoglobin, which as such might clarify the lower haptoglobin fragment peaks in sarcoidosis patients. Therefore, total haptoglobin of the sarcoidosis and healthy control serum samples were compared. There was no significant difference between both groups. This can be caused due to the fact that the $17 \mathrm{kDa}$ peak is only the alpha- 2 chain of haptoglobin and the total haptoglobin assay measures the total haptoglobin complex. Therefore, specific antibodies against the alpha chain of haptoglobin should be used to compare both groups.

Another explanation might be the fact that the $17 \mathrm{kDa}$ peak is not a single marker, but it is part of a multimarker. The 2-DE gel of the healthy control also clearly shows that there are four protein spots around a MW of $17 \mathrm{kDa}$ with different pl values in the 2-DE gel. These spots are not visible in the 2-DE gel of the sarcoidosis samples. This indicates that there are more proteins with the same MW, but these proteins have another pl value.

Recently, Kriegova et al. ${ }^{25}$ compared protein profiles from sarcoidosis patients with healthy controls in bronchoalveolar lavage fuid (BALF). In line with our findings, they found a peak with a MW of $11.7 \mathrm{kDa}$ upregulated in sarcoidosis versus controls. However, no further analyzing or identifying of this sarcoidosis associated peak was performed. Because the calibration procedure is not described in the study of Kriegova et al., we are not absolutely sure if we detected the same peak. However, in most SELDI-TOF-MS studies, the All-in-1 peptide and the All-in-1 protein molecular mass standards (Ciphergen Biosystems) are used for the external calibration, like in our study.

In the present study serum was used for the protein profiling experiments, because collection of blood is much less invasive compared to collection of BALF. Although the results seem promising, one of the major limitations was the rather small sample size. Future studies, in a larger cohort of well-defined sarcoidosis patients, are necessary to evaluate the clinical value of this observation. The collection of well-defined sarcoidosis samples is time consuming. Moreover, to establish the diagnostic value a population of patients suffering from other interstitial lung diseases should be included as well. Further attempts will be undertaken, because the identification of these two markers will lead to a better understanding of sarcoidosis and would be of great interest. In future studies, we will enlarge the sample group and we will also validate our markers with a blind sample set. After this validation, we can search for disease activity markers. Eventually, 
Chapter 5

implementation of a quantitative immunoassay, is needed, to give a good prediction of the disease state and disease severity.

In conclusion, the present study showed that protein profiling in serum could be used in the management of sarcoidosis. The peak of the multimarker at $\mathrm{m} / \mathrm{z}$ 17,377 was identified as the alpha- 2 chain of haptoglobin. 


\section{References}

1. Baughman RP, Lower EE, Du Bois RM. Sarcoidosis. Lancet 2003;361:1111-1118.

2. Kataria YP, Holter JF. Sarcoidosis: A Model of Granulomatous Inflammation of Unknown Etiology Associated with a Hyperactive Immune System. Methods 1996;9:268-294.

3. Judson MA, Baughman RP, Thompson BW, Teirstein AS, Terrin ML, Rossman MD, Yeager H Jr, McLennan G, Bresnitz EA, DePalo L, Hunninghake G, lannuzzi MC, Johns CJ, Moller DR, Newman LS, Rabin DL, Rose C, Rybicki BA, Weinberger SE, Knatterud GL, Cherniak R. Two year prognosis of sarcoidosis: the ACCESS experience. Sarcoidosis Vasc Diffuse Lung Dis 2003;20:204-211.

4. Rybicki BA, Maliarik MJ, Major M, Popovich J Jr, lannuzzi MC. Epidemiology, demographics, and genetics of sarcoidosis. Semin Respir Infect 1998;13:166-173.

5. Baughman RP, Winget DB, Bowen EH, Lower EE. Predicting respiratory failure in sarcoidosis patients. Sarcoidosis Vasc Diffuse Lung Dis 1997;14:154-158.

6. Arcasoy SM, Christie JD, Pochettino A, Rosengard BR, Blumenthal NP, Bavaria JE, Kotloff RM. Characteristics and outcomes of patients with sarcoidosis listed for lung transplantation. Chest 2001;120:873-880.

7. Anderson NL, Anderson NG. The human plasma proteome: history, character, and diagnostic prospects. Mol Cell Proteomics 2002;1:845-867.

8. Srinivas PR, Verma M, Zhao Y, Srivastava S. Proteomics for cancer biomarker discovery. Clin Chem 2002;48:1160-1169.

9. Hutchens TW, Yip T. New Desorption strategies for the mass spectrometric analysis of macromolecules. Rapid Commun Mass Spectrom 1993;7:576-580.

10. Petricoin III EF, Mills GB, Kohn EC, Liotta LA. Proteomic patterns in serum and identification of ovarian cancer. The Lancet 2002;360:170-171.

11. Petricoin EF, Ardekani AM, Hitt BA, Levine PJ, Fusaro VA, Steinberg SM, Mills GB, Simone C, Fishman DA, Kohn EC, Liotta LA. Use of proteomic patterns in serum to identify ovarian cancer. Lancet 2002;359:572-577.

12. Kozak KR, Amneus MW, Pusey SM, Su F, Luong MN, Luong SA, Reddy ST, Farias-Eisner R. Identification of biomarkers for ovarian cancer using strong anion-exchange ProteinChips: potential use in diagnosis and prognosis. Proc Natl Acad Sci U S A 2003;100:12343-12348.

13. Zhang Z, Bast RC Jr, Yu Y, Li J, Sokoll L, Rai AJ, Rosenzweig JM, Cameron B, Wang YY, Meng XY, Berchuck A, Van Haaften-Day C, Hacker NF, de Bruijn HW, van der Zee AG, Jacobs IJ, Fung ET, Chan DW. Three biomarkers identified from serum proteomic analysis for the detection of early stage ovarian cancer. Cancer Res 2004;64:5882-5890.

14. Vlahou A, Schorge JO, Gregory BW, Coleman RL. Diagnosis of Ovarian Cancer Using Decision Tree Classification of Mass Spectral Data. J Biomed Biotechnol 2003;2003:308-314.

15. Ye B, Cramer DW, Skates SJ, Gygi SP, Pratomo V, Fu L, Horick NK, Licklider L, Schorge JO, Berkowitz RS, Mok SC. Haptoglobin-alpha subunit as potential serum biomarker in ovarian cancer: identification and characterization using proteomic profiling and mass spectrometry. Clin Cancer Res 2003;9:2904-2911.

16. Rai AJ, Zhang Z, Rosenzweig J, Shih le M, Pham T, Fung ET, Sokoll LJ, Chan DW. Proteomic approaches to tumor marker discovery. Arch Pathol Lab Med 2002;126:1518-1526.

17. Banez LL, Prasanna P, Sun L, Ali A, Zou Z, Adam BL, McLeod DG, Moul JW, Srivastava S. Diagnostic potential of serum proteomic patterns in prostate cancer. J Urol 2003;170:442-446.

18. Adam BL, Qu Y, Davis JW, Ward MD, Clements MA, Cazares LH, Semmes OJ, Schellhammer PF, Yasui Y, Feng Z, Wright GL Jr. Serum protein fingerprinting coupled with a pattern-matching algorithm distinguishes prostate cancer from benign prostate hyperplasia and healthy men. Cancer Res 2002;62:3609-3614.

19. Petricoin EF $3^{\text {rd }}$, Ornstein DK, Paweletz CP, Ardekani A, Hackett PS, Hitt BA, Velassco A, Trucco C, Wiegand L, Wood K, Simone CB, Levine PJ, Linehan WM, Emmert-Buck MR, Steinberg SM, Kohn EC, Liotta LA. Serum proteomic patterns for detection of prostate cancer. J Natl Cancer Inst 2002; 94:1576-1578. 
20. Qu Y, Adam BL, Yasui Y, Ward MD, Cazares LH, Schellhammer PF, Feng Z, Semmes OJ, Wright GL. Jr. Boosted decision tree analysis of surface-enhanced laser desorption/ionization mass spectral serum profiles discriminates prostate cancer from noncancer patients. Clin Chem 2002;48:1835-1843.

21. Li J, White N, Zhang Z, Rosenzweig J, Mangold LA, Partin AW, Chan DW. Detection of prostate cancer using serum proteomics pattern in a histologically confirmed population. J Urol 2004;171: 1782-1787.

22. Zhukov TA, Johanson RA, Cantor AB, Clark RA, Tockman MS. Discovery of distinct protein profiles specific for lung tumors and pre-malignant lung lesions by SELDI mass spectrometry. Lung Cancer 2003;40:267-279.

23. Poon TC, Hui AY, Chan HL, Ang IL, Chow SM, Wong N, Sung JJ. Prediction of liver fibrosis and cirrhosis in chronic hepatitis $B$ infection by serum proteomic fingerprinting: a pilot study. Clin Chem 2005;51:328-335.

24. Zhu XD, Zhang WH, Li CL, Xu Y, Liang WJ, Tien P. New serum biomarkers for detection of HBVinduced liver cirrhosis using SELDI protein chip technology. World J Gastroenterol 2004;10: 2327-2329.

25. Kriegova E, Melle C, Kolek V, Hutyrova B, Mrazek F, Bleul A, du Bois RM, von Eggeling F, Petrek M. Protein Profiles of Bronchoalveolar Lavage Fluid from Patients with Pulmonary Sarcoidosis. Am J Respir Crit Care Med 2006;173:1145-1154.

26. Magi B, Bini L, Perari MG, Fossi A, Sanchez JC, Hochstrasser D, Paesano S, Raggiaschi R, Santucci A, Pallini V, Rottoli P. Bronchoalveolar lavage fluid protein composition in patients with sarcoidosis and idiopathic pulmonary fibrosis: a two-dimensional electrophoretic study. Electrophoresis 2002; 23:3434-3444.

27. Sabounchi-Schutt F, Astrom J, Hellman U, Eklund A, Grunewald J. Changes in bronchoalveolar lavage fluid proteins in sarcoidosis: a proteomics approach. Eur Respir J 2003;21:414-420.

28. Sabounchi-Schutt F, Mikko M, Eklund A, Grunewald J, AStröm J. Serum protein pattern in sarcoidosis analysed by a proteomics approach. Sarcoidosis Vasc Diffuse Lung Dis 2004;21: 182-190.

29. Song Z, Marzilli L, Greenlee BM, Chen ES, Silver RF, Askin FB, Teirstein AS, Zhang Y, Cotter RJ, Moller DR. Mycobacterial catalase-peroxidase is a tissue antigen and target of the adaptive immune response in systemic sarcoidosis. J Exp Med 2005;201:755-767.

30. Ziegenhagen MW, Rothe ME, Schlaak M, Muller-Quernheim J. Bronchoalveolar and serological parameters reflecting the severity of sarcoidosis. Eur Respir J 2003;21:407-413.

31. Muller-Quernheim J. Serum markers for the staging of disease activity of sarcoidosis and other interstitial lung diseases of unknown etiology. Sarcoidosis Vasc Diffuse Lung Dis 1998;15:22-37.

32. Rothkrantz-Kos S, van Dieijen-Visser MP, Mulder PG, Drent M. Potential usefulness of inflammatory markers to monitor respiratory functional impairment in sarcoidosis. Clin Chem 2003;49:1510-1517.

33. ATS/ERS/WASOG Committee. Statement on sarcoidosis. Sarcoidosis Vasc Diffuse Lung Dis 1999;16:149-173.

34. Bons JA, de Boer D, van Dieijen-Visser MP, Wodzig WK. Standardization of calibration and quality control using surface enhanced laser desorption ionization-time of flight-mass spectrometry. Clin Chim Acta 2006;366:249-256.

35. Quanjer PH, Tammeling GJ, Cotes JE, Pedersen OF, Peslin R, Yernault JC. Lung volumes and forced ventilatory flows. Report Working Party Standardization of Lung Function Tests, European Community for Steel and Coal. Official Statement of the European Respiratory Society. Eur Respir J Suppl 1993;16:5-40.

36. Hunninghake GW, Costabel U, Ando M, Baughman R, Cordier JF, Du Bois R, Eklund A, Kitaichi M, Lynch J, Rizzato G, Rose C, Selroos O, Semenzato G, Sharma OP. ATS/ERS/WASOG statement on sarcoidosis. American Thoracic Society/European Respiratory Society/World Association of Sarcoidosis and other Granulomatous Disorders. Sarcoidosis Vasc Diffuse Lung Dis 1999;16: 149-173.

37. DeRemee RA. The roentgenographic staging of sarcoidosis. Historic and contemporary perspectives. Chest 1983;83:128-133. 
38. DeLong ER, DeLong DM, Clarke-Pearson DL. Comparing the areas under two or more correlated receiver operating characteristic curves: a nonparametric approach. Biometrics 1988;44: 837-845.

39. Solassol J, Marin P, Demettre E, Rouanet P, Bockaert J, Maudelonde T, Mange A., Proteomic detection of prostate-specific antigen using a serum fractionation procedure: potential implication for new low-abundance cancer biomarkers detection. Anal Biochem 2005;338:26-31.

40. Linke T, Ross AC, Harrison EH. Profiling of rat plasma by surface-enhanced laser desorption/ionization time-of-flight mass spectrometry, a novel tool for biomarker discovery in nutrition research. J Chromatogr A 2004;1043:65-71.

41. Liu W, Guan M, Wu D, Zhang Y, Wu Z, Xu M, Lu Y. Using tree analysis pattern and SELDI-TOF-MS to discriminate transitional cell carcinoma of the bladder cancer from noncancer patients. Eur Urol 2005;47:456-462.

42. Bouwman F, Renes J, Mariman E. A combination of protein profiling and isotopomer analysis using matrix-assisted laser desorption/ionization-time of flight mass spectrometry reveals an active metabolism of the extracellular matrix of 3T3-L1 adipocytes. Proteomics 2004;4:3855-3863.

43. Bouwman F, Suylen D, Renes J, Mariman E. Evaluation and improving the success rate of protein identification by peptide mass fingerprinting using matrix-assisted laser desorption/ionization time-of-flight mass spectrometry. Rapid Commun Mass Spectrom 2005;19:2465-2468.

44. Grutters JC, Fellrath JM, Mulder L, Janssen R, Van Den Bosch JMM, van Velzen-Blad H. Serum SIL2R measurement in sarcoidosis patients: a clinical evaluation. Chest 2003;124:186-195.

45. Koopmann J, Zhang Z, White N, Rosenzweig J, Fedarko N, Jagannath S, Canto MI, Yeo CJ, Chan DW, Goggins M. Serum diagnosis of pancreatic adenocarcinoma using surface-enhanced laser desorption and ionization mass spectrometry. Clin Cancer Res 2004; 10:860-868.

46. Jock CA, Paulauskis JD, Baker D, Olle E, Bleavins MR, Johnson KJ, Heard PL. Influence of matrix application timing on spectral reproducibility and quality in SELDI-TOF-MS. Biotechniques 2004; 37:30-32, 34.

47. Cordingley HC, Roberts SL, Tooke P, Armitage JR, Lane PW, Wu W, Wildsmith SE. Multifactorial screening design and analysis of SELDI-TOF ProteinChip array optimization experiments. Biotechniques 2003;34:364-365, 368-373.

48. Langlois MR, Delanghe JR. Biological and clinical significance of haptoglobin polymorphism in humans. Clin Chem 1996;42:1589-1600.

49. Dhaliwal G, Cornett PA, Tierney LM Jr. Hemolytic anemia. Am Fam Physician 2004;69:2599-2606. 



\section{Chapter 6}

\section{Potential biomarkers for diagnosis of ankylosing spondylitis using SELDI-TOF-MS}

Judith A.P. Bons, Désirée van der Heijde, Freek G. Bouwman, Edwin C.M. Mariman, Marja P. van Dieijen-Visser, Robert Landewé, Sjef van der Linden, Will K.W.H. Wodzig

Biomarkers in Medicine, 2008;2:23-30 


\section{Abstract}

\section{Background}

Ankylosing spondylitis (AS) is a chronic systemic inflammatory rheumatic disorder that primarily affects the axial skeleton, with sarcoiliitis as its hallmark. It has been estimated that at least $30 \%$ of patients do develop severe spinal restriction during the natural course of the disease. Until now there is no satisfying biomarker for diagnosis or prognosis of AS. This study is focused on the detection of potential biomarkers for the diagnosis of AS using Surface-Enhanced Laser Desorption/Ionization Time-of-Flight Mass Spectrometry (SELDI-TOF-MS).

\section{Methods}

Sera of 38 AS patients and 38 healthy controls were used to detect potential biomarkers. Serum was separated using an anion exchange fractionation procedure. In the screening experiments, three ProteinChip array surfaces; cation exchange (CM10), metal affinity binding array coupled with copper $\left(\mathrm{IMAC}-\mathrm{Cu}^{2+}\right)$, and hydrophobic, were compared to find out which condition resulted in the optimal discrimination of both groups.

\section{Results}

The optimal discrimination was reached with the following conditions; CM10 array with the organic serum fraction and IMAC-Cu²+ array with denatured serum. Analyses of all AS and healthy control samples on CM10 arrays resulted in a sensitivity of $66 \%$ and a specificity of $74 \%$ using a multimarker approach of two peaks. The peak at $\mathrm{m} / \mathrm{z} 4172$ was used as first splitter in the decision tree and was upregulated in the AS group and the peak at $\mathrm{m} / z$ 28,144 was used as second splitter. Analyses of all AS and healthy control samples on IMAC- $\mathrm{Cu}^{2+}$ arrays resulted in a sensitivity and specificity of both $70 \%$ using a multimarker approach of two peaks. The peak at $m / z 6644$ was used as first splitter and was down-regulated in the AS group and the peak at $m / z$ 13,875 was used as second splitter. The peaks at $m / z 28,144$ and 13,875 were both successfully identified as apolipoprotein A-I.

\section{Conclusions}

This is the first study that shows that protein profiling in serum using SELDI-TOF-MS can be used as a diagnostic tool for AS. In future studies, the sample group will be enlarged and we will also validate our markers with a blind sample set. 


\section{Introduction}

Ankylosing spondylitis (AS), a frequent, chronic, inflammatory rheumatic disease, is the prototype and the most severe form of the spondylarthritides. AS affects young patients, predominantly males, most frequently starting in the third decade of life, with a prevalence of $0.1-1.1 \%^{1}$. AS is characterized by spinal inflammation with sacroiliitis, spondylitis, spondylodiscitis, and spondylarthritis, but also by new bone formation with syndesmophytes and ankylosis ${ }^{2}$. It has been estimated that at least $30 \%$ of patients do develop severe spinal restriction during the natural course of the disease ${ }^{3}$. As in most rheumatic diseases, the severity of symptoms varies greatly among patients and varies over time in individual patients ${ }^{4}$. It may lead to major functional limitations not only because of spinal disease but also because of extraspinal disease manifestations such as peripheral arthritis, inflammatory bowel disease and uveitis 5 .

Spinal structural damage can be assessed on conventional radiographs as destructive and proliferative lesions ultimately leading to syndesmophyte formation. There is a wide variation in the amount of damage among patients ranging from no spinal damage to complete bamboo spine. However, the underlying pathogenetic mechanisms remain largely unknown. With proteomics analysis, potential biomarkers can be detected which can possibly improve the understanding of the underlying pathogenetic mechanisms of AS. Proteomics analysis using Surface-Enhanced Laser Desorption/Ionization Time-of-Flight Mass Spectrometry (SELDI-TOF-MS) has been successfully employed in the discovery of new biomarkers in different human diseases ${ }^{6}$. SELDI-TOF-MS is a technology first introduced by Hutchens and Yip ${ }^{7}$. One of the key features of SELDI-TOF-MS is its ability to provide a rapid protein expression profile from a variety of biological and clinical samples ${ }^{8}$. It consists of selective protein extraction and retention on chromatographic chip surfaces and their subsequent analysis by a simple laser desorption ionization mass spectrometer ${ }^{9}$. For the detection of potential biomarkers, protein profiles of different groups are compared to find distinctive patterns which can clearly discriminate the different groups. Till now this was mainly applied in cancer ${ }^{10-13}$ and chronic inflammation ${ }^{14-16}$ research to find biomarkers.

To our knowledge, this proteomics approach using SELDI-TOF-MS has never been applied in AS. The present study is focusing on the detection of potential biomarkers for the diagnosis of AS using SELDI-TOF-MS. It might also provide new insight in the underlying pathological mechanism. In future studies, we will enlarge our sample set and we will also search for biomarkers which indicate the severity of the disease. 


\section{Materials and methods}

Blood samples of patients with AS $(n=38)$ and healthy controls $(n=38)$ were analyzed. The study was performed in accordance to the Declaration of Helsinki and its amendments and the Medical Ethical Committee of the Hospital approved the procedure followed. Informed consent was obtained from all participants. Characteristics of the studied population are illustrated in Table 6.1. Collection of serum samples was standardized according to World Healthy Organization (WHO) recommendations on anticoagulants in diagnostic laboratory investigations (2002) by using a clotting time of $30 \mathrm{~min}$ at room temperature, spinning for $15 \mathrm{~min}$ (3000 g) and storage of the samples in aliquots within one hour at $-80^{\circ} \mathrm{C}$ after blood collection. All fractionated serum samples were thawed only twice from collection to analyzing.

During screening experiments, sera of eight unrelated human leucocyte antigen B27 (HLA-B27) positive AS patients and sera of eight healthy controls were used to determine the optimal conditions. The HLA-B27 positive AS patients had significant spinal damage and radiological progression over the past two years determined with the modified Stoke Ankylosing Spondylitis Spine Score (mSASSS) method ${ }^{17}$.

Table 6.1 Patient characteristics.

\begin{tabular}{lcc}
\hline & Ankylosing spondylitis patients & Healthy controls \\
\hline $\mathrm{n}$ & 38 & 38 \\
Gender, M/F & $29 / 9$ & $18 / 20$ \\
Age, years & $47.5 \pm 10.5$ & $46.4 \pm 10.9$ \\
Disease duration since diagnosis, years & $10.5 \pm 8.4$ & \\
mSASSS baseline & $18.5 \pm 17.7$ \\
HLA B27-haplotype, M/F & $29 / 7$ \\
CRP (mg/dl) & $13.2 \pm 12.2$ \\
ESR (mm/first hour) & $11.5 \pm 6.7$ \\
BASMI (10-point scale) & $4.2 \pm 1.5$ \\
BASDAl & $3.6 \pm 2.0$ & \\
BASFI & $4.2 \pm 2.2$ & \\
NSAID use, M/F & $29 / 9$ & \\
\hline
\end{tabular}

BASDAl: Bath Ankylosing Spondylitis Disease Activity Index, BASFI: Bath Ankylosing Spondylitis Functional Index, BASMI: Bath Ankylosing Spondylitis Metrology Index (BASMI), CRP: C-reactive protein, ESR: erythrocyte sedimentation rate, HLA-B27: human leucocyte antigen B-27, mSASSS: modified Stoke Ankylosing Spondylitis Spine Score, NSAID: Non-Steroidal Anti-Inflammatory Drugs.

Variables presented as mean $\pm \mathrm{SD}$, as they follow a Gaussian distribution.

\section{SELDI-TOF-MS analysis}

An anion exchange procedure was used, which allowed high-throughput fractionation of serum as described by Solassol et al. ${ }^{18}$. Serum was separated into six different fractions ( $\mathrm{pH} 9, \mathrm{pH} 7, \mathrm{pH} 5, \mathrm{pH} 4, \mathrm{pH} 3$, and organic wash). The anion exchange fractionation was standardized according to the Bio-Rad (Bio-Rad Laboratories, Inc., Herculus, CA, USA) protocols. For the anion exchange 
fractionation, we used $20 \mu \mathrm{l}$ serum and $30 \mu \mathrm{l}$ (9M urea, 2\% Chaps, $50 \mathrm{mM}$ Tris-HCL pH9) as starting material. During the screening experiment the denatured serum samples and the six fractions of the eight unrelated HLA-B27 positive AS patients and of the eight healthy unrelated controls were applied to three different ProteinChip array surfaces (Bio-Rad); cation exchange (CM10), metal affinity binding coupled with copper (IMAC- $\mathrm{Cu}^{2+}$ ), and hydrophobic (H50) to find out which condition resulted in the best discrimination of both groups. The CM10, IMAC-Cu ${ }^{2+}$ and $\mathrm{H} 50$ experiments were performed according to the Bio-Rad protocols. The ProteinChip arrays were read on a Protein Biosystem Ilc (Bio-Rad) instrument. A well defined protocol for calibration of the PBS Ilc, implementation of quality control (QC) samples and acceptance criteria for QC were used in this study 19 .

\section{Data analysis}

For the detection of AS biomarkers, serum protein profiles of AS patients and healthy controls were compared. Peaks were auto detected using Ciphergen Express Data manager 3.0.6 (Bio-Rad). The biomarker Wizard parameters were as followed; signal-to-noise ratio $(\mathrm{S} / \mathrm{N})$ for the first pass: 5.0 (peak height) and 3.0 (valley depth) and for the second pass: 3.0 (peak height) and 1.0 (valley depth). The minimal peak threshold was $50 \%$ of all spectra. The cluster mass window was set at 1.0 peak width and the specified $\mathrm{m} / \mathrm{z}$ range was 2000 to 30,000 for the low range, 5000 to 100,000 for the mid range, and 10,000 to 200,000 for the high range. The Mann-Whitney Wilcoxon test (U-test)) was used to detect significant differences in the intensities of the $m / z$ values between both groups. The biomarker wizard clusters were exported to Biomarker Patterns (BPS) 5.0.2 (Bio-Rad).

BPS uses the peak information generated by the training set of known samples to build a binary decision tree algorithm. The algorithm functions by assigning each sample in the data set into one of the two groups or nodes with a rule based on the intensity of a particular peak or splitter. Each sub node has a different rule that further divides the data set and this process continues until all cases are assigned into terminal nodes. This results in correct classification percentages of the so called "learn set". The software generates and tests the models, using a process of cross-validation by randomly picking $10 \%$ of the samples. The peaks that formed the main splitters of the tree with the highest prediction rates in the crossvalidation analysis were then selected to make a final decision tree with the greatest possible predictive power and this results in correct classification percentages of the so called "test set". So the classification ability of the decision tree algorithms in the learning set to distinguish between AS and controls was validated after cross-validation, which results in a test set.

A Bayesian approach was used to calculate the expected probabilities of each class in each terminal node. Sensitivity was calculated as the ratio of the number of correctly classified disease samples to the total number of disease samples. 
Specificity was calculated as the ratio of the number of control samples correctly classified to the total number of control samples ${ }^{12}$.

\section{Identification}

Protein identification was performed by sodium dodecyl sulphate-polyacrylamide gel electrophoresis (SDS-PAGE) with $12.5 \%$ sodium dodecyl sulphate polyacrylamide (Bio-Rad) and 20-25\% gradient sodium dodecyl sulphate polyacrylamide gels followed by MALDI-TOF-MS. To identify a biomarker, samples were chosen which presented a clear up- or down-regulation in the protein spectra. Ten $\mu \mathrm{l}$ of denatured serum or fraction were diluted in $90 \mu \mathrm{l} \mathrm{Mi-Q}$. Ten $\mu \mathrm{l}$ of these diluted serum samples were subsequently diluted with $2 \mu 10 \%$ SDS sample buffer (312.5 mmol/I TRIS-HCl, 10\% SDS, 33\% glycerol, 0.01\% bromophenol blue) and loaded on $12.5 \%$ sodium dodecyl sulphate-polyacrylamide gels. For the $20-25 \%$ gradient sodium dodecyl sulphate polyacrylamide gels, $10 \mu \mathrm{l}$ of denatured serum or fraction were diluted in $15 \mu \mathrm{l}$ Mi-Q plus $15 \mu \mathrm{l}$ 4\% SDS sample buffer $(62.5 \mathrm{mmol} / \mathrm{I}$ TRIS-HCl, 4\% SDS, 22\% glycerol, 0.01\% bromophenol blue). The digestion procedure was performed as described in the studies of Bouwman et al.20,21 with minor modifications.

\section{MALDI-TOF-MS}

The MALDI-TOF-MS analysis was performed as described in the studies of Bouwman et al. ${ }^{20,21}$ with minor modifications. For Matrix Assisted Laser Desorption Ionization-Time of Flight-Mass Spectrometry (MALDI-TOF-MS), $1.5 \mu \mathrm{l}$ of each peptide mixture and $0.5 \mu \mathrm{l}$ matrix solution $(2.5 \mathrm{mg} / \mathrm{ml} \mathrm{CHCA}$ in $50 \%$ acetonitrile/0.1\% trifluoroacetic acid (TFA)) were spotted automatically onto a 96well-format target plate. The spots were allowed to air dry for homogeneous crystallization. Spectra were obtained using a M@LDI-LR mass spectrometer (Waters, Milford, MA, USA). The instrument was operated in positive reflector mode. The peptide mass list was searched with ProteinLynx Global Server v2.0 (Waters) or Mascot search engine against the Swiss-Prot database. One miss-cleavage was tolerated, carbamidomethylation was set as a fixed modification and oxidation of methionine as an optional modification. The peptide mass tolerance was set to $100 \mathrm{ppm}$. No restrictions were made on the protein $\mathrm{Mr}_{\mathrm{r}}$ and the pl. A protein was regarded as identified when it had a significant ProteinLynx or Mascot probability score $(p<0.05)$, a minimum of four peptides were required to match. 


\section{Results}

\section{Screening experiment}

For choosing the optimal fraction and array type, the number of significant mass-tocharge $(m / z)$ values and the cluster plots were evaluated for each condition with the Ciphergen Express software. For single charged molecules, the $m / z$ value is equal to the molecular weight (MW) in dalton (Da). The cluster plots illustrate the distribution of the intensities for each $\mathrm{m} / \mathrm{z}$ value. With an increased number of significant $m / z$ values $(p<0.05)$ and superior cluster plots, the chance to detect a potential biomarker in a larger sample set is theoretically higher. A cluster plot is superior when there is only minor or no overlap between the data points of the AS patients compared to the control samples, which means that there is a great absolute difference between the mean intensities of both groups, which results in a good discrimination between both groups. By comparing the different chips and fractions in the screening experiments with eight AS patients and eight healthy control samples, we detected the most significant $\mathrm{m} / \mathrm{z}$ values $(p<0.05)$ with superior cluster plots in samples of fraction 6 (the organic fraction on the CM10 arrays $(n=5)$ and in the denatured serum samples $(n=6)$ on the IMAC-Cu' ${ }^{2+}$ arrays. These two conditions were used for performing the CM10 and IMAC-Cu2+ experiments with all AS and all control samples. The numbers of the significant peaks with a superior cluster plot are illustrated in Table 6.2.

Table 6.2 The numbers of significant peaks with a superior cluster per ProteinChip array and fraction.

\begin{tabular}{lccc}
\hline Fraction & $\begin{array}{c}\mathrm{CM} 10 \\
\text { ProteinChip arrays }\end{array}$ & $\begin{array}{c}\mathrm{IMAC}-\mathrm{Cu}^{2+} \\
\text { ProteinChip arrays }\end{array}$ & $\begin{array}{c}\mathrm{H} 50 \\
\text { ProteinChip arrays }\end{array}$ \\
\hline Denatured & 3 & 6 & - \\
Fraction 1 $(\mathrm{pH}$ 9) & 2 & 1 & - \\
Fraction 2 $(\mathrm{pH} \mathrm{7)}$ & - & - & - \\
Fraction 3 $(\mathrm{pH} \mathrm{5)}$ & 2 & 3 & 3 \\
Fraction 4 $(\mathrm{pH} \mathrm{4)}$ & - & 1 & - \\
Fraction 5 $(\mathrm{pH}$ 3) & 1 & 1 & 1 \\
Fraction 6 (organic wash) & 5 & 4 & \\
\hline
\end{tabular}

\section{SELDI-TOF-MS analysis}

Analyses of all AS and healthy control samples on CM10 arrays resulted in a sensitivity of $66 \%$ and a specificity of $74 \%$ using a multimarker approach of two peaks ( $m / z 4172$ and 28,114). The peak at $m / z 4172$ was used as first splitter in the decision tree and was up-regulated in the AS group and the peak at $\mathrm{m} / \mathrm{z}$ 28,144 was used as second splitter (Figure 6.1A). The second splitter was used to further classify the samples, but this peak at $m / z 28,144$ only showed a slight, not significant up-regulation in the AS group. Analyses of all AS and healthy control 
samples on IMAC-Cu ${ }^{2+}$ arrays resulted in a sensitivity and specificity both of $70 \%$ using a multimarker approach of two peaks $(\mathrm{m} / \mathrm{z} 6644$ and 13,875). The peak at $m / z 6644$ was used as first splitter in the decision tree and was down-regulated in the AS group and the peak at $m / z$ 13,875 was used as second splitter (Figure 6.1B). This second splitter was also used to further classify the samples, but this peak at $m / z 13,875$ only showed a slight, not significant down-regulation in the AS group.

The peak splitters with their cut-off values of the peak intensities, and the correct classified percentages of the learn and test set for AS and healthy control samples for the CM10 arrays and the IMAC-Cu2 ${ }^{2+}$ arrays are illustrated in Table 6.3 and Table 6.4 , respectively. The protein spectra of the $\mathrm{m} / \mathrm{z} 4172$ peak on the CM10 arrays are shown in Figure 6.2 and the protein spectra of the $\mathrm{m} / \mathrm{z} 6644$ peak on the IMAC-Cu ${ }^{2+}$ arrays are shown in Figure 6.3.

In the present study we also divided our AS group in subgroups to find some markers for disease severity based on spinal structural damage. The following subgroups were made; damage $(n=19)$ vs non-damage $(n=19)$, progression during the last two years $(n=17)$ vs non-progression $(n=21)$, progression and damage $(n=12)$ vs the rest of the AS group $(n=26)$. A few statistically significant peaks were found between the subgroups, but there was a high proportion of incorrect classification of individual patients and controls using decision tree algorithm.
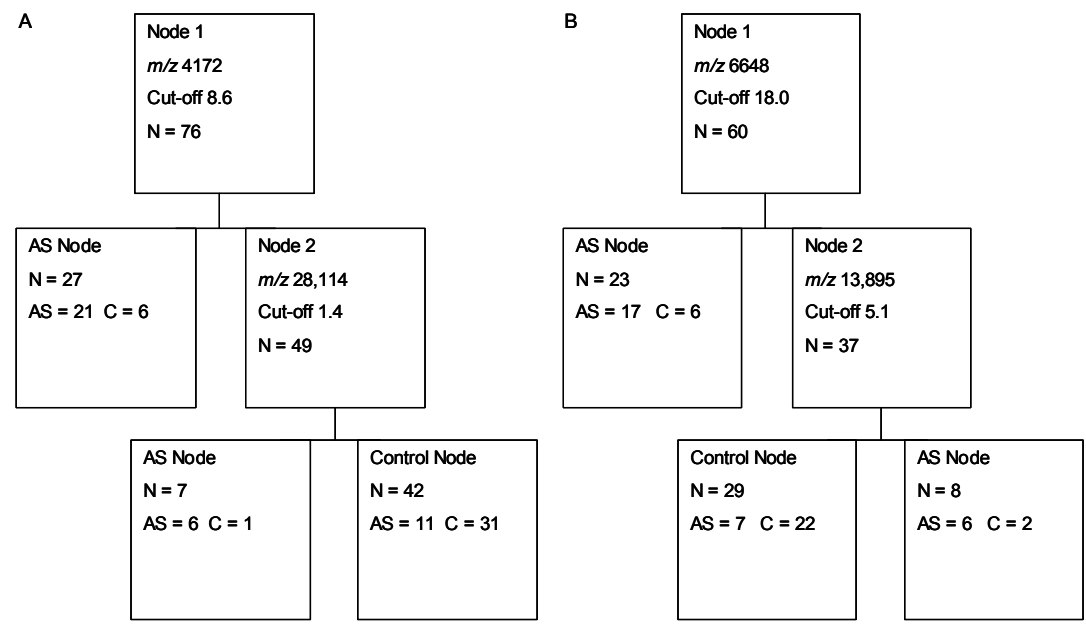

Figure 6.1 Decision trees of the multimarker on the CM10 arrays (A) and on the IMAC-Cu ${ }^{2+}$ arrays (B). The splitter nodes with accessory $\mathrm{m} / \mathrm{z}$ values and cut-off values, end nodes and the number of ankylosing spondylitis (AS) and control (C) per node are illustrated. 


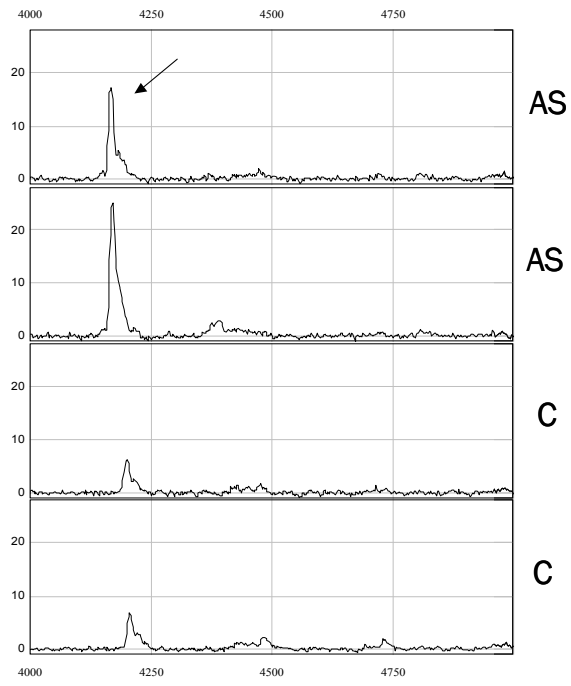

Figure 6.2 SELDI-TOF mass spectra of the $\mathrm{m} / \mathrm{z} 4172$ peak on the CM10 arrays. Protein spectra of two ankylosing spondylitis (AS) and two control (C) samples are illustrated. The biomarker is indicated with a vector. The mass is given as $m / z$ value on the $x$-axis and the intensity is displayed along the y-axis.

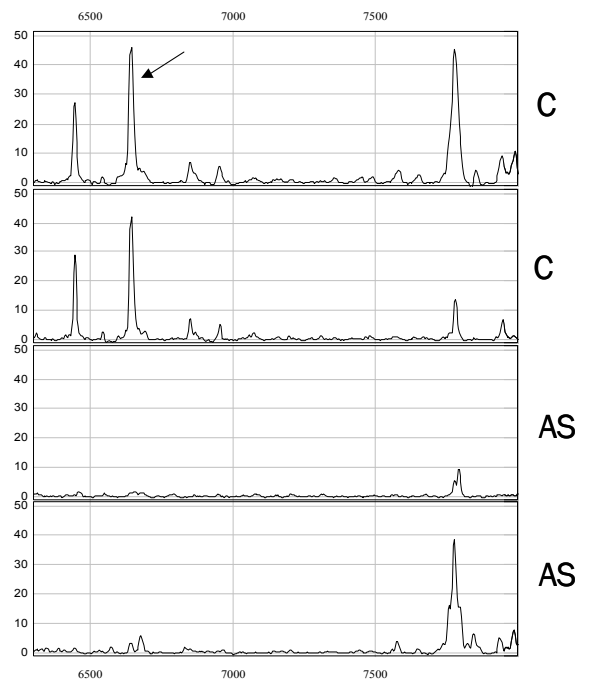

Figure 6.3 SELDI-TOF mass spectra of the $m / z 6648$ peak on the IMAC-Cu ${ }^{2+}$ arrays. Protein spectra of two ankylosing spondylitis (AS) and two control (C) samples are illustrated. The biomarker is indicated with a vector. The mass is given as $m / z$ value on the $x$-axis and the intensity is displayed along the y-axis. 
Table 6.3 The laser settings, $\mathrm{m} / \mathrm{z}$ values of the peak splitters, the cut-off values of the peak intensities, and the correct classified percentages of the learn and test set for AS and healthy control samples using the CM10 ProteinChip arrays with the organic fraction samples.

\begin{tabular}{lccrr}
\hline Laser setting & $m / z$ value $(\mathrm{Da})$ & $\begin{array}{c}\text { Cut-off } \\
\text { peak intensity }\end{array}$ & Learn set & Test set \\
\hline LI: 210 & 4172 & 8.6 & AS: $27 / 38=71 \%$ & AS: $25 / 38=66 \%$ \\
SE: 7 & 28.144 & 1.4 & C: $31 / 38=82 \%$ & C: $28 / 38=82 \%$ \\
\hline
\end{tabular}

LI: laser intensity, SE: detector sensitivity, AS: ankylosing spondylitis, C: healthy controls

Table 6.4 The laser settings, $m / z$ values of the peak splitters, the cut-off values of the peak intensities, and the correct classified percentages of the learn and test set for AS and healthy control samples using the IMAC ProteinChip arrays with denatured serum samples.

\begin{tabular}{lccrr}
\hline Laser setting & $m / z$ value $(\mathrm{Da})$ & $\begin{array}{c}\text { Cut-off } \\
\text { peak intensity }\end{array}$ & Learn set & Test set \\
\hline LI: 200 & 6648 & 18.0 & AS: $23 / 30=77 \%$ & AS: $21 / 30=70 \%$ \\
SE: 7 & 13.895 & 5.1 & C: $22 / 30=73 \%$ & C: $21 / 30=70 \%$ \\
\hline
\end{tabular}

LI: Iaser intensity, SE: detector sensitivity, AS: ankylosing spondylitis, C: healthy controls

\section{Identification}

The peaks at $\mathrm{m} / \mathrm{z} 28,144$ and 13,875 were both successfully identified as apolipoprotein A-I (ApoA1), [Swiss-Prot: P02647] with probability Mascot scores (probability based mowse score) of 160 and 86, respectively. Protein scores greater than 66 are significant $(p<0.05)$. Unfortunately, the peaks at $m / z 4172$ and $6644 \mathrm{kDa}$ could not be identified.

\section{Discussion}

This pilot study indicates that profiling studies can be useful for the diagnosis of AS. The present study demonstrates that there appears to be a great variety in the protein patterns between patients, but also within controls. This variation is caused by the biological variation and analytical variation of SELDI-TOF-MS ${ }^{19}$. But in spite of this variation in intensities and biological variability, we were able to find two potential multimarkers using a multimarker approach. The first multimarker $(\mathrm{m} / \mathrm{z}$ 4172 and 28,144 ) using the CM10 arrays resulted in a sensitivity of $66 \%$ and a specificity of $74 \%$. The second multimarker $(\mathrm{m} / \mathrm{z} 6644$ and 13,875) using the IMAC-Cu ${ }^{2+}$ arrays resulted in a sensitivity and specificity both of $70 \%$.

We only tried to identify the four peaks ( $m / z 4172,6644,13,875$, and 28,144) which were used in the decision tree algorithms. The other $m / z$ peaks were not identified. Using Mascot search engine against the Swiss-Prot database we found 
that the peaks at 14 and $28 \mathrm{kDa}$, excised from the SDS-PAGE gel, were both successfully identified as apolipoprotein A-I (ApoA1). Unfortunately we were not able to identify the two peaks with the smaller molecular weights.

Although the results of this pilot study seem promising, one of the major limitations of this study was the rather small sample size. Future studies, in a larger cohort of well defined AS patients, are necessary to evaluate the clinical value of this observation. The collection of well defined AS samples is time consuming. Moreover, to establish the diagnostic value a population of patients suffering from other rheumatoid diseases should be included as well. Further attempts will be undertaken to identify the two peaks $(\mathrm{m} / \mathrm{z} 4172, \mathrm{~m} / \mathrm{z} 6644)$, because the identification of these two markers will lead to a better understanding of AS and would be of great interest. Unfortunately we were not able to classify the AS patients in different subgroups of severity based on spinal structural damage. The number of patients in the subgroups should be increased. In future studies, we will enlarge the sample group and we will also validate our markers with a blind sample set.

\section{Conclusions}

This is the first study that shows that protein profiling in serum using SELDI-TOF-MS can be used as a diagnostic tool for AS. In future studies, we will enlarge the sample group and we will also validate our markers with a blind sample set. After this validation, we can search for disease activity markers. Eventually, implementation of a quantitative immunoassay, is needed, to give a good prediction of the disease state and disease severity. 


\section{References}

1. Braun J, Bollow M, Remlinger G, Eggens U, Rudwaleit M, Distler A, Sieper J: Prevalence of spondylarthropathies in HLA-B27 positive and negative blood donors. Arthritis Rheum 1998; 41:58-67.

2. Zink A, Listing J, Klindworth $\mathrm{C}$, Zeidler $\mathrm{H}$ : The national database of the German Collaborative Arthritis Centres: I. Structure, aims, and patients. Ann Rheum Dis 2001;60:199-206.

3. Carette S, Graham D, Little H, Rubenstein J, Rosen P: The natural disease course of ankylosing spondylitis. Arthritis Rheum 1983;26:186-190.

4. Chorus AM, Boonen A, Miedema HS, van der Linden S: Employment perspectives of patients with ankylosing spondylitis. Ann Rheum Dis 2002;61:693-699.

5. Boonen A, Chorus A, Miedema H, van der Heijde D, van der Tempel H, van der Linden S: Employment, work disability, and work days lost in patients with ankylosing spondylitis: a cross sectional study of Dutch patients. Ann Rheum Dis 2001;60:353-358.

6. Srinivas PR, Verma M, Zhao Y, Srivastava S: Proteomics for cancer biomarker discovery. Clin Chem 2002;48:1160-1169.

7. Hutchens TW, Yip T: New Desorption strategies for the mass spectrometric analysis of macromolecules. Rapid Commun Mass Spectrom 1993;7:576-580.

8. Issaq HJ, Veenstra TD, Conrads TP, Felschow D: The SELDI-TOF MS Approach to Proteomics: Protein Profiling and Biomarker Identification. Biochemical and Biophysical Research Communications 2002;292:587-592.

9. Caputo E, Moharram R, Martin BM: Methods for on-chip protein analysis. Anal Biochem 2003; 321:116-124.

10. Kozak KR, Amneus MW, Pusey SM, Su F, Luong MN, Luong SA, Reddy ST, Farias-Eisner R: Identification of biomarkers for ovarian cancer using strong anion-exchange ProteinChips: potential use in diagnosis and prognosis. Proc Natl Acad Sci U S A 2003;100:12343-12348.

11. Petricoin EF, 3rd, Ornstein DK, Paweletz CP, Ardekani A, Hackett PS, Hitt BA, Velassco A, Trucco C, Wiegand L, Wood $\mathrm{K}$ et al: Serum proteomic patterns for detection of prostate cancer. J Natl Cancer Inst 2002;94:1576-1578.

12. Liu W, Guan M, Wu D, Zhang Y, Wu Z, Xu M, Lu Y: Using tree analysis pattern and SELDI-TOF-MS to discriminate transitional cell carcinoma of the bladder cancer from noncancer patients. Eur Urol 2005;47:456-462.

13. Koopmann J, Zhang Z, White N, Rosenzweig J, Fedarko N, Jagannath S, Canto MI, Yeo CJ, Chan DW, Goggins M: Serum diagnosis of pancreatic adenocarcinoma using surface-enhanced laser desorption and ionization mass spectrometry. Clin Cancer Res 2004;10:860-868.

14. Zhu XD, Zhang WH, Li CL, XU Y, Liang WJ, Tien P: New serum biomarkers for detection of HBVinduced liver cirrhosis using SELDI protein chip technology. World J Gastroenterol 2004;10: 2327-2329.

15. Poon TC, Hui AY, Chan HL, Ang IL, Chow SM, Wong N, Sung JJ: Prediction of Liver Fibrosis and Cirrhosis in Chronic Hepatitis B Infection by Serum Proteomic Fingerprinting: A Pilot Study. Clin Chem 2004;51:328-335.

16. Bons JA, Drent M, Bouwman FG, Mariman EC, van Dieijen-Visser MP, Wodzig WK: Potential biomarkers for diagnosis of sarcoidosis using proteomics in serum. Respir Med 2007;101: 1687-1695.

17. Wanders A, Landewe R, Dougados M, Mielants H, van der Linden S, van der Heijde D: Association between radiographic damage of the spine and spinal mobility for individual patients with ankylosing spondylitis: can assessment of spinal mobility be a proxy for radiographic evaluation? Ann Rheum Dis 2005;64:988-994.

18. Solassol J, Marin P, Demettre E, Rouanet P, Bockaert J, Maudelonde T, Mange A: Proteomic detection of prostate-specific antigen using a serum fractionation procedure: potential implication for new low-abundance cancer biomarkers detection. Anal Biochem 2005;338:26-31.

19. Bons JA, de Boer D, van Dieijen-Visser MP, Wodzig WK: Standardization of calibration and quality control using surface enhanced laser desorption ionization-time of flight-mass spectrometry. Clin Chim Acta 2006;366:249-256. 
20. Bouwman F, Renes J, Mariman E: A combination of protein profiling and isotopomer analysis using matrix-assisted laser desorption/ionization-time of flight mass spectrometry reveals an active metabolism of the extracellular matrix of 3T3-L1 adipocytes. Proteomics 2004;4:3855-3863.

21. Bouwman F, Suylen D, Renes J, Mariman E: Evaluation and improving the success rate of protein identification by peptide mass fingerprinting using matrix-assisted laser desorption/ionization time-of-flight mass spectrometry. Rapid Commun Mass Spectrom 2005;19:2465-2468. 



\section{Chapter 7}

\section{Haptoglobin in lacunar stroke: a SELDI-TOF- MS study with subsequent phenotyping}

Julie Staals, Judith A. P. Bons, Robert J. van Oostenbrugge, Iris L.H. Knottnerus, Marja P. van Dieijen-Visser, Freek G. Bouwman, Edwin C.M. Mariman, Joris R. Delanghe, Jan Lodder, Will K.W.H. Wodzig

Submitted 


\section{Abstract}

\section{Background}

Using Surface-Enhanced Laser Desorption/Ionization Time-of-Flight Mass Spectrometry, we aimed to detect differences in protein expression profile in serum samples of two lacunar stroke subtypes.

\section{Methods}

Surface-Enhanced Laser Desorption/Ionization Time-of-Flight Mass Spectrometry, followed by protein identification, was performed in samples of eight first-ever lacunar stroke patients with MR imaging showing a single symptomatic lacunar lesion (type I), and eight with multiple additional "silent" lacunar lesions and extensive white matter lesions (type II).

\section{Results}

A $16 \mathrm{kDa}$ protein, identified as alpha-2-chain of haptoglobin $(\mathrm{Hp})$, was up-regulated in type I compared to type II (peak intensity 12.5 vs. 5.0; p=0.02). A polymorphism with two alleles, Hp-1 and Hp-2, determines the presence of alpha-1 and/or alpha-2-chains in the Hp-molecule. Therefore, Hp phenotypic analysis was performed. Hp-1 : Hp-2 allele frequency was $0.562: 0.438$ in type I and 0.812 : 0.188 in type II (population reference $\sim 0.4: 0.6$ ).

\section{Conclusions}

The up-regulation of the alpha-2-chain in type I is (partly) related to a higher Hp-2 allele frequency. Yet, compared to population reference, the phenotype distribution in both lacunar stroke patient groups deviates towards a high $\mathrm{Hp}-1$ allele frequency, suggesting a role for the $\mathrm{Hp}$ gene in the etiology of cerebral small vessel disease. The even higher $\mathrm{Hp}-1$ allele frequency in type II than in type I implies a promoting role for $\mathrm{Hp}-1$ in developing multiple silent lacunar lesions and white matter lesions and could be a reflection of a difference in underlying vascular pathology between the two types, but needs confirmation in larger series. 


\section{Introduction}

Lacunar infarcts are small, deeply in the brain located infarcts, mostly caused by occlusion of a small perforating artery ${ }^{1}$. They can present with an acute lacunar stroke syndrome, but can also remain asymptomatic. Lacunar strokes account for about $25 \%$ of all ischemic strokes. Lacunar stroke patients in whom cerebral imaging shows multiple additional "silent" lacunar lesions, differ clinically from those patients with only a single symptomatic lesion in that they show more extensive cerebral white matter lesions (WML) on neuro-imaging, have more often hypertension, and have worse prognosis on functional outcome, a higher stroke recurrence rate, higher short- and long-term mortality and higher rate of asymptomatic lesion progression ${ }^{2-6}$. Whether these two types of small vessel disease (SVD) are both ends of one pathogenetic spectrum, or represent two pathogenetically different entities, remains subject of debate. Research into the underlying pathogenetic mechanisms thus far focused on known proteins that are thought to be involved in vascular pathogenesis, such as coagulation and inflammation factors ${ }^{7-10}$.

To obtain new insight in the underlying pathogenesis of lacunar stroke, we set out to look for possible differences in protein expression profile in lacunar stroke patients with or without extensive concomitant silent cerebral SVD using SurfaceEnhanced Laser Desorption/Ionization Time-of-Flight Mass Spectrometry (SELDITOF-MS) in serum samples. This technology provides a rapid method to detect expressed proteins in a biological sample. It uses chip surfaces, which bind a subset of proteins from a sample. An energy-absorbing matrix is added so that when laser energy is applied to the chip the proteins become ionized, enabling their mass to be measured by time-of-flight mass spectrometry. Protein profiles of different patient groups can be compared to find distinctive patterns.

This proteomic approach led us to the finding of a difference between the two lacunar stroke types in the expression of a $16 \mathrm{kDa}$ protein, which was identified as alpha-2 chain of haptoglobin ( $\mathrm{Hp}$ ). These results brought us to the analysis of Hp 1/2 polymorphism.

\section{Materials and methods}

\section{Study population}

From May 2003 on, all patients who present with a first-ever stroke are registered in the Maastricht Stroke Registry, a prospective stroke database at University Hospital Maastricht, the Netherlands. Lacunar stroke is defined as an acute stroke syndrome with an MRI finding compatible with the clinical findings and consisting of a T2-weighted hyperintense subcortical small lesion of less than $20 \mathrm{~mm}$ in 
diameter; or an acute stroke syndrome compatible with one of the lacunar syndromes in the absence of such MRI lesion ${ }^{11}$. With informed consent, these patients participate in an ongoing lacunar stroke research project for which the local Medical Ethical Committee gave approval. From this cohort we carefully selected two groups of each eight Caucasian patients, according to pre-defined criteria. Group 1 were patients in whom brain MRI showed only one single symptomatic lacunar lesion (type I). Group 2 consisted of eight patients in whom brain MRI additionally showed multiple (four or more) asymptomatic lacunar lesions as well as extensive WML (type II). Extensive WML was defined according to Fazekas' classification as confluent deep white matter hyperintensities and irregular periventricular hyperintensities extending into the deep white matter ${ }^{12}$. Patients had no potential source of cardiac embolism, diabetes mellitus, ischemic heart disease (known or treated angina pectoris, or a history of myocardial infarction), peripheral arterial vessel disease or carotid stenosis. Hypertension was defined as known and treated hypertension, or blood pressure recordings higher than $140 / 90 \mathrm{mmHg}$ on at least two separate occasions before or at least two weeks after stroke. Patient baseline characteristics are shown in Table 7.1. Fasting blood samples were taken at least three months after stroke. Collection of serum samples was standardized by using a clotting time of $30 \mathrm{~min}$ at room temperature, spinning for ten min at 4000 RPM (3000 g) and storage in aliquots within one hour after blood collection at $-80^{\circ} \mathrm{C}$.

Table 7.1 Patient baseline characteristics

\begin{tabular}{|c|c|c|c|}
\hline Lacunar stroke & Type I & \multicolumn{2}{|c|}{ Type II } \\
\hline Total number of patients & 8 & 8 & \\
\hline Age (median in years) & $57 \quad(46-80)$ & 67 & $(44-79)$ \\
\hline Male (absolute number) & 4 & 4 & \\
\hline Hypertension (absolute number) & 6 & 6 & \\
\hline Smoking (absolute number) & 2 & 1 & \\
\hline Number of lacunes (median) & 1 & 5.5 & (5-11) \\
\hline
\end{tabular}

\section{SELDI-TOF-MS analysis}

Anion exchange fractionation: Serum samples were pre-treated using an anion exchange procedure, which allowed high-throughput fractionation of all 16 serum samples based on the biophysical properties of proteins, as described by Solassol et al. ${ }^{13}$. Serum was separated into six different fractions $(\mathrm{pH} 9, \mathrm{pH} 7, \mathrm{pH} 5, \mathrm{pH} 4$, $\mathrm{pH} 3$, and organic wash). The anion exchange fractionation was standardized according to the Ciphergen protocols. All fractionated serum samples had only two thaw steps from collection to analyzing. The anion exchange procedure is illustrated in Figure 7.1. After this fractionation the samples were applied on the ProteinChips. 


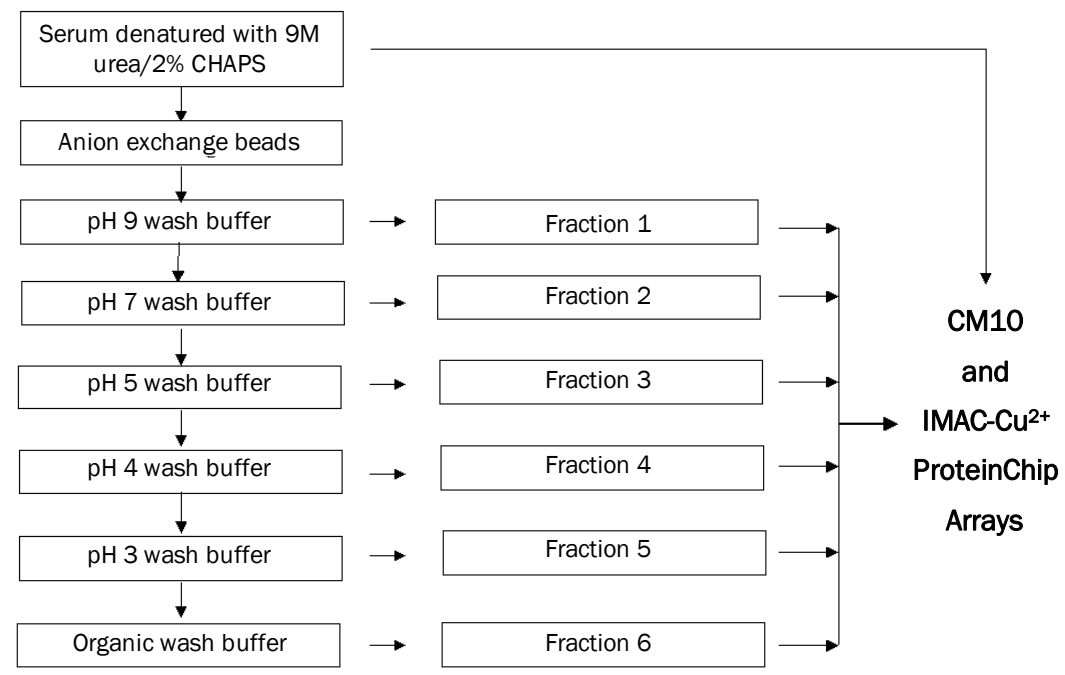

Figure 7.1 Schematic view of the anion exchange fractionation procedure: Anion exchange beads were supplied in a 96-well filtration plate. Samples were added to the plate and eluted in a stepwise manner, by altering the $\mathrm{pH}$ of the wash buffer. Serum was separated into six different fractions ( $\mathrm{pH} 9, \mathrm{pH} 7, \mathrm{pH} 5, \mathrm{pH} 4, \mathrm{pH}$, and organic wash).

ProteinChip arrays: In the screening experiment, denatured serum and six fractions of all 16 patients were applied to two different array surfaces (Ciphergen Biosystems Inc., Fremont, CA, USA) to find out the optimal array and fraction. The weak cation exchange (CM10) and the immobilized metal affinity capture coupled with copper $\left(\mathrm{IMAC}^{-} \mathrm{Cu}^{2+}\right)$ ProteinChip arrays were used. The CM10 and IMAC-Cu${ }^{2+}$ experiments were performed according to the Ciphergen protocols. The ProteinChip arrays were read on a Protein Biosystem Ilc (Ciphergen Biosystems Inc.) instrument. A well defined protocol for calibration of the PBS Ilc, implementation of quality control (QC) samples and acceptance criteria for QC were used in this study ${ }^{14}$.

\section{Data Analysis}

Serum protein profiles of both lacunar stroke groups were compared. Peaks were identified after mass calibration, background subtraction, and normalization using Ciphergen Express Data manager 3.0.6 (Ciphergen Biosystems, Inc.). Cluster analysis was performed using the Biomarker Wizard in the Ciphergen Express Software. The biomarker Wizard parameters were as follows: signal-to-noise ratio $(\mathrm{S} / \mathrm{N})$ for the first pass: 5.0 (peak height) and 3.0 (valley depth) and for the second pass: 3.0 (peak height) and 1.0 (valley depth). The minimal peak threshold was $50 \%$ of all spectra. The cluster mass window was set at 1.0 peak width and the 
specified $\mathrm{m} / \mathrm{z}$ range was 2000 to 30,000 for the low range, 5000 to 100,000 for the mid range, and 10,000 to 200,000 for the high range. The Mann-Whitney Wilcoxon test (U-test) was used to detect significant differences in the intensities of the $m / z$ values between both groups.

\section{Identification}

Protein identification was performed by one-dimensional gel electrophoresis (1-DE) and two-dimension gel electrophoresis (2-DE) followed by Matrix Assisted Laser Desorption/Ionization Time-of-Flight Mass Spectrometry (MALDI-TOF-MS) as described in the studies of Bouwman et al. with minor modifications ${ }^{15,16}$. Two patient samples of each group were chosen which presented a clear up- or downregulation in the protein spectra. To identify the $16.1 \mathrm{kDa}$ marker, $10 \mu \mathrm{l}$ of denatured serum sample was diluted in $90 \mu \mathrm{l}$ Milli-Q. Ten $\mu \mathrm{l}$ of this diluted serum sample was subsequently diluted with $2 \mu \mathrm{l} 6$ x sample buffer (10\% SDS, 0.6 M DTT, $30 \%$ glycerol, $0.012 \%$ bromophenol blue, $0.35 \mathrm{M}$ Tris) and loaded on $12.5 \%$ sodium dodecyl sulphate-polyacrylamide gel electrophoresis (SDS-PAGE) gels. For the 2-DE, $10 \mu \mathrm{l}$ of the denatured serum sample was diluted in $190 \mu \mathrm{l}$ 2-DE buffer (6 M urea, 30\% glycerol, 2\% SDS and $50 \mathrm{mM}$ Tris-HCL) and was loaded for the first dimension.

\section{Total Hp concentration and Hp phenotyping}

Because of the results of SELDI analysis and protein identification, we measured total $\mathrm{Hp}$ concentration, using particle-enhanced immunonephelometry on the BN Prospec (Dade Behring Inc., Deerfield, IL, USA). Hp 1/2 phenotyping was carried out using starch gel electrophoresis according to Smithies et al. ${ }^{17}$.

\section{Results}

\section{SELDI-TOF-MS analysis}

Although the anion exchange fractionating procedure was performed, the best distinctive pattern was found with denatured serum on the IMAC-Cu ${ }^{2+}$ ProteinChip array. Three peaks were significantly different between both groups. The peak at $m / z 16,122$ was the most prominent discriminating peak. The peak at $m / z 16,122$ was up-regulated in lacunar stroke type I versus type II with mean intensities of 12.5 and 5.0 for type I and type II patients, respectively $(p=0.02)$. The clusterplot and protein spectra are illustrated in Figure 7.2 and 7.3. 


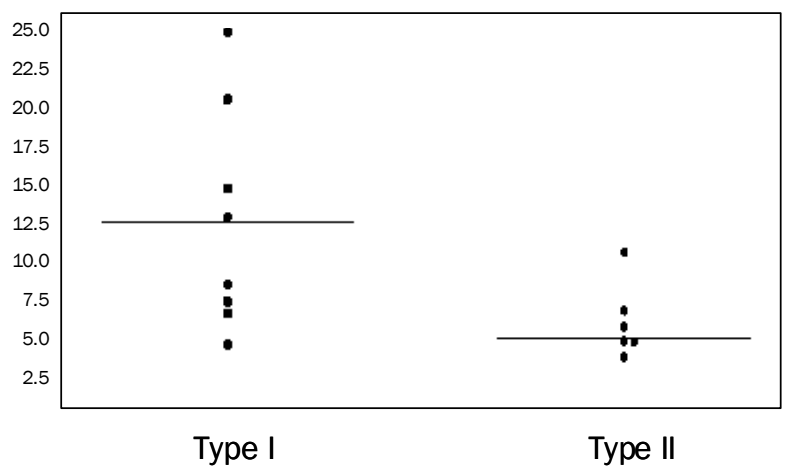

Figure 7.2 The cluster plot of the peak at $m / z$ 16,122. The lacunar groups are indicated on the $x$-axis and the normalized intensities are indicated on the $y$-axis. The horizontal bars present the mean intensities for the type I and type II group.

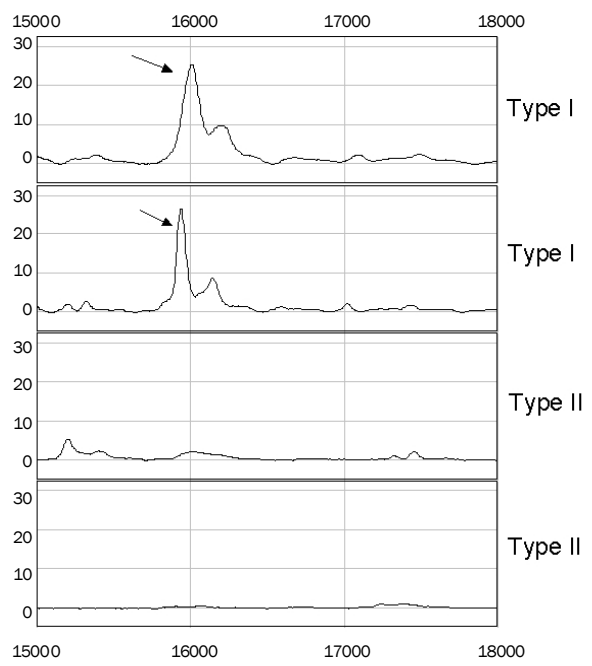

Figure 7.3 SELDI mass spectra of the marker at $m / z$ 16.122. Protein spectra of two type I and two type II patient samples are illustrated. The marker is indicated with an arrow. The mass is given as $m / z$ values on the $x$-axis and the intensity is displayed along the $y$-axis.

\section{Identification}

1-DE and 2-DE were used for isolation and purification of the $m / z$ 16,122 marker, followed by MALDI-TOF-MS analysis, which was used for identification. Denatured serum samples of two type I patients which showed a high peak intensity at $m / z$ 16,122 on the IMAC-Cu2+ ProteinChip arrays and denatured serum samples of two type II patients which showed a low peak intensity were used.

Figure 7.4 illustrates that the band at a molecular weight (MW) of $16 \mathrm{kDa}$, which 
represents the peak at $m / z 16,122$, is clearly visible in the two type I patient samples and absent in the two type II samples. This agrees with the SELDI-TOF-MS results. After excising the $16.1 \mathrm{kDa}$ peak out of the SDS-PAGE gel, identification with the Mascot search engine against the Swiss-Prot database revealed the following protein as the best candidate of database searches: alpha-chain of $\mathrm{Hp}$ (P00738) with a probability Mascot score (probability based mowse score) of 68 . Protein scores $>67$ are significant $(p<0.05)$. The alpha-chain of $\mathrm{Hp}$ exists in two variants, alpha-1 $(8.9 \mathrm{kDa})$ and alpha-2 (16 kDa), the latter being compatible with the marker at $m / z 16,122$.

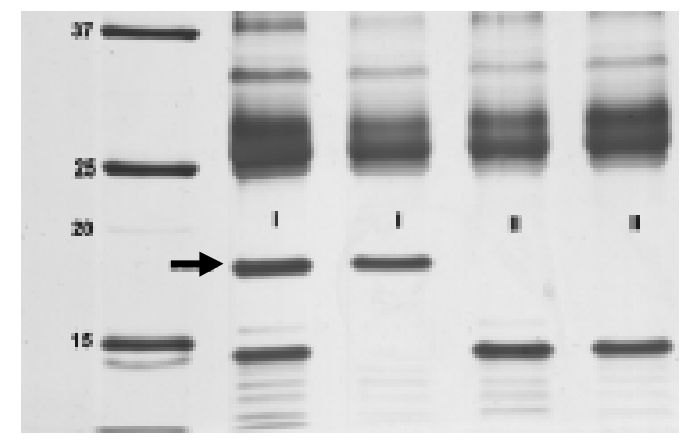

Figure 7.4 Silver stained band pattern of two type I and two type II patient samples separated by SDSPAGE. There was one band at $16 \mathrm{kDa}$ present for the type I patient samples, which was absent in the type II patient samples. The bands are indicated with an arrow.

There were three protein spots on 2-DE gels horizontally surrounding the $16 \mathrm{kDa}$ spot which were clearly present in the type I patient samples and absent in the type II patient samples. All spots were successfully identified as alpha-chain of $\mathrm{Hp}$ (Probability Mascot scores: 69-75). These spots are probably isoforms of the alphachain, with the same MW, but different pl value (pl 4-7).

\section{Haptoglobin}

Because the peak of the marker at $m / z$ 16,122 was identified as the alpha-2-chain of $\mathrm{Hp}$, total $\mathrm{Hp}$ concentration and phenotype distribution were measured. Results are presented in Table 6.2. Mean Hp concentration in lacunar stroke type I was not significantly different from that in type II (t-test; $p=0.62$ ). Hp phenotype distribution and $\mathrm{Hp}-1: 2$ allele frequency are presented with a western European reference population. 18 
Table 7.2 Results of the SELDI-TOF-MS analysis, total haptoglobin ( $\mathrm{Hp}$ ) concentration measurement, and $\mathrm{Hp}$ phenotyping.

\begin{tabular}{lccc}
\hline & Type I & Type II & reference population \\
\hline 16 kDa peak intensity & 12.5 & 5.0 & \\
Mean Hp (g/L) & $1.69 \pm 0.47$ & $1.81 \pm 0.51$ & $0.25-1.90$ \\
Hp phenotype $(1-1: 2-1: 2-2)^{a}$ & $2: 5: 1$ & $5: 3: 0$ & $15: 50: 3518$ \\
Hp-1: Hp-2 allele frequency & $0.562: 0.438$ & $0.812: 0.188$ & $0.40: 0.6018$ \\
\hline
\end{tabular}

a absolute numbers in type I and II, percentages in reference population

${ }^{b} X^{2}$ test : $p=0.13$ in type I vs. type II; $p=0.02$ in lacunar stroke (type I and II combined) vs. reference population

\section{Discussion}

The first important finding of our study is that we detected differences in protein profile between lacunar stroke patients with or without concomitant signs of silent cerebral SVD using SELDI-TOF-MS. A protein at $\mathrm{m} / \mathrm{z} 16,122$ was successfully identified as the alpha-2-chain of $\mathrm{Hp}$. It was found up-regulated in patients without silent lesions (type I) compared to those with additionally multiple silent lacunar lesions and extensive WML (type II).

$\mathrm{Hp}$ is a plasma protein synthesized in the liver. It has hemoglobin-binding capacity and can be regarded as a major antioxidant. It also plays a role in inflammatory reactions, being an inflammation-sensitive protein. Its production is induced by cytokines $^{18}$. There is a plausible role for $\mathrm{Hp}$ in vascular disease as both oxidative and inflammatory factors are important in the pathogenesis of atherosclerosis, and its presence has been shown in atherosclerotic coronary lesions ${ }^{19,20}$. High levels of $\mathrm{Hp}$ have been associated with the incidence of stroke $\mathrm{e}^{21,22}$.

$\mathrm{Hp}$ consists of alpha- and beta-polypeptide chains, linked by disulfide bonds ${ }^{18}$. Three Hp phenotypes, Hp 1-1 [structural formula $\left.\left(\alpha^{1} \beta\right)_{2}\right]$, Hp 2-1 $\left[\left(\alpha^{1} \beta\right)_{2}+\left(\alpha^{2} \beta\right)_{n}\right.$ ] and $\mathrm{Hp} 2-2\left[\left(\alpha^{2} \beta\right)_{n}\right]$, are genetically determined by a polymorphism with two alleles: $\mathrm{Hp}-1$ and $\mathrm{Hp}-2$. This polymorphism results in variants in alpha-chains: alpha-1 $(8.9 \mathrm{kDa})$ and alpha-2 $(16 \mathrm{kDa})^{18}$. The beta-chain $(40 \mathrm{kDa})$ is identical in all $\mathrm{Hp}$ phenotypes. One explanation for an up-regulation of the alpha-2-chain would be a higher total $\mathrm{Hp}$ concentration, however, total $\mathrm{Hp}$ concentration did not differ significantly between our two lacunar groups. Another explanation could be that the multimeric Hp-2 proteins are larger sized in type I. This was not further explored. Thirdly, it could represent a higher $\mathrm{Hp}-2$ allele frequency. Indeed Hp phenotypic analysis showed a higher Hp-2 allele frequency in type I. We conclude that the upregulation of the alpha-2-chain in type I compared to type II is (partly) related to a higher $\mathrm{Hp}-2$ allele frequency in the former. Yet, in contrast to a reference population 18 , in both lacunar stroke groups $\mathrm{Hp}-1$ outweighed $\mathrm{Hp}-2$ allele frequency. This brings in the second important finding of our study: Hp-1 is associated with cerebral SVD. Understanding the genetic basis of lacunar stroke may help clarifying 
the aetiology and pathogenesis. However, knowledge about genetic factors modulating differences in lacunar stroke types is limited. Our study brings in a new candidate gene. The association between Hp-1 and SVD can be viewed in just a quantitative way, given the even higher Hp-1 allele frequency in type II than type I (although not significantly, due to small sample groups), suggesting a role for $\mathrm{Hp}-1$ in developing more extensive disease. However, based on the pathology work of Fisher and Lammie, we hypothesized earlier that the two lacunar types that we distinguish on neuro-imaging and clinical grounds, represent distinct vascular pathologies, namely microatheromatosis and lipohyalinosis (also called arteriolosclerosis) ${ }^{1,2,4,23}$. The influence of the $\mathrm{Hp}$ phenotype may thus be relevant in predisposing to one type of small vessel pathology more than the other.

The mechanism underlying the association between Hp phenotype and SVD is speculative but could be related to blood pressure regulation. Hp levels have been associated with systolic blood pressure ${ }^{21}$. Weinberger et al. reported a relationship between $\mathrm{Hp}-1$ and sodium-sensitive hypertension ${ }^{24}$. A more recent study by Depypere et al. associated Hp-1 with more severe hypertension in preeclamptic women ${ }^{25}$. Hypertension is an important risk factor for both lacunar stroke and WML, whereas multiple silent lacunar lesions are more often associated with hypertension than single lacunar lesions ${ }^{2}$. Hypertension was equally present in both our patient groups. However, there are indications that some other characteristics of the 24-hour blood pressure profile, such as nocturnal dipping, may be more important in small vessel pathogenesis than just the label "hypertension", which is defined at an arbitrarily fixed value ${ }^{26}$.

It was suggested that blood-brain barrier failure with leakage of plasma components into brain tissue might be an early stage of the process that ultimately leads to lacunar infarcts and WML27. Hp-1 passes the blood-brain barrier, while $\mathrm{Hp}-2$ may pass to a far less extent due to its larger size. In barrier dysfunction the passage is increased ${ }^{28}$. Hp phenotype may play a role in determining the severity of SVD once a barrier defect has developed.

As opposed to our findings, studies on $\mathrm{Hp}$ polymorphism in extracerebral large vessel atherosclerotic disease show $\mathrm{Hp}-2$ to be a risk factor in developing peripheral vascular disease and coronary artery disease 29,30 . In the Strong Heart Study Hp-2 was a strong predictor for cardiovascular disease, including stroke, in diabetic patients ${ }^{31}$. However, lacunar strokes were not separately distinguished. Hp polymorphism has also been studied in the development of extracerebral small vessel vasculopathy: the $\mathrm{Hp}-1$ allele may protect against nephropathy and retinopathy in diabetic patients ${ }^{32,33}$. As the distribution of the $\mathrm{Hp}-2$ protein in extravascular fluids is restricted by its larger molecular mass, its antioxidative capacity is lower18.

A drawback of our study is the small sample size of 16 patients. However, one needs to remind that the study was not designed primarily with the intent to study polymorphisms; haptoglobin phenotypic analysis arose from the results of the 
SELDI-TOF-MS analysis. The small sample size followed from the strictly chosen predefined inclusion criteria. In many patients MR imaging shows some silent lesions that are sometimes difficult to discern from dilated perivascular spaces. To increase the chance of finding a difference in protein expression profile we avoided this in-between area and included only the extreme ends of the spectrum: those with just a single symptomatic versus those with multiple concomitant silent lesions. Because of its possible confounding influence, we also excluded patients with coexisting large vessel disease. Although some degree of subclinical vascular disease may still have been present, we do not expect it to be overrepresented in one of the groups.

In conclusion, the SELDI-TOF-MS technique appeared to be useful to detect differences in protein expression between two lacunar stroke types which leads to new ideas about cerebral small vessel pathogenesis and its genetic basis. If a larger study would confirm our results, the association between $\mathrm{Hp}-1$ and lacunar stroke signifies a new candidate gene involved in cerebral SVD etiology. The trend for a difference in $\mathrm{Hp}-1$ association between two lacunar stroke types could be a reflection of a difference in underlying vascular pathology. 


\section{References}

1. Fisher CM. The arterial lesions underlying lacunes. Acta neuropath (Berl). 1969;12:1-15.

2. Boiten J, Lodder J, Kessels F. Two clinically distinct lacunar infarct entities? A hypothesis. Stroke. 1993;24:652-656.

3. Mast H, Thompson JLP, Lee S-H, Mohr JP, Sacco RL. Hypertension and diabetes mellitus as determinants of multiple lacunar infarcts. Stroke. 1995;26:30-33.

4. de Jong G, Kessels F, Lodder J. Two types of lacunar infarcts, further arguments from a study on prognosis. Stroke. 2002;33:2072-2076.

5. van Zagten M, Boiten J, Kessels F, Lodder J. Significant progression of white matter lesions and small deep (lacunar) infarcts in patients with stroke. Arch Neurol. 1996;53:650-655.

6. Spolveri S, Baruffi MC, Cappelletti C, Semerano F, Rossi S, Pracucci G, Inzitari D. Vascular risk factors linked to multiple lacunar infarcts. Cerebrovasc Dis. 1998;8:152-157.

7. Kario K, Matsuo T, Kobayashi H, Asada R, Matsuo M. 'Silent' cerebral infarction is associated with hypercoagulability, endothelial cell damage, and high $\mathrm{Lp}(\mathrm{a})$ levels in elderly Japanese. Arterioscler Thromb Vasc Biol. 1996;16:734-741.

8. Kilpatrick TJ, Matkovic Z, Davis SM, McGrath CM, Dauer RJ. Hematologic abnormalities occur in both cortical and lacunar infarction. Stroke. 1993;24:1945-1950.

9. van Dijk EJ, Prins ND, Vermeer SE, Vrooman HA, Hofman A, Koudstaal PJ, Breteler MMB. Creactive protein and cerebral small-vessel disease; the Rotterdam scan study. Circulation. 2005;112:900-905.

10. Hassan A, Hunt BJ, O'Sullivan M, Parmar K, Bamford JM, Briley D, Brown MM, Thomas DJ, Markus HS. Markers of endothelial dysfunction in lacunar infarction and ischaemic leukoaraiosis. Brain. 2003;126:424-432.

11. Bamford J, Sandercock P, Jones L, Warlow C. The natural history of lacunar infarction: the Oxfordshire community stroke project. Stroke. 1987;18:545-551.

12. Fazekas F, Chawluk JB, Alavi A, Hurtig HI, Zimmerman RA. MR signal abnormalities at $1.5 \mathrm{~T}$ in Alzheimer's dementia and normal aging. AJR. 1987;149:351-356.

13. Solassol J, Marin P, Demettre E, Rouanet P, Bockaert J, Maudelonde T, Mange A. Proteomic detection of prostate-specific antigen using a serum fractionation procedure: potential implication for new low-abundance cancer biomarker detection. Anal Biochem. 2005;338:26-31.

14. Bons JA, de Boer D, van Dieijen-Visser MP, Wodzig WK. Standardization of calibration and quality control using surface enhanced laser desorption ionization-time of flight-mass spectrometry. Clin Chim Acta. 2006;366:249-256.

15. Bouwman F, Renes J, Mariman E. A combination of protein profiling and isotopomer analysis using matrix-assisted laser desorption/ionization-time of flight mass spectrometry reveals an active metabolism of the extracellular matrix of 3T3-L1 adipocytes. Proteomics. 2004;4:3855-3863.

16. Bouwman F, Suylen D, Renes J, Mariman E. Evaluation and improving the success rate of protein identification by peptide mass fingerprinting using matrix-assisted laser desorption/ionization time-of-flight mass spectrometry. Spectrom. 2005;19:2465-2468.

17. Smithies O, Connell G, Dixon G. Inheritance of haptoglobin subtypes. Am J Hum Genet. 1962;14:14-21.

18. van Vlierberghe $\mathrm{H}$, Langlois $\mathrm{M}$, Delanghe $\mathrm{J}$. Haptoglobin polymorphisms and iron homeostasis in health and in disease. Clin Chim Acta. 2004;345:35-42.

19. Ross R. Atherosclerosis-an inflammatory disease. NEJM. 1999;340:115-126.

20. Matuszek M, Aristoteli L, Bannon P, Hendel P, Hughes C, Jessup W, Dean R, Kritharides L. haptoglobin elutes from human atherosclerotic coronary arteries-a potential marker of arterial pathology. Atherosclerosis. 2003;168:389-396.

21. Engstrom G, Lind P, Hedblad B, Stavenow L, Janzon L, Lindgarde F. Long-term effects of inflammation-sensitive plasma proteins and systolic blood pressure on incidence of stroke. Stroke. 2002;33:2744-2749.

22. Engstrom G, Lind P, Hedblad B, Stavenow L, Janzon L, Lindgarde F. Effects of cholesterol and inflammation-sensitive plasma proteins on incidence of myocardial infarction and stroke in men. Circulation. 2002;105:2632-2637. 
23. Lammie GA, Brannan F, Slattery J, Warlow CP. Nonhypertensive cerebral small-vessel disease. An autopsy study. Stroke. 1997;28:2222-2229.

24. Weinberger M, Miller J, Fineberg N, Luft F, Grim C, Christian J. Association of haptoglobin with sodium sensitivity and resistance of blood pressure. Hypertension. 1987;10:443-446.

25. Depypere HT, Langlois MR, Delanghe JR, Temmerman M, Dhont M. Haptoglobin polymorphism in patients with preeclampsia. Clin Chem Lab Med. 2006;44:924-928.

26. Staals J, Lodder J. Hypertension and lacunar stroke. In: Mohler E, Townsend R, eds. Advanced therapy in hypertension and vascular disease. Hamilton: B.C.Decker; 2006:152-160.

27. Wardlaw JM, Sandercock PAG, Dennis MS, Starr J. Is breakdown of the blood-brain barrier responsible for lacunar stroke, leukoaraiosis, and dementia ? Stroke. 2003;34:806-812.

28. Chamoun V, Zeman A, Blennow K, Fredman P, Wallin A, Keir G, Giovannoni G, Thompson EJ. Haptoglobins as markers of blood-CSF barrier dysfunction: the findings in normal CSF. J Neurol Sci. 2001;182:117-121.

29. Delanghe J, Cambier B, Langlois M, de Buyzere M, Neels H, de Bacquer D, van Cauwelaert P. Haptoglobin polymorphism, a genetic risk factor on coronary artery bypass surgery. Atherosclerosis. 1997;132.

30. Delanghe J, Langlois M, Duprez D, de Buyzere M, Clement D. Haptoglobin polymorphism and peripheral arterial occlusive disease. Atherosclerosis. 1999;145:287-292.

31. Levy AP, Hochberg I, Jablonski K, Resnick HE, Lee ET, Best L, Howard BV. Haptoglobin phenotype is an independent risk factor for cardiovascular disease in individuals with diabetes: the Strong Heart Study. J Am Coll Cardiol. 2002;40:1984-1990.

32. Nakhoul F, Marsh S, Hochberg I, Leibu R, Miller B, Levy A. Haptoglobin genotype as a risk factor for diabetic retinopathy. JAMA. 2000;284:1244-1245.

33. Nakhoul F, Zoabi R, Kanter Y, Zoabi M, Skorecki K, Hochberg I, Leibu R, Miller B, Levy A. Haptoglobin phenotype and diabetic nephropathy. Diabetologia. 2001;44:602-604. 



\section{Chapter 8}

\section{A specific immunoprecipitation method for isolating isoforms of insulin-like growth factor binding protein-3 from serum}

Judith A.P. Bons, Etienne C.H.J. Michielsen, Douwe de Boer, Freek G. Bouwman, Jaak Jaeken, Marja P. van Dieijen-Visser, Estela M.E. Rubio-Gozalbo, Will K.W.H. Wodzig

Clin Chim Acta 2008;387:59-65 


\section{Abstract}

\section{Background}

This report describes an in-house developed immunoprecipitation method to isolate insulin-like growth factor binding protein-3 (IGFBP-3) and its isoforms from serum. The method was compared to other existing immunoprecipitation methods. The study of IGFBP-3 isoforms is relevant for further studies on congenital defects in glycosylation (CDG), galactosemia, and alcoholic liver cirrhosis.

\section{Methods}

Monoclonal and/or polyclonal anti-human IGFBP-3 antibodies were covalently immobilised on protein-A Sepharose beads using dimethyl pimelimidate as cross-linker. By incubation with these immobilised antibodies, intact IGFBP-3 and fragments of IGFBP-3 were isolated from serum. Enzyme-linked immunosorbent assay (ELISA) and one-dimensional gel electrophoresis (1-DE) experiments were performed to define the optimal immunoprecipitation method. Isolated proteins were separated by 1-DE and two-dimensional gel electrophoresis (2-DE) and visualised by Western blotting.

\section{Results}

ELISA and 1-DE results illustrated that an optimal isolation was performed using PBS for the incubation with serum. Laemmli sample buffer, containing 2-amino-2-(hydroxymethyl)-1,3-propanediol hydrochloride and sodium dodecyl sulphate, or urea/CHAPS was optimal for the elution. Clinical validation was performed using CDG-la serum samples. The 2-DE experiments showed characteristic isoform patterns for CDG-la.

\section{Conclusions}

The optimized in-house developed immunoprecipitation method resulted in specific detection of IGFBP-3 isoforms and is suitable for further studies on glycosylation defects. 


\section{Introduction}

Immunoprecipitation methods are very useful for the purification and identification of low-abundance proteins from complex matrices, like serum or plasma. In most studies, the immunoprecipitation technique was developed for extracting and concentrating proteins from cell lysates ${ }^{1,2}$ and not from serum. An immunoprecipitation method for extracting and concentrating low-abundance proteins from cell lysates using dimethyl pimelimidate (DMP) cross-linked antibodies to protein-A Sepharose beads was described by Schneider et al. ${ }^{3}$. Sisson et al. ${ }^{4}$ modified the procedure of Schneider et al. in two ways to improve the crosslinking efficiency. First, the number of coupling reactions was increased and secondly the cross-linker solution was prepared immediately prior to matrix construction. Michielsen et al. ${ }^{5}$ used the previously described method of Sisson et al. for extracting and concentrating low-abundance proteins from human serum. The cross-linking method using DMP as a cross-linker is rarely used.

Conventional methods of immobilizing antibodies on solid matrices usually employ cyanogen bromide-activated Sepharose although other matrices have also been used, like brome acetylated cellulose or other activated matrices 6 . These conventional methods do not use cross-linkers and tend to be low-efficiency methods due to the fact that there are numerous reactive sites on an antibody for covalent binding to the matrix. Thus the orientation of the antibody relative to the matrix is often such that the combining site participates in the cross-linking or is sterically blocked to its orientation 7 . Protein-A Sepharose beads overcome these difficulties, because protein-A from Staphylococcus aureus binds specifically to the fragment crystallizable region (Fc region) of an antibody ${ }^{4}$. The Fc region is the constant region of an antibody composed of two heavy chains that each contribute three or four constant domains, depending on the class of the antibody. This results in an optimal surface orientation of the antibodies, leaving the antigenbinding sites free from antigen capture. Antibodies are covalently cross-linked to solid surfaces or micro particles to prevent loss of antigen binding capacity due to unwanted desorption, caused by weak non-covalent binding, competitive inhibition with antibodies present in samples, or harsh elution conditions. A typical cross-link protocol using imido-esters starts with the non-covalent capture of antibodies by immobilised protein-A or -G. The choice of either protein-A or protein-G depends on the subclass of the antibody and should be determined individually for each antibody. In this study, protein-A Sepharose beads were used. After antibody capture, DMP was added at a pH between 8 and 9 for covalent cross-linking of the antibody to protein-A Sepharose. Because DMP was susceptible to hydrolysis even at basic $\mathrm{pH}$, it was added in two or more portions with regular intervals to ensure complete reaction, which was also described by Sisson et al. ${ }^{4}$. Remaining free reactive groups are quenched with ethanolamine and all non-bound antibodies were eluted. 
In this study a specific immunoprecipitation method developed by our group ${ }^{5}$ was optimized. Western blotting and enzyme-linked immunosorbent assay (ELISA) experiments were performed to define the optimal condition to purify and isolate insulin-like growth factor binding protein-3 (IGFBP-3) from serum. In blood insulinlike growth factors (IGFs) are bound by IGF-binding proteins, which serve as carriers of circulating IGFs and modulators of IGF action ${ }^{8}$. IGFBP-3, a $\sim 43 / 45 \mathrm{kDa}$ glycoprotein, is most abundant in serum and sequesters insulin-like growth factor I en II into a ternary $150 \mathrm{kDa}$ complex with the $85 \mathrm{kDa}$ acid-labile subunit ${ }^{9}$. Because IGFBP-3 levels are in the range of $1-9 \mathrm{mg} / \mathrm{I}$ (dependent on age and assay), a specific immunoprecipitation method is needed to isolate and purify IGFBP-3. The aim of the present study was to optimize our immunoprecipitation assay for the isolation and purification of IGFBP-3 from serum to study the isoforms of IGFBP-3. The study of IGFBP-3 isoforms in different disease entities such as congenital defects in glycosylation, galactosemia ${ }^{8}$, and alcoholic liver cirrhosis ${ }^{10}$ is important to unravel pathogenetic mechanisms. The method described in this study was clinically validated by comparing serum samples of CDG-la children with serum samples of healthy children. The CDG-la samples were used as positive controls to clinically validate our method because CDG-la patients have a genetic defect in $\mathrm{N}$-glycan synthesis. This causes hypoglycosylation of serum transferrin ${ }^{11}$ and many other glycoproteins. Serum IGFBP-3 contains three N-glycosylation sites ${ }^{12}$, and should thus be hypoglycosylated in CDG-la.

\section{Materials and methods}

\section{Patients and samples}

The serum samples of CDG-la children were collected at the University Hospital Gasthuisberg, Leuven, Belgium. The CDG-la children were 11 years (female) and 8 years (male) old, and showed a typical clinical presentation. Two serum samples of healthy children were collected at the University Hospital Maastricht and were matched by sex and age.

\section{Antibodies covalently bound to beads using DMP}

One hundred mg protein-A Sepharose (GE Healthcare Bio-Sciences Corp., Piscataway, USA) beads were blocked with $10 \mathrm{ml}$ of phosphate buffered saline (PBS) containing $0.1 \%$ bovine serum albumin (Sigma-Aldrich Co., St. Louis, MO, USA) for $10 \mathrm{~min}$ at room temperature. This resulted in $400 \mu \mathrm{l}$ of diluted protein-A Sepharose beads which can be used for antibody coupling. Seventy $\mu g$ mouse monoclonal anti-human IGFPB-3 antibody (R\&D Systems, Inc. Minneapolis, MN, USA) and $70 \mu \mathrm{g}$ rabbit polyclonal anti-human IGFPB-3 antibody (RDI Division of Fitzgerald Industries, Concord, MA, USA) in $10 \mathrm{ml}$ of PBS containing $0.1 \%$ bovine 
serum albumin were mixed with the $400 \mu$ l of diluted Sepharose beads and rotated for one hour at room temperature. After binding of the antibodies, the beads were washed twice with excessive PBS. Antibodies were cross-linked to protein-A Sepharose by the addition of $200 \mathrm{mmol} / \mathrm{I}$ triethanolamine in PBS to which $20 \mathrm{mmol} / \mathrm{I}$ DMP (Sigma-Aldrich) was added directly before use ( $\mathrm{pH} \mathrm{8-9).} \mathrm{After}$ rotation for $30 \mathrm{~min}$ at room temperature, the beads were washed with $200 \mathrm{mmol} / \mathrm{I}$ triethanolamine in PBS at room temperature. The cross-linking and washing steps were repeated twice to improve cross-linking efficiency. The remaining reactive amino groups were quenched by addition of $50 \mathrm{mmol} / \mathrm{l}$ ethanolamine in PBS for one hour at room temperature. Antibodies not cross-linked to beads were removed by incubation twice (20 min each time) with $1.0 \mathrm{~mol} / \mathrm{I}$ glycine- $\mathrm{HCl}(\mathrm{pH} \mathrm{3.0})$ at $56^{\circ} \mathrm{C}$. The antibodies cross-linked to beads were stored at $4^{\circ} \mathrm{C}$ in PBS containing $0.2 \mathrm{ml} / \mathrm{I}$ Tween-20 (PBST) and $0.2 \mathrm{~g} / \mathrm{l}$ sodium azide until use. Batches, containing antibodies cross-linked to beads, were divided in tubes. Each tube contained $200 \mu \mathrm{l}$ of the stored batch, which corresponded with $2.5 \mathrm{mg}$ (dry weight) of antibody-coupled Sepharose beads. This in-house developed immunoprecipitation was compared to other immunoprecipitation methods where no DMP was used as cross-linker.

\section{Antibodies non-covalently bound to beads without using DMP}

Antibodies were non-covalently bound to beads without using DMP as cross-linker. For this method, batches were prepared as described in detail above with the exception that no DMP was used.

\section{Antibodies not bound to beads}

Antibody-serum complexes were generated by first adding the antibodies to the serum. Subsequently protein-A Sepharose beads were added to the antibodyserum mixtures without using DMP as cross-linker.

\section{Incubation and elution conditions for immunoprecipitation}

To investigate the most efficient conditions, the immunoprecipitation of IGFBP-3 was performed with different amounts of diluted antibody-coupled Sepharose beads $(200-800 \mu \mathrm{l})$. To each tube, we added $75-500 \mu \mathrm{l}$ of serum, with $200 \mu \mathrm{l}$ of PBST and $100 \mu \mathrm{l}$ of PBS or $6 \mathrm{M}$ urea. Beads were rotated for $90 \mathrm{~min}$ and then washed twice with PBST. Three different elution solutions were used; A) glycine solution: $1 \mathrm{M}$ glycine- $\mathrm{HCl}$ ( $\mathrm{pH} \mathrm{3),} \mathrm{B)} \mathrm{Laemmli} \mathrm{solution:} 62.5 \mathrm{mmol} / \mathrm{l}$ 2-amino-2(hydroxymethyl)-1,3-propanediol hydrochloride (TRIS-HCl), 2\% sodium dodecyl sulphate (SDS), 25\% glycerol, 0.01\% bromophenol blue) (Bio-Rad Laboratories, Inc., Herculus, CA, USA), C) urea/CHAPS solution: $8 \mathrm{M}$ urea, 2\% ([3-[(3cholamidopropyl)-dimethylammonio]propanesulfonate]) (CHAPS). Elution was 
performed by heating $\left(56^{\circ} \mathrm{C}\right)$ for $20 \mathrm{~min}$ in $20-50 \mu \mathrm{l}$ of glycine, Laemmli, or urea/CHAPS solutions. The samples were centrifuged and the supernatant was kept for analysis.

\section{One- and two-dimensional gel electrophoresis}

The samples were prepared for one-dimensional gel electrophoresis (1-DE) by adding 5 or $10 \mu \mathrm{l}$ of $10 \%$ SDS sample buffer (312.5 mmol/I TRIS-HCl, 10\% SDS, $33 \%$ glycerol, $0.01 \%$ bromophenol blue) to 20 or $40 \mu$ of eluate, except for the Laemmli eluates. We applied $20 \mu \mathrm{l}$ of this mixture to a $4-15 \%$ linear gradient TRIS$\mathrm{HCl}$ polyacrylamide precast gel (Bio-Rad). The SeeBlue Plus2 Pre-Stained Standard (Invitrogen Corp., San Diego, CA, USA) was used as the molecular mass marker. Electrophoresis was conducted for $15 \mathrm{~min}$ at $100 \mathrm{~V}$ for stacking followed by $40 \mathrm{~min}$ at $150 \mathrm{~V}$. For the two-dimensional gel electrophoresis (2-DE), $20 \mu \mathrm{l}$ of eluate were loaded for the first dimension. Isoelectric focusing was performed on an IPGphor electrophoresis unit (GE Healthcare Bio-Sciences) at $20^{\circ} \mathrm{C}$. ReadyStrip IPG strips (pH 3-10 not linear, $11 \mathrm{~cm}$ long) (Bio-Rad) were rehydrated overnight in $180 \mu \mathrm{l}$ of $8 \mathrm{M}$ urea, 2\% CHAPS, 0.5\% Bio-lite 3-10 (Bio-Rad) at $30 \mathrm{~V}$. Isoelectric focusing was performed using the following program: $100 \mathrm{~V}$ for $1 \mathrm{~h}, 500 \mathrm{~V}$ for $1 \mathrm{~h}, 1000 \mathrm{~V}$ for $1 \mathrm{~h}$, increased to $8000 \mathrm{~V}$ with a one hour linear gradient, and a final step at $8000 \mathrm{~V}$ for $2.5 \mathrm{~h}$. After focusing, IPG strips were equilibrated for $15 \mathrm{~min}$ in $50 \mathrm{mM}$ TRIS-HCl, pH 6.8, $6 \mathrm{M}$ urea 30\% glycerol, 2\% SDS and were placed onto a slab gel and sealed with a $0.5 \%$ agarose solution in Laemmli buffer with a trace of bromophenol blue. The second dimension run was carried out on $12.5 \%$ SDS polyacrylamide gels (SDS-PAGE). Electrophoresis was conducted at a constant voltage of $200 \mathrm{~V}$ for one hour in an $11 \mathrm{~cm}$ Criterian cell (Bio-Rad).

\section{Western Blotting}

The gel was blotted on a nitrocellulose membrane (Bio-Rad) at $4^{\circ} \mathrm{C}$ at $100 \mathrm{~V}$ for 60 min. The membrane was blocked for 60 min in PBS containing $33 \mathrm{~g} / \mathrm{l}$ non-fat dry milk. The primary mouse monoclonal anti-human IGFPB-3 antibody was added at a 1:1250 dilution in wash buffer. The membrane was incubated overnight at $4^{\circ} \mathrm{C}$. The membrane was washed three times in wash buffer. The secondary antibody (peroxidase-labeled goat-anti-mouse, Dako, Glostrup Denmark) was then added at a 1:5000 dilution in wash buffer and incubated for $60 \mathrm{~min}$ at $4^{\circ} \mathrm{C}$. To reduce nonspecific binding, $250 \mu \mathrm{l}$ of human serum were added to the wash buffer. The additional serum in the wash buffer resulted in less background signal. The membrane was washed four times with wash buffer and finally once with PBS. Membranes were developed with enhanced chemiluminescence buffer and captured on Kodak X-Omat Blue film (both from Perkin-Elmer Life Sciences, Waltham, MA, USA). Quantitative analysis of the negative images of the 1-DE Western blots was performed using the imaging and analyzing software program 
Quantity One (Bio-Rad). The relative quantity is the trace quantity of a band expressed as a percentage of the total quantity of the bands in the lanes.

\section{Protease inhibitors}

Protease inhibitor cocktail (mixture of 4-(2-aminoethyl)benzenesulfonyl fluoride, E-64, bestatin, leupeptin, aprotinin, and sodium ethylenediamine tetraacetic acid (EDTA) with broad specificity for the inhibition of serine, cysteine, aspartic, and metalloproteases (Sigma-Aldrich) was added to control serum of a healthy person directly after venipuncture to ensure that the detected fragments of IGFBP-3 were no in-vitro artefacts. This was also verified by applying an immunoprecipitated and non-immunoprecipitated human recombinant IGFBP-3 standard from Sigma-Aldrich ( $41 \mathrm{kDa}$ ) on 4-15\% linear gradient TRIS-HCl polyacrylamide precast gel (Bio-Rad).

\section{ELISA}

The IGFBP-3 ELISA kit (Diagnostic Systems Laboratories Inc., Webster, TX, USA) was performed according the recommendations of the manufacturer. The absorbance measured was directly proportional to the concentration of IGFBP-3 present. A set of IGFBP-3 standards was used, in adapted matrices when relevant, to plot a standard curve of absorbance versus IGFBP-3 concentration from which the IGFBP-3 concentrations in the samples can be calculated. Because the elution was performed in three different solutions; glycine, Laemmli, and urea/CHAPS solutions, the standards and controls were diluted two times in $2 \mathrm{M}$ glycine- $\mathrm{HCl}$ (pH 3), concentrated Laemmli buffer (125 mmol/I TRIS-HCl, 4\% SDS, 50\% glycerol, $0.01 \%$ bromophenol blue), and $10 \mathrm{M}$ urea/ 2\% CHAPS for plotting curves in adapted matrices. The initial IGFBP-3 concentrations of the serum samples were 5 , 7 , and $6 \mathrm{mg} / \mathrm{l}$ for the incubation and elution solution experiment, the serum experiment, and the beads experiment, respectively.

\section{Results}

\section{Generation of antibody-serum complexes}

To check the influence of cross-linking with DMP three different types of immunoprecipitation were compared. We compared a batch of mouse monoclonal anti-human IGFBP-3 antibodies covalently bound to beads using DMP as crosslinker with a separate batch of antibodies non-covalently bound to beads without using DMP as cross-linker. This second batch of antibodies non-covalently bound to beads resulted in very low density signals of the intact IGFBP-3. The fragments were not visible on the negative image of the 1-DE Western blot, probably because of the low densities of these fragment bands. In another method, antibody-serum 
complexes were generated by first adding the antibodies to the serum. Subsequently protein-A Sepharose beads were added to the antibody-serum mixtures without using DMP as cross-linker. With this last method, the intact IGFBP-3 including the fragments were detected, but the densities of these bands were low. The method with cross-linking resulted in the most clear and highest density bands (intact and fragments). These results demonstrate that the method described in this study, with DMP as cross-linker is optimal for purifying and isolating IGFBP-3 from serum. The results are illustrated in Figure 8.1.

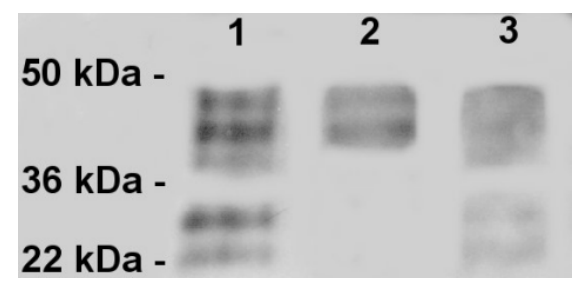

Figure 8.1 Influence of DMP as cross-linker.

Three different types of immunoprecipitation were compared using mouse monoclonal anti-human IGFBP-3 antibodies. Type I: the antibodies were covalently bound to beads using DMP as cross-linker (lane 1). Type II: the antibodies were non-covalently bound to beads without using DMP as cross-linker (lane 2). Type III: antibody-serum complexes were generated by first adding the antibodies to the serum. Subsequently the protein-A Sepharose beads were added to the antibody-serum mixtures without using DMP as crosslinker (lane 3).

\section{Protease inhibitors}

Protease inhibitor cocktail was added to serum to demonstrate that the IGFBP-3 fragments were formed in vivo and not in vitro. With protease inhibitors, intact IGFBP-3 and fragments were still seen, although with less density due to dilution. Even with an excess of protease inhibitors, fragments of IGFBP-3 remain unchanged. To confirm that the fragments were not the result of the immunoprecipitation itself, the IGFBP-3 standard from Sigma-Aldrich ( 41 kDa) was immunoprecipitated. The 41 kDa IGFBP-3 standard from Sigma-Aldrich did not show any additional fragmentation after immunoprecipitation.

\section{ELISA}

To investigate the optimal incubation and elution conditions, $200 \mu \mathrm{l}$ of diluted beads and $250 \mu \mathrm{l}$ of serum were used. These amounts of beads and serum were used by Michielsen et al. ${ }^{5}$ to isolate cardiac troponin T (cTnT) from serum. Because cTnT is also a very low-abundance protein (reference value: $0.01-0.10 \mu \mathrm{g} / \mathrm{l}$ ), the same conditions were used in the first instance. In previous experiments was also found that 90 min incubation resulted in the most optimal elution (data not 
shown). To determine the optimal conditions to isolate IGFBP-3 from serum with immunoprecipitation, different incubation solutions (PBS and $6 \mathrm{M}$ urea, both in combination with a PBST solution), and elution solutions (glycine, Laemmli, and urea/CHAPS solutions) were compared. Subsequently, different amounts of serum (75-500 $\mu \mathrm{l})$ and protein-A Sepharose beads (200-800 $\mu \mathrm{l})$ were compared.

\section{Incubation and elution solution experiment}

In this study batches with monoclonal and polyclonal antibodies were used for the isolation. Immunoprecipitation of IGFBP-3 from serum in the presence of $100 \mu \mathrm{l}$ of $6 \mathrm{M}$ urea and $200 \mu \mathrm{l}$ of PBST was compared with immunoprecipitation in the presence of $100 \mu \mathrm{l}$ of PBS and $200 \mu \mathrm{l}$ of PBST. Both incubation conditions were combined with glycine, Laemmli, and urea/CHAPS elution solutions. All three elution solutions showed a higher amount of IGFBP-3 using PBS instead of $6 \mathrm{M}$ urea to dilute the serum for immunoprecipitation using the monoclonal batch, except for the elution with Laemmli solution using the polyclonal batch (Figure 8.2). Elution with Laemmli or urea/CHAPS solutions resulted in a clearly higher absolute amounts of IGFBP-3 compared to elution with glycine solution. This was in agreement with the negative images of the 1-DE Western blots. These negative images also illustrated that the elution with Laemmli and urea/CHAPS solutions resulted in a more intense signal compared to elution with glycine solution (data not shown).

Incubation and elution solutions experiment

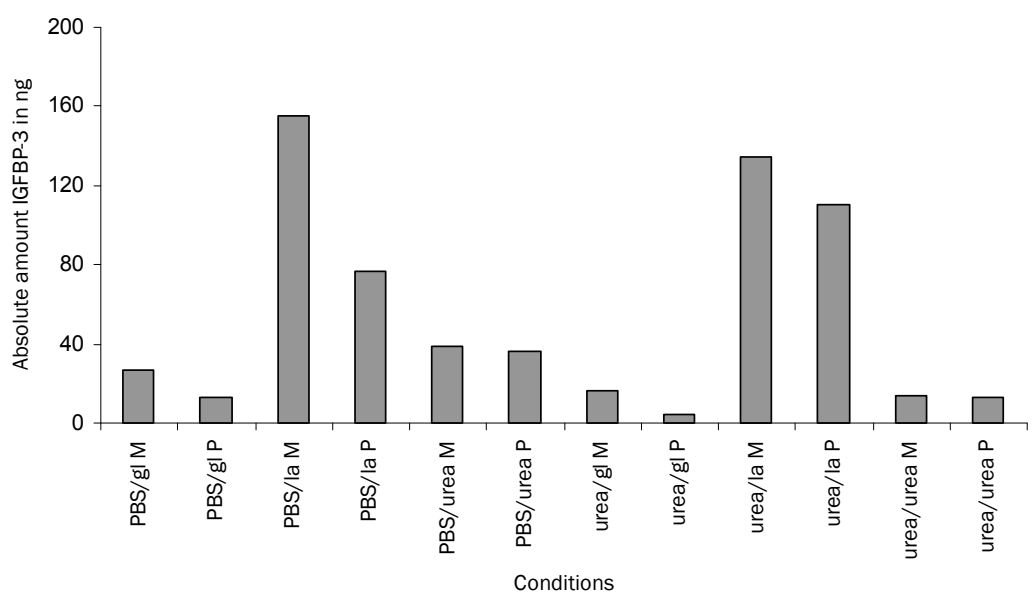

Figure 8.2 The absolute amount of IGFBP-3 (in ng) after immunoprecipitation of IGFBP-3 from serum in the presence of PBS or $6 \mathrm{M}$ urea (both in combination with a PBST solution). Both incubation conditions were combined with glycine (gl), Laemmli (la) or urea/CHAPS (urea) elution solutions. The monoclonal batch (mouse monoclonal anti-human IGFPB-3 antibody) (M) and the polyclonal batch (rabbit polyclonal anti-human IGFPB-3 antibody) (P) were used. Two hundred $\mu \mathrm{l}$ of protein-A Sepharose beads and $250 \mu \mathrm{l}$ of serum were used for the immunoprecipitation. 


\section{Serum experiment}

Secondly, different amounts of serum (75 / 125 / 250 / $500 \mu \mathrm{l})$ were added to $100 \mu \mathrm{l}$ of PBS and $200 \mu \mathrm{l}$ of PBST. A constant incubation time of $90 \mathrm{~min}$ and 200 $\mu \mathrm{l}$ of protein-A Sepharose beads (coupled with monoclonal antibody), which corresponds to $2.5 \mathrm{mg}$ (dry weight) beads, were used for the immunoprecipitation. Figure 8.3 clearly illustrates that the highest absolute amount of IGFBP-3 was eluated using $250 \mu \mathrm{l}$ of serum. By using $250 \mu \mathrm{l}$ of serum, $8 \mathrm{ng}$ IGFBP-3 could be eluated, while the absolute amounts for the other conditions were lower, namely $3.5,5$, and 6 ng IGFBP-3 when using 75,125 or $500 \mu$ l of serum, respectively. The elution-binding ratios were also determined by dividing the percentage of elution by that of binding for the four different conditions. The highest elution-binding ratio was also reached when $250 \mu$ of serum were used.

Serum experiment



Figure 8.3 The absolute amount of IGFBP-3 (in ng) after elution with urea/CHAPS solution using different serum amounts.

Different amounts of serum: $75 / 125 / 250 / 500 \mu$ l were used with $200 \mu$ l of protein-A Sepharose beads (coupled with mouse monoclonal anti-human IGFPB-3 antibody) for the immunoprecipitation.

\section{Beads experiment}

In the third experiment, different amounts of protein-A Sepharose beads, 200 / $300 / 400 / 800 \mu \mathrm{l}$ of beads (coupled with monoclonal antibody), which correspond to 2.5 / 3.75 / 5.0 / $10.0 \mathrm{mg}$ (dry weight) beads, and $250 \mu \mathrm{l}$ of serum were used for the immunoprecipitation. Figure 8.4 illustrates that the highest amount of IGFBP-3 was eluated when using $800 \mu$ of protein-A Sepharose beads. By using $800 \mu$ of protein-A Sepharose beads, 25 ng IGFBP-3 could be eluated, while the absolute amounts for the other conditions were lower, namely 8,11 , and 19 ng IGFBP-3 when using 200, 300 or $400 \mu$ of protein-A Sepharose beads, respectively. The highest elution-binding ratio was also reached when $800 \mu \mathrm{l}$ of protein-A Sepharose beads were used. 
Beads experiment

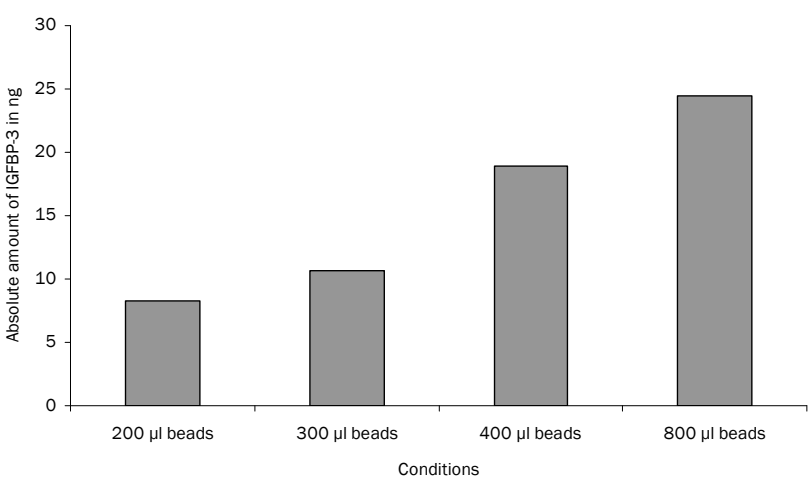

Figure 8.4 The absolute amount of IGFBP-3 (in ng) after elution with urea/CHAPS solution using different protein-A Sepharose beads amounts.

Different amounts of protein-A Sepharose beads (coupled with mouse monoclonal antihuman IGFPB-3 antibody): $200 / 300 / 400 / 800 \mu \mathrm{l}$, which correspond to 2.5 / 3.75 / $5.0 / 10.0 \mathrm{mg}$ (dry weight) beads were used with $250 \mu \mathrm{l}$ of serum for the immunoprecipitation.

\section{1-DE}

Different isolation batches were used to compare the signals on the negative images of the 1-DE Western blot. In Figure 8.5 is illustrated that isolation with a batch with monoclonal antibodies, polyclonal antibodies, or a mixture of monoclonal and polyclonal antibodies resulted in a different pattern when visualized with mouse monoclonal anti-human IGFPB-3 antibody as primary antibody and peroxidase-labeled goat-anti-mouse as secondary antibody. The third and fifth band clearly show more density using the monoclonal batch compared to the other batches.

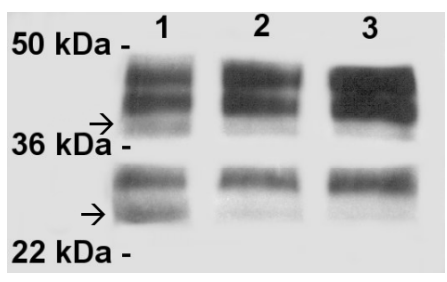

Figure 8.5 Negative image of a 1-DE Western blot from a control serum sample of a healthy person. Different batches were used for the isolation. The monoclonal batch (mouse monoclonal anti-human IGFPB-3 antibody) (lane 1), mixture batch of monoclonal and polyclonal batch (rabbit polyclonal anti-human IGFPB-3 antibody) (lane 2), and polyclonal batch (lane 3). Mouse monoclonal anti-human IGFPB-3 antibody was used as primary antibody and peroxidase-labeled goat-anti-mouse as secondary antibody. The third and fifth band are indicated with a vector. 
The eluates from the serum experiment with $75 / 125 / 250 / 500 \mu \mathrm{l}$ of serum were also applied on 1-DE using mouse monoclonal anti-human IGFPB-3 antibody as primary antibody and peroxidase-labeled goat-anti-mouse as secondary antibody for the Western blotting (Figure 8.6). The band densities were quantified and are illustrated in Table 8.1. Four of the five bands gave the highest relative quantity using $250 \mu \mathrm{l}$ of serum. These results were comparable with the ELISA results.

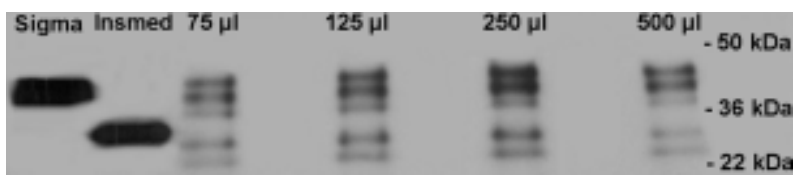

Figure 8.6 Negative image of a 1-DE Western blot from the serum experiment with 75 / 125 / 250 / $500 \mu \mathrm{l}$ of serum.

Mouse monoclonal anti-human IGFPB-3 antibody was used as primary antibody and peroxidase-labeled goat-anti-mouse as secondary antibody. In the first lane the IGFBP-3 standard with a molecular weight of $41 \mathrm{kDa}$ from Sigma-Aldrich was added and in the second lane the IGFBP-3 standard with a molecular weight of $28 \mathrm{kDa}$ from Insmed (Insmed, Inc. Richmond, VA, USA) was added as positive control.

Table 8.1 The results of imaging and quantifying analysis of the negative image of the 1-DE Western blot from the serum experiment with $75 / 125 / 250 / 500 \mu l$ of serum.

\begin{tabular}{lcccr}
\hline & $75 \mu \mathrm{l}$ serum & $125 \mu \mathrm{l}$ serum & $250 \mu \mathrm{l}$ serum & $500 \mu \mathrm{l}$ serum \\
\hline Band 1 & 9.7 & 20.2 & 23.6 & 21.5 \\
Band 2 & 25.2 & 22.6 & 26.8 & 25.8 \\
Band 3 & 12.3 & 12.3 & 10.3 & 9.6 \\
Band 4 & 12.8 & 14.3 & 16.8 & 11.5 \\
Band 5 & 5.9 & 10.6 & 11.5 & 9.3 \\
\hline
\end{tabular}

Quantitative analysis of the negative image of the 1-DE Western blot was performed using the software program Quantity One. The relative quantities of the 5 bands which were present in all different conditions (75 / $125 / 250 / 500 \mu \mathrm{l}$ of serum) are illustrated. The relative quantity is the trace quantity of a band expressed as a percentage of the total quantity of the bands in the lanes.

\section{2-DE}

To investigate the isoforms of IGFBP-3, 2-DE Western blotting was used. The immunoprecipitation method described in this study was validated by using different serum samples; two serum samples of CDG-la children and two control serum samples of healthy children, matched by sex and age. Three areas of interest were identified, at which significant differences were observed. More acidic intact IGFBP-3 isoforms and more acidic fragment isoforms were detected in the serum samples of the healthy children compared to the CDG-la children samples. Although there were less acidic intact and fragment isoforms detected in the CDGla samples, there were more basic fragment isoforms detected in the CDG-la samples. Thus, a shift of the fragment isoforms from the acidic side to the basic side was found for the CDG-la children samples (Figure 8.7). 


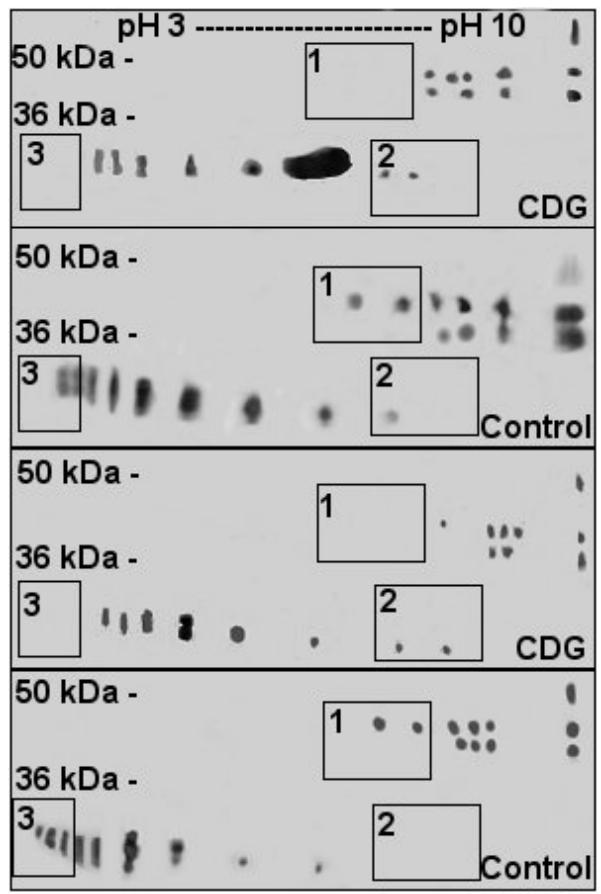

Figure 8.7 Negative images of 2-DE Western blots from two serum samples of CDG-la children (CDG) and two control serum samples of healthy children (Control).

The isoforms of intact IGFBP-3 $(\sim 41-45 \mathrm{kDa})$ and the isoforms of the fragments $(\sim 24-30$ $\mathrm{kDa}$ ) of IGFBP-3 are visible on these negative images of Western blots using rabbit polyclonal anti-human IGFPB-3 antibody as primary antibody and peroxidase-labeled goatanti-rabbit as secondary antibody. ReadyStrip IPG strips (pH 3-10 not linear, $11 \mathrm{~cm}$ long) were used. The acidic isoforms are illustrated on the left side and the basic isoforms are illustrated on the right side. The areas with number 1 and 3 contain more spots in healthy control serum of healthy children compared to serum of CDG-la children. In contrast to this, the areas with number 2 contain more spots in the serum of CDG-la children.

\section{Discussion}

This report describes the optimization of an in-house developed immunoprecipitation method which can be used to isolate low-abundance proteins from serum. In our case, we have chosen for the low-abundant protein IGFBP-3, because we are interested in IGFBP-3 isoforms. Information about the IGFBP-3 isoforms can be useful to understand pathogenetic mechanisms in different disease entities such as congenital defects of glycosylation, galactosemia ${ }^{8}$, and alcoholic liver cirrhosis ${ }^{10}$. Our immunoprecipitation method was validated by 
performing 2-DE Western blotting with serum samples of CDG-la children and serum samples of healthy children.

In this study was demonstrated that our immunoprecipitation resulted in the highest density bands on the negative image of the 1-DE Western blot compared to two other methods without using DMP as cross-linker. By using the protease inhibitor cocktail and by immunoprecipitating the human recombinant IGFBP-3 standard from Sigma-Aldrich we could confirm that the fragments originate in vivo and not in vitro.

To check which condition resulted in the optimal elution of IGFBP-3, ELISA and 1-DE experiments were performed. Both the ELISA and the 1-DE experiments illustrated that dilution of serum in PBS was superior to dilution in $6 \mathrm{M}$ urea for the immunoprecipitation and the elutions with Laemmli or urea/CHAPS solutions were superior to elution with glycine solution. Optimal elution was reached when $250 \mu \mathrm{l}$ of serum and $800 \mu \mathrm{l}$ of protein-A Sepharose beads were used. The highest absolute amounts of IGFBP-3 and the highest elution-binding ratios were reached using $250 \mu \mathrm{l}$ of serum and $800 \mu \mathrm{l}$ of protein-A Sepharose beads. Imaging and quantifying analysis of the negative image of the 1-DE Western blot also illustrated that the highest relative quantities of both intact protein and fragments were reached using $250 \mu$ l of serum.

More studies have been focused on IGFBP proteins. The aim of the study described by Nedic et al. ${ }^{13}$ was to investigate possible changes in the serum IGF-IGFBP system among patients with alcoholic liver cirrhosis. The serum samples were not immunoprecipitated, but after SDS-PAGE of the serum samples and Western blotting, autoradiography with ${ }^{125}$ I-labelled IGF-I or IGF-II was used. In the study of Nedic et al. was shown that all control subjects exhibited the characteristic IGFBP doublet in the region of 40-45 $\mathrm{kDa}$, while some of them contained a faint band at approximately $34 \mathrm{kDa}$. Zapf et al. ${ }^{14}$ also detected a $42-45 \mathrm{kDa}$ doublet and an extra band at approximately $31 \mathrm{kDa}$ using autoradiography with ${ }^{125}$-labelled IGF-I or IGF-II. They described that a glycosylated degradation product of IGFBP-3 presumably lacking the carboxylic terminus can be assigned to the $31 \mathrm{kDa}$ band.

Weber et al. ${ }^{8}$ performed 2-DE and Western ligand blot analysis using autoradiography with ${ }^{125}$ l-labelled IGF-I or IGF-II to characterise the human IGFBP proteins. They found glycosylated IGFBP-3 as a broad band of spots with molecular masses of 41 and $45 \mathrm{kDa}$. The identity of IGFBP-3 was also confirmed by immunoblotting. The immunoblot showed some additional spots in the range of 29-31 kDa. These immunoreactive spots lacked binding capacity for labeled IGFligands and most likely represent proteolytic fragments of IGFBP-3. In our study we also detected a doublet in the range of 40-45 kDa, an extra band at approximately $36 \mathrm{kDa}$, and two lower fragments between approximately $24 \mathrm{kDa}$ and $30 \mathrm{kDa}$ were seen. The extra band in our study at $36 \mathrm{kDa}$ can also be a glycosylated degradation product as described above by Zapf et al. The two lower fragments are probably proteolytic fragments, which were also detected by Weber et al.. The band patterns 
on the negative images of the Western blots depend on the specificity of the antibodies, the molecular mass markers and the kind of polyacrylamide gels used. The advantage of our method in comparison to other methods $8,13,14$ is that we do not have to use radioactive isotopes to detect IGFBP-3.

To detect IGFBP-3 isoforms, the isolated proteins were separated according to charge and mass using 2-DE. The optimal immunoprecipitation conditions described in this study were used for the 2-DE experiments. Elution with urea/CHAPS is preferable for 2-DE followed by Western blotting. By comparing the serum samples of two paediatric CDG type la patients and 2 paediatric healthy persons, we could detect differences in IGFBP-3 isoform patterns. CDG-la is due to phosphomannomutase deficiency ${ }^{15}$, a key enzyme in the synthesis of guanosine 5'-diphosphate-D-mannose which is required for N-glycan assembly. Deficient synthesis of $\mathrm{N}$-glycans results in a deficient incorporation of sialic acid, the terminal negatively charged sugar, so that glycoprotein molecules acquire a more positive charge, which causes a shift in the IEF patterns from more acidic to more basic ${ }^{16}$. Abnormal isoelectric focusing of transferrin in CDG with a shift towards the cathode was described earlier by Jaeken et al.. They found these features in CDG ${ }^{17}$ and in untreated classic galactosemia ${ }^{18}$. IGFBP-3 has three N-glycosylation sites and disturbed glycosylation results in a cathodal shift ${ }^{12}$. In conclusion, the in-house developed immunoprecipitation method described in this study is suitable for studying IGFBP-3 isoforms. To confirm our results, the groups will be enlarged and we will also study IGFBP-3 isoforms in other patient groups such as other CDG types and galactosemia. 


\section{References}

1. Karlsson GB, Platt FM. Analysis and isolation of human transferrin receptor using the OKT-9 monoclonal antibody covalently crosslinked to magnetic beads. Anal Biochem 1991;199: 219-222.

2. Veldscholte J, Berrevoets CA, Zegers ND, van der Kwast TH, Grootegoed JA, Mulder E. Hormoneinduced dissociation of the androgen receptor-heat-shock protein complex: use of a new monoclonal antibody to distinguish transformed from nontransformed receptors. Biochemistry 1992;31:7422-7430.

3. Schneider C, Newman RA, Sutherland DR, Asser U, Greaves MF. A one-step purification of membrane proteins using a high efficiency immunomatrix. J Biol Chem 1982;257:10766-10769.

4. Sisson TH, Castor CW. An improved method for immobilizing IgG antibodies on protein A-agarose. J Immunol Methods 1990;127:215-220.

5. Michielsen EC, Diris JH, Hackeng CM, Wodzig WK, Van Dieijen-Visser MP. Highly sensitive immunoprecipitation method for extracting and concentrating low-abundance proteins from human serum. Clin Chem 2005;51:222-224.

6. Wilchek M, Jakoby WB. The literature on affinity chromatography. Methods Enzymol 1974;34: 3-10.

7. Gersten DM, Marchalonis JJ. A rapid, novel method for the solid-phase derivatization of IgG antibodies for immune-affinity chromatography. J Immunol Methods 1978;24:305-359.

8. Weber MM, Spottl G, Gossl C, Engelhardt D. Characterization of human insulin-like growth factorbinding proteins by two-dimensional polyacrylamide gel electrophoresis and Western ligand blot analysis. J Clin Endocrinol Metab 1999;84:1679-1684.

9. Storch S, Kubler B, Honing S, Ackmann M, Zapf J, Blum W, et al. Transferrin binds insulin-like growth factors and affects binding properties of insulin-like growth factor binding protein-3. FEBS Lett 2001;509:395-398.

10. Nedic O, Nikolic JA, Prisic S, Acimovic J, hajdukovic-Dragojlovic L. Reactivity of IGF binding protein3 isoforms towards concanavalin $A$ in healthy adults and subjects with cirrhosis. Addict Biol 2003;8:81-88.

11. Jaeken J, Matthijs G. Congenital Disorders of Glycosylation: A Rapidly Expanding Disease Family. Annu Rev Genomics Hum Genet 2007;8:261-278.

12. Firth SM, Baxter RC. Characterisation of recombinant glycosylation variants of insulin-like growth factor binding protein-3. J Endocrinol 1999;160:379-387.

13. Nedic O, Nikolic JA, Hajdukovic-Dragojlovic L, Todorovic V, Masnikosa R. Alterations of IGF-binding proteins in patients with alcoholic liver cirrhosis. Alcohol 2000;21:223-229.

14. Zapf J, Kiefer M, Merryweather J, Musiarz F, Bauer D, Born W, et al. Isolation from adult human serum of four insulin-like growth factor (IGF) binding proteins and molecular cloning of one of them that is increased by IGF I administration and in extrapancreatic tumor hypoglycemia. J Biol Chem 1990;265:14892-14898.

15. Van Schaftingen E, Jaeken J. Phosphomannomutase deficiency is a cause of carbohydratedeficient glycoprotein syndrome type I. FEBS Lett 1995;377:318-320.

16. Grunewald S, Matthijs G, Jaeken J. Congenital disorders of glycosylation: a review. Pediatr Res 2002;52:618-624.

17. Jaeken J, van Eijk HG, van der Heul C, Corbeel L, Eeckels R, Eggermont E. Sialic acid-deficient serum and cerebrospinal fluid transferrin in a newly recognized genetic syndrome. Clin Chim Acta 1984;144:245-247.

18. Jaeken J, Kint J, Spaapen L. Serum lysosomal enzyme abnormalities in galactosaemia. Lancet 1992;340:1472-1473. 


\section{Chapter 9}

General discussion 



\section{Proteomics}

The successful completion of the human genome project had led to a tremendous increase in our understanding of the molecular basis of diseases. However, a comprehensive understanding of the dynamic protein pathways involved in normal and disease states, and in response to medical treatment, is required if we want to effectively treat diseases. The next major challenge towards this aim is to identify the constituents of the human proteome in order to understand the human genome $^{1}$. Advances in proteomics technology offer great promise in the understanding and treatment of the molecular basis of disease. Proteome analysis is based on the combination of three technologies: a resolutive method for separating proteins as a function of different physicochemical criteria (e.g., mass, isoelectric point and hydrophobicity), mass spectrometry and bioinformatics tools ${ }^{2}$. The true scientific goal of proteomic pattern analysis is in fact biomarker discovery. However, since the study by Petricoin et al. ${ }^{3}$ on proteomic patterns to detect ovarian cancer, the use of Surface-Enhanced Laser Desorption/Ionization Time-of-Flight Mass Spectrometry (SELDI-TOF-MS) protein profiling as a diagnostic tool, has become an important subject of investigation too 4 . Until now, this approach has been suggested for different diseases, like ovarian ${ }^{3,5-9}$, prostate ${ }^{10-14}$ and lung ${ }^{15}$ cancer, but also for inflammatory diseases ${ }^{16,17}$. This thesis is especially focused on the SELDI-TOF-MS technique.

Recently, Poon ${ }^{18}$ described some major limitations of the SELDI-TOF-MS technology. One important issue is that the limited sensitivity causes difficulty in the identification of potential diagnostic proteins present at concentrations below the $\mathrm{mg} / \mathrm{l}$ level in serum and/or plasma. To date, this technology has not yet identified protein markers present at the $\mu \mathrm{g} / \mathrm{I}$ level. Unfortunately, the dynamic range of serum/plasma proteins covers ten orders of magnitude (low ng/l to $\mathrm{g} / \mathrm{l}$ ) in abundance. To overcome limited detection sensitivity, fractionation by anionexchange chromatography by stepwise $\mathrm{pH}$ gradient elution can be performed. Other fractionation technologies, like isoelectric focusing and reverse phase chromatography can also be applied to the fractionation step. Alternately, removal of the major abundant serum proteins can also help to identify low-abundance proteins.

Another important issue is that most of the diagnostic SELDI-TOF-MS peaks were found to be acute-phase proteins, their fragments or isoforms. Diamandis ${ }^{19}$ and others ${ }^{20-22}$ indicated that a very large number of candidate cancer biomarkers previously identified using the SELDI-TOF-MS technology are liver-derived products originating from common disease mechanisms, like infection or cachexia resulting in for instance an acute phase response. Unfortunately until now most studies present biomarkers related to these non-specific common disease mechanisms.

Diamandis also described that it is strange that in many cancer studies a large number of discriminatory peaks are found which are down-regulated in the cancer 
population, in comparison to normal controls. He indicated that there are currently no useful markers whose concentration is actually decreased in the serum of patients with cancer. The most useful cancer biomarkers originate from tumor cells and their concentration is increased in the circulation and correlates with tumor burden. A possible gene down-regulation effect in tumor cells would have been highly speculative unless the marker under discussion has absolute tissue specificity and the tumor overtakes the normal tissue, thus reducing the marker concentration in serum. A more likely explanation is that these molecules represent highly abundant proteins produced by the liver or other organs, whose concentration is decreased due to cancer cachexia or malnutrition, non-specific effects for many cancer types, as described before. Another important aspect put forward by Diamandis is that it is known that there is a proportional relationship between biomarker concentration and tumor stage. In most of the published data, such a relation was not found.

There is no doubt that SELDI-TOF-MS is a useful tool in biomedical research, particularly in biomarker discovery. Since reliability and stability of the Proteinchip arrays have been questioned worldwide, improvement of their quality and stability, or providing the proof of negligible batch-to-batch variations in their quality are needed urgently. Systematic investigations of the effects of various experimental variables on the SELDI-TOF-MS proteomic profiles are needed. With reliable ProteinChip arrays, optimized standard operating procedures, appropriate study design and experimental precautions, the proteomic profiling results should become more reliable ${ }^{18}$.

The importance of the pre-and post-analytical strategies were reported in chapter 2 of this thesis. This overview clearly underlines the need for better standardization and careful description of the methods including technical details in all future studies. It is essential that sample collection from both the patient and control populations is completely identical and accurately standardized. A standard protocol for the collection of serum samples according to World Healthy Organization (WHO) recommendations on "Anticoagulants in diagnostic laboratory investigations" (2002) is suggested in this thesis. There are other international organizations, such as the International Federation of Clinical Chemistry (IFCC) and the Human Proteome Organization (HUPO) that are looking into some standardization issues.

In chapter 3 was indicated that any new technology, particularly one being presented as a potential diagnostic tool, requires stringent quality control to evaluate analytical performance over time. Instrument performance must be compared not only during one experiment, but also over the course of time. Therefore a standard protocol for calibration of the Matrix Assisted Laser Desorption/Ionization-Time of Flight-Mass Spectrometry (MALDI-TOF-MS) part of the Protein Biosystem IIc (PBS IIc) instrument was defined and acceptance criteria for the independent certified quality control (QC) samples were established in this 
thesis. The acceptance criteria can be exceeded because of different factors, like errors during preparations and handling of the calibration or QC sample as well as instrumental problems. Because an error introduced during processing can be difficult or impossible to trace once the experiment is completed. It is best to rigorously control the experimental procedure to minimize the introduction of variation in the first place

Besides biomarker discovery, SELDI-TOF-MS can also be used in basic research, for example for discovery of protein-protein interactions ${ }^{23}$. ProteinChip arrays can be coated with a particular DNA sequence to examine the interaction between a DNA molecule and transcription factors ${ }^{24}$. With coating of specific antibodies on the binding surface of the ProteinChip arrays, the SELDI-TOF-MS technology can be used as a specific novel immunoassay for the quantification of different variants of the target protein 25 .

\section{Detection of potential biomarkers}

This thesis contains a review (Chapter 4) about proteomics studies in multiple sclerosis, rheumatic diseases and lung inflammatory diseases. A lot of proteins were identified and in some of the studies the identified proteins were also validated with other tests. The heat shock proteins were entitled as biomarkers with potential for further research in multiple sclerosis. Myeloid-Related protein 8 MRP-8 was found in three different rheumatoid arthritis studies with different sample materials and could be a potential marker for rheumatoid arthritis. Alpha1-antitrypsin was validated in two studies as a marker for sarcoidosis, although in one study sarcoidosis patients were compared with idiopathic pulmonary fibrosis patients and in the other study the sarcoidosis patients were compared with healthy control samples. Alpha1-antitrypsin was also found as a marker for cystic fibrosis (CF), together with myeloperoxidase and immunoglobulin $\mathrm{G}(\lg \mathrm{G})$. This thesis also contains own data regarding biomarker finding with proteomics in two chronic inflammatory diseases and in lacunar stroke. The aim of the study described in chapter 5 was the detection of potential biomarkers for sarcoidosis using SELDI-TOF-MS. The markers obtained with SELDI-TOF-MS resulted in higher sensitivity and specificity compared to the routinely used markers angiotensin converting enzyme (ACE) and soluble Interleukin-2 Receptor (sIL-2R). We were able to identify one peak as the alpha-2 chain of haptoglobin. The clinical problems associated with sarcoidosis might be related to a decreased anti-oxidant defense ${ }^{26}$. Glucose-6-phosphate dehydrogenase (G6PD) is involved in the anti-oxidant defence. It is known that in the presence of oxidative stress, G6PD deficiency leads to hemolysis ${ }^{27}$, which causes a decrease in haptoglobin, which as such might clarify the lower haptoglobin fragment peaks in sarcoidosis patients. 
The aim of the study presented in chapter 6 was to detect potential biomarkers for ankylosing spondylitis (AS). Sera of AS patients and healthy controls were used to detect potential biomarkers for the diagnosis of AS. Two multimarkers were found which could classify the AS and healthy control samples. Not all peaks could be identified, but two peaks were both successfully identified as apolipoprotein A-I (ApoA1).

In Chapter 7 a study was described to detect potential biomarkers for lacunar stroke. SELDI-TOF-MS, followed by protein identification, was performed in samples of first-ever lacunar stroke patients with magnetic resonance imaging showing a single symptomatic lacunar lesion (type I), and samples of patients with multiple additional "silent" lesions and extensive white matter lesions (type II). A 16 kDa protein, identified as alpha-2-chain of haptoglobin, was up-regulated in type I compared to type II. The up-regulation of the alpha-2-chain in type I is related to a higher haptoglobin-2 allele frequency. The phenotype distribution deviates towards a high haptoglobin-1 allele frequency in both groups compared to population reference, suggesting a role for the haptoglobin gene in the etiology of cerebral small vessel disease. The even higher haptoglobin-1 allele frequency in type II than in type I implies a promoting role for haptoglobin-1 in developing multiple silent lacunar lesions and as a result white matter lesions. The haptoglobin-1 allele frequency could be a reflection of a difference in underlying vascular pathology between the two types and the influence of the haptoglobin phenotype may thus be relevant in predisposing to one type of small vessel pathology more than the other. Both the results of the review article as our own proteomics studies illustrate that especially biomarkers associated with acute-phase reaction and biomarkers with a relatively high serum concentration were detected and identified. The biomarkers, which are presented in this thesis, need to be validated in the future by using blind sample sets. To verify the robustness of the potential markers, samples from different institutions should also be included, to check if the sensitivities and specificities could be reproduced.

\section{Glycomics}

The analytical techniques described above for finding biomarkers can also be used for more extensive analysis of proteins, like protein glycosylation. In this thesis, we looked for glycosylation defects in congenital disorders of glycosylation (CDG) and galactosemia. The hypothesis is that glycan abnormalities of IGFBP-3 can be the cause of the diminished bone mass and growth in classic galactosemia. The aim of this study was to detect possible differences in IGFBP-3 isoforms (intact protein and fragments) in patients with galactosemia, CDG and healthy controls. Chapter 8 provides detailed information about the optimization of the immunoprecipitation method used in this study to purify and isolate IGFBP-3 from serum. Because the 
glycosylation defect in CDG type la is known, we started to compare CDG type la samples with healthy controls. CDG-la is due to phosphomannomutase deficiency28, a key enzyme in the synthesis of guanosine 5'-diphosphate-Dmannose which is required for $\mathrm{N}$-glycan assembly. Deficient synthesis of N-glycans results in a deficient incorporation of sialic acid, the terminal negatively charged sugar, so that glycoprotein molecules acquire a more positive charge, which causes a shift in the IEF patterns from more acidic to more basic ${ }^{29}$. Abnormal isoelectric focusing of transferrin in CDG with a shift towards the cathode was described earlier by Jaeken et al. They found these features in CDG30 and in untreated classic galactosemia31. IGFBP-3 has three $\mathrm{N}$-glycosylation sites and disturbed glycosylation results in a cathodal shift ${ }^{32}$. By comparing the serum samples of paediatric CDG type la patients and control serum of paediatric healthy persons, we could detect a shift from more acidic to more basic isoforms for the IGFBP-3 protein in CDG type la. This is in agreement with the transferrin results. By using CDG type la samples we were able to clinically validate our method and in future studies we will enlarge our sample group and we will also investigate the isoform patterns of IGFBP-3 in galactosemia to confirm that glycan abnormalities of IGFBP-3 can be the cause of the diminished bone mass and growth in classic galactosemia. 


\section{Directions for future research}

Because the limited sensitivity of the SELDI-TOF-MS causes difficulties in the identification of potential diagnostic proteins present at concentrations below the $\mathrm{mg} / \mathrm{I}$ level, advancements in the MS instrumentation part of the SELDI-TOF-MS technology or similar technologies, like tandem mass spectrometry (MS/MS), are needed and will lead to the identification of potential biomarkers at $\mu \mathrm{g} / \mathrm{l}$ or even lower level. For example, combination of SELDI-TOF-MS technology and MALDI tandem TOF-MS can offer much greater resolution and sensitivity and it will give the potential for direct protein identification. Combined use of $m / z$ values and $\mathrm{N}$-/C-terminal sequence tags can provide unambiguous identities of the SELDI-TOF-MS peaks ${ }^{18}$.

Currently, the pipeline from translation of new biomarkers into diagnostic tests appears to have a bottleneck. A number of technical obstacles, like the limited sensitivity and relative low reproducibility, remain before routine proteomic analysis can be achieved in the clinic. Standardization of methodologies and dissemination of proteomic data into publicly available databases is starting to overcome part of these hurdles. At present the most promising application for proteomics is the detection of specific subsets of protein biomarkers for certain diseases, rather than large scale full protein profiling ${ }^{1}$. As described before, this thesis is especially focused on the SELDI-TOF-MS technology. For future proteomic profiling studies with the SELDI-TOF-MS technology it is important to examine the effect of sample collection and storage conditions on the data, but also other variables that could potentially bias the data, either biologically of bioinformatically. It is also essential to identify the discriminative peaks successfully and find a link with the disease pathobiology. In cancer studies, the peak intensities should correlate with the tumor burden or tumor stage. The SELDI-TOF-MS technology can also be used for purifying proteins. Antibodies can be coupled on the ProteinChip arrays.

For the IGFBP-3 study, negative images of two-dimensional gel electrophoresis (2-DE) Western blots of paediatric galactosemic patients, CDG patients and healthy controls will be compared and the (glyco)proteins in the discriminating spots will be identified with MALDI-TOF-MS. 


\section{References}

1. Verrills NM. Clinical proteomics: present and future prospects. Clin Biochem Rev 2006;27:99-116.

2. Solassol J, Jacot W, Lhermitte L, Boulle N, Maudelonde T, Mange A. Clinical proteomics and mass spectrometry profiling for cancer detection. Expert Rev Proteomics 2006;3:311-320.

3. Petricoin III EF, Mills GB, Kohn EC, Liotta LA. Proteomic patterns in serum and identification of ovarian cancer. Lancet 2002;360:170-171.

4. Petricoin EF, Ardekani AM, Hitt BA, Levine PJ, Fusaro VA, Steinberg SM, Mills GB, Simone C, Fishman DA, Kohn EC, Liotta LA. Use of proteomic patterns in serum to identify ovarian cancer. Lancet 2002;359:572-577.

5. Kozak KR, Amneus MW, Pusey SM, Su F, Luong MN, Luong SA, Reddy ST, Farias-Eisner R. Identification of biomarkers for ovarian cancer using strong anion-exchange ProteinChips: potential use in diagnosis and prognosis. Proc Natl Acad Sci U S A 2003;100: 12343-12348.

6. Zhang Z, Bast RC Jr, Yu Y, LiJ, Sokoll L, Rai AJ, Rosenzweig JM, Cameron B, Wang YY, Meng XY, Berchuck A, Van Haaften-Day C, Hacker NF, de Bruijn HW, van der Zee AG, Jacobs IJ, Fung ET, Chan DW. Three biomarkers identified from serum proteomic analysis for the detection of early stage ovarian cancer. Cancer Res 2004;64:5882-5890.

7. Vlahou A, Schorge JO, Gregory BW, Coleman RL. Diagnosis of Ovarian Cancer Using Decision Tree Classification of Mass Spectral Data. J Biomed Biotechnol 2003;2003:308-314.

8. Ye B, Cramer DW, Skates SJ, Gygi SP, Pratomo V, Fu L, Horick NK, Licklider L, Schorge JO, Berkowitz RS, Mok SC. Haptoglobin-alpha subunit as potential serum biomarker in ovarian cancer: identification and characterization using proteomic profiling and mass spectrometry. Clin Cancer Res 2003;9:2904-2911.

9. Rai AJ, Zhang Z, Rosenzweig J, Shih le M, Pham T, Fung ET, Sokoll L, Chan DW. Proteomic approaches to tumor marker discovery. Arch Pathol Lab Med 2002;126:1518-1526.

10. Banez LL, Prasanna P, Sun L, Ali A, Zou Z, Adam BL, McLeod DG, Moul JW, Srivastava S. Diagnostic potential of serum proteomic patterns in prostate cancer. J Urol 2003; 170:442-446.

11. Adam BL, Qu Y, Davis JW, Ward MD, Clements MA, Cazares LH, Semmes OJ, Schellhammer PF, Yasui Y, Feng Z, Wright GL Jr. Serum protein fingerprinting coupled with a pattern-matching algorithm distinguishes prostate cancer from benign prostate hyperplasia and healthy men. Cancer Res 2002;62:3609-3614.

12. Petricoin EF $3^{\text {rd }}$, Ornstein DK, Paweletz CP, Ardekani A, Hackett PS, Hitt BA, Velassco A, Trucco C, Wiegand L, Wood K, Simone CB, Levine PJ, Linehan WM, Emmert-Buck MR, Steinberg SM, Kohn EC, Liotta LA. Serum proteomic patterns for detection of prostate cancer. J Natl Cancer Inst 2002;94:1576-1578.

13. Qu Y, Adam BL, Yasui Y, Ward MD, Cazares LH, Schellhammer PF, Feng Z, Semmes OJ, Wright GL Jr. Boosted decision tree analysis of surface-enhanced laser desorption/ionization mass spectral serum profiles discriminates prostate cancer from noncancer patients. Clin Chem 2002;48: 1835-1843.

14. Li J, White N, Zhang Z, Rosenzweig J, Mangold LA, Partin AW, Chan DW. Detection of prostate cancer using serum proteomics pattern in a histologically confirmed population. J Urol 2004;171:1782-1787.

15. Zhukov TA, Johanson RA, Cantor AB, Clark RA, Tockman MS. Discovery of distinct protein profiles specific for lung tumors and pre-malignant lung lesions by SELDI mass spectrometry. Lung Cancer 2003;40:267-279.

16. Poon TC, Hui AY, Chan HL, Ang IL, Chow SM, Wong N, Sung JJ. Prediction of Liver Fibrosis and Cirrhosis in Chronic Hepatitis B Infection by Serum Proteomic Fingerprinting: A Pilot Study. Clin Chem 2004;51:328-335.

17. Zhu XD, Zhang WH, Li CL, Xu Y, Liang WJ, Tien P. New serum biomarkers for detection of HBVinduced liver cirrhosis using SELDI protein chip technology. World J Gastroenterol 2004; 10:2327-2329.

18. Poon TC. Opportunities and limitations of SELDI-TOF-MS in biomedical research: practical advices. Expert Rev Proteomics 2007;4:51-65. 
19. Diamandis EP. Serum Proteomic Profiling by Matrix-Assisted Laser Desorption-Ionization Time-ofFlight Mass Spectrometry for Cancer Diagnosis: Next Steps. Cancer Res 2006;66:5540-5541.

20. Le L, Chi K, Tyldesley S, Flibotte S, Diamond DL, Kuzyk MA, Sadar MD. Identification of serum amyloid $\mathrm{A}$ as a biomarker to distinguish prostate cancer patients with bone lesions. Clin Chem 2005;51:695-707.

21. Lee IN, Chen CH, Sheu JC, Lee HS, Huang GT, Chen DS, Yu CY, Wen CL, Lu FJ, Chow LP. Identification of complement $\mathrm{C} 3 \mathrm{a}$ as a candidate biomarker in human chronic hepatitis $\mathrm{C}$ and HCV-related hepatocellular carcinoma using a proteomics approach. Proteomics 2006;6: 2865-2873.

22. Engwegen JY, Helgason HH, Cats A, Harris N, Bonfrer JM, Schellens JH, Beijnen JH. Identification of serum proteins discriminating colorectal cancer patients and healthy controls using surfaceenhanced laser desorption ionisation-time of flight mass spectrometry. World J Gastroenterol 2006;12:1536-1544.

23. Howell JM, Winstone TL, Coorssen JR, Turner RJ. An evaluation of in vitro protein-protein interaction techniques: assessing contaminating background proteins. Proteomics 2006;6: 2050-2069.

24. Bane TK, LeBlanc JF, Lee TD, Riggs AD. DNA affinity capture and protein profiling by SELDI-TOF mass spectrometry: effect of DNA methylation. Nucleic Acids Res 2002;30:e69.

25. Schweigert FJ, Wirth K, Raila J. Characterization of the microheterogeneity of transthyretin in plasma and urine using SELDI-TOF-MS immunoassay. Proteome Sci 2004;2:5.

26. Rothkrantz-Kos S, Drent M, Vuil H, De Boer M, Bast A, Wouters EF, Roos D, van Dieijen-Visser MP. Decreased redox state in red blood cells from patients with sarcoidosis. Sarcoidosis Vasc Diffuse Lung Dis 2002;19:114-120.

27. Dhaliwal G, Cornett PA, Tierney LM Jr. Hemolytic anemia. Am Fam Physician 2004;69: 2599-2606.

28. Van Schaftingen E, Jaeken J. Phosphomannomutase deficiency is a cause of carbohydratedeficient glycoprotein syndrome type I. FEBS Lett 1995;377:318-320.

29. Grunewald S, Matthijs G, Jaeken J. Congenital disorders of glycosylation: a review. Pediatr Res 2002;52:618-624.

30. Jaeken J, van Eijk HG, van der Heul C, Corbeel L, Eeckels R, Eggermont E. Sialic acid-deficient serum and cerebrospinal fluid transferrin in a newly recognized genetic syndrome. Clin Chim Acta 1984;144:245-247.

31. Jaeken J, Kint J, Spaapen L. Serum lysosomal enzyme abnormalities in galactosaemia. Lancet 1992;340:1472-1473.

32. Firth SM, Baxter RC. Characterisation of recombinant glycosylation variants of insulin-like growth factor binding protein-3. J Endocrinol 1999;160:379-387. 
Chapter 10

Summary 



\section{Summary}

The field of proteomics has developed rapidly in recent years. The essence of proteomics is to characterize the behavior of a group of proteins, the system rather than the behavior of any single protein component. The successful completion of the human genome project has led to a tremendous increase in our understanding of the molecular basis of diseases. However, a comprehensive understanding of the dynamic protein pathways involved in normal and disease states, and in response to medical treatment, is required if we want to effectively treat diseases. The next major challenge towards this aim is to identify the constituents of the human proteome. Advances in proteomics technology offer great promise in the understanding and treatment of the molecular basis of diseases. The past decade of proteomics research, the study of dynamic protein expression, post-translational modifications, cellular and sub-cellular protein distribution, and protein-protein interactions, has culminated in the identification of many disease-related biomarkers and potential new drug targets.

Proteomic analysis requires the combination of various technologies, including biochemistry, mass spectrometry and bioinformatics. Important techniques for expression analysis of proteins are two-dimensional gel electrophoresis (2-DE) combined with Matrix Assisted Laser Desorption/Ionization Time-of-Flight Mass Spectrometry (MALDI-TOF-MS), Surface-Enhanced Laser Desorption/Ionization Time-of-Flight Mass spectrometry (SELDI-TOF-MS) and/or Liquid Chromatography Tandem Mass Spectrometry (LC-MS/MS).

The aim of this thesis was to detect potential biomarkers for sarcoidosis, ankylosing spondylitis, and lacunar stroke using proteomic pattern analysis with SELDI-TOF-MS. In contrast to proteomics, glycomics or glycobiology deals with the structure and function of oligosaccharides (chains of sugars). The identity of the entire repertoire of carbohydrates in an organism is thus collectively referred to as the glycome. The analytical techniques used for biomarker finding can also be used for more extensive analysis of proteins, like protein glycosylation. In this thesis, we look for glycosylation defects in galactosemia. Patients with classical galactosemia, an inborn error of galactose metabolism with secondary glycosylation abnormalities, are at risk for a diminished bone mass since early age. The lack of evidence for the presence of any of the well established risk factors for a diminished bone led us to hypothesize a glycosylation defect of proteins involved in bone metabolism in these patients.

Chapter 1 provides an introduction on proteomics and glycomics. The SELDI-TOFMS technique is used to detect potential biomarkers for sarcoidosis, ankylosing spondylitis, and lacunar stroke, which are described in this thesis. The background of these diseases is summarized in this chapter. Other technologies, like immunoprecipitation, gel electrophoresis and Western blot are described here 
because they were applied in this thesis to look for glycosylation defects in galactosemia.

Chapter 2 gives an overview of the diagnostic value of protein profiles obtained with SELDI-TOF-MS on prostate and ovarian cancer. The pre- and post analytical aspects of proteomics studies are mentioned in this chapter and the pre- and post analytical strategies of the different prostate and ovarian cancer studies are discussed. Some own data are also included in this chapter. After comparing the different studies, there appear to be clear differences in sample pre-treatment and storage conditions. The effects of these pre-treatment steps are highly underestimated. It is essential that sample collection from both the patient and control populations should be completely identical and accurately standardized in future studies. An important conclusion of this chapter is that there is a need for a better and careful description of the methods, including technical details and data analyses, to use protein profiles as a diagnostic tool. A standardized protocol is not only needed for the pre- and post analytical strategies, but also for the quality control procedures.

In chapter 3 a standard protocol for calibration of the MALDI-TOF-MS part of the SELDI-TOF-MS is described. Acceptance criteria for the independent certified quality control $(\mathrm{QC})$ sample are established. This is also possible for other instrument types. By checking the calibration every week, the QC procedure acts prospectively, while in some studies the quality control acts retrospectively by including the QC samples in the profiling experiments and in some studies there is even no quality control procedure described at all. Actions need to be taken when the quality control samples exceed the acceptance criteria. The acceptance criteria can be exceeded because of different factors, like errors during preparation and handling of the calibration or quality control sample, as well as instrumental problems. Any new technology, particularly one being presented as a potential diagnostic tool, requires stringent quality control to evaluate analytical performance over time.

In chapter 4 a review on the use of different proteomics techniques to detect potential and/or common biomarkers in chronic inflammatory diseases is given. Different proteomics strategies are explained and also the clinical background of the three chronic inflammatory diseases, multiple sclerosis, rheumatic diseases, and lung inflammatory diseases to which biomarker finding was applied, are described in this chapter. The identified and validated proteins detected in the different studies are compared and discussed to conclude if there are some common markers which can be used in the diagnosis and prognosis of the three chronic inflammatory diseases described in this chapter. A lot of proteins are identified and in some of the studies the identified proteins are also validated with other tests. For multiple sclerosis, the heat shock protein family is entitled to contain biomarkers with potential for further research. In three different rheumatoid arthritis studies using different sample material, myeloid-related 
protein 8 is found as a potential marker. Alpha1-antitrypsin is validated in two studies as a marker for sarcoidosis and $\alpha 1$-antitrypsin is found to be a marker for cystic fibrosis (CF), together with myeloperoxidase and Immunoglobulin $\mathrm{G}$.

Chapter 5 is focused on the detection of potential biomarkers in serum for the diagnosis of sarcoidosis using SELDI-TOF-MS. Sarcoidosis is a multi-systemic inflammatory disorder, which affects the lungs in 90 percent of the cases. The main pathologic feature is chronic inflammation resulting in non-caseating granuloma formation. Until now there is no satisfying biomarker for diagnosis or prognosis of sarcoidosis. For detection of potential biomarkers, protein profiles of anion exchange fractionated serum of 35 sarcoidosis patients and 35 healthy controls are compared using SELDI-TOF-MS. Sensitivities and specificities of the potential biomarkers obtained with SELDI-TOF-MS, generated with decision tree algorithm, are compared to the conventional markers angiotensin converting enzyme (ACE) and soluble Interleukin-2 Receptor (SIL-2R). An optimal classification is achieved with metal affinity binding ProteinChip arrays coupled with copper (IMAC-Cu ${ }^{2+}$ ProteinChip array). A single marker with a mass-to-charge $(m / z)$ value of 11,955 results in a sensitivity and specificity of $86 \%$ and $63 \%$, respectively. $A$ multimarker approach of two peaks, $m / z$ values of 11,734 and 17,377 , results in a sensitivity and specificity of $74 \%$ and $71 \%$, respectively. These sensitivities and specificities are higher compared to measurements of ACE and SIL-2R. Identification of the peak at $\mathrm{m} / \mathrm{z} 17,377$ results in the alpha-2 chain of haptoglobin. In future studies, we will enlarge the sample group and we will also validate our markers with a blind sample set. After this validation, we will search for disease activity markers. Eventually, implementation of a quantitative immunoassay, is needed, to give a good prediction of the disease state and disease severity.

In chapter 6 we try to find potential biomarkers for ankylosing spondylitis (AS) using SELDI-TOF-MS. AS is a chronic systemic inflammatory rheumatic disorder that primarily affects the axial skeleton, with sarcoiliitis as its hallmark. Spinal structural damage can be assessed on conventional radiographs as destructive and proliferative lesions ultimately leading to syndesmophyte formation. Sera of 38 AS patients and 38 healthy controls are used to detect potential biomarkers. Serum is separated with an anion exchange fractionation procedure. In the screening experiments, three ProteinChip array surfaces; CM10, IMAC-Cu ${ }^{2+}$, and hydrophobic, are compared to find out which condition results in the best discrimination of both groups. The optimal discrimination is reached with the following conditions; CM10 array with the organic serum fraction and IMAC-Cu ${ }^{2+}$ array with denatured serum. Analyses of all AS and healthy control samples on CM10 arrays results in a sensitivity of $66 \%$ and a specificity of $74 \%$ using a multimarker approach of two peaks. $M / z 4172$ is used as first splitter in the decision tree and is up-regulated in the AS group and $m / z 28,144$ is used as second splitter. Analyses of all AS and healthy control samples on IMAC-Cu ${ }^{2+}$ arrays results in a sensitivity and specificity 
of $70 \%$ using a multimarker approach of two peaks. $M / z 6644$ is used as first splitter in the decision tree and is down-regulated in the AS group and $m / z 13,875$ is used as second splitter. The peaks at $m / z 28,144$ and 13,875 are both successfully identified as apolipoprotein A-I (ApoA1). This is the first study that shows that protein profiling in serum using SELDI-TOF-MS can be used as a diagnostic tool for AS. In future studies, we will enlarge the sample group and we will also validate our markers with a blind sample set. After this validation, we can search for disease activity markers. Eventually, implementation of a quantitative immunoassay, is needed, to give a good prediction of the disease state and disease severity.

Chapter 7 describes a study with the aim to detect differences in protein expression profiles in serum samples of two lacunar stroke subtypes using SELDITOF-MS. Lacunar infarcts are small, deeply in the brain located infarcts, mostly caused by occlusion of a small perforating artery. Lacunar stroke patients in whom cerebral imaging shows only a single symptomatic lesion differ clinically from those patients with multiple additional "silent" lacunar lesions. Lacunar stroke patients with multiple lesions have more extensive cerebral white matter lesions on neuro-imaging, have more often hypertension, and have worse prognosis on functional outcome, a higher stroke recurrence rate, higher short- and long-term mortality and higher rate of asymptomatic lesion progression. Two groups are defined according to pre-defined criteria. Group 1 consists of eight patients in whom brain magnetic resonance imaging (MRI) show only one single symptomatic lacunar lesion (type I). Group 2 consists of eight patients in whom brain MRI additionally show multiple (4 or more) asymptomatic lacunar lesions as well as extensive white matter lesions (type II). An anion exchange procedure is used, which allows high-throughput fractionation of all 16 serum samples. All fractions are applied to two different ProteinChip array surfaces (Ciphergen Biosystems Inc); the weak cation exchange (CM10) and the IMAC-Cu${ }^{2+}$. The best distinctive pattern is found on the IMAC-Cu ${ }^{2+}$ ProteinChip array with denatured serum. One clearly potential marker at $\mathrm{m} / \mathrm{z} 16,122$ is up-regulated in type I vs type II with mean intensities of 12.5 and 5.0, respectively. Protein identification is performed by 1-DE and 2-DE followed by MALDI-TOF-MS. The peak at $\mathrm{m} / z 16,122$ is identified as the alpha-chain of haptoglobin. The alpha-chain of haptoglobin exists in two variants, alpha-1 (8.9 kDa) and alpha-2 (16 kDa), the latter being compatible with the marker at $m / z 16,122$. The haptoglobin concentration and phenotype distribution are determined. As the total haptoglobin concentration does not differ between the two lacunar groups, the up-regulation of the alpha-2-chain in type I compared to type II represents a higher haptoglobin-2 allele frequency in the former. Yet, in comparison to the reference population, in both lacunar stroke groups haptoglobin1 outweighs haptoglobin-2 allele frequency. The even higher haptoglobin-1 allele frequency in type II implies a promoting role for haptoglobin-1 in developing multiple silent lacunar lesions and cerebral white matter lesions (WML). The 
association between haptoglobin-1 and lacunar stroke brings in a new candidate gene in the study of genetic factors in cerebral small vessel disease etiology. The trend for a difference in haptoglobin-1 association between two lacunar stroke types could be a reflection of a difference in underlying vascular pathology. The results need confirmation in a large group in future studies.

Chapter 8 describes an in-house developed immunoprecipitation method to isolate insulin-like growth factor binding protein-3 (IGFBP-3) and its isoforms from serum to investigate glycan abnormalities in IGFBP-3. Patients with classical galactosemia are at risk for a diminished bone mass without evidence of nutritional factors being the cause. Our hypothesis is that dysglycosylation of glycoproteins of the Growth Hormone/IGF-I (insulin-like growth factor type I) axis play an important role in these disturbances. IGF-I is over $75 \%$ bound with IGFBP-3. To detect glycan abnormalities in IGFBP-3, a low abundant protein, isolation followed by glycan analysis is aimed. Our immunoprecipitation method is compared to other existing immunoprecipitation methods. The study of IGFBP-3 isoforms is relevant for further studies on congenital defects in glycosylation, galactosemia, and alcoholic liver cirrhosis. The immunoprecipitation method is validated using Western blotting and enzymelinked immunosorbent assay (ELISA). The in-house developed immunoprecipitation method using dimethyl pimelimidate as a cross-linker results in improved detection of IGFBP-3 isoforms from serum compared to existing non cross-linking methods. In this study we also perform a clinical validation by using patient serum samples. Because it is known that patients with congenital defects in glycosylation (CDG) type la have a deficient synthesis of $\mathrm{N}$-glycans which results in a deficient incorporation of sialic acid, the CDG type la samples are used as positive controls. By comparing the serum samples of paediatric CDG type la patients and control serum of paediatric healthy persons, we detect a different pattern in the IGFBP-3 isoforms. A shift from more acidic to more basic isoforms for the IGFBP-3 protein in CDG type la is detected and will probably be caused by the deficient incorporation of sialic acid, which is also seen in other glycoproteins containing $\mathrm{N}$-glycosylation sites, like transferrin. To confirm that glycan abnormalities in IGFBP-3 can cause diminished bone mass in classic galactosemia, the isoform patterns of IGFBP-3 in galactosemia will also be investigated.

From the investigations in this study it becomes clear that, although several analytical problems have to be overcome, biomarker screening using proteomics followed by identification is a promising tool needing further development. 

Samenvatting 



\section{Samenvatting}

In de afgelopen jaren heeft het proteomics onderzoek zich snel ontwikkeld. Kenmerkend voor het proteomics onderzoek is dat het veel meer gaat om het karakteriseren van een verzameling eiwitten, de analyse van het systeem en niet zozeer het bekijken van een enkele component. Het succes van het humaan genoom project heeft gezorgd voor veel inzicht in verschillende ziekten op moleculair niveau. Om ziekten uiteindelijk effectief te kunnen behandelen, is het nodig dat we de dynamiek van de eiwitten die betrokken zijn bij de verschillende ziekten en hun stadia kunnen doorgronden. De volgende belangrijke uitdaging is het identificeren van de onderdelen van het humane proteoom.

De technologische ontwikkelingen op het gebied van proteomics zullen op moleculaire niveau leiden tot beter inzicht in de verschillende ziekten. De laatste decennia heeft proteomics onderzoek, met name de studie naar dynamische eiwitexpressie, post-translationele modificaties, cellulaire en subcellulaire eiwitverdeling en eiwit-eiwit interacties, gezorgd voor de identificatie van vele ziekte-gerelateerde biomarkers en nieuwe potentiële doelwitten voor medicijnen. Bij proteomics analyses worden verschillende technologieën gecombineerd, inclusief biochemie, massaspectrometrie en bioinformatica. Belangrijke technieken voor het onderzoeken van eiwitexpressie zijn: 2-dimensionale gel-elektroforese (2-DE) gecombineerd met Matrix Assisted Laser Desorption/lonization Time-of-Flight Mass Spectrometry (MALDI-TOF-MS), Surface-Enhanced Laser Desorption/ Ionization Time-of-Flight Mass spectrometry en/of Liquid Chromatography Tandem Mass Spectrometry (LC-MS/MS).

Het doel van dit proefschrift is het detecteren van nieuwe potentiële biomarkers voor sarcoïdose, ankylosing spondylitis (ziekte van Bechterew) en lacunair herseninfarct door middel van het vergelijken van eiwitprofielen met SELDI-TOFMS. In tegenstelling tot proteomics richt glycomics oftewel glycobiologie zich op de structuur en functie van oligosaccharides (suikerketens). Het geheel van suikerketens in een organisme wordt het glycoom genoemd. In dit proefschrift kijken we tevens naar glycosylerings defecten bij galactosemie. Patiënten met klassieke galactosemie, een aangeboren afwijking van het galactose metabolisme met secundaire glycosylerings defecten, lopen op jonge leeftijd al risico op een verminderde botdichtheid. Er is tot nu toe nog onvoldoende bewijs waardoor deze verminderde botdichtheid wordt veroorzaakt bij deze galactosemie patiënten. De hypothese die beschreven is in dit proefschrift luidt dat glycosylerings defecten van eiwitten die betrokken zijn bij het botmetabolisme een oorzaak kunnen zijn voor de verminderde botdichtheid.

Hoofdstuk 1 bevat een introductie over proteomics en glycomics. De SELDI-TOF-MS techniek wordt in dit proefschrift gebruikt om potentiële biomarkers te detecteren voor sarcoïdose, ankylosing spondylitis en lacunair herseninfarct. De 
achtergronden van deze ziekten zijn opgesomd in dit hoofdstuk. Andere technieken, zoals immunoprecipitatie, gel-elektroforese en Western-blotting worden beschreven omdat ze in dit proefschrift zijn aangewend om glycosylerings defecten bij galactosemie te bestuderen.

In hoofdstuk 2 wordt een overzicht gegeven van de diagnostische waarde van eiwitprofielen verkregen met behulp van de SELDI-TOF-MS techniek in verschillende studies met betrekking tot prostaat- en ovariumkanker. De pre- en post analytische aspecten van proteomics onderzoek worden in dit hoofdstuk besproken en de pre- and post analytische strategieën van de verschillende prostaat- en ovariumkanker studies worden bediscussieerd. Tevens zijn er eigen data opgenomen in dit hoofdstuk. Na vergelijking van de verschillende studies, ziet men duidelijke verschillen in de voorbehandeling en de opslag van de monsters. De effecten hiervan worden onderschat. Het is essentieel dat de monster verzameling identiek is voor de onderzochte groepen en gestandaardiseerde protocollen moeten gebruikt worden voor zowel de opwerking, opslag als de data analyse. Een belangrijke conclusie van dit hoofdstuk is dat de technische details duidelijk beschreven moeten worden in gepubliceerde wetenschappelijke artikelen, zoals de opwerkmethoden en de data analyses, voordat eiwitprofilering gebruikt kan worden als diagnostisch hulpmiddel. Een strikt gestandaardiseerd protocol is niet alleen nodig voor de pre- and post analytische aspecten, maar ook voor de kwaliteitscontrole procedures.

Hoofdstuk 3 beschrijft een standaard protocol voor de calibratie van het MALDI-TOF-MS gedeelte van de SELDI-TOF-MS. Acceptatie criteria voor de onafhankelijke gecertificeerde controlemonsters zijn opgesteld. Deze kwaliteitscontrole procedure kan ook gebruikt worden voor andere instrument typen. Door wekelijks de calibratie te controleren, werkt de kwaliteitsprocedure prospectief, terwijl in sommige studies de kwaliteitscontrolemonsters alleen worden meegenomen tijdens de experimenten, waardoor de kwaliteitscontrole retrospectief is. Zodra de onafhankelijke kwaliteitscontrolemonsters buiten de acceptatiecriteria vallen, dient er actie ondernomen te worden. Er kunnen verschillende oorzaken zijn voor de overschrijding van de acceptatiecriteria zoals; fouten die ontstaan tijdens het maken van de kwaliteitscontrolemonsters en de calibratie chip, maar ook instrumentele fouten. Elke nieuwe technologie, vooral wanneer deze wordt gebruikt als potentiële diagnostische test, heeft een strenge kwaliteitscontrole nodig om de kwaliteit van de analyse in de tijd te evalueren.

Hoofdstuk 4 geeft een overzicht van het gebruik van verschillende proteomics strategieën om potentiële en/of overeenkomstige biomarkers te detecteren bij chronische ontstekingsziekten. De verschillende proteomics strategieën en de achtergronden van de drie chronische ontstekingsziekten, multiple sclerosis, reumatoïde artritis en longontsteking, worden uitgelegd in dit hoofdstuk. De geïdentificeerde en gevalideerde eiwitten worden met elkaar vergeleken om te bekijken of er overeenkomstige biomarkers zijn die gebruikt kunnen worden bij de 
diagnose en prognose van de drie chronische ontstekingsziekten beschreven in dit hoofdstuk. Er worden enorm veel eiwitten geïdentificeerd en in sommige studies worden de eiwitten ook nog eens gevalideerd met andere testen. Uit deze studies blijkt dat de "heat shock protein" familie mogelijke potentiële biomarkers bevat voor multiple sclerosis. Myeloid-related protein 8 wordt in drie verschillende reumatoïde arthritis studies gevonden als potentiële marker, waarbij in elke studie ook nog eens een ander soort monstermateriaal werd gebruikt. Alpha1-antitrypsin is in twee studies gevalideerd als marker voor sarcoïdose. Alpha1-antitrypsin blijkt ook een potentiële biomarker te zijn voor cystic fibrosis (CF), samen met myeloperoxidase en immunoglobuline $\mathrm{G}$.

Hoofdstuk 5 is gericht op de detectie van potentiële biomarkers in serum voor de diagnose van sarcoïdose met behulp van de SELDI-TOF-MS techniek. Sarcoïdose is een multi-systemische ontstekingsziekte, waarbij in 90\% van de gevallen de longen zijn aangedaan. Het kenmerk van sarcoïdose is een granuloom oftewel een chronische ontstekingshaard. Tot nu toe is er nog geen goede biomarker beschikbaar om de diagnose en prognose van sarcoïdose te voorspellen. Om potentiële biomarkers te detecteren, worden de eiwitprofielen verkregen met de SELDI-TOF-MS met elkaar vergeleken. Sera van 35 sarcoïdose patiënten en 35 gezonde vrijwilligers worden in deze studie gebruikt. Het serum is voorbehandeld door gebruik te maken van anion exchange fractionering. De sensitiviteit en specificiteit die bepaald is met behulp van de SELDI-TOF-MS techniek worden vergeleken met de sensitiviteit en specificiteit van de veel gebruikte bloedmarkers angiotensin converting enzyme (ACE) and soluble Interleukin-2 Receptor (sIL-2R). Met behulp van een beslisboom algoritme, wordt een optimale classificatie bereikt met de metaal affiniteit binding arrays gekoppeld met koper (IMAC-Cu ${ }^{2+}$ ). Een separate marker met een massa/lading $(\mathrm{m} / \mathrm{z})$ waarde van 11.955 resulteert respectievelijk in een sensitiviteit en een specificiteit van $86 \%$ en $63 \%$. Een multimarker benadering van 2 pieken, $m / z$ waarden 11.734 en 17.377 , resulteert respectievelijk in een sensitiviteit en specificiteit van 74 en $71 \%$. Deze sensitiviteiten en specificiteiten zijn hoger vergeleken met de sensitiviteiten en specificiteiten verkregen met de ACE en sIL-2R metingen. De piek met een $\mathrm{m} / \mathrm{z}$ waarde van 17.377 is succesvol geïdentificeerd als the alpha-2 keten van haptoglobine. In toekomstige studies, zullen de groepen moeten worden uitgebreid en zullen de markers ook gevalideerd dienen te worden door gebruik te maken van geblindeerde monsters. Nadat de validatie voltooid is, kunnen we kijken naar biomarkers die de activiteit van de ziekte kunnen voorspellen. Met behulp van een kwantitatieve immunoassay, kan uiteindelijk misschien een goede schatting worden gegeven van de activiteit en de ernst van het ziektebeeld sarcoïdose.

In hoofdstuk 6 proberen we potentiële biomarkers te detecteren voor ankylosing spondylitis (AS). AS is een inflammatoire reumatische aandoening waarbij een ontstekingsreactie optreedt in de gewrichten, met een duidelijke voorkeur voor de wervelkolom. Structurele schade aan de wervelkolom kan worden aangetoond met 
behulp van conventionele radiografie. Destructieve laesies zullen zichtbaar zijn die uiteindelijk leiden tot syndesmofyt formatie. Syndesmofyt is een verbening, uitgegaan van een ligament. Voor AS is dit een tussenwervelbrug. Sera van 38 AS patiënten en 38 gezonde vrijwilligers zijn gebruikt om te potentiële biomarkers op te sporen. Het serum is voorbehandeld door middel van anion exchange fractionering. Tijdens de screenings experimenten, zijn drie ProteinChip arrays met elkaar vergeleken namelijk; CM10, IMAC-Cü ${ }^{2+}$ en $\mathrm{H} 50$. Het beste onderscheid wordt bereikt met de volgende condities: CM10 ProteinChip arrays met de organische serum fractie en de IMAC-Cu2+ ProteinChip arrays met gedenatureerd serum. Analyse van alle AS en controlemonsters op de CM10 arrays resulteert in een sensitiviteit van $66 \%$ en een specificiteit van $74 \%$. Hierbij wordt gebruik gemaakt van een multimarker benadering. $M / z 4172$ wordt gebruikt als eerste knoop in de beslisboom en is verhoogd in de AS groep en $m / z 28.144$ wordt gebruikt als tweede knoop. Analyse van alle AS en controlemonsters op de IMAC$\mathrm{Cu}^{2+}$ arrays resulteert in een sensitiviteit en specificiteit van $70 \%$. Hierbij wordt ook gebruik gemaakt van een multimarker benadering. $M / z 6644$ wordt gebruikt als eerste knoop in de beslisboom en is verlaagd in de AS groep en $m / z 13.875$ wordt gebruikt als tweede knoop. De pieken met een $m / z$ waarde van 28.144 and 13.875 zijn beide succesvol geïdentificeerd als apolipoprotein A-I (ApoA1). Dit is de eerste studie die laat zien dat het vergelijken van eiwitprofielen in serum met behulp van de SELDI-TOF-MS techniek gebruikt kan worden om ankylosing spondylitis te diagnosticeren. In toekomstige studies worden de groepen uitgebreid en zullen de markers ook gevalideerd dienen te worden door gebruik te maken van geblindeerde monsters. Na de uitbreiding van de groepen en de validatie, kunnen we specifiek kijken naar biomarkers voor de ziekte-activiteit. Uiteindelijk is een kwantitatieve immunoassay nodig om een goede schatting te geven over de activiteit en de ernst van het ziektebeeld ankylosing spondylitis.

Het doel van de studie in hoofdstuk 7 is het detecteren van verschillen in eiwit profielen in serummonsters van twee verschillende types herseninfarct met behulp van de SELDI-TOF-MS techniek. Een herseninfarct is het gevolg van onderbreking van de bloedtoevoer naar een deel van de hersenen. Het achterliggende hersenweefsel krijgt niet meer genoeg zuurstof en dat deel van de hersenen zal beschadigen of afsterven. Een herseninfarct wordt meestal veroorzaakt door een verstopping van klein, diep gelegen arteriën in de hersenen. Er wordt onderscheid gemaakt tussen herseninfarcten waarbij een enkele symptomatische laesie is te zien en waarbij meerdere "silent" hersenlaesies te zien zijn. De herseninfarcten waarbij meerdere laesies te zien zijn, laten ook meer cerebrale witte stof zien en er is vaak sprake van een hoge bloeddruk. Deze patiënten hebben vaak ook een hogere bloeddruk, een slechtere prognose, meer kans op een tweede infarct, hogere mortaliteit op korte en lange termijn, en een grotere kans op progressie van een asymptomatische laesie. In deze studie worden twee groepen onderscheiden op grond van goed gedefinieerde criteria. Groep 1 bestaat uit acht patiënten 
waarbij de hersen-MRI één enkele symptomatische hersenlaesie laat zien (type I). Groep 2 bestaat uit acht patiënten waarbij de hersen-MRI 4 of meerdere asymptomatische laesies inclusief cerebrale witte stof (type II) afwijkingen laat zien. Anion exchange fractionering wordt gebruikt om de 16 serummonsters te scheiden in verschillende fracties. Alle fracties worden op twee verschillende arrays (Ciphergen Biosystems Inc) gebracht; de zwakke cationenwisselaar (CM10) en de IMAC-Cu ${ }^{2+}$. Het meest optimaal discriminerend patroon wordt gevonden op de IMAC-Cu ${ }^{2+}$ ProteinChip arrays met gedenatureerd serum. Een duidelijke potentiële marker met een $\mathrm{m} / \mathrm{z}$ waarde van 16.122 is verhoogd in type I vs type II met een gemiddelde intensiteit van 12,5 en 5,0, respectievelijk. Eiwit identificatie wordt uitgevoerd door middel van 1- en 2-dimensionale gel-elektroforese gevolgd door MALDI-TOF-MS. De piek met een $\mathrm{m} / \mathrm{z}$ waarde van 16.122 wordt geïdentificeerd als de alpha keten van haptoglobine. De alpha keten bestaat uit twee varianten, alpha$1(8,9 \mathrm{kDa})$ and alpha-2 (16 kDa), de laatste komt overeen met de marker $\mathrm{m} / \mathrm{z}$ 16.122. De totale haptoglobine concentratie en de fenotype verdeling zijn bepaald. De totale haptoglobine concentratie is niet significant verschillend voor de 2 groepen, maar de type I groep geeft een hogere haptoglobine-2 allel frequentie t.o.v. van de type II groep. In beide groepen is de haptoglobine-1 allel frequentie duidelijk hoger ten opzichte van de referentie populatie. De haptoglobine-1 allel frequentie is hoger in type II versus type I. Dit suggereert dat haptoglobine-1 een rol speelt bij het ontwikkelen van meerdere "silent" herseninfarcten met cerebrale witte stof. De associatie tussen haptoglobine-1 en herseninfarct geeft nieuwe inzichten in de genetische factoren die een oorzaak kunnen zijn voor het ontstaan van deze herseninfarcten. In toekomstige studies, zullen de resultaten moeten worden bevestigd in grotere patiënten groepen.

Hoofdstuk 8 beschrijft een in huis ontwikkelde immunoprecipitatiemethode om in serum insulin-like growth factor binding protein-3 (IGFBP-3) en zijn isovormen te isoleren uit serum met het doel om afwijkingen van de suikerketens (glycaan abnormaliteiten) in IGFBP-3 te onderzoeken. Patiënten met klassieke galactosemie lopen risico op het verkrijgen van een verminderde botdichtheid zonder enig bewijs dat deze verminderde botdichtheid wordt veroorzaakt door voedingsfactoren. Onze hypothese is dat disglycosylatie van glycoproteïnen (eiwitten) van de growth hormone/IGF-I (insulin-like growth factor type I) as een rol speelt bij deze verstoringen. IGF-I is voor meer dan $75 \%$ gebonden aan IGFBP-3. Om glycaan abnormaliteiten te detecteren in IGFBP-3, is isolatie van dit eiwit, gevolgd door glycaan analyse nodig. Onze immunoprecipitatiemethode is vergeleken met andere bestaande immunoprecipitatiemethoden. Het bestuderen van IGFBP-3 isovormen is relevant voor studies op het gebied van congenitale defecten in glycosylatie, galactosemie en alcoholische levercirrose. De immunoprecipitatiemethode is gevalideerd met behulp van Western-blotting en enzyme-linked immuno-sorbent assay (ELISA). De in huis ontwikkelde immunoprecipitatiemethode, waarbij dimethyl pimelimidate wordt gebruikt als cross-linker, resulteert in een verbeterde 
detectie van IGFBP-3 isovormen uit serum in vergelijking met bestaande immunoprecipitatiemethoden waarbij geen cross-linking wordt gebruikt. In deze studie hebben we ook een klinische validatie uitgevoerd door gebruik te maken van patiëntenmateriaal. Omdat het bekend is dat er bij patiënten met congenitale defecten in glycosylatie (CDG) type la sprake is van onvoldoende synthese van $\mathrm{N}$ glycanen wat resulteert in een deficiënte inbouw van siaalzuur, zijn de CDG type la monsters gebruikt als positieve controles. Door serummonsters van kinderen met CDG type la en controle serum van kinderen te vergelijken, konden we een verschil zien in het patroon van de IGFBP-3 isovormen. Een verschuiving van de zure isovormen naar de basische isovormen werd gezien voor het IGFBP-3 eiwit in CDG type la versus controle. Deze verschuiving wordt waarschijnlijk veroorzaakt door een defect in het inbouwen van siaalzuren. Dit wordt ook gezien bij andere glycoproteinen die $\mathrm{N}$-glycanen bevatten zoals transferrine. Om te bevestigen dat glycaan afwijkingen de oorzaak zijn voor de verminderde botdichtheid bij galactosemie, zullen we de IGFBP-3 isovorm patronen in galactosemie ook gaan onderzoeken.

Uit dit proefschrift blijkt dat biomarkerscreening met behulp van proteomics gevolgd door identificatie een goed diagnostisch hulpmiddel kan zijn. Echter om de verschillende analytische problemen op te lossen, is verdere ontwikkeling van de proteomics technologie noodzakelijk. 


\section{List of publications}





\section{List of publications}

\section{International publications with Impact Factor (Wi-1)}

1. Bons JAP, Wodzig WKWH, van Dieijen-Visser MP. Protein profiling as a diagnostic tool in clinical chemistry: a review. Clin Chem Lab Med 2005;43:1281-1290.

2. Bons JAP, de Boer D, van Dieijen-Visser MP, Wodzig WKWH. Standardization of calibration and quality control using Surface-Enhanced Laser Desorption/Ionization Time-of-Flight Mass Spectrometry. Clin Chim Acta 2006;366:249-256.

3. Bons JAP, van Dieijen-Visser MP, Wodzig WKWH. Clinical proteomics in chronic inflammatory diseases, a review. Proteomics Clin. Appl. 2007;1:1123-1133.

4. Bons JAP, Drent M, Bouwman FG, Mariman EC, van Dieijen-Visser MP, Wodzig WKWH. Potential biomarkers for diagnosis of sarcoidosis using proteomics in serum. Respiratory Medicine 2007;101:1687-1695.

5. Bons JAP, Michielsen ECHJ, de Boer D, Bouwman FG, Jaeken J, van DieijenVisser MP, Rubio-Gozalbo ME, Wodzig WKWH. A specific immunoprecipitation method for isolating isoforms of insulin-like growth factor binding protein-3 from serum. Clin Chim Acta 2008;387:59-62.

6. Bons JAP, van der Heijde D, Bouwman FG, Mariman EC, van Dieijen-Visser MP, Landewé R, van der Linden S, Wodzig WKWH. Potential biomarkers for diagnosis of ankylosing spondylitis using SELDI-TOF-MS. Biomarkers in Medicine 2008,2:23-30.

7. Staals J, Bons JAP, van Oostenbrugge RJ, Knottnerus I, van Dieijen-Visser MP, Bouwman FG, Mariman EC, Delanghe JR, Lodder J, Wodzig WKWH. Haptoglobin phenotype in lacunar stroke: a SELDI-TOF-MS protein profiling study with subsequent phenotypic analysis. Submitted.

International publications (Wi-2)

8. Bons JAP, Wodzig WKWH, de Boer D, Drent M, van Dieijen-Visser MP. Application of SELDI-TOF-MS in protein profiling: promises and pitfalls. Jugoslov Med Biochem 2006;25:201-210. 


\section{National publications (Wn)}

9. Bons JAP, de Boer D, van Dieijen-Visser MP, Wodzig WKWH. Standardization of calibration and quality control using Surface-Enhanced Laser Desorption/Ionization Time-of-Flight Mass Spectrometry. Ned. Tijdschr. Klin. Chem. Labgeneesk 2006; 31:202-204.

10. van Dieijen-Visser MP, Bons JAP, de Boer D, Wodzig WKWH. Application of SELDI-TOF-MS in protein profiling: state of the art. Ned Tijdschr Klin Chem Labgeneesk 2007;32:88-93.

11. Bons JAP, Wodzig WKWH, Drent M, van Dieijen-Visser MP. Detection of potential protein biomarkers with Surface-Enhanced Laser Desorption/Ionization Time-of-Flight Mass Spectrometry useful in the diagnosis and follow-up of sarcoidosis. Ned. Tijdschr. Klin. Chem. Labgeneesk 2005;30:289-291. 
Dankwoord 



\section{Dankwoord}

Graag maak ik gebruik van deze gelegenheid om iedereen te bedanken voor zijn of haar bijdrage aan dit proefschrift. Dit boekje was niet tot stand gekomen zonder de support en hulp van velen, waarvan ik enkele mensen speciaal wil benoemen.

Op de eerste plaats wil ik mijn co-promotor, dr. Will Wodzig en mijn promotor Prof. dr. Marja van Dieijen-Visser bedanken. Zij hebben mij enorm geholpen met het opzetten van de verschillende studies en bij het schrijven van mijn manuscripten. Tijdens mijn promotietraject had ik natuurlijk ook tegenslagen te verwerken, maar dankzij het enthousiasme en de positieve instelling van Will en Marja, bleef ik er altijd vol voor gaan. Het waren dan ook vooral Will en Marja die me enthousiast maakten voor het vak Klinische Chemie. Ik ben ontzettend blij dat ik ook tijdens mijn opleiding tot Klinisch Chemicus nog met jullie mag blijven samenwerken.

Beste Will, ik kon altijd bij je binnenwandelen als ik de opzet van mijn experimenten of mijn resultaten wilde bespreken. Het was erg prettig om samen te brainstormen en discussiëren. ledere keer kwam je met goede ideeën en alternatieven en over de snelheid waarmee je de artikelen corrigeerde was ik keer op keer verbaasd.

Beste Marja, jouw manier van werken is echt een voorbeeld voor mij. Het is ongelooflijk hoe jij alles weet te combineren en hoe $\mathrm{jij}$ ondanks je vele verplichtingen rust weet uit te stralen. Ik vond het erg fijn dat je ondanks je drukke werkschema altijd tijd wist vrij te maken om de voortgang van ons onderzoek te bespreken.

Natuurlijk wil ik alle patiënten en vrijwilligers bedanken voor deelname aan mijn onderzoeken. Zonder hun medewerking was het niet mogelijk geweest om de onderzoeken uit te voeren.

Prof. dr. Marjolein Drent, beste Marjolein. Jij kwam met het geweldige idee om tijdens de Sarcoïdose patiëntendag, bloed te verzamelen van de patiënten en de partners. Samen met Gé en Esther werd deze dag een succes en kon ik daarna met de bloedmonsters aan de slag.

Prof. dr. Désirée van der Heijde en dr. Robert Landewé. Beste Désirée en Robert, ik wil jullie bedanken voor jullie hulp en kritische blik bij het opzetten van de AS studie en het schrijven van ons manuscript. Els, Janine en Dyonne, bedankt voor het tijdig bellen naar mijn sein. Ik heb wat meters gemaakt naar het provisorium.

Samen met de neurologie groep, bestaande uit Julie Staals, Prof. dr. Jan Lodder en dr. Robert van Oostenbrugge, en Prof. dr. J. Delanghe uit Gent hebben we nieuwe 
ideeën opgedaan om de twee typen herseninfarcten van elkaar te onderscheiden met behulp van fenotypering. Toekomstig onderzoek zal uitwijzen of onze suggesties juist zijn. Ik wil jullie allen bedanken voor jullie bijdrage aan het onderzoek.

Dr. Estela Rubio. Beste Estela, in het laatste jaar van mijn promotie hebben we kennis met elkaar gemaakt in verband met het IGFBP-3 project. Onze samenwerking was prettig en je positieve instelling werkte aanstekelijk. Hopelijk kunnen we de glycosylatie defecten bij galactosemie in de toekomst ontrafelen.

Prof. dr. J. Jaeken, $U$ wil ik hartelijk danken voor het opsturen van de GDG monsters en uw bijdrage aan het manuscript.

Dr. D. de Boer. Beste Douwe, ik wil je vooral bedanken voor jouw kritische blik, niet alleen voor de opzet van het onderzoek, de interpretatie van resultaten, maar ook bij het corrigeren van de manuscripten. Ik heb ontzettend veel van je geleerd en ook tijdens de opleiding hoop ik nog veel van je te leren.

Ik wil Freek Bouwman en Prof. dr. Edwin Mariman bedanken voor de hulp bij de identificatie van potentiële markers. Freek, bedankt dat je tijd voor me vrij wilde maken en dankzij jou hebben we de 2-DE technologie nu ook bij ons op het lab lopen.

Tijdens mijn promotieperiode heb ik hulp gehad van goede stagiaires, Maud Starmans, Janine Semeleer, Judith Peulen, Anne-Charlotte Dubbelman en Rianne Klinkenberg. Ik wil jullie hartstikke bedanken voor jullie inzet en ik wens jullie veel succes in de toekomst.

Uiteraard wil ik mijn collega-promovendi bedanken. Etienne Michielsen en Robert op den Buijsch zijn lange tijd mijn kamergenoten geweest en ik wil hen dan ook bedanken voor de gezellige tijd samen. De etentjes in Maastricht en het vieren van onze verjaardagen was altijd erg geslaagd. Ook bedankt voor alle goede tips, hulp en suggesties rondom het hele onderzoek. Ik wens jullie allebei heel veel succes in jullie verdere carrière. Alma Mingels, Leo Jacobs en Bianca Pulinx, de nieuwe onderzoekers, ik wens jullie veel succes met jullie promotieonderzoek. Snjezana, ik wil je bedanken voor alle tips en hulp voor de opleiding. Succes met je verdere carrière als Klinisch Chemicus.

De mensen van de staf die ik nog niet heb genoemd, Otto, Paul, Jaap, Jart, Serva, Loe en Huub, bedankt voor de werkgerelateerde discussies aan de koffietafel en tijdens het refereren, maar ook bedankt voor het gezellige kletsen over van alles en nog wat. 
Natuurlijk wil ik de dames van het SIRC; Hanne, Annita, Mia en Annemie, ook bedanken voor de leuke sfeer op het lab. Ik heb veel Belgische woorden bijgeleerd. Dankzij jullie heb ik op een prettige manier mijn experimenten kunnen uitvoeren.

Verder wil ik iedereen op het lab Klinische Chemie bedanken voor de leuke en gezellige tijd. Ik ben erg blij dat ik bij jullie mag blijven op het lab en ik hoop tijdens de opleiding veel van jullie te leren.

Ik wil Tiny Wouters graag nog apart bedanken voor de hulp rondom de lay-out van het proefschrift.

Natuurlijk wil ik ook mijn vriendinnetjes bedanken die ik ken van de basisschool, middelbare school, studietijd Nijmegen en stage periodes. Anneke, Anke, Charlotte, Dewi, Ellen, Floor, Janneke, Judith, Karin, Kirsten, Larissa, Laura, Marion, Marjolein, Nadine, Renee, Sharon en Tanja. Ik vond het fijn dat jullie altijd zoveel interesse toonden. De etentjes, feestjes en uitjes waren erg gezellig. Hopelijk blijven we de dates voortzetten.

Lieve Petra en Femke, mijn paranimfen. Ik vind het heel erg leuk dat jullie mijn paranimfen willen zijn tijdens mijn promotie.

Ik wil graag mijn sport- en lunchvriendinnetje Femke bedanken. Het was altijd fijn om met jou over het onderzoek te hebben, maar het was ook fijn om tijdens het spinnen juist even de gedachten op nul te zetten.

Petra, mijn zus(je), bedankt voor je interesse als ik weer eens artikelen de deur uit had gedaan. Ik wens jou nog veel succes met de studie verpleegkunde en ik wens jou en Guido een hele mooie toekomst samen.

Lieve pap en mam, ik vond het leuk dat jullie altijd zo benieuwd waren naar de stand van zaken wat betreft mijn onderzoek. Dankzij jullie ben ik zover gekomen en ben ik de persoon geworden die ik nu ben. Bedankt voor alles! Mijn schoonfamilie, Fie, Lutz, Ralph en Emmie bedankt voor jullie interesse en de altijd gezellige tijd in Lomm.

Ten slotte wil ik mijn lieve vriend Jens bedanken voor alles! Je moest altijd maar mijn verhalen aanhoren over experimenten, artikelen, cursussen, presentaties enz.. Het is zo fijn dat jij altijd zo rustig en kalm blijft in alle situaties. Nu we samenwonen hoeven we elkaar gelukkig doordeweeks niet meer zo te missen. Ik ben ontzettend gelukkig met jou en ik weet zeker dat we samen een hele mooie toekomst tegemoet gaan. 

Curriculum vitae 



\section{Curriculum vitae}

Judith Bons was born on August 16, 1981 in Tegelen, The Netherlands. After she finished secondary school at the Thomascollege in Venlo in 1999, she started with her academic education Biomedical Health Sciences at the Catholic University of Nijmegen. Two research projects were conducted. The first project was conducted from April - July 2002 at the department of Molecular Pharmacology \& Toxicology of the University Medical Centre Nijmegen, on characterization of the transport of organic anions by Oap3 (S/c21a7) in Xenopus laevis oocytes under supervision of drs. K. Kooiman and dr. R. Masereeuw. The second project was conducted from January - July 2003 at the department of Toxicology and Drug Deposition of Organon in Schaijk, on development and validation of an immune function test to screen for immunotoxicological effects of drugs under supervision of drs. S. Spanhaak and dr. F. van Och. She obtained her Master of Science degree in Biomedical Health Sciences in August 2003. In March 2004 she started as a researcher at the Department of Clinical Chemistry at the University Hospital Maastricht under supervision of Prof. dr. M.P. van Dieijen-Visser and dr. W.K.W.H. Wodzig. She has now started with the training in Clinical Chemistry, also at the Department of Clinical Chemistry at the University Hospital Maastricht. 